\title{
Instrumentación para Neuroprótesis Vestibles
}

\author{
Tesis de Doctorado
}

\section{Federico Nicolás Guerrero}

Presentada ante la Facultad de Ingeniería de la

Universidad Nacional de La Plata

como requisito para la obtención del grado académico de

DOCTOR EN INGENIERÍA

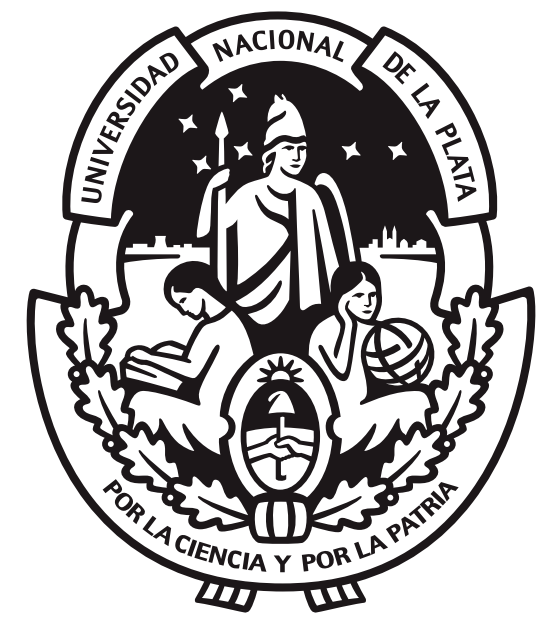

Dirección de tesis:

Enrique M. Spinelli

Jurado de Tesis:

Pedro David Arini

Natalia Martina López

Franco Simini

Fecha de la defensa oral y pública:

10 de Marzo de 2017

La Plata, Buenos Aires, Argentina 

Dedico esta Tesis, sin orden específico, al Abuelo Nicolás y a la Abuela Lula, al Tata Fede y a la Abuela Celina, $\mathrm{y}$ a mis padres. 



\title{
Resumen
}

La tesis pretende contribuir al conocimiento en adquisición de biopotenciales mediante técnicas no invasivas con aplicación a neuroprótesis (NPs). Las NPs son dispositivos que, interactuando con el cuerpo humano, permiten recuperar o reemplazar capacidades perdidas o disminuidas incrementando drásticamente la comodidad e independencia de las personas. Por lo tanto es de interés que las NPs se utilicen de forma muy sencilla y sin asistencia profesional, en correspondencia con el paradigma de los sistemas "vestibles". El objetivo general de la tesis es desarrollar etapas de instrumentación que permitan adquirir biopotenciales útiles a las NPs en forma robusta en las condiciones de medida impuestas por los sistemas vestibles. Por lo tanto, se desarrollan sistemas de adquisición de señal mixta en el estado del arte como plataformas para validar los modelos y circuitos de acondicionamiento propuestos, y se diseñan, implementan y verifican experimentalmente circuitos de acondicionamiento analógico que permiten enfrentar este desafío. En primer lugar, se desarrolla un circuito de realimentación de modo común con ganancia aumentada como estrategia general para la robustez frente a interferencia electromagnética. En segundo lugar se proponen electrodos activos para la medición de señales de electromiograma, desarrollando herramientas de análisis e implementando amplificadores para electrodos de múltiples contactos. Finalmente, los electrodos secos son el factor clave del registro de biopotenciales en sistemas vestibles. Por lo tanto, se desarrolla un electrodo activo con impedancia de entrada aumentada utilizando bootstrap de fuente y conservando una topología de baja complejidad.

\begin{abstract}
This thesis contributes to the topic of non-invasive biopotential acquisition techniques applied to Neuroprostheses (NPs). NPs are technological devices that, through interaction with the body, allow to recover or replace lost or diminished capabilities, thus dramatically increasing the comfort and independence of a person. It is desirable for NPs to be able to be used in a simple manner without professional assistance, in correspondence with the paradigm of wearable devices. The general objective of the thesis is to develop instrumentation circuits which allow to acquire the biopotential signals that NPs need robustly, even under the measurement conditions imposed by wearable systems. Therefore, state of the art mixed-signal acquisition systems are developed as a platform upon which models and conditioning circuits can be validated, and a set of analog conditioning circuits are designed, implemented, and experimentally tested. First, a common mode feedback circuit with increased gain is developed as a general strategy for increased robustness against electromagnetic interference. Next, active electrodes for electromyography signal measurement are proposed. An analysis tool as well as an implementation alternative for multipleinput electrodes are proposed. Finally, dry-contact electrodes are a key factor in wearable biopotential measurements. Hence, an active electrode with increased input impedance is developed using power supply bootstrapping and a low complexity topology.
\end{abstract}





\section{Índice general}

1 Introducción 1

1.1. La promesa de las neuroprótesis vestibles . . . . . . . . . . . . 1

1.2. El impacto en la instrumentación de biopotenciales . . . . . . . 2

1.3. Objetivos de la tesis . . . . . . . . . . . . . . . 3

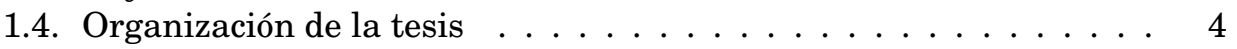

2 Conceptos preliminares $\quad 7$

2.1. Neuroprótesis Vestibles . . . . . . . . . . . . . . . . . . 7

2.2. Origen y caracterización de biopotenciales . . . . . . . . . . . . 9

2.3. Electrodos para la medida no invasiva de biopotenciales . . . . . 11

2.3.1. Propósito y clasificación de los electrodos . . . . . . . . . 11

2.3.2. Modelo eléctrico de la interfaz electrodo-piel . . . . . . . . 12

2.3.3. Electrodos secos . . . . . . . . . . . . . . . . . . 14

2.3.4. Ruido de la interfaz electrodo-piel . . . . . . . . . . . 15

2.4. Topologías para la medida de biopotenciales . . . . . . . . . . 15

2.5. Interferencia electromagnética . . . . . . . . . . . . . . . 18

2.5.1. Características de las fuentes EMI . . . . . . . . . . . 18

2.5.2. Modelo EMI . . . . . . . . . . . . . . . . . 20

2.5.3. Interferencia de modo diferencial . . . . . . . . . . . . 21

2.5.4. Transformaciones de modo . . . . . . . . . . . . . 23

2.5.5. Interferencia por rechazo finito de amplificadores . . . . . 23

2.6. Conclusiones . . . . . . . . . . . . . . . . 25

3 Instrumentación para Biopotenciales $\quad 27$

3.1. Desafíos en la instrumentación para biopotenciales . . . . . . . 27

3.2. Solución tradicional . . . . . . . . . . . . . . . . . . 28

3.3. Estado del arte . . . . . . . . . . . . . . . . . . . . 30

3.4. Aplicación en neuroprótesis vestibles . . . . . . . . . . . . . . 31

3.4.1. Electrodos activos . . . . . . . . . . . . . . . 31

3.4.2. Alta impedancia de entrada . . . . . . . . . . . . . . 33

3.4.3. Reducción tensión de modo común . . . . . . . . . . . 33

3.5. Conclusiones . . . . . . . . . . . . . . . . . 35

4 Sistema de Adquisición de Biopotenciales $\quad 37$

4.1. Instrumentación basada en $\mathrm{AFE} \Sigma-\Delta \ldots \ldots \ldots \ldots$

4.1.1. Núcleo del sistema . . . . . . . . . . . . . . . . . . . 38

4.1.2. Características de los convertidores $\Sigma-\Delta \ldots \ldots \ldots$

4.1.3. Seguridad eléctrica . . . . . . . . . . . . . . . . 39

4.2. Realimentación de modo común independiente . . . . . . . . . 41

4.3. Electrodos activos . . . . . . . . . . . . . . . . . 44

4.4. Implementación I: Equipo de laboratorio . . . . . . . . . . . . . 46 
4.4.1. Diseño e Implementación . . . . . . . . . . . . . . . . 46

4.4.2. Resultados . . . . . . . . . . . . . . . 48

4.5. Implementación II: Módulo para plataforma vestible $\ldots \ldots \ldots$. . . 49

4.5.1. Diseño e Implementación . . . . . . . . . . . . . . . 49

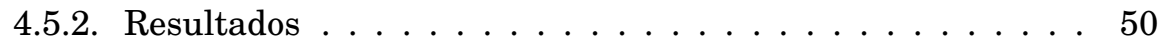

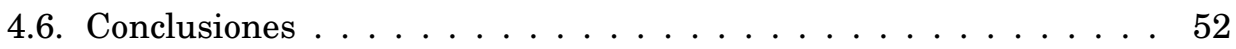

5 Circuito DRL con mejora de ganancia 53

5.1. Realimentación de modo común . . . . . . . . . . . . 53

5.2. Una compensación alternativa $\ldots \ldots \ldots \ldots \ldots \ldots$

5.3. Implementación del DRL . . . . . . . . . . . . . . . . 57

5.4. Validación del DRL propuesto . . . . . . . . . . . . 58

5.4.1. Diseño experimental . . . . . . . . . . . . . 58

5.4.2. Resultados y discusión . . . . . . . . . . . . . 60

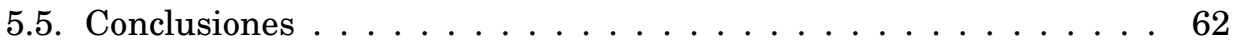

6 Electrodos activos doble-diferenciales para EMG 63

6.1. Multi-Electrodos para la medida de sEMG . . . . . . . . . . 63

6.2. Modos de señal en electrodos doble-diferenciales . . . . . . . . . 66

6.2.1. Definición de modos de señal . . . . . . . . . . . . . 66

6.2.2. Transformaciones de modo . . . . . . . . . . . . 67

6.3. Electrodos activos de tipo branched . . . . . . . . . . . 68

6.3.1. Características y diseño . . . . . . . . . . . . . 68

6.3.2. Implementación y resultados . . . . . . . . . . . . 69

6.3.3. Conclusiones: simplicidad y limitaciones . . . . . . . . . . 70

6.4. Electrodo activo doble diferencial . . . . . . . . . . . . . . 72

6.4.1. Limitaciones de la topología de 3 AI . . . . . . . . . . 72

6.4.2. Amplificador Doble Diferencial . . . . . . . . . . . . . 73

6.4.3. Figuras de mérito . . . . . . . . . . . . . . . 74

6.4.4. Resultados Experimentales . . . . . . . . . . . 75

6.5. Conclusiones . . . . . . . . . . . . . . . 79

7 Electrodo de Dos Hilos con bootstrap de fuente 81

7.1. Introducción . . . . . . . . . . . . . . . . . . 81

7.1.1. Electrodos Activos: Interferencia de modo común . . . . . . . 81

7.1.2. La limitación de la impedancia de entrada . . . . . . . . . 82

7.1.3. La solución de Bootstrapping . . . . . . . . . . . . 83

7.1.4. Electrodos Activos: Artefactos . . . . . . . . . . . . . 84

7.1.5. Electrodos de dos hilos . . . . . . . . . . . . . . . 85

7.2. Solución propuesta . . . . . . . . . . . . . 86

7.2.1. Desarrollo del circuito . . . . . . . . . . . . . 86

7.2.2. Circuito práctico . . . . . . . . . . . . . . . . . 89

7.2.3. Análisis de estabilidad . . . . . . . . . . . . . 91

7.2.4. Análisis de ruido . . . . . . . . . . . . . . 93

7.3. Resultados . . . . . . . . . . . . . . . 95

7.3.1. Implementación del circuito . . . . . . . . . . . 95

7.3.2. Aumento de la impedancia de entrada . . . . . . . . . . . 95

7.3.3. Tensión de ruido . . . . . . . . . . . . . . . . . . . 96

7.3.4. Uso en sistema de adquisición para NPV . . . . . . . . . . 97

7.4. Conclusiones . . . . . . . . . . . . . . . . 98

8 Conclusiones 101 
A Modos de señal en electrodos normal-doble-diferenciales 105

B Relación entre parámetros del amplificador operacional 107

C Cálculo de ruido del circuito de bootstrap negativo

Bibliografía

Agradecimientos 



\section{Algunas abreviaciones utilizadas en esta tesis ${ }^{1}$}

ADC Convertidor analógico-digital

AFE Frente analógico

AO Amplificador operacional

ASIC Circuito integrado de aplicación específica

ASSP Producto estándar de aplicación específica

BPD Conductor de potencial del cuerpo

CMRR Coeficiente de rechazo de modo común

DD Doble diferencial

DRL Conductor de pierna derecha

EA Electrodo Activo

EEG Electroencefalograma

EMG Electromiograma

EMI Interferencia electromagnética

ENOB Número efectivo de bits

ICC Interfaz cerebro-computadora

IED Distancia inter-electródica

IHM Interfaz hombre-máquina

NP Neuroprótesis

NPV Neuroprótesis vestible

MC Modo común

MD Modo diferencial

PD Polo dominante

PSRR Coeficiente de rechazo de la fuente de alimentación

\footnotetext{
${ }^{1}$ Algunas definiciones corresponden a las siglas en inglés de los términos. Se utilizaron abreviaciones en inglés cuando representan nombres técnicos o se encuentran difundidas de esa manera incluso en la literatura en español.
} 



\title{
Introducción
}

\begin{abstract}
En este capítulo se presenta la aplicación que motiva esta tesis: las neuroprótesis vestibles; dispositivos de asistencia que, con una instalación tan sencilla como vestir una prenda de indumentaria, deben ser capaces de interpretar la voluntad de su usuario y actuar sobre el mundo físico en consecuencia. ¿ Cómo impactan estas especificaciones sobre la instrumentación de biopotenciales encargada de medir las señales de EEG y EMG, testigos de la voluntad?. Tras comentar brevemente el problema y el alcance de las soluciónes propuestas, se datalla la organización de la tesis.
\end{abstract}

\subsection{La promesa de las neuroprótesis vestibles}

Encerrado dentro de nuestra piel hay un mundo de señales eléctricas, producidas por las células nerviosas para comunicar mensajes o por los tejido de órganos como los músculos para coordinar acciones. Estas señales transportan información no sólo sobre el estado de salud del cuerpo, sino sobre la voluntad, las ideas y los deseos de la persona en quienes se originan.

Muchas personas son afectadas por enfermedades o accidentes que interrumpen el camino que estas señales recorren o impiden que puedan generar las acciones deseadas. Por ejemplo, los accidentes cerebro-vasculares pueden producir parálisis parciales y afectar la capacidad de utilizar un brazo o pierna normalmente. Las neuroprótesis (NPs) son dispositivos que permiten reemplazar o ayudar a rehabilitar estas funciones perdidas. Las NPs llamadas sensoriales miden parámetros del mundo y los comunican a la persona, sin embargo esta tesis se centra en las NPs que intentan manifestar la voluntad del individuo en el mundo exterior. La composición básica de una de tales neuroprótesis es:

- Una interfaz con una persona, usualemente a través de la medida de los biopotenciales de su sistema nervioso o muscular.

- Una etapa de procesamiento para interpretar los biopotenciales y decidir acciónes.

- Una interfaz con el mundo físico, sea un actuador mecánico o la emisión de comandos en una plataforma digital. 
Un ejemplo representativo de neuroprótesis son las prótesis de brazos y manos con articulaciones motorizadas que se comandan a partir de potenciales biológicos. Algunas pueden accionarse a través de la contracción de músculos en otros sectores del cuerpo (usualmente músculos del hombro); otras a través de señales originadas en el cerebro disparadas por estímulos visuales. En estos casos, una etapa de instrumentación para señales de biopotencial se encarga de adquirir la señal eléctrica muscular (electromiograma o EMG) o la señal de la corteza cerebral (electroencefalograma o EEG), que luego se procesa para detectar la activación de un músculo o la presencia de componentes en la corteza visual correlacionados con el estímulo, y finalmente se produce una acción en la prótesis.

Otra alternativa son los exoesqueletos, dispositivos mecánicos afirmados a los miembros del cuerpo capaces de moverlos o de reforzar sus movimientos. Algunos exoesqueletos se activan a partir de la detección de señales en un nervio o músculo. Los exoesqueletos pueden servir para terapias de rehabilitación, ayudando de forma inteligente el movimiento del miembro a rehabilitar.

En personas con parálisis severas, la detección de ritmos particulares de EEG, como el ritmo $\alpha$ generado al relajar la vista, permite emitir comandos en una computadora y utilizarla sin asistencia (lo que se conoce como interfaz cerebro-computadora o ICC).

El objetivo de las NPs es, fundamentalmente, devolver el confort y la independencia a una persona, y por lo tanto deben operar de la forma menos disruptiva posible. En ningún esta tecnología debe constituir una nueva barrera a superar. Las terapias de rehabilitación son más exitosas cuanto más esfuerzo y tiempo se les dedica, pero el profesional de rehabilitación sólo puede dedicar un tiempo finito a un tratamiento por costo y disponibilidad. Una neuroprótesis tiene el potencial de extender este tiempo y hacer también más eficiente los ejercicios, pero para ello no debe insumir tiempo extra su colocación y realmente debe invitar a la persona a utilizarla sin asistencia. Si una NP tiene la función de comunicar a personas con su entorno, para ello debe ser vestida en forma continua sin que disminuya su efectividad, y ser de uso extremadamente sencillo y confiable. Estos requisitos causan un fuerte impacto sobra la tecnología necesaria para implementarlas.

Hay dos tipos de NP, las implantables y las no implantables, conocidas como "no invasivas". Esta tesis está dedicada a la instrumenación de este segundo tipo de NP, y dentro de este grupo a las que apuntan a ser mínimamente obstructoras, con la misma simplicidad de uso que una prenda de vestir. Estas condiciones corresponden al paradigma de los dispositivos conocidos como "vestibles" objetivo fundamental de los dispositivos vestibles no sólo es poder portarlos sobre el cuerpo, sino también funcionar sin una instalación atendida por profesionales con largos tiempos de colocación.

\subsection{El impacto en la instrumentación de biopotenciales}

Una gran parte de la responsabilidad para lograr la funcionalidad no disruptiva de las neuroprótesis vestibles (NPVs) recae en la instrumentación para medir los biopotenciales: la vía por la cual la voluntad de la persona fluye hacia la NP.

\footnotetext{
${ }^{1}$ La palabra vestible no existe en el idioma español. En las publicaciones científicas, mayormente en inglés, se utiliza el término "wearable". Se eligió adoptar la palabra vestible, incipientemente usada en algunas publicaciones español, para abarcar ese concepto
} 
En un dispositivo vestible, los electrodos que captan los biopotenciales deben operar simplemente apoyados sobre la capa más externa de la piel, sin preparación y sin ser colocados por un profesional. Como resultado, el contacto eléctrico con la fuente de biopotencial, la selectividad y la robustez frente a artefactos, son de baja calidad. Sin embargo, aún en estas condiciones, la interfaz debe permanecer siendo robusta y confiable.

Contradictoriamente, los sistemas de instrumentación de NPVs deben ser de fácil mantenimiento y con partes reemplazables para la tranquilidad de uso y una disponibilidad asegurada, sin embargo el mercado reducido de estos dispositivos los aleja de las ventajas de la producción en grandes volúmenes, por eso sus requisitos deben cumplirse con implementaciones basadas a su vez en dispositivos de amplia disponibilidad comercial y bajo costo.

En los últimos años se ha dedicado un significativo esfuerzo al desarrollo de electrodos de biopotencial aptos para encarar este desafío y a la instrumentación que permite utilizarlos. Los llamados "electrodos secos" no necesitan la aplicación de electrolitos líquidos o en pasta y pueden ser utlizados por períodos muy prolongados de tiempo sin irritar la piel ni degradar la calidad de la señal, con factores de forma diversos adaptables a distintas partes del cuerpo. La instrumentación para biopotenciales ha dado un salto tecnológico importante en la última década, migrando el foco desde el "amplificador de biopotencial" al front-end analógico integrado. Sin embargo los front-ends genéricos, por estar apuntados a un mercado masivo más general, por si solos no cumplen las estrictas necesidades de los electrodos para dispositivos vestibles.

\subsection{Objetivos de la tesis}

\section{Objetivo general}

En esta tesis se describen soluciones de diseño de ingeniería para problemas clave de la etapa de instrumentación de neuroprótesis vestibles.

El objetivo general de la tesis fue desarrollar etapas de instrumentación que permitan capturar las señales de biopotencial que sirven de fuente de información a las neuroprótesis en forma robusta en las condiciones de medida impuestas por los sistemas vestibles.

\section{Objetivos particulares}

El primer objetivo particular fue desarrollar un sistema de adquisición acorde al estado del arte en el tema. El desarrollo e implementación de un sistema con las últimas tendencias permite contar con una plataforma para validar los modelos y circuitos de acondicionamiento propuestos.

Los objetivos particulares siguientes corresponden a la adaptación o extensión de los sistemas integrados de adquisición de producción masiva modernos a las condiciones de los sistemas vestibles. El desarrollo de los periféricos o circuitos de acondicionamiento necesarios para esto comprenden los aportes de esta tesis.

En primer lugar se desarrolló una mejora del circuito de realimentación de modo común que permite atacar directamente el problema de la interferencia electromagnética para la adquisición general de señales de biopotencial.

Como segundo objetivo particular se planteó desarrollar electrodos activos para la medición de señales de EMG. La medida de EMG superficial es un ejemplo donde los electrodos secos son una necesidad, debido a que la aplicación de gel es impráctica cuando los puntos de contacto son muy próximos entre sí. 
Equipos comerciales de medida de EMG y neuroprótesis utilizan la geometría de electrodo doble diferencial con este propósito. Este electrodo utiliza tres contactos para aumentar la selectividad espacial de las medida. Sin embargo en la literatura su desarrollo es escaso y se encuentra divorciado de la especialidad de diseño analógico, que puede aportar a la mejora de sus parámetros de funcionamiento y reducción de complejidad, y por lo tanto costo, innecesaria.

Finalmente, los electrodos secos son el factor clave del registro de biopotenciales en sistemas vestibles. Su alta impedancia y variabilidad provoca que la tensión de modo común interfiera en las medidas a través de transformaciones de modo que el equipo de medida no puede rechazar. Se requiere una solución robusta para el problema de la impedancia de entrada de los electrodos activos, que no requiera calibración ni ajustes. La técnica apropiada para esto es el denominado bootstrap de fuente, sin embargo debe poder implementarse sin aumentar excesivamente la complejidad del sistema. El objetivo asociado a este tema fue desarrollar un electrodo activo con impedancia de entrada aumentada utilizando bootstrap de fuente y conservando una topología de baja complejidad.

En todas las soluciones se siguió un criterio de diseño que buscó lograr robustez a partir de considerar condiciones pesimistas, simplicidad como punto de llegada, y disponibilidad a través del uso de componentes comerciales del mercado de consumo. Estos criterios apuntan a quebrar la barrera de aplicación en el laboratorio al mundo real.

\subsection{Organización de la tesis}

Instrumentación para neuroprótesis vestibles

Introducción En este capítulo se presenta la aplicación que motiva esta tesis: las neuroprótesis vestibles; dispositivos de asistencia que, con una instalación tan sencilla como vestir una prenda de indumentaria, deben ser capaces de interpretar la voluntad de su usuario y actuar sobre el mundo físico en consecuencia. ¿Cómo impactan estas especificaciones sobre la instrumentación de biopotenciales encargada de medir las señales de EEG y EMG, testigos de la voluntad?. Tras comentar brevemente el problema y el alcance de las soluciónes propuestas, se datalla la organización de la tesis.

Conceptos preliminares y antecedentes El problema a tratar se describe y se exploran en detalle las bases preliminares para enfrentarlo. Se exponen los requisitos que plantean las neuroprótesis vestibles, caracterizando los biopotenciales de interés y las técnica para su medida. Luego se exploran las características de los electrodos secos que exige el paradigma de los sistemas vestibles, y se presentan los modelos de instrumentación que permiten estudiar y diseñar soluciones para la problemática de interferencia electromagnética.

Adquisición de biopotenciales La adquisición de biopotenciales vio abrirse una nueva posibilidad a partir de la disponibilidad comercial de sistemas complejos integrados. Como alternativa al paradigma tradicional de medida basado en el amplificador de biopotenciales acoplado en alterna, existe uno protagonizado por los convertidores analógico digitales de muy alto rango dinámico, con ventajas en aplicaciones vestibles. En este capítulo se expone el diseño según este paradigma y los bloques de acondicionamiento 
analógico que requiere para adaptarse a las aplicaciones vestibles: electrodos activos para usos específicos, y mejoras en la realimentación de modo común.

Sistema de Adquisición de Biopotenciales En este capítulo se describe la implementación de un sistema de adquisición de biopotenciales en el estado del arte según el paradigma de medida basado en convertidores analógico digitales de alto rango dinámico. Se detalla el núcleo del sistema basado en un front-end integrado y los periféricos de acondicionamiento implementados en esta primera etapa: electrodos activos y un circuito independiente de rechazo de modo común. Se realizaron dos implementaciones: una para pruebas de laboratorio y otra como módulo de instrumentación para un sistema vestible.

Realimentación de modo común mejorada El circuito de realimentación de modo común tradicional con compensación por polo dominante, ha resultado un diseño sumamente exitoso, estable frente a la incertidumbre presente en el modelo de interferencia electromagnética, aunque imponiendo un límite al rechazo que puede obtenerse. Las condiciones de los sistemas vestibles y la evolución de la interferencia electromagnética hacen necesario mejorar el rechazo aportado por este circuito de acondicionamiento. En este capítulo se presenta una compensación alternativa que permite mejorar el rechazo sin comprometer la estabilidad del sistema, ya que su diseño se basa en los mismos criterios ampliamente probados en la práctica. El circuito resultante posee el mismo grado de complejidad que el tradicional, pero permite aumentar el rechazo cerca de $20 \mathrm{~dB}$ aportando a la robustez de los sistemas vestibles.

Electrodo activos para EMG Los biopotenciales musculares son una herramienta extremadamente útil para las neuroprótesis vestibles. Para esta aplicación es deseable conseguir una mayor selectividad espacial de las medidas y evitar interferencia de origen no sólo electromagnético sino también de otros músculos. Esto se logra mediante el uso de electrodos activos con amplificadores de múltiples entradas. En este capítulo se desarrollan herramientas teóricas para el análisis de estos amplificadores y se presenta un electrodo doble diferencial de baja complejidad.

Electrodo de dos hilos con bootstrap de fuente La punta de lanza de los sistemas de instrumentación para neuroprótesis vestibles es el electrodo activo, y, específicamente, su alta impedancia de entrada necesaria para atenuar las transformaciones de modo y artefactos que producen los electrodos secos. Este parámetro debe mejorarse respecto al disponible en dispositivos comerciales para dar el paso necesario hacia la robustez deseada de las neuropótesis vestibles. Se propone entonces un método de muy baja complejidad que permite superar estas limitaciones aumentando la impedancia de entrada a través de la técnica de bootstrap de fuente y permitiendo además utilizar solo dos conductores para transmitir señal y alimentación. 



\title{
Conceptos preliminares
}

\begin{abstract}
El problema a tratar se describe y se exploran en detalle las bases preliminares para enfrentarlo. Se exponen los requisitos que plantean las neuroprótesis vestibles, caracterizando los biopotenciales de interés y las técnica para su medida. Luego se exploran las características de los electrodos secos que exige el paradigma de los sistemas vestibles, $y$ se presentan los modelos de instrumentación que permiten estudiar y diseñar soluciones para la problemática de interferencia electromagnética.
\end{abstract}

\subsection{Neuroprótesis Vestibles}

Neuroprótesis (NP) es un "término paraguas" que abarca un conjunto de tecnologías. Existen dispositivos como los marcapasos (Haddad et al., 2006) que restablecen funciones autónomas del cuerpo, completamente transparentes para las personas; otros sensan parámetros del mundo físico y los alimentan al sistema nervioso de la persona, como los implantes cocleares (Zeng et al., 2008); algunos detectan la intención de movimiento y estimulan músculos del cuerpo, como los dispositivos de estimulación eléctrica funcional acoplados a medidas de EMG (Hart et al., 1998).

A grandes rasgos, puede establecerse una primera distinción de NPs en tres categorías: un grupo reemplaza o asiste funciones autónomas del cuerpo, otras proveen información a la persona reemplazando o aumentando los sentidos, y por último otras interpretan la voluntad y producen una acción en el mundo externo o el cuerpo mismo en consecuencia. Este último grupo es el de interés en esta tesis.

La voluntad de una persona encuentra su manifestación y consecuencia última en acciones, en el movimiento de su cuerpo ya sea para accionar mecánicamente sobre objetos o para comunicarse oralmente. Este proceso nace en el cerebro, se comunica a través del sistema nervioso y termina en órganos efectores. Un número de enfermedades o accidentes puede inhibir o directamente cortar estas vías de manifestación de la voluntad. Por ejemplo, la esclerosis lateral amiotrófica degenera la médula espinal y los nervios, los accidentes cerebrovasculares pueden causar hemiplejia, entre otras. Ante estas enfermedades, 
surge el desafío de restaurar la relación entre la persona y el mundo físico por la vía tecnológica alternativa que proveen las neuroprótesis.

Estos dispositivos que interpretan la intención del usuario dependen de los biopotenciales como entradas. En particular el EEG, ENG y el EMG permiten acceder a esta información. Las aplicaciones en neuroprótesis hacen uso extensivo de estas señales (Navarro et al., 2005; Woźniak et al., 2013; Mihajlovic et al., 2015), las cuales proveen un enlace directo a actividad eléctrica que el usuario puede controlar voluntariamente.

Los biopotenciales pueden medirse de forma invasiva y no invasiva. La primera provee un muy buen acceso a la información y es utilizada en las neuroprótesis implantables. Sin embargo, la decisión de someterse al procedimiento de implante de los dispositivos de medida es difícil de tomar y conlleva algunos riesgos. Aún más, el uso de muchas neuroprótesis es de carácter transitorio, como los exoesqueletos para rehabilitación, o aquellas que deban modificarse al progresar una enfermedad. En estos casos se recurre al uso de tecnologías no invasivas.

Pueden agruparse como NPs una serie de tecnologías que son capaces de operar en forma no invasiva:

Las interfaces cerebro-computadora (ICCs): Son dispositivos basados principalmente en electroencefalografía que intentan descifrar la actividad neuronal orientada a producir respuestas motoras y utilizar esa información para emitir comandos en una computadora. Las versiones más difundidas son los deletreadores como el muy popular deletreador de Farwell y Donchin, 1988 basado en P300. Técnicas con una tasa de datos mayor permiten implementar interfaces más complejas (Cheng et al., 2002).

Las interfaces hombre-máquina (IHMs): Un término más general que ICC, también se basan en señales de EEG o de EMG e interpretan la voluntad del usuario o el efecto de la misma sobre sus músculos, pero su fin es controlar dispositivos mecánicos como prótesis o exoesqueletos. Un área muy promisoria es en rehabilitación motora tras accidentes cerebro-vasculares (Looned et al., 2014), donde la medida localizada de EMG es muy importante para evaluar el progreso pero también para determinar cuándo y con cuanta fuerza el mecanismo de rehabilitación debe accionarse (Ang y Guan, 2015).

Los dispositivos de estimulación eléctrica funcional (FES): El objetivo es estimular el sistema nervioso o muscular para producir movimientos o sensaciones en el usuario. Muchos sistemas son implantables, mientras otros utilizan estimulación transcutánea (Pons et al., 2013). Las neuroprótesis basadas en FES pueden estar comandadas por señales electroencefalográficas (en modo similar a las HMIs) o por señales electromiográficas.

En todas estas aplicaciones existe un fuerte interés por obtener dispositivos cada vez más confortables para el paciente o usuario, con la posibilidad de utilizarlos en ambientes no controlados y sin supervisión profesional (Waterhouse, 2003; Park y Jayaraman, 2003; Zheng et al., 2014). Sistemas simplificados, amigables y aptos para su uso en el hogar podrían habilitar sesiones de terapia diaria, o proveer la confianza y comodidad para ser usados diariamente por personas que de otra manera necesitan asistencia permanente (Berger et al., 2008).

Pero para que su uso sea realmente exitoso deben ser suficientemente confortables y otorgar independencia al usuario. Así se arriba al concepto de tecnología "vestible".

Para incrementar realmente la independencia y calidad de vida del usuario, las NPs no invasivas deben contar con una serie de propiedades correspondientes al paradigma de los dispositivos vestibles (Mihajlovic et al., 2015): aquellos que 
se usan con la misma simplicidad que una prenda de vestir. Deben poder ser utilizadas en ambientes no controlados y sin supervisión profesional, no deben obstruir la actividad diaria ni quitar confort a sus usuarios (Berger et al., 2008; Zheng et al., 2014). Como restricción adicional debe considerarse la barrera de acceso que representa el costo y mantenimiento para usuarios e instituciones de salud.

Una gran parte de la responsabilidad para lograr esos objetivos recae en la instrumentación para adquirir las señales, y estas condiciones hacen que los desafíos tradicionales de la instrumentación de biopotenciales, principalmente el rechazo a interferencia electromagnética y artefactos, tomen una nueva y profunda relevancia. La instrumentación no solo debe cumplir con requisitos estrictos de tamaño, peso, eficiencia energética y robustez; sino que además es fundamental que el sensor de biopotenciales sea el electrodo de tipo seco (Berger et al., 2008; Chin-Teng Lin et al., 2014). Estos transductores son excelentes en cuanto al confort y simplicidad de instalación, pero sus propiedades eléctricas son muy pobres comparadas con los electrodos húmedos: poseen impedancias de alto valor, impredecibles y desbalanceadas (Searle y Kirkup, 2000; Chi, Y. T. Wang et al., 2012), que conducen a sistemas muy vulnerables a fuentes de EMI y artefactos (E. M. Spinelli, Mayosky et al., 2006).

\subsection{Origen y caracterización de biopotenciales}

Los organismos biológicos producen potenciales eléctricos y dependen de ellos para transmitir información. Las células pueden establecer potenciales de transmembrana controlando el flujo de iones, manteniendo, en estado de reposo, un potencial en el orden de los $70 \mathrm{mV}$. En la membrana, cuentan con canales que pueden permitir, como compuertas, el paso de iones siguiendo el gradiente de potencial despolarizando la membrana. Para volver a su estado de reposo, bombas de iones permiten recomponer la polarización gastando energía metabólica. Este mecanismo además está acompañado de otro de gran importancia: la membrana detecta cuando el potencial en regiones adyacentes cae por debajo de un umbral y dispara el mecanismo de despolarizaciónrepolarización. Así, el fenómeno se propaga a lo largo de la membrana celular, dando lugar a una señal que se desplaza en el espacio conocida como potencial de acción (Hodgkin y Huxley, 1939). Estos potenciales de acción son la herramienta básica de las células para procesar información en el cerebro y transmitirla en el sistema nervioso y los músculos.

Si bien los potenciales de acción se originan como diferencias de potencial eléctrico entre el interior y el exterior de la membrana celular, el flujo de iones que se produce cuando son emitidos resulta en diferencias de potencial en la solución y tejidos del entorno de la célula (Plonsey y Barr, 2000). Como ejemplo puede aproximarse un nervio como una célula cilíndrica con un eje alargado, como se representa en la figura 2.1. Si un potencial de acción está transitando por la pared de este cilindro, localizado en un punto $A$ en un tiempo $t$, en el punto $A_{1}$ existirá una fuente de corriente iónica tratando de despolarizar la membrana para que el potencial avance, y en el punto $A_{2}$ otra intentando repolarizarla. Por lo tanto pueden dibujarse esquemáticamente líneas de densidad de flujo de corriente iónica en el medio extracelular, producidas por las células. Si el medio externo se considera un conductor de volumen, estas corrientes producen caídas de potencial según la conductividad de este elemento, y el efecto de las fuentes de varias células puede superponerse. Las líneas de flujo de corriente más alejadas llegan incluso a la piel y dan origen a los biopotenciales superficiales. 


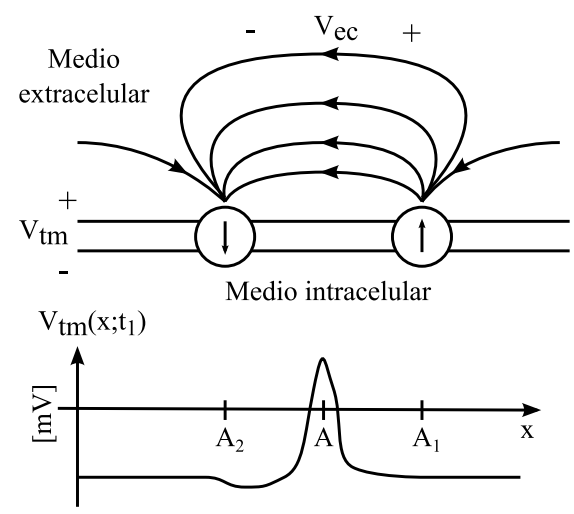

Figura 2.1: Representación esquemática de la generación de biopotenciales extracelulares a partir de potenciales de acción.

En el cerebro, las neuronas utilizan constantemente potenciales de acción y existe una gran concentración espacial de disparos de estos potenciales. Excepto en casos especiales, los flujos de corriente iónica generados por las neuronas tienen orientaciones con una distribución aleatoria sin características reconocibles. Sin embargo, estos casos especiales son los que permiten observar ciertas funciones del cerebro desde la piel. Cuando muchas neuronas se sincronizan en una actividad, la superposición de corrientes iónicas resulta constructiva y desarrolla señales identificables, con magnitudes suficientemente amplias para diferenciarlas de la actividad del fondo de ruido.

Así, cuando las neuronas del centro de procesamiento visual del cerebro (en la zona occipital) se relajan al cerrar los ojos, sus potenciales sincronizados producen una onda de aspecto senoidal en el orden de los $10 \mathrm{~Hz}$ que puede desarrollar diferencias de potencial en el cuero cabelludo en el orden de las decenas de $\mu \mathrm{V}$. La clínica médica les ha dado nombres particulares a las señales originadas por procesos identificables, el caso ejemplificado se denomina ritmo $\alpha$ y suele utilizarse como señal de prueba al medir biopotenciales del cerebro por ser fácil de provocar y repetible.

Los biopotenciales originados en el cerebro se miden en un electro-encefalograma o EEG. Entre las señales registradas en el EEG aparecen algunas que se relacionan con acciones que la persona realiza, o piensa en realizar, voluntariamente: el mencionado ritmo $\alpha$, potenciales evocados motores; otras señales pueden ser provocados en forma repetible a partir de estímulos, como la onda P300 provocada por la sorpresa, o los potenciales evocados visuales. La tabla 2.1 lista como referencia algunos potenciales cerebrales relacionados con la voluntad o el estímulo y los parámetros usuales considerados como señales eléctricas.

En contraste con la organización de células del cerebro, las fibras musculares se agrupan en ramos conectados a un único nervio en un punto de anclaje. Este conjunto se conoce como unidad motora, y es la mínima unidad muscular que el cerebro puede comandar en forma independiente. La contracción de un músculo requiere el reclutamiento de varias de sus unidades motoras. Las neuronas en la corteza motora del cerebro disparan trenes de potenciales de acción que viajan por el sistema nervioso periférico hasta las unidades motoras. Para aumentar el esfuerzo de contracción de una unidad motora, la neurona envía trenes de potenciales de mayor frecuencia, y para aumentar la fuerza total ejercida se reclutan cada vez más unidades motoras y músculos. 
2.3. Electrodos para la medida no invasiva de biopotenciales

\begin{tabular}{llll}
\hline Registro & Señal & $\begin{array}{l}\text { Ancho de ban- } \\
\text { da }[\mathrm{Hz}]\end{array}$ & Amplitud $[\mathrm{uV}]$ \\
\hline EEG & Ritmo $\alpha$ & $7.5-13$ & $10-100$ \\
& SSVEP & $3.5-75$ & $2-20$ \\
& P300 & $0.1-10$ & $2-5$ \\
\multirow{2}{*}{ EMG } & EEG general & $0.1-100$ & $1-100$ \\
& Espigas & $10-4000$ & $10-1000$ \\
& EMG general & $10-450$ & $10-1000$ \\
\hline
\end{tabular}

Tabla 2.1: Valores característicos de señales de biopotencial (Webster, 1988; Amiri et al., 2013; Prutchi y Norris, 2005).

Los trenes de potenciales de acción pueden ser capturados mediante un electro-neuro-grama o ENG, antes de arribar al músculo, o ya en el músculo mediante un electro-mio-grama o EMG. Debido a la participación de varias unidades motoras en un mismo esfuerzo, el potencial sobre la piel es el resultante de la superposición de muchos potenciales de acción. Como resultado, si bien la amplitud de los potenciales de acción es siempre constante, al aumentar el esfuerzo aumenta la amplitud de la envolvente de la señal de EMG. En la tabla 2.1 se muestran parámetros característicos de la señal de EMG.

\subsection{Electrodos para la medida no invasiva de biopotenciales}

\subsubsection{Propósito y clasificación de los electrodos}

Los potenciales de origen biológico se originan por concentración de cargas iónicas, por lo tanto para medirlos con equipos electrónicos es necesario utilizar transductores. Estos transductores reciben el nombre de electrodos y son una pieza determinante en un sistema de medición de biopotenciales.

El método más directo para medir las señales de biopotencial es colocar electrodos lo más cerca posible de la fuente: los electrodos de tipo aguja penetran en el cuerpo y se posicionan en el entorno cercano del nervio, fibra muscular, e incluso vecindad de neuronas cuya actividad eléctrica se desea conocer. Estos métodos se conocen como "invasivos". Otra clase de dispositivos funcionan en base a señales obtenidas sin penetrar la piel, en lo que se conoce como medidas de biopotenciales no invasivas.

La figura 2.2 muestra una representación esquemática del electrodo aplicado sobre la piel. La placa de contacto del electrodo en si está formada por materiales muy diversos, desde metales como plata o acero inoxidable hasta gomas conductoras.

En los electrodos de tipo húmedo se aplica un electrolito entre la placa de contacto y la piel que puede ser, por ejemplo, líquido o un gel. El electrolito facilita el intercambio electrónico entre los iones que portan las cargas de los biopotenciales y la placa de contacto que está conectada al circuito de medida. Los electrodos descartables comerciales de uso más difundido poseen una placa de plata $(\mathrm{Ag})$ recubierta por cloruro de plata $(\mathrm{AgCl})$ y un electrolito en forma de gel pre-adherido a la placa de contato. En la figura 2.3(a) se observa una foto de uno de estos electrodos. Existen distintos factores de forma y área según la aplicación. Los electrodos húmedos para EEG suelen tener forma cóncava que les permite retener pasta electrolítica, como se muestra en la figura 2.3(b), o tener 


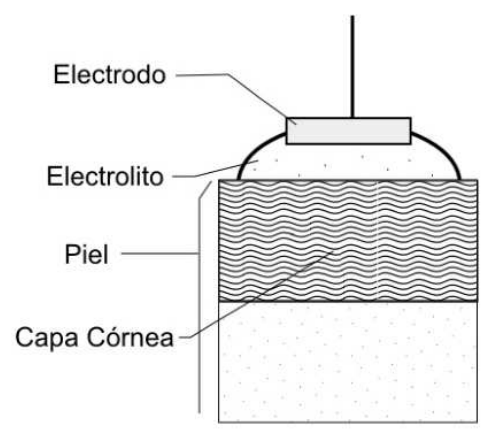

Figura 2.2: Representación esquemática de un electrodo colocado sobre la piel.

adherido un material esponjoso para embeber un electrolito líquido. El área de estos electrodos suele estar entre $0.1 \mathrm{~cm}^{2}$ y $1 \mathrm{~cm}^{2}$

Por otro lado, en los electrodos llamados "secos", no se aplica un electrolito pero, transcurrido un tiempo luego de su aplicación, se acumula transpiración debajo de la placa de contacto del electrodo (Geddes y Valentinuzzi, 1973) que cumple una función similar. Los electrodos para EMG en algunos casos se colocan más cerca unos de otros y la aplicación de electrolito puede cortocircuitar sus placas de contacto, por lo que es necesario que sean secos. Su área está en el orden o por debajo de $0.1 \mathrm{~cm}^{2}$ y muchos tienen forma de varilla como se observa en la figura 2.3(c). En el caso de electrodos secos para EEG, un desafío importante, aunque en principio luce trivial, es el cabello. Sin aplicación de electrolito, los electrodos secos buscan distintas estrategias mecánicas para lograr tomar contacto con el cuero cabelludo evitando el cabello. Una estrategia que alcanzó relativo éxito es la de electrodos incorporando varios "dedos", como se observa en la figura $2.3(\mathrm{~d})$.

La piel sobre la que se coloca el electrodo a su vez puede representarse en forma simplificada por dos capas, una más externa, usualmente más seca, y la interna. La capa externa de piel, el estrato córneo, es el factor más problemático en las medidas de biopotencial, y en esto radica una de las mayores diferencias entre los sistemas vestibles y otros equipos de instrumentación de biopotenciales. En entornos controlados, puede prepararse la piel limpiándola, frotándola con un paño embebido en un electrolito, por ejemplo solución fisiológica, e incluso raspando la capa externa. Los electrodos secos utilizados en NPV, se apoyan directamente sobre la capa más externa de piel sin preparación.

Para estudiar el impacto que el tipo y modo de uso de los electrodos tiene sobre los sistemas de medida de biopotenciales, los mismos se modelan con parámetros eléctricos que permiten incluirlos en los circuitos de instrumentación.

\subsubsection{Modelo eléctrico de la interfaz electrodo-piel}

La figura 2.4 muestra un modelo eléctrico lineal y de parámetros concentrados del electrodo aplicado sobre la piel (Geddes y Valentinuzzi, 1973; Searle y Kirkup, 1999).

El fenómeno inicialmente más notorio es que la interfaz entre el material de la placa de contacto del electrodo y el electrolito aplicado, o la humedad de la piel, produce un potencial de continua $E$. Debido a la naturaleza de las reacciones en los electrodos, se produce una separación de cargas, con iones de un signo formando una película sobre la superficie metálica del electrodo, y una 


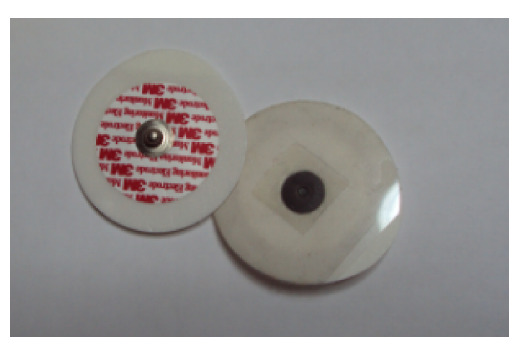

(a)

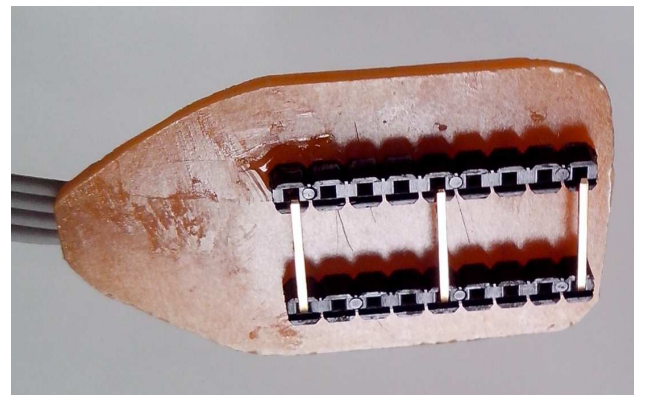

(c)

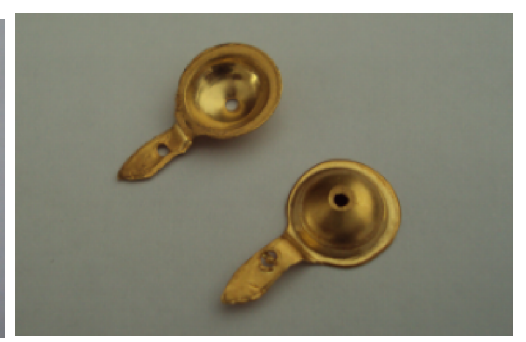

(b)

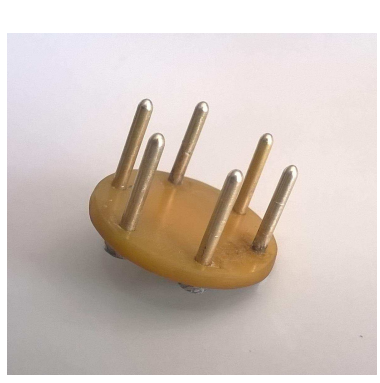

(d)

Figura 2.3: (a) Electrodo húmedo de $\mathrm{Ag} / \mathrm{AgCl}$. (b) Placas de contacto de electrodos húmedos para EEG de cobre dorado, se utilizan con pasta electrolítica. (c) Tres electrodos secos de EMG de tipo varilla, de cobre dorado. (d) Electrodo seco para EEG.

capa inmediatamente adyacente con iones de signo opuesto. Esto tiene el efecto de producir una tensión constante, dependiente del metal del electrodo y los iones del electrolito, conocida como potencial de semipila. Por ejemplo, al utilizar electrodos húmedos comunes descartables de $\mathrm{Ag} / \mathrm{AgCl}$, la reacción establece un potencial de hasta $200 \mathrm{mV}$. La amplitud del potencial $E$ resulta variable aún entre pares similares de electrodos.

La interfaz electrodo-electrolito y su característica doble capa iónica presenta una impedancia representada por la capacidad $C_{w}$ en paralelo con la resistencia $R_{w}$ que da cuenta de la corriente galvánica que también circula por la interfaz. El electrolito en sí presenta un resistencia $R_{w b}$. En forma similar, la piel presenta una capa externa mas bien aislante, en el caso extremo sólo existiría un acople capacitivo $C_{s}$ entre el electrodo y el tejido conductivo en el interior del cuerpo. Sin embargo, ante la presencia de un electrolito o la humedad natural de la piel existe conducción galvánica representada por la resistencia $R_{s}$. La capa más interna de piel presenta una resistencia $R_{s b}$. Por último, se diferencia la resistencia del tejido interno en el recorrido hasta la fuente de biopotencial, $R_{b}$.

Todos los parámetros que componen el modelo del electrodo tienen valores altamente variables de acuerdo a una lista significativa de factores:

- El material del electrodo y la composición del electrolito

- El área y factor de forma del electrodo

- La presión aplicada

- El grosor, humedad, y composición electrolítica de la piel

- El tiempo de aplicación en el corto plazo (segundos a minutos) debido a la variación de la humedad de la piel

- El tiempo de aplicación en el largo plazo (horas) debido a la variación de humedad del electrolito 


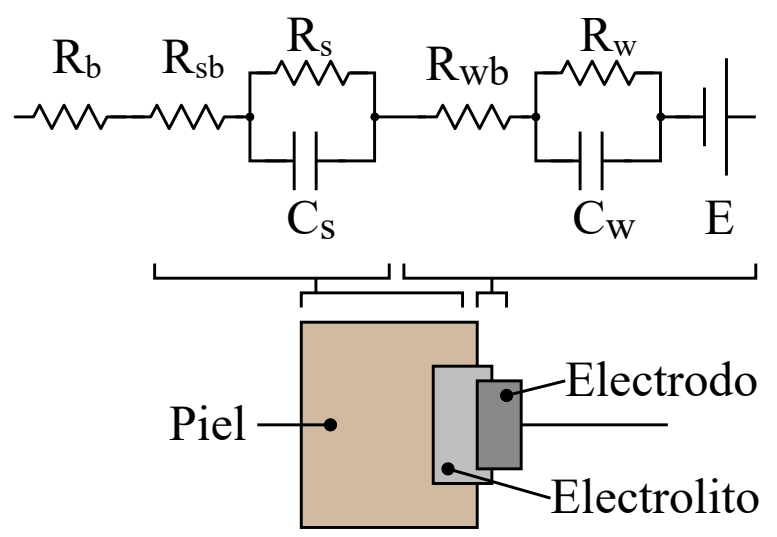

Figura 2.4: Modelo circuital equivalente del electrodo.

Por lo tanto, el rango de valores que pueden tomar los parámetros del modelo es difícil de determinar y en general se definen órdenes de magnitud para distintas situaciones de medida.

En el caso de los electrodos húmedos colocados sobre piel preparada, los componentes del modelo que resultan dominantes son los resistivos, y la resistencia total resulta relativamente consistente con valores entre 1 y $10 \mathrm{kHz}$ (Searle y Kirkup, 1999; Prutchi y Norris, 2005). En este caso la impedancia es determinada mayormente por las características de la interfaz electrodoelectrolito (Grimnes, 1983).

\subsubsection{Electrodos secos}

Cuando se utilizan electrodos secos, en cambio, resulta dominante la impedancia de la piel. En los primeros instantes luego de aplicar el electrodo, domina la capacidad $C_{s}$ pero rápidamente (en el orden de algunos segundos) la humedad que aporta la transpiración vuelve dominante el componente resistivo $R_{s}$. Este componente resistivo de la piel es además mayor que el total de la impedancia correspondiente a la interfaz electrodo-electrolito, y por lo tanto es razonable representar a todo el electrodo por un componente resistivo equivalente (Geddes y Valentinuzzi, 1973).

Un gran cuerpo de trabajos en la literatura se han dedicado a la obtención de electrodos secos aptos para medidas de biopotenciales y al estudio de su impedancia. Como conclusión general, se encuentra que los electrodos secos tienen mayores valores de impedancia comparados con los electrodos húmedos y alcanzan valores en el orden de $100 \mathrm{M} \Omega$ en casos extremos, y en el caso general entre $100 \mathrm{k} \Omega$ y $10 \mathrm{M} \Omega$ en las frecuencias de medida de biopotenciales (Geddes y Valentinuzzi, 1973; Searle y Kirkup, 2000; Gandhi et al., 2011; H. C. Jung et al., 2012; Taji et al., 2013; Yokus y Jur, 2015; Kappel y Kidmose, 2015). Aquellos que alcanzan valores resistivos por debajo de los $100 \mathrm{k} \Omega$ tienen una superficie mayor a $1 \mathrm{~cm}$ (Liao et al., 2012; Yoo et al., 2009). Al aumentar la humedad debido a la acumulación de transpiración bajo el electrodo disminuye la impedancia, y puede tomarse como referencia un valor de $100 \mathrm{k} \Omega$.

La evolución comparativa en el tiempo de la impedancia de electrodos secos y húmedos se representa esquemáticamente en el gráfico de la figura 2.5. Si bien los motivos para preferir electrodos secos a pesar de su elevada impedancia se originan en evitar tiempos prolongados de preparación, no requirir suministros extra ni descartar electrodos, y evitar posibles irritaciones de la piel, se observa 


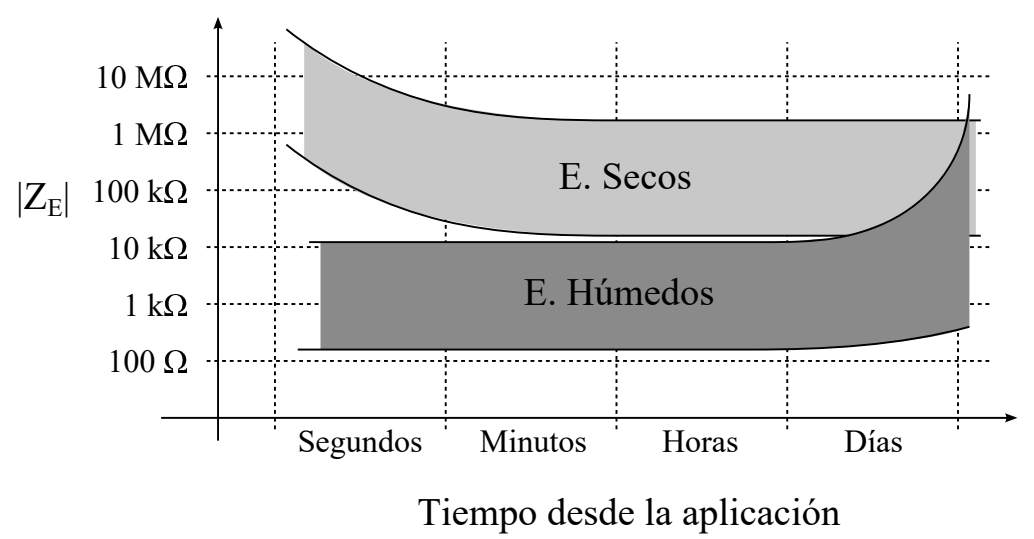

Figura 2.5: Representación esquemática de la evolución de la impedancia (en módulo) de electrodos húmedos y secos.

que una ventaja clave de los electrodos secos radica en su posibilidad de uso de largo plazo (Fonseca et al., 2007; Chi, T.-P. Jung et al., 2010; Yokus y Jur, 2015). Por ejemplo, superando el uso en el rango de 8 horas, los electrodos húmedos de EEG comienzan a secarse y se degrada significativamente el funcionamiento de los equipos (Davis et al., 2013).

\subsubsection{Ruido de la interfaz electrodo-piel}

Existen múltiples fenómenos en la interfaz electrodo-electrolito que producen variaciones rápidas en la tensión de offset. Adicionalmente, cuando el electrodo se aplica sobre la piel, se forma una nueva interfaz entre el electrolito y el tejido. Searle y Kirkup, 2000 concluyen que el ruido del electrodo es mayor al ruido térmico producido por una resistencia de valor equivalente a su impedancia , y su origen se encuentra predominantemente en la interfaz entre el electrolito y la piel y por lo tanto varía con sus propiedades.

El espectro de potencia en del ruido producido en el conjunto electrodoelectrolito-piel tiene una característica que puede aproximarse por una función $1 / f^{\alpha}$, con $1,5<\alpha<2$. En un ancho de banda entre $0.5 \mathrm{~Hz}$ y $500 \mathrm{~Hz}$, el valor eficaz cuadrático medio varía entre 1 y $5 \mu \mathrm{V}_{\text {rms }}$ para electrodos de $\mathrm{Ag} / \mathrm{AgCl}$, aunque puede llegar a los $10 \mu \mathrm{V}_{\text {rms }}$ cuando se utilizan soluciones electrolíticas en gel con menor humedad. En general la tensión de ruido tiende a decrecer con el transcurso del tiempo, aunque muy lentamente en el espacio de varios minutos.

Nathan y Jafari, 2014 reportan ruido para los electrodos secos de tipo "dedos" para EEG de $3.5 \mu \mathrm{V}_{\text {rms }}$ pero logran reducirlo a un promedio de $2 \mu \mathrm{V}_{\text {rms }}$ a través de la selección activa de los dedos de los que se tomará señal. Este es un límite inferior que puede esperarse para este tipo de electrodos.

Los electrodos también presentan variaciones muy lenta en su offset. La expresión "fluctuaciones lentas" se utiliza para denominar las desviaciones que ocurren el tiempos del orden de las decenas de minutos, en la línea de base, i.e., el valor de continua sobre el que se ve "montada" la señal.

\subsection{Topologías para la medida de biopotenciales}

Conocidos los biopotenciales y electrodos de interés para las aplicaciones de neuroprótesis vestibles, surge la pregunta de cómo medir, desde el punto de 


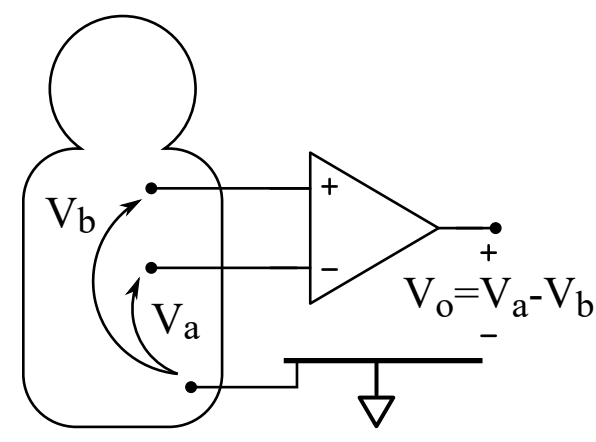

(a)

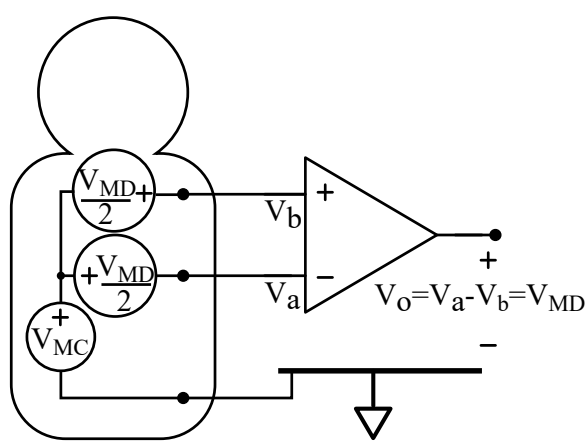

(b)

Figura 2.6: (a) Medida diferencial de biopotenciales con tercer contacto de referencia. (b) Representación en modo común y modo diferencial.

vista de la instrumentación, esos potenciales con las condiciones que imponen los transductores existentes.

Debido a que los biopotenciales se originan en fuentes dentro del cuerpo, es natural que deban medirse siempre referidos a otro potencial del cuerpo mismo. Por ello naturalmente las medidas de biopotenciales son diferenciales.

Por otro lado, el sistema de medida puede admitir un cierto rango de potenciales en su entrada respecto de la masa del circuito. En principio, el cuerpo se encuentra a un potencial desconocido respecto al potencial de masa, sin nada que los vincule. Se hace necesario por lo tanto un tercer contacto con el cuerpo para establecer ese potencial de referencia. Esta situación de medida se diagrama en la figura 2.6(a), donde el sistema de medida se representa por un amplificador diferencial de ganancia unitaria.

En la figura 2.6(a) se ha identificado la señal de interés a partir de dos señales de amplitud $V_{a}$ y $V_{b}$, que constituyen los potenciales de cada entrada referidos a la masa del sistema. Sin embargo, cada una de estas señales no son representativas de los fenómenos de interés. Es más útil obtener la diferencia entre estos potenciales por un lado, y su promedio por el otro, lo que se conoce como señal de modo diferencial $V_{M D}$ y modo común $V_{M C}$ respectivamente, con la representación de la figura 2.6(b) y la siguiente expresión:

$$
\left[\begin{array}{l}
V_{\mathrm{MD}} \\
V_{\mathrm{MC}}
\end{array}\right]=\left[\begin{array}{cc}
1 & -1 \\
1 / 2 & 1 / 2
\end{array}\right]\left[\begin{array}{l}
V_{a} \\
V_{b}
\end{array}\right]
$$

Esta descomposición es útil porque el modo diferencial corresponde, en principio, a la señal de biopotencial, que es la señal de interés que el amplificador diferencial debe entregar libre de distorsión o interferencia. La señal de modo común tiene un origen distinto, e interesa rechazarla.

El modelo eléctrico completo, útil para el análisis de interferencia que se verá en la sección 2.5.2, incluye el modelo de electrodo en cada conexión con el cuerpo. El origen de la señal se representa por una fuente de tensión en el cuerpo y la resistencia interna de bajo valor hasta los puntos de contacto, como se representa en la figura 2.7. Se observan en este modelo los siguientes puntos clave:

- Los potenciales de continua de los electrodos quedan interpuestos en serie con la fuente de biopotencial en la medida; resultan en un potencial de continua en el modo diferencial. El offset neto será $E_{1}-E_{2}$, pero debido al desbalance que puede existir entre los dos potenciales, en general 


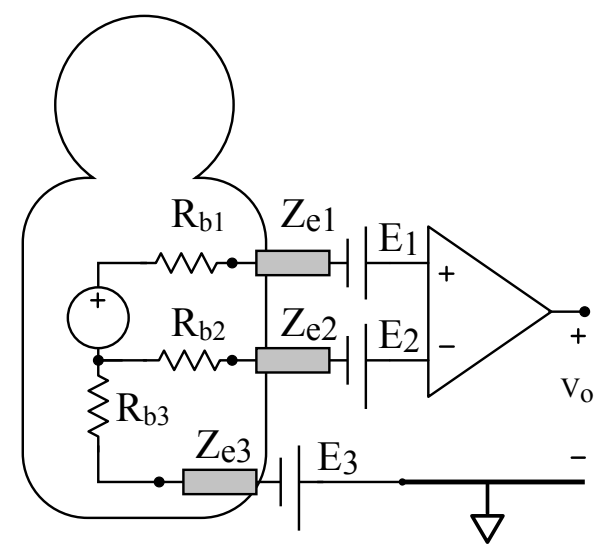

Figura 2.7: Modelo completo de la medida de biopotencial.

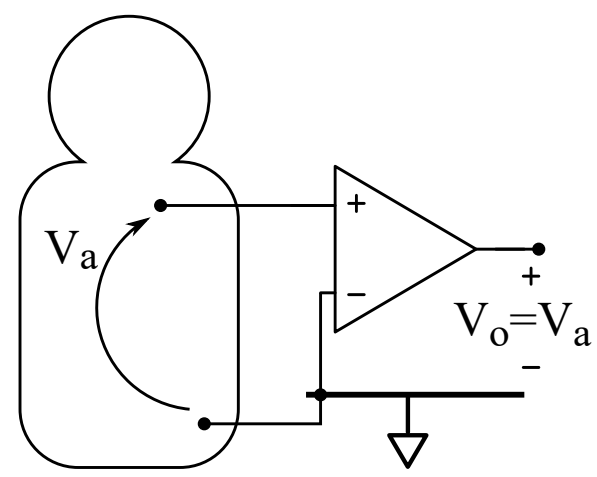

Figura 2.8: Medida single-ended.

el orden de magnitud esperable de esta tensión está en los $100 \mathrm{mV}$. Una cota ampliamente usada es la mencionada en la norma AAMI para electrocardiógrafos (2007) que estipula que los equipos de medida deben admitir un offset de $\pm 300 \mathrm{mV}$.

- La conexión de "referencia de potencial" o tercer electrodo, incluye una impedancia en general elevada y las corrientes que puedan circular por ella producirán una tensión de modo común.

- Para muchos casos de estudio, es suficiente considerar un modelo simplemente resistivo para $Z_{e}$. Los valores de $Z_{e 1}, Z_{e 2}$ y $Z_{e 3}$ serán en general distintos con desbalances en el orden del $100 \%$ aún para electrodos cercanos y similares.

Una alternativa a la medida diferencial es la que se conoce por el término inglés single-ended o SE. Conceptualmente también constituye una diferencia de dos potenciales, pero la conexión del segundo electrodo con el sistema de medida tiene características distintas, no es balanceada, y esto modifica el circuito haciéndolo en general menos robusto frente a interferencia. La figura 2.8 demuestra esta medida.

Los conceptos anteriores pueden extenderse a sistemas de medida multicanal. Cada canal puede obtenerse a partir de un par diferencial independiente, o puede referirse a un potencial de referencia común a todos. Además existe una tercer alternativa, denominada topología monopolar, que consiste en referir 


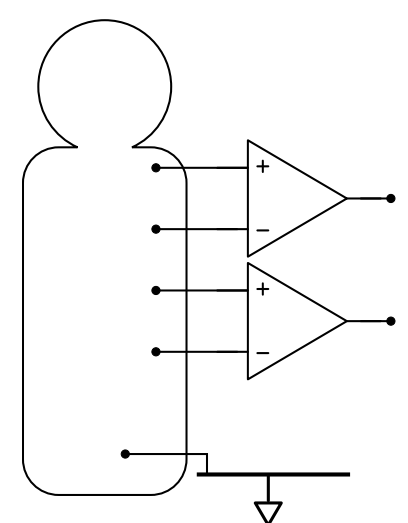

(a)

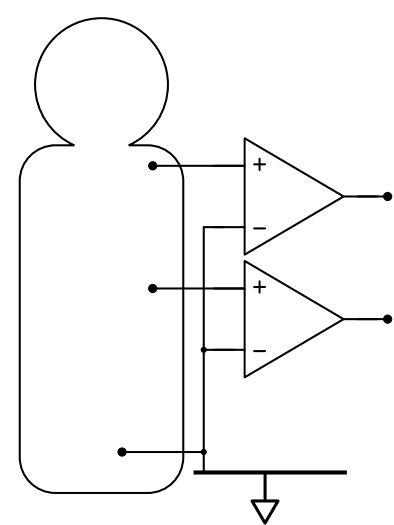

(b)

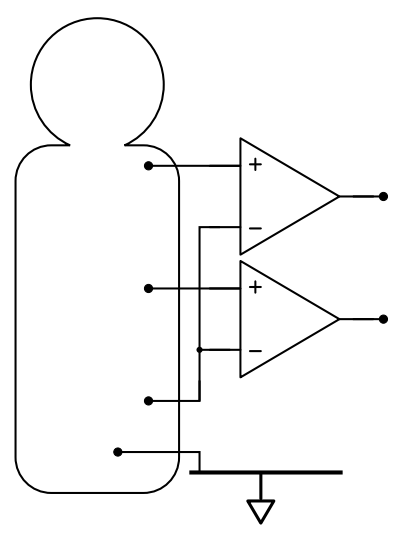

(c)

Figura 2.9: Topologías multicanal (a) Diferencial (b) Monopolar (c) Single-Ended .

todos los canales a un electrodo en común, en lugar de utilizar un potencial constante. Estas topologías se muestras en las figuras 2.9(a), 2.9(b) y 2.9(c) respectivamente.

\subsection{Interferencia electromagnética}

\subsubsection{Características de las fuentes de interferencia electromagnética}

El principal desafío que enfrentan los equipos de medida de biopotenciales es rechazar las fuentes de interferencia electromagnética (EMI). La presencia de una señal extraña en una medida es claramente un problema en la clínica médica porque conduce al diagnóstico erróneo o al descarte de un estudio; en un sistema autónomo como las NPVs, puede provocar pérdida de funcionalidad y falsas detecciones de eventos.

Distintos mecanismos hacen a los circuitos de medida víctimas de las señales eléctricas que se desarrollan durante el funcionamiento normal de otros dispositivos: radios, teléfonos celulares, infraestructura de red inalámbrica, instalaciones de iluminación, y la línea de transmisión de energía eléctrica, entre otras.

Las fuentes de interferencia de alta frecuencia (HF, VHF y UHF) actúan en general a través de la emisión de ondas electromagnéticas para las cuales porciones del circuito de medida pueden funcionar como antenas. Si bien la frecuencia de este tipo de interferencia está varios órdenes de magnitud alejada de la de señales de biopotencial, su demodulación en componentes no lineales del circuito puede producir tensiones dentro de esta banda, y variaciones de offset (Van Der Horst et al., 1998). Los teléfonos celulares logran en algunos casos enmascarar las señales de biopotencial de mayor amplitud como el ECG (Wong et al., 2012). Este problema es de relativamente fácil solución ya que el blindaje y los filtros para altas frecuencias son sencillos de implementar. Inclusive, los amplificadores operacionales de precisión modernos suelen incluir filtros de EMI de alta frecuencia, con frecuencias de corte en el orden de $10 \mathrm{MHz}$ (Hall y Kuehl, 2015).

La fuente de interferencia más nociva para la instrumentación de biopotenciales es la red de distribución de energía eléctrica, debido a que la frecuencia fundamental de $50 / 60 \mathrm{~Hz}$ y sus armónicos se encuentran dentro de la banda de 


\begin{tabular}{ccc}
\hline $\begin{array}{c}\text { Orden del } \\
\text { armónico }\end{array}$ & $\begin{array}{c}\text { Frecuencia } \\
{[\mathrm{Hz}]}\end{array}$ & $\begin{array}{c}\text { Amplitud relativa } \\
\text { al 1er armónico }\end{array}$ \\
\hline 3 & 150 & $5 \%$ \\
\hline 5 & 250 & $6 \%$ \\
\hline 7 & 350 & $5 \%$ \\
\hline
\end{tabular}

Tabla 2.2: Valores presentados por Berthet et al., 2003 para armónicos de red.

interés de las señales de biopotencial. El problema es especialmente importante porque todos los ambientes en los que las personas desarrollan actividades a diario están provistos de una instalación eléctrica con conductores incluso cercanos al cuerpo por largos períodos al utilizar veladores de escritorio, PCs, entre otros.

Las fuentes de baja frecuencia (SLF y ULF) pueden interferir con el circuito de medida a través de acoplamientos capacitivos o inductivos. La EMI de red ha sido profusamente estudiada en la literatura y los mecanismos de interferencia son conocidos, sin embargo, un gran volumen de trabajos que intentan remediar el problema a través del procesamiento de las señales adquiridas y la incorporación de filtros de supresión de banda de interferencia (fitros notch) en dispositivos comerciales (Costa y Tavares, 2009; Zivanovic y González-Izal, 2013) evidencia que es un problema activo para medidas no invasivas. A su vez, la mayor parte de la bibiliografía se dedica a estudiar este fenómeno en el contexto de las medidas de ECG, y quizás por ese motivo no se hace énfasis en el problema de los armónicos sino en el rechazo que el sistema presenta a la frecuencia fundamental de red. Las medidas de EMG se extienden desde el orden de los $\mathrm{Hz}$ hasta los $450 \mathrm{~Hz}$ y por lo tanto los nueve primeros armónicos de red caen en la banda de interés.

El uso creciente de dispositivos electrónicos en el mercado de consumo produce niveles significativos de armónicos en las redes de baja tensión. Berthet et al., 2003 analizan estadísticamente los armónicos en estaciones transformadoras de baja tensión en varias ciudades francesas. Encuentran que los armónicos impares están en valores cercanos a los límites permitidos por las regulaciones para el 3er, 5to y $7 \mathrm{mo}$ armónico, superando estos límites en el caso particular del 5 to armónico. Concluyen que la situación es peor en las redes cercanas a los usuarios debido a que las medidas se efectúan en puntos donde los armónicos están atenuados respecto a su valor en lugar de origen. Por lo tanto es razonable asumir que en general la red tendrá una presencia de armónicos 3 al 7 con valores en el orden de los límites descriptos en ese trabajo, presentados en la tabla 2.2 .

En general, desde la década de 1990 se ha producido un aumento en la amplitud del tercer y quinto armónico (Berthet et al., 2003; Jewell y Ward, 2002), y un aumento no cuantificado en los armónicos pares (Bollen y Olofsson, 2015), que están dentro de la banda del EMG. Otro fenómeno relativamente reciente es la aparición de los llamados supra-armónicos entre 1 y $10 \mathrm{kHz}$ ocasionados, por ejemplo, por los circuitos de las luces fluorescentes (E. M. Spinelli, Martínez et al., 1999) y más recientemente de las luminarias LED (Bollen y Olofsson, 2015). 


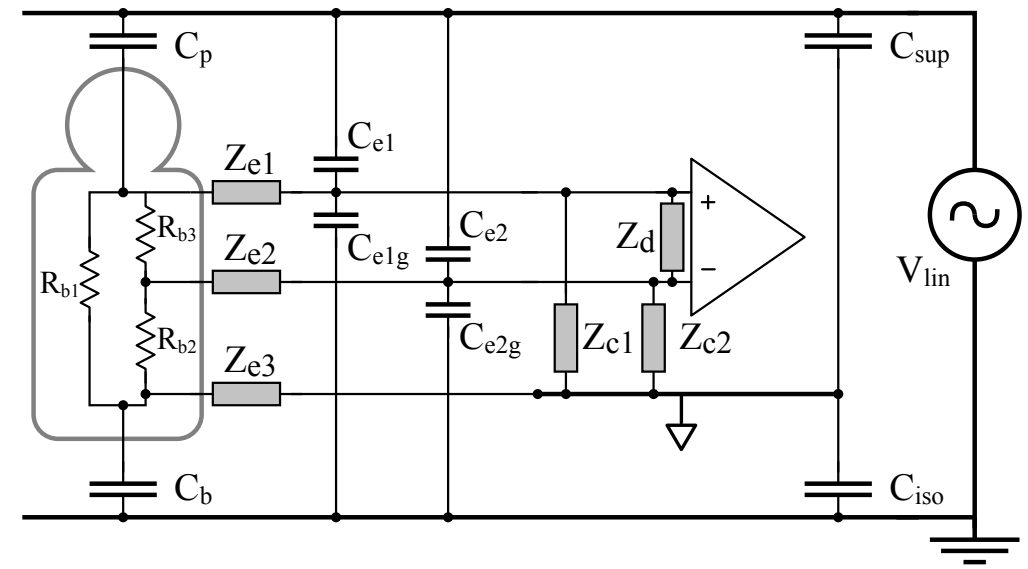

Figura 2.10: Modelo circuital para el análisis de la interferencia electromagnética.

\subsubsection{Modelo EMI}

Para analizar los mecanismos por los cuales las fuentes de interferencia actúan sobre el circuito de medida, se recurre al modelo circuital equivalente de parámetros concentrados de la figura 2.10, ampliamente aceptado en la literatura (Huhta y Webster, 1973; Metting van Rijn et al., 1990; Chimeno y Pallàs-Areny, 2000).

Este modelo incluye las capacidades de acoplamiento del paciente $C_{p}$ y $C_{b}$ con la tensión de línea $V_{l i n}$ y tierra, la resistencia interna del cuerpo $R_{b i}$, las impedancias de electrodo $Z_{e i}$, y el acoplamiento de sus cables mediante las capacidades $C_{e i}$. El sistema de medida se representa por sus impedancias de modo común y diferencial, y el acoplamiento entre la masa del circuito y tierra se modela como una capacidad $C_{\mathrm{ISO}}$.

Los parámetros de este modelo relacionados con componentes circuitales o partes manufacturadas para el equipo pueden ser conocidos o controlados. Es más difícil conocer los valores de acoplamiento del paciente y el equipo a la línea. En la tabla 2.3 se presenta una recopilación de valores de la literatura que permite estimar los valores de capacidad.

El trabajo de Huhta y Webster, 1973 plantea un análisis del modelo EMI orientado a distinguir los distintos caminos que producen interferencia, aún cuando en realidad todos interactúan simultáneamente. De esta manera, pueden diseñarse soluciones apropiadas a cada uno. Estos mecanismos permiten a la red interferir:

1. Como una tensión directamente superpuesta en el modo diferencial con la señal de biopotencial a través de:

a) El acoplamiento magnético en lazos cerrados (principalmente los formados cables de pares diferenciales)

b) El acoplamiento capacitivo al cuerpo del paciente

c) El acoplamiento capacitivo a los cables de electrodos

2. Como resultado de una transformación de modo, del modo común al modo diferencial debido a:

a) Transformación de MC a MD causadas por los electrodos

b) Transformación de $\mathrm{MC}$ a MD debido al rechazo de modo común finito del sistema de medida 


\begin{tabular}{lllll}
\hline & $\mathrm{a}$ & $\mathrm{b}$ & $\mathrm{c}$ & $\mathrm{d}$ \\
\hline$C_{b}$ & 200 & 300 & 200 & $116-273$ \\
\hline$C_{p}$ & 2 & 3 & 1 & $0.06-2.8$ \\
\hline$C_{s}$ & 200 & $30-100$ & 120 & $18-99$ \\
\hline$C_{\text {sup }}$ & 0 & $0-100$ & - & $0.03-3.31$ \\
\hline
\end{tabular}

Tabla 2.3: Valores de acoplamiento capacitivo para el modelo de la figura 2.10 relevados en la literatura: (a) Winter y Webster, 1983, (b) Metting van Rijn et al., 1990, (c) Chimeno y Pallàs-Areny, 2000, (d) M. Haberman, Cassino et al., 2011. Todos los valores están dados en $\mathrm{pF}$.

c) Transfromación de modo aislante a MD

\subsubsection{Interferencia de modo diferencial}

\section{Acoplamiento capacitivo del cuerpo}

El acoplamiento capacitivo del cuerpo con la línea de $220 \mathrm{~V}$ y tierra mediante $C_{p}$ y $C_{b}$ produce interferencia directamente superpuesta a la señal de biopotencial. Sin considerar el equipo de medida, se observa que el cuerpo cierra un circuito con la red como fuente a través de estos elementos y una corriente circulará por las resistencias internas $\mathrm{R}_{1-3}$.

La tabla 2.3 muestra que la capacidad $C_{p}$ tiene un valor de hasta $3 \mathrm{pF}$, mientras que $C_{b}$ tiene un valor dos órdenes de magnitud mayor, en el orden de $300 \mathrm{pF}$. Por lo tanto la impedancia de la capacidad $C_{b}$ y la de las resistencias del cuerpo son despreciables frente a la de $C_{p}$ y la tensión de línea queda virtualmente aplicada sobre esta última.

Entonces puede verse a la fuente de interferencia como una fuente de corriente de valor $V_{l i n} / Z_{C_{p}} \equiv V_{l i n}\left(\omega C_{p}\right)$. Esta corriente produce una tensión diferencial superpuesta directamente a la señal de interés al atravesar $\mathrm{R}_{\mathrm{b} 1}$, de valor en el orden de los $100 \Omega$.

Si se consideran los límites para los componentes armónicos de orden $i=$ $3 \ldots 5$ de la tabla 2.2 y se aplica un factor proporcional según ese porcentaje $\varphi_{i}$ para obtener la amplitud de cada armónico de frecuencia $f_{i}$, puede obtenerse la tensión diferencial de interferencia $V_{d i}$ para cada armónico según la ecuación

$$
\begin{aligned}
& V_{d}=V_{\text {lin }} \varphi_{i} \times 2 \pi f_{i} C_{p} \times R_{b 1} \\
& \varphi_{i}=\begin{array}{lllll}
1 & 0,05 & 0,06 & 0,05
\end{array} \\
& f_{i}=\begin{array}{lllll}
50 & 150 & 250 & 350
\end{array}
\end{aligned}
$$

Se obtienen los valores de amplitud:

$$
V_{d 1}=36 \mu \mathrm{V} \quad V_{d 3}=5 \mu \mathrm{V} \quad V_{d 5}=11 \mu \mathrm{V} \quad V_{d 7}=13 \mu \mathrm{V}
$$

Este es un caso con una capacidad de acoplamiento $C_{p}$ y una resistencia interna $R_{b 1}$ pesimistas. En general, los puntos de medida de señales de EMG o EEG están próximos entre si y la resistencia $R_{b 1}$ es menor, por lo cual el nivel de interferencia queda por debajo del piso de ruido de los electrodos.

De no ocurrir, la única solución posible es disminuir capacidad de acoplamiento cambiando la ubicación de la persona; no puede tomarse ninguna acción práctica desde el punto de vista de la instrumentación para combatir esta 
interferencia y en la práctica no suele ser un problema. Sin embargo, estos valores sirven para observar cómo los armónicos de bajo orden, aún teniendo amplitudes en el orden del $5 \%$ del componente fundamental, pueden tener un efecto de interferencia significativo.

\section{Acoplamiento capacitivo de los electrodos}

Entre la línea de $220 \mathrm{~V}$, el potencial de tierra, y los cables de electrodo también existe acoplamiento capacitivo, como se representa en la figura 2.10 con los capacitores $C_{e}$.

Nuevamente puede simplificarse el circuito notando que las capacidades $C_{e 1}$ y $C_{e 2}$ son las más pequeñas, con valores en el orden de $0.1 \mathrm{pF}$ y similares entre sí. La impedancia que presentan en el circuito completo entre la línea y tierra será dominante, y puede aproximarse la corriente a través de cualquiera de estas capacidades como $i_{e}=V_{l i n} / Z_{C_{e}}$. El camino de menor impedancia que la corriente encuentra para retornar a la fuente es a través de la capacidad el paciente con tierra, $C_{b}$, pero debe atravesar las impedancias de los electrodos. Las resistencias del cuerpo son de valor comparativamente bajo y puede despreciarse su efecto.

Por lo tanto existirá una tensión diferencial de interferecia $V_{d}$ :

$$
\begin{aligned}
V_{d} & \approx i_{C_{e 1}} Z_{e 1}-i_{C_{e 2}} Z_{e 2} \\
& \approx V_{l i n} \times \omega C_{e} \times \Delta Z_{e} \quad \text { si } C_{e 1} \approx C_{e 2}
\end{aligned}
$$

Considerando un para de electrodos secos aplicados por algunos minutos, alcanzando una resistencia de $100 \mathrm{k} \Omega$ y un desbalance de $10 \%$, con los valores de armónicos de red propuestos en la tabla 2.2, la ecuación 2.3 resulta:

$$
V_{d 1}=120 \mu \mathrm{V} \quad V_{d 3}=18 \mu \mathrm{V} \quad V_{d 5}=36 \mu \mathrm{V} \quad V_{d 7}=42 \mu \mathrm{V}
$$

Estos valores son excesivamente altos, aún mas considerando el escenario optimista de impedancia de electrodos con el que se estimaron. Este es uno de los problemas que la instrumentación debe resolver.

\section{Inducción Magnética}

Entre el amplificador y los electrodos se extienden dos cables por cada canal diferencial, conformando un lazo de área $S$. Este lazo es atravesado por el campo magnético producido por las líneas de distribución de energía eléctrica, que si se supone sinusoidal, de amplitud $B$ y frecuencia $\omega$, y en el peor caso perpendicular al área del lazo, genera una f.e.m. inducida de amplitud $\epsilon=\omega B$. Si se considera $\omega=2 \pi 50 \mathrm{~Hz}$, un valor de $B=300 \mathrm{nT}$ y cables de $1 \mathrm{~m}$ separados $10 \mathrm{~cm}\left(S=1 \mathrm{~m}^{2}\right)$ resulta $\epsilon=10 \mu \mathrm{V}$. El aporte de los armónicos de la corriente de línea también es significativo debido a la dependencia proporcional a la frecuencia.

La amplitud de esta señal de interferencia es proporcional al área del lazo y por lo tanto puede reducirse tranzando los cables (Wood et al., 1995), reduciendo su longitud, o procurando que áreas con distinto sentido de lazo se anulen mutuamente (Yamamoto y Nakamura, 1998).

En medidas de EMG o EEG, los electrodos se colocan en puntos muy cercanos, por lo cual resulta práctico llegar hasta el paciente con cables trenzados o unidos, y separarlos lo más cerca posible del lugar de medida, lo cual en general logra eliminar esta interferencia.

Debe notarse que en topologías de medida SE, cada uno de los cables de electrodo forma un lazo con el cable del electrodo de referencia de potencial y se desarrollará una tensión $\epsilon_{i}$ en el canal $i$-ésimo. Como cada electrodo se 
coloca en una posición distinta, las áreas de lazo serán en general distintas. Al obtener luego una señal de biopotencial a través de la resta de dos canales $j$ y $k$, se hará presente una interferencia $\Delta \epsilon=\epsilon_{j}-\epsilon_{k}$. Por lo tanto debe cuidarse también el tendido del cable de referencia con las mismas precauciones que un par diferencial.

\subsubsection{Transformaciones de modo}

\section{Tensión de modo común}

El segundo mecanismo principal por el cual la EMI puede superponerse a la señal diferencial de interés es la transformación de modo. Esto ocurre cuando tensiones de modo común o modo aislante, debido a desbalances del circuito, producen tensiones en la entrada diferencial del amplificador

La primera pregunta que surge es cómo aparece y qué amplitud tiene la tensión de modo común $V_{M C}$. El circuito equivalente simplificado de la figura 2.11(a) permite responder esta pregunta. En este circuito se han despreciado las resistencias internas del cuerpo y los acoplamientos de cables por representar impedancias serie muy pequeñas en el primer caso y paralelas muy grandes en el otro, comparadas con las demás involucradas.

La impedancia del tercer electrodo $Z_{e 3}$ vincula el potencial del cuerpo con la masa del sistema de medida. Cierra por tanto un circuito por el que puede circular corriente proveniente de $V_{\text {lin }}$ y desarrollará una tensión que será de modo común para el sistema de medida.

Puede simplificarse aún más el circuito considerando que $C_{p}$ es mayor que $C_{\text {sup }}$ (ya que el área del cuerpo es mayor que la del equipo de adquisición) y mucho menor que $C_{b}$ (ya que el área con superficies al potencial de tierra es mucho mayor que la de los cables a $V_{l i n}$ ). Por lo tanto, puede utilizarse el modelo de fuente de corriente equivalente con

$$
i_{p} \approx V_{l i n} \times\left(\omega C_{p}\right)
$$

La corriente $i_{p}$ encontrará el retorno a la fuente por $C_{\mathrm{ISO}}$, atravesando $Z_{e 3}$. Esta simplificación resulta en una aproximación pesimista. Considerando además $Z_{e 3}$ con una impedancia puramente resistiva de $10 \mathrm{M} \Omega$ y una capacidad de acoplamiento $C_{p}$ de $3 \mathrm{pF}$ se obtienen las siguientes amplitudes para los componentes armónicos de la tensión de modo común:

$$
V_{M C, 1}=3.6 \mathrm{~V} \quad V_{M C, 3}=0.5 \mathrm{~V} \quad V_{M C, 5}=1.1 \mathrm{~V} \quad V_{M C, 7}=1.2 \mathrm{~V}
$$

Si se quiere mantener la interferencia por debajo de $1 \mu \mathrm{V}$ de amplitud, el sistema de medida necesitará una atenuación de modo común de $130 \mathrm{~dB}$ para la componente fundamental y no menor a $120 \mathrm{~dB}$ para los armónicos.

Los parámetros considerados son muy pesimistas y la exigencia impuesta sobre el sistema es demandante. Sin embargo, diseñar los sistemas de instrumentación siguiendo estos criterios es un enfoque apropiado para aplicaciones que requieren robustez ante todo, como las NPVs.

\subsubsection{Interferencia por rechazo finito de amplificadores}

Las tensiones de modo común $V_{M C}$ y de modo aislante $V_{I S O}$ interfieren con la medida por otro mecanismo: las transformaciones de modo debido los rechazos de modo común y modo aislante finitos del amplificador. 


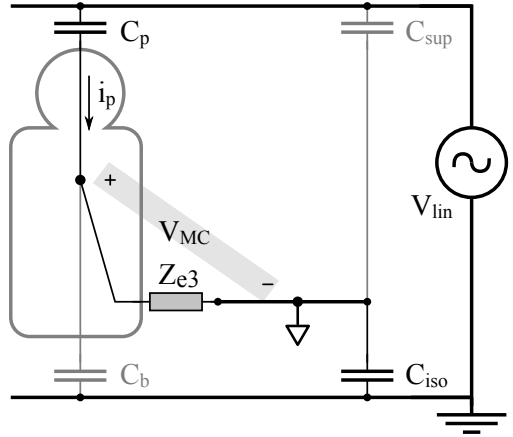

(a)

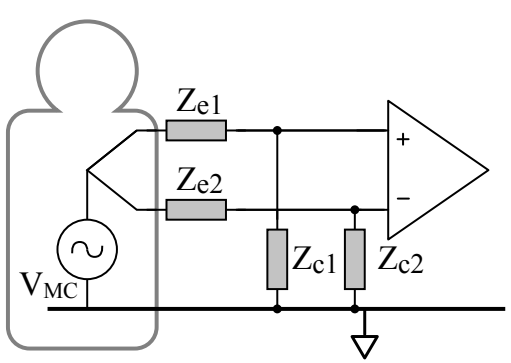

(b)

Figura 2.11: (a) Establecimiento de la tensión de modo común. (b) Efecto divisor de potencial.

Un amplificador diferencial idealmente tiene una salida proporcional a la tensión diferencial de entrada. Sin embargo, distintas no-idealidades pueden producir transformaciones del modo común al diferencial, de manera que la salida single-ended será:

$$
\begin{aligned}
V_{o} & =V_{M D} G_{d d}+V_{M C} G_{c d} \\
& =G_{d d}\left(V_{M D}+V_{M C} \frac{G_{c d}}{G_{d d}}\right)
\end{aligned}
$$

La razón entra la ganancia diferencial $G_{d d}$ y la ganancia de modo común a diferencial $G_{c d}$ del amplificador se define como coeficiente de rechazo de modo común, CMRR por sus siglas en inglés, y es parte de las especificaciones de cualquier amplificador operacional.

\section{Efecto divisor de potencial}

El efecto divisor de potencial se debe al desbalance en impedancias de electrodo y es un problema fundamental para los sistemas de instrumentación de biopotenciales debido a que produce una transformación de modo que no puede ser rechazada por el equipo.

El circuito de la figura 2.11(b) permite analizar este fenómeno. La tensión $V_{\mathrm{CM}}$ entre el cuerpo del paciente y la masa del circuito puede producir corriente en dos lazos: uno formado por $Z_{e 1}$ y $Z_{c 1}$, y el otro por $Z_{e 2}$ y $Z_{c 2}$. Si $Z_{c 1} \approx Z_{c 2}$, se obtiene a la entrada del sistema de medida una tensión proporcional a la diferencia de las impedancias de electrodo:

$$
V_{d} \approx V_{M C} \frac{\Delta Z_{e}}{Z_{C}}
$$

Para un caso de medida con impedancias de electrodo de $100 \mathrm{k} \Omega$ con desbalances de $10 \%$, y una impedancia de entrada de un amplificador operacional con capacitad de $5 \mathrm{pF}$, los valores de interferencia se mantienen en el orden de $1 \mu \mathrm{V}$.

Evidentemente, las condiciones de los sistemas vestibles pueden provocar fácilmente una tensión de interferencia excesiva debido a este efecto. 


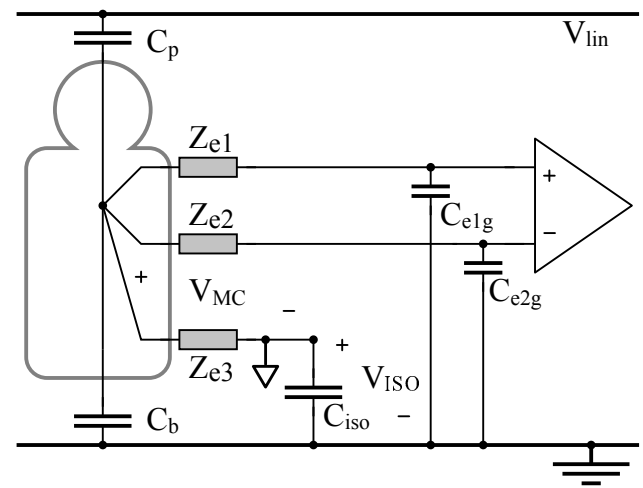

Figura 2.12: Circuito equivalente simplificado para el análisis de la transformación de modo aislante.

\section{Transformación de modo aislante}

La tensión de modo aislante $v_{I S O}$ se establece sobre la impedancia que presenta la capacidad $C_{I S O}$, debido a la corriente por el lazo formado por Cp , Ze3 y $C_{I S O}$, y puede llegar tomar valores en el orden de las decenas de $\mathrm{V}$.

En la figura 2.12 se aprecia cómo afecta a la medida. El cuerpo del paciente está prácticamente al potencial $V_{I S O}$ respecto a tierra, ya que esta tensión es al menos 1 orden de magnitud mayor que $V_{C M}$. La transformación de modo aislante a modo diferencial ocurre por fenómeno análogo al efecto divisor de potencial. Los lazos formados por las capacidades $C_{e 1 g}$ y $C_{e 2 g}$ con $Z_{e 1}$ y $Z_{e 2}$ determinan una tensión diferencial $v_{d}$. Suponiendo ambas capacidades entre los cables y tierra de impedancia similar de valor $Z_{C_{e, g}}$, y considerando que su valor domina sobre las demás impedancias del lazo, resulta:

$$
v_{d}=v_{I S O} \Delta Z_{e} / Z_{C_{e, g}}
$$

\subsection{Conclusiones}

Las Neuroprótesis Vestibles deben operar en la forma menos disruptiva posible para cumplir su objetivo de devolver la independencia o mejorar el confort de las personas. Para ello se apoyan en una etapa de instrumentación de invasividad mínima que utiliza electrodos secos para adquirir las señales de EMG o EEG que transportan información de entrada para la NPV.

Los electrodos secos presentan impedancias muy elevada, desbalanceadas e impredecibles. Al mismo tiempo, la impedancia de electrodo es un factor determinante para la interferencia electromagnética en el sistema de medida, que es el principal desafío de la instrumentación para biopotenciales.

La tensión de modo común que puede desarrollarse en un sistema con electrodos secos es alta, exigiendo el nivel de atenuación necesario para que no interfiera en medidas de biopotencial. Aún en el caso de contar con un CMRR extremadamente elevado, la transformación de modo ocasionada por el efecto divisor de potencial puede producir niveles de interferencia inaceptables.

En sistemas vestibles, este fenómeno cobra entonces una importancia protagónica. Por lo tanto, en estos sistemas es necesario potenciar vías alternativas para el rechazo de interferencia, como la reducción de la tensión de modo común y el balance y aumento de la impedancia de entrada. 



\title{
Instrumentación para Biopotenciales
}

\begin{abstract}
La adquisición de biopotenciales vio abrirse una nueva posibilidad a partir de la disponibilidad comercial de sistemas complejos integrados. Como alternativa al paradigma tradicional de medida basado en el amplificador de biopotenciales acoplado en alterna, existe uno protagonizado por los convertidores analógico digitales de muy alto rango dinámico, con ventajas en aplicaciones vestibles. En este capítulo se expone el diseño según este paradigma y los bloques de acondicionamiento analógico que requiere para adaptarse a las aplicaciones vestibles: electrodos activos para usos especificos, $y$ mejoras en la realimentación de modo común.
\end{abstract}

\subsection{Desafíos en la instrumentación para biopotenciales}

Los biopotenciales transportan información valiosa para interpretar la voluntad de una persona y puede accederse a un importante subconjunto de este conglomerado de señales utilizando instrumentación electrónica no invasiva. El deseo es, al igual que un audiófilo intentando oír en sus parlantes el vibrar de una cuerda como si estuviese en el auditorio, poder registrar estas señales con una alta calidad: sin perder detalles entre el ruido de los propios equipos electrónicos, sin interferencia de fuentes externas, y sin perturbaciones introducidas por otras variables en la medida.

La primera dificultad en este tipo de medidas radica en la lejanía con la fuente de biopotencial. La densidad de la corriente iónica en el cuerpo considerado como conductor de volumen disminuye a medida que aumenta la distancia a la fuente, y por lo tanto la caída de potencial que produce. Así, potenciales de trasmembrana en el orden de decenas de $\mathrm{mV}$ sólo producen tensiones en el orden de $10 \mu \mathrm{V}$ a algunos $\mathrm{mV}$ sobre la piel.

Cuando Willem Einthoven en el año 1902 publicó el primer electrocardiógrafo práctico probablemente se enfrentó al desafío de lograr la resolución y amplificación necesaria para esa medida (Rivera-Ruiz et al., 2008). Hoy esto no es un problema porque el ruido referido a la entrada de los amplificadores 
comerciales de precisión está en el orden de $1 \mu \mathrm{V}_{\text {rms }}$ en el ancho de banda de los biopotenciales.

El dispositivo en el que se basaba el electrocardiógrafo de Einthoven, el galvanómetro de cuerda, tiene una ventaja inherente: responde a variaciones en el potencial independientemente de su valor absoluto respecto a una referencia, o nivel de continua. Es decir, el equipo estaba naturalmente acoplado en alterna.

Este es un aspecto determinante para los sistemas de medida de biopotenciales. Como se describió en la sección 2.3 (ver figura 2.7), los electrodos superponen un desplazamiento del nivel de continua a la señal diferencial de biopotencial de hasta $\pm 300 \mathrm{mV}$ mientras que las señales de biopotencial se desarrollan con resoluciones en el orden de $1 \mu \mathrm{V}$. Es decir que el rango dinámico $(\mathrm{RD})$ de la señal es de 300.000 veces $(110 \mathrm{~dB})$ mientras que un convertidor analógico-digital de 16 bits, los de mayor resolución entre los convertidores convencionales, sólo tiene un RD de 65.360 veces (96 dB).

Un problema que probablemente no se manifestaba en 1902 es la omnipresencia de múltiples fuentes de interferencia electromagnética en todo el espectro, como se describió en la sección 2.5.2. Sobre todo debido a las características de impedancia de los electrodos secos utilzados para EEG y EMG en sistemas vestibles, las fuentes de interferencia encuentran caminos para victimizar al equipo de medida.

Por último, fenómenos asociados a otras variables como fuerzas aplicadas al electrodo, e.g. por el tironeo de los cables, que producen alteraciones en la señal de biopotencial llamadas artefactos. En algunos casos los artefactos no pueden remediarse, por ejemplo ante el desprendimiento total de un electrodo, y la responsabilidad para evitarlos recae mas bien en el diseño mecánico del dispositivo. Sin embargo una gran cantidad de artefactos ocurren como resultado de la variación de la impedancia del electrodo al moverse; en este caso el diseño de instrumentación puede palear este efecto. Incluso cuando existe una pérdida momentánea de la señal, el circuito de medida puede procurar que se restablezca en el menor tiempo posible.

Los desafíos que encuentran los sistemas de medida de biopotenciales tienen un factor común que es el electrodo. En la aplicación de neuroprótesis vestibles los electrodos están optimizados para el confort y la facilidad de uso, lo cual degrada sus propiedades eléctricas. Si bien el diseño de estos equipos está ampliamente estudiado, las altas impedancias de electrodo impuestas por los dispositivos vestibles lo vuelve a situar como tema de investigación activo y demandante de soluciones clave.

\subsection{Solución tradicional}

La solución establecida para la adquisición de biopotenciales (Webster, 1988; Nagel, 1995; Neuman, 2009), ampliamente difundida en equipos comerciales, se resume con el diagrama de bloques de la figura 3.1.

El corazón de los sistemas de instrumentación tradicionales es el amplificador de biopotenciales acoplado en alterna. Al eliminar la continua con un filtrado pasa-altos (pasivo o activo) se relajan los requisitos de rango dinámico (Metting van Rijn et al., 1990; E. M. Spinelli, Pallàs-Areny et al., 2003) y puede amplificarse la señal sin riesgo de saturación. El amplificador en si debe tener una serie de propiedades: ancho de banda apropiado, ruido suficientemente bajo, impedancia de entrada alta, y rechazo de modo común elevado. Finalmente, la salida del amplificador puede ser digitalizada con un convertidor analógico- 


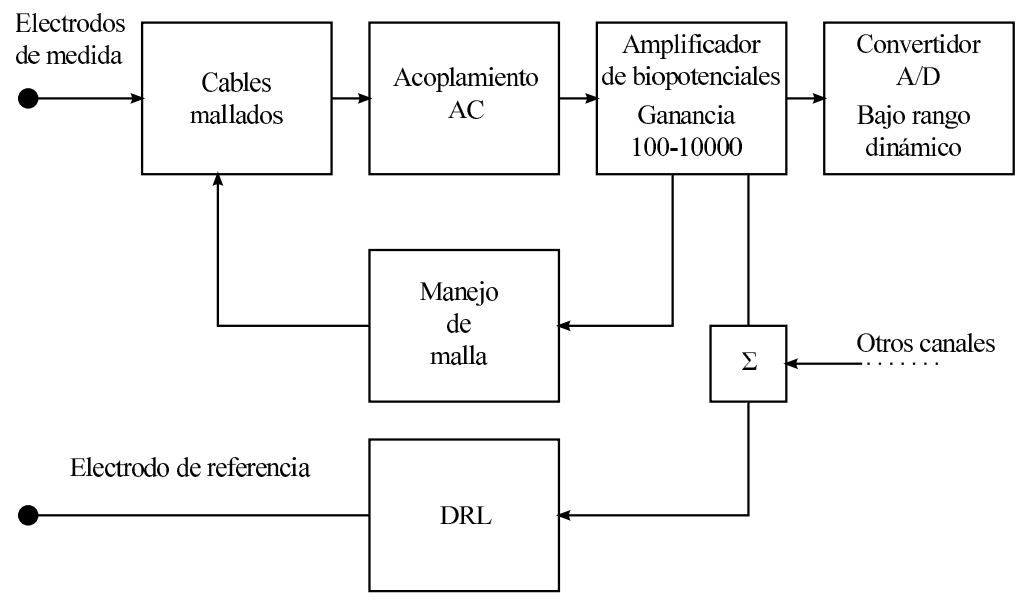

Figura 3.1: Paradigma tradicional de adquisición de biopotenciales

digital de un rango dinámico suficiente para la señal biomédica, en el orden de $80 \mathrm{~dB}$.

Esta solución, sin embargo tiene algunas de desventajas asociadas a la implementación del acoplamiento en alterna. En primer lugar, las señales de biopotencial tienen componentes hasta frecuencias muy bajas, muchas veces debajo de $1 \mathrm{~Hz}$. Por lo tanto, las constantes de tiempo del filtrado pasa-altos son grandes y, frente a fluctuaciones de la línea base o artefactos, se necesitan tiempos largos o circuitos especiales de recuperación rápida para restablecer la operación normal (Thorsen, 1999). En segundo lugar, los filtros implementados por cada canal tendrán desbalances que degradan la robustez frente a la interferencia electromagnética (E. M. Spinelli, Pallàs-Areny et al., 2003), exceptuando el caso en que puedan utilizarse topologías completamente diferenciales. Adicionalmente, algunos biopotenciales, como el electro-oculograma entre otros, tienen componentes que se verían indefectiblemente limitados por el filtrado pasa-altos (Vanhatalo et al., 2005; Tallgren et al., 2005).

También como parte de la solución tradicional ampliamente difundida en equipos médicos, para combatir las fuentes de interferencia por acoplamiento capacitivo a los cables de electrodos se recurre a mallas que blindan el conductor de señal y desvían a masa las corrientes sin causar potenciales de interferencia. La malla, sin embargo, aumenta la capacidad de entrada del sistema, por lo que es común que se convierta en una guarda, adicionando un circuito conocido como conductor de blindaje o shield driver que le permite seguir el potencial de salida del electrodo.

La interferencia ocasionada por transformaciones de modo se combate a través del diseño del amplificador para lograr un alto CMRR, acompañado de un circuito de reducción activa de modo común conocido como DRL (del inglés para "conductor de pierna derecha", por sus orígenes en ECG). El circuito de DRL se detallará más adelante en la sección 3.4.3, en este punto interesa describir su función a grandes rasgos: permite establecer una referencia de potencial entre el cuerpo de una persona y la masa del sistema de medida cumpliendo dos funciones principales:

- Asegurar que el potencial del cuerpo se encuentre dentro del rango de medida del sistema de adquisición

- Disminuir la tensión de modo común. 


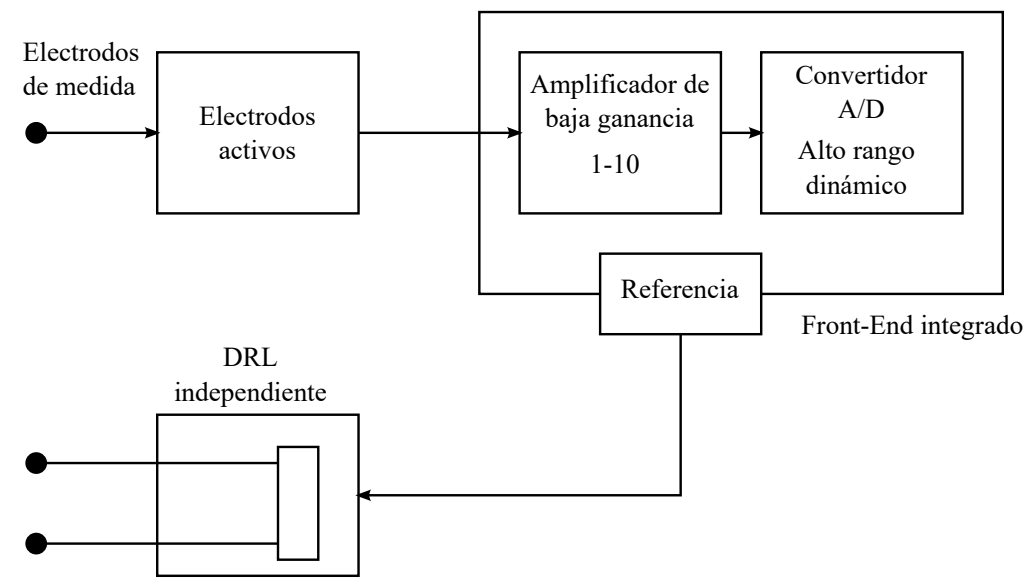

Figura 3.2: Diagrama de bloques del sistema alternativo de medida basado en convertidores $\Sigma-\Delta$ de alto rango dinámico y electrodos activos.

En su implementación tradicional, el DRL aporta entre 30 y $40 \mathrm{~dB}$ de rechazo adicional a la frecuencia de red, 50 o $60 \mathrm{~Hz}$ según el país.

\subsection{Estado del arte}

A partir del progreso en los sistemas complejos integrados, surgieron nuevas herramientas para implementar sistemas de adquisición de biopotenciales. En la década de 1980 comenzó el desarrollo de los convertidores llamados $\Sigma-\Delta$ partiendo de la primera aplicación de modulación $\Sigma-\Delta$ a un convertidor A/D para instrumentación en 1978 (Plassche, 1978). Hacia la década de 1990, esta tecnología permitió alcanzar niveles de rango dinámico superiores a las alternativas existentes hasta el momento.

El problema de medir la pequeña señal biomédica admitiendo la continua de los electrodos se resuelve al contar con un convertidor analógico digital de 19 bits o más de resolución, lo cual le confiere un rango dinámico superior a $110 \mathrm{~dB}$ y surge la posibilidad de cambiar el paradigma de medida abandonando el amplificador acoplado en alterna (Curtin, 1994).

Los convertidores $\Sigma-\Delta$, sin embargo, operan en base a un sobre-muestreo de baja resolución seguido de un filtro digital y decimación para entregar una señal de alta resolución con la tasa de muestreo desada. Por lo tanto, si se cambia la señal de entrada existe un tiempo de latencia, correspondiente al transitorio inicial del filtro digital, hasta obtener muestras útiles a la salida. En consecuencia, no pueden multiplexarse las señales de entrada y debe utilizarse un convertidor $\Sigma-\Delta$ por cada canal de adquisición.

La industria de semiconductores solucionó este problema creando integrados que incluían varios convertidores $\Sigma-\Delta$, lo cual permitió utilizarlos en aplicaciones prácticas de instrumentación multicanal. En 1995 Analog Devices introdujo el integrado AD7716 que incluía 4 canales completos con preamplificador de ganancia variable y 4 convertidores $\Sigma-\Delta$.

Con este dispositivo comenzaron las primeras aplicaciones de un nuevo paradigma de medida de biopotenciales presentado en la figura 3.2 (McKee et al., 1996; Kurikov et al., 1998). Este esquema tiene como componente central un convertidor $\Sigma-\Delta$, solo requiere un nivel bajo de ganancia entre 2 y 10 veces (Berry et al., 2009), o incluso puede utilizarse sin amplificación previa. 
En los años siguientes, la evolución en las tecnologías de integración de sistemas complejos y de señal mixta que acompañó la demanda del mercado de consumo de dispositivos móviles, permitió la maduración de los sistemas integrados basados en convertidores $\Sigma-\Delta$, reduciendo su costo, consumo y aumentando las tasas de adquisición (Aksenov et al., 2001).

La mayor parte de la etapa de instrumentación para un sistema de adquisición de biopotenciales portable moderno está resuelta por circuitos integrados de señal mixta que incorporan filtros, amplificadores, y convertidores analógico digitales para múltiples canales de adquisición, todo en un mismo encapsulado. Algunos de estos dispositivos son circuitos integrados de aplicación específica (ASICs por sus siglas en inglés) sobre todo para una alta densidad de canales (e.g. Barone y Merletti, 2013; Morrison et al., 2014; T.-Y. Wang et al., 2014); otros son productos estándar de aplicación específica (ASSPs) (serie ADS129x de Texas Instruments, serie RHD2000 de INTAN Technologies, AD8232 de Analog Devices). Los ASSPs representan un compromiso atractivo entre funcionalidad y costo ya que si bien incorporan tecnologías específicas para instrumentación de biopotenciales, son producidos a escala industrial. Un denominador comunmente utilizado para estos circuitos de adquisición integrados es la sigla AFE, del inglés analog front-end o "frente analógico".

En particular, el AFE ADS1298 de Texas Instruments fue un hito para los sistemas de adquisición de biopotenciales. Se comenzó a comercializar en el año 2011-2012 y provee 8 canales completos de adquisición con amplificadores programables, filtros de EMI de alta frecuencia y tasa de adquisición programable, además de funciones específicas para la medida de ECG. Más adelante, dio lugar a una familia de AFEs para biopotenciales como el ADS1299 orientado a EEG.

Estos componentes presentan una solución íntegra para la instrumentación del caso general de medida de biopotenciales.

\subsection{Aplicación en neuroprótesis vestibles}

Las NP vestibles se distinguen del caso general por su uso de electrodos con muy alta impedancia y la necesaria robustez frente a artefactos y ambientes con interferencia electromagnética agresiva. En particular, dos fenómenos producen interferencia que el ASSP no es capaz de manejar: las corrientes en los cables de electrodo causadas por acoplamiento capacitivo, y el efecto divisor de potencial producido por las impedancias de electrodo. Estos problemas requieren soluciones específicas.

\subsubsection{Electrodos activos}

El esquema de rechazo de interferencia por acoplamiento en los cables descripto en la sección 3.2 es ampliamente utilizado en los instrumentos más difundidos para la práctica médica. Sin embargo, aún fuera de las aplicaciones vestibles, los cables mallados cuentan con desventajas que motivaron la búsqueda de soluciones alternativas. Estos cables son más costosos que los cables simples, son más rígidos promoviendo los artefactos, y requieren un circuito conductor de malla.

Una alternativa tempranamente desarrollada fue la incorporación de electrónica en el mismo sitio del electrodo. De esa manera se tiene un muy corto trayecto vulnerable desde el electrodo hasta el circuito directamente sobre él, y puede luego conectarse este circuito al equipo principal de adquisición con técnicas apropiadas para evitar la interferencia. El conjunto de electrodo y el circuito asociado se denomina electrodo activo (Hagemann et al., 1985). 


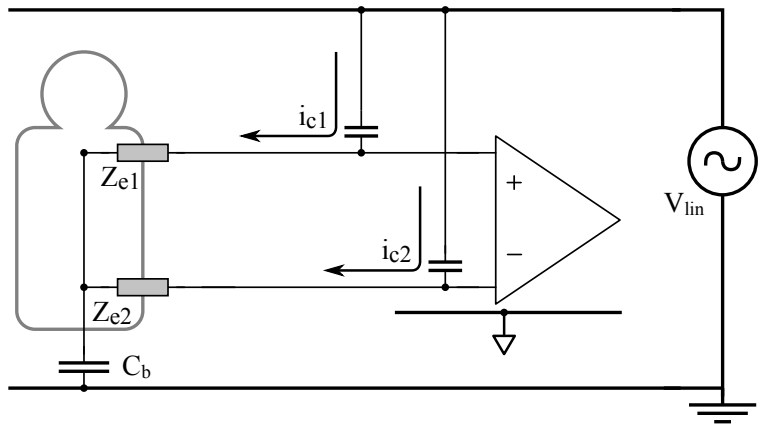

(a)

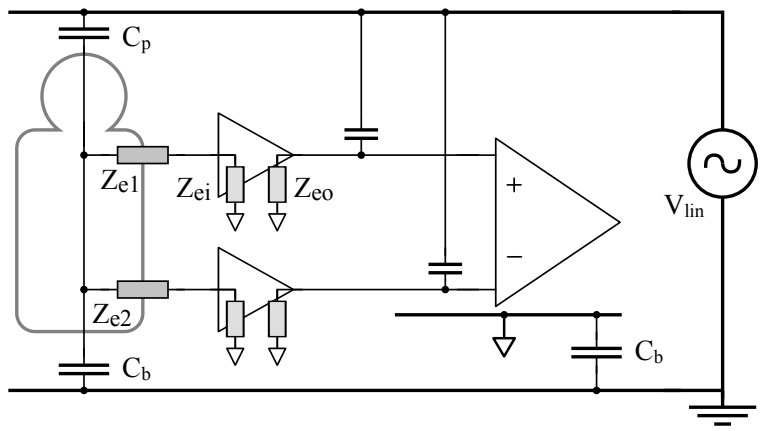

(b)

Figura 3.3: (a) Interferencia por corrientes acoplades en los cables de electrodo. (b) $\mathrm{Su}$ solución por medio de electrodos activos, que conducen estas corrientes a tierra sin producir tensiones apreciables.

La solución que aporta es doble: por un lado permite utilizar una etapa especial con alta impedancia de entrada (quitando esa responsabilidad al amplificador) y por otro proveer una baja impedancia de salida de manera que las corrientes acopladas a los cables de electrodo no producen tensiones de interferencia apreciables, como se aprecia en la figura 3.3.

Los primeros desarrollos de electrodos activos (EAs) se basaron en transistores (Hagemann et al., 1985) e incluso diseños modernos muestran las vantajas de esta implementación (T. Degen, Torrent et al., 2007); sin embargo con el bajo costo y ubicuidad posterior de los amplificadores operacionales de bajo ruido y alta impedancia de entrada, pasaron a predominar los diseños basados en un amplificador operacional configurado como seguidor (Nishimura et al., 1992; Taheri et al., 1994).

Si bien en primera instancia parece ventajoso aprovechar el amplificador operacional para dar ganancia en el electrodo mismo, los esquemas para balancear las ganancias evitando nuevas transformaciones de modo y para evitar que la continua de los electrodos saturen el amplificador necesitan circuitos auxiliares y resultan complejos (T. Degen y Jäckel, 2004; Valchinov y Pallikarakis, 2004). El AO en configuración de seguidor con ganancia unitaria resulta una versión apropiada de electrodo activo para sistemas de bajo costo y simple mantenimiento, con probados resultados de reducción de interferencia (Fernandez y Pallàs-Areny, 1996).

Los amplificadores operacionales utilizados para implementar EAs pueden seleccionarse dentro de un subconjunto que debe contar con: 
- Baja tensión de ruido

- Baja corriente de ruido, ya que circulará por la impedancia de electrodo

- Baja capacidad de entrada (en el orden de las unidades de pF)

- Para el caso de sistemas portables también son buenas propiedades el ser de bajo consumo y de operación riel-a-riel ${ }^{1}$ con fuente simple de $5 \mathrm{~V}$ o menor.

Actualmente, el uso de electrodos activos predomina en soluciones para la medida de biopotenciales con electrodos secos (Chi, T.-P. Jung et al., 2010) y son de común adopción en las soluciones comerciales que utilizan electrodos secos de EEG (Mihajlovic et al., 2015).

\subsubsection{Alta impedancia de entrada}

La alta impedancia de los electrodos secos presenta un desafío no trivial a los sistemas de instrumentación de biopotenciales.

El efecto divisor de potencial, tratado en la sección 2.5.5, puede producir EMI a partir de la tensión de modo común aún si el amplificador tiene un alto CMRR. La interferencia resultante es inversamente proporcional a la impedancia de entrada del sistema medida. Por este motivo, incluso para equipos de EEG tradicionales que se utilizan con electrodos húmedos, que deben mantener impedancias por debajo de los $20 \mathrm{k} \Omega$, se requiere una impedancia de entrada mayor a $100 \mathrm{M} \Omega$ (Nuwer et al., 1998). En equipos de sEMG se recomiendan impedancias al menos 100 veces mayores a la mayor impedancia esperada de electrodo (C. De Luca, 1997; Merletti, Botter et al., 2009), que puede fácilmente alcanzar un valor de $1 \mathrm{M} \Omega$ inclusive con preparación previa de la piel.

Por otro lado, los artefactos son un problema especialmente para sistemas vestibles donde no pueden evitarse raspando la capa más externa de piel (Tam y Webster, 1977) y el usuario o paciente estará en general en movimiento. La impedancia de entrada del sistema de medida puede ayudar a mitigar algunos artefactos provenientes de la variación de impedancia de electrodo con el movimiento (Nonclercq y Mathys, 2010) si es suficentemente alta.

Las etapas de entrada de los ASSPs como el ADS1298 tienen impedancias elevadas pero no lo suficiente para afrontar las excesivas impedancias de los electrodos secos sobre piel sin preparar en forma robusta. Por ello en sistemas vestibles deben ser acompañados por circuitos de acondicionamiento que logren este objetivo. Los electrodos activos tienen el potencial de implementar altas impedancias de entrada, aunque los límites tecnológicos de los amplificadores operacionales comerciales pueden requerir soluciones adicionales. Existen esfuerzos en este sentido por lograr los llamados buffers de impedancia "ultra alta" e.g. Gargiulo et al., 2010; Chi, Maier et al., 2011; Lányi, 2001.

\subsubsection{Reducción tensión de modo común}

El efecto divisor de potencial provoca una degradación del rechazo de modo común que el sistema de medida no puede resolver a través del CMRR. En los sistemas vestibles el problema se potencia debido a las altas impedancias de los electrodos secos.

Por otra parte, al diseñar sistemas con componentes comerciales y topologías sencillas no se tiene el control sobre los desbalances que afectan el CMRR como en sistemas monolíticos integrados o de mayor complejidad. Aún en el caso de un canal diferencial compuesto por un par de electrodos activos implementados

\footnotetext{
${ }^{1}$ Traducción literal del término en inglés rail-to-rail que indica que la entrada o salida de un amplificador operacional puede alcanzar los potenciales de alimentación o "rieles".
} 


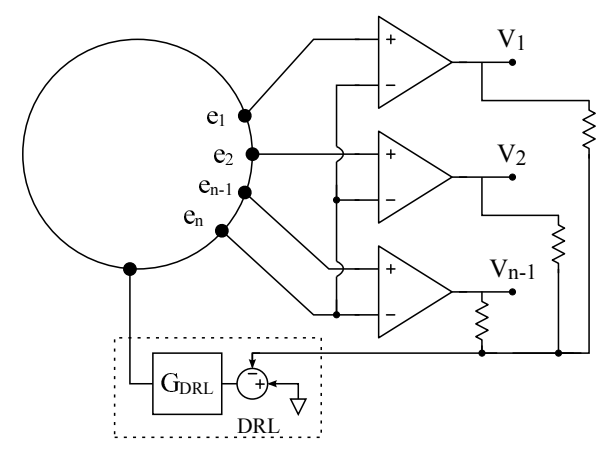

(a)

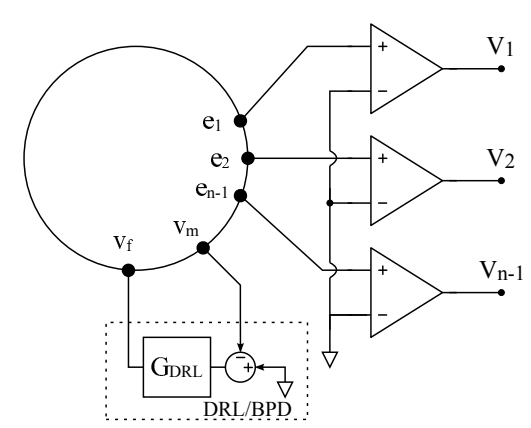

(b)

Figura 3.4: (a) Esquema de medida monopolar utilizando el DRL clásico. (b) Medida single-ended utilizando el conductor de potencial del cuerpo.

como seguidores de tensión, el CMRR no será mejor que el peor de los dos dispositivos, o incluso más bajo si el desbalance tiene el mismo signo (PallásAreny y Webster, 1991).

Como consecuencia, en esta topología no resulta efectivo enfrentar el problema de la tensión de modo común a través de un alto CMRR. Sin embargo, en esta aplicación se busca una reducción de modo común robusta ya que el ambiente EMI no es controlado, y la impedancia del tercer electrodo será alta por tratarse de un electrodo seco.

Por este motivo, en el paradigma de la figura 3.2 toma un rol protagónico la reducción de modo común activa por medio del circuito de DRL. Este circuito debe medir la tensión de modo común del cuerpo para lograr minimizar el error respecto a la referencia. El método más común para lograrlo es el promediado de todos los canales de medida o un subconjunto de ellos, como se muestra en la figura 3.4(a) con el ejemplo de una medida monopolar. La desventaja de esta técnica es que todos los electrodos deben tener buen contacto con el cuerpo para obtener una señal válida de modo común. En un sistema vestible colocado sin asistencia profesional, puede ocurrir que alguno de los contactos tenga una calidad peor que el resto y es deseable que el sistema siga siendo funcional, aún parcialmente.

Una segunda alternativa, propuesta por C. Levkov, 1982, es el esquema de la figura 3.4(b). En este esquema, un circuito independiente con su propio electrodo de medida establece el potencial del cuerpo respecto al de masa. Algunos autores le dan al DRL así utilizado el nombre de circuito conductor de potencial del cuerpo $^{2}$ o BPD por sus siglas en inglés.

Si el circuito de BPD logra un rechazo de interferencia de modo común suficiente, puede utilizarse una topología de medida single-ended, como se enfatiza en la figura 3.4(b). Esta topología tiene la ventaja de distribuir entre los canales de adquisición un potencial de referencia en lugar de la salida de un electrodo. Es una estrategia utilizada en equipos comerciales (ActiveTwo de BioSemi); las señales monopolares equivalentes pueden obtenerse con un

\footnotetext{
${ }^{2}$ Traducción de Body Potential Driver. En el trabajo de Levkov (1982), se da este nombre al circuito por su funcionamiento independiente del resto del equipo de medida. Sin embargo en la literatura técnica actual se utiliza para referirse los circuitos de realimentación de modo común que no están asociados específicamente a medidas de ECG (de donde proviene el término DRL). En algunos casos se utiliza este nombre cuando la fuente de alimentación es única (no partida) y el DRL debe elevar el potencial a una referencia distinta de masa.
} 


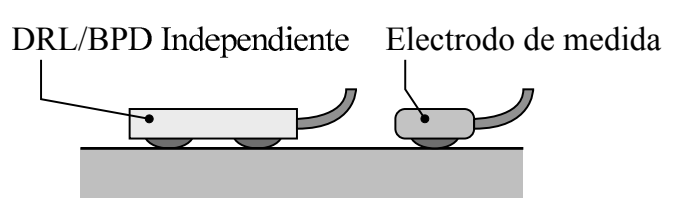

Figura 3.5: Representación del uso del DRL o BPD independiente implementado como un módulo con electrodos de medida y realimentación propios, junto a un electrodo de medida para la señal de biopotencial.

pos-procesamiento digital. En este caso, se desprecia la impedancia interna del cuerpo frente a la del tercer electrodo y se considera equipotencial.

El circuito de BPD puede implementarse como un módulo independiente, con el electrodo de medida y realimentación en un mismo soporte, suficientemente separados para que no exista un camino de baja impedancia en la superficie de la piel, como se muestra en la figura 3.5. Esta alternativa es atractiva en aplicaciones vestibles porque se obtiene un único punto crítico para asegurar el funcionamiento del sistema, mientras que el resto de los electrodos pueden fallar sin comprometer la calidad de las señales restantes.

\subsection{Conclusiones}

Las aplicaciones vestibles con electrodos secos de alta impedancia y desbalance requieren un nuevo paradigma de instrumentación de biopotenciales para alcanzar la robustez que exige el uso autónomo sin asistencia profesional.

Este paradigma está basado en el uso de convertidores de altro rango dinámico, que permiten evitar una etapa de filtrado pasa-altos con grandes constantes de tiempo, haciendo al sistema robusto ante artefactos, pero también posibilitando extender el rango de adquisición de bajas frecuencias.

La economía de gran escala permite incorporar estos dispositivos complejos en equipos multicanal de bajo costo y por lo tanto el núcleo de un sistema de las características mencionadas pasó de ser el amplificador de biopotencial al sistema integrado de adquisición, que incluye varios canales con un convertidor de alta resolución, amplificador de baja ganancia, filtrado anti-replicado y de altas frecuencias. Sin embargo, por ser estas plataformas productos estándar, no estan preparados para las exigencias de las NPV y necesiten circuitos de acondicionamiento analógico adicional, en particular para combatir artefactos y los problemas de interferencia ocasionados por la elevada impedancia de los electrodos secos. Los electrodos activos y el circuito de DRL independiente son soluciones actualmente aceptadas, atractivas para cumplir este rol. 



\title{
Sistema de Adquisición de Biopotenciales
}

\begin{abstract}
En este capítulo se describe la implementación de un sistema de adquisición de biopotenciales en el estado del arte según el paradigma de medida basado en convertidores analógico digitales de alto rango dinámico. Se detalla el núcleo del sistema basado en un front-end integrado y los periféricos de acondicionamiento implementados en esta primera etapa: electrodos activos y un circuito independiente de rechazo de modo común. Se realizaron dos implementaciones: una para pruebas de laboratorio y otra como módulo de instrumentación para un sistema vestible.
\end{abstract}

\subsection{Instrumentación basada en AFE $\Sigma-\Delta$}

Con el objetivo de contar con una plataforma de desarrollo sobre la cual implementar módulos de instrumentación para NPV se diseñó un sistema de instrumentación para biopotenciales en el estado del arte basado en AFEs $\Sigma-\Delta$, según lo descripto en el capítulo 3.

El primer paso fue diseñar el sistema como plataforma de investigación; los objetivos particulares fueron lograr versatilidad para implementar distintas topologías de medida y admitir distintos electrodos activos y circuitos auxiliares de rechazo de interferencia, y permitir la transferencia de datos en forma sencilla y confiable a una PC. Por lo tanto se realizó una primera implementación del sistema para uso en laboratorio, con conexión a través del bus USB a una PC que le permite transferir datos y al mismo tiempo obtener alimentación. Se dotó al equipo de un conexionado de electrodos configurable para distintas topologías de medida buscando la generalidad de uso. Un sistema de adquisición de estas características es directamente aplicable para neuroprótesis de rehabilitación o ICCs que se utilicen con personas sentadas frente a un escritorio, pero su factor de forma no es apropiado para sistemas vestibles.

En una segunda etapa, se trasladó el diseño a una implementación apropiada para constituir la instrumentación de una NPV con la posibilidad de posicionar el dispositivo completo sobre el cuerpo para probar su uso en condiciones reales. 


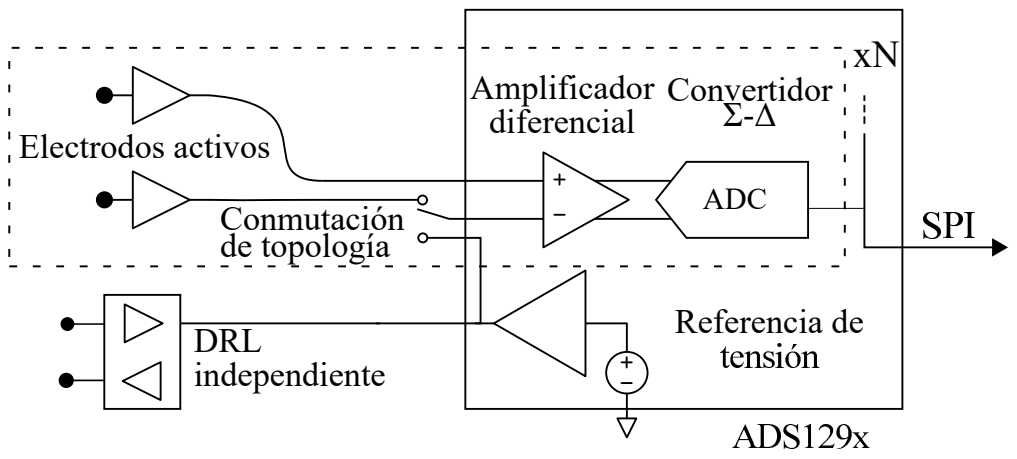

Figura 4.1: Topología multicanal basada en front-end con convertidores $\Sigma-\Delta$.

Este módulo de instrumentación es directamente transferible a un dispositivo vestible, desacoplado del módulo de transferencia de datos.

\subsubsection{Núcleo del sistema}

El núcleo del sistema de adquisición se basó en los front-ends integrados de la familia ADS129x de Texas Instruments. Estos componentes son representantes muy completos de los sistemas integrados descriptos en el capítulo 3 ya que logran implementar la conversión $\mathrm{A} / \mathrm{D} \Sigma-\Delta$ multicanal en un único componente monolítico con consumo de energía y costo en el orden de los más bajos comercialmente disponibles.

El front-end incluye varios canales de adquisición, cada uno compuesto por un amplificador de ganancia programable y un convertidor $\Sigma-\Delta$ por canal. La figura 4.1 muestra esquemáticamente la propuesta de diseño.

La entrada de los canales es completamente diferencial. En los ADS129x una red de conmutadores a la entrada de los canales permite cambiar la señal medida, por ejemplo para inyectar una señal cuadrada generada internamente para calibración. También puede conectarse la señal de salida de los amplificadores de ganancia programable para obtener un promedio para el DRL. En algunos componentes con aplicaciones específicas, también pueden implementarse funciones como el cálculo de la terminal central de Wilson (de uso en electrocardiografía). Sin embargo, estos conmutadores no dan la posibilidad de cambiar la topología de medida y por lo tanto debe implementarse externamente. La conmutación de topología consiste en admitir, en lugar de una entrada diferencial por cada canal, una entrada single-ended referida a un potencial específico. Para eso se conecta la tensión se referencia del sistema a la entrada inversora (ver figura 4.1). Para obtener el máximo rango de excursión, el potencial de referencia se establece en general a la mitad de la tensión de alimentación.

La alimentación de este ASSP puede ser de fuente simple, de 2.7 a $5 \mathrm{~V}$, o partida, y posee una referencia interna de bajo ruido. En particular esta tensión de referencia puede direccionarse a un pin externo y aprovecharse para proveer la referencia de potencial del circuito de DRL y en las medidas single ended. Al contar con $\mathrm{N}$ canales single-ended, pueden obtenerse los canales equivalentes a una medida monopolar refiriendo digitalmente $\mathrm{N}-1$ canales al Nésimo.

Los parámetros de funcionamiento del equipo completo dependerán fuertemente de las características del AFE, en particular de las particularidades de los convertidores $\Sigma-\Delta$. 


\subsubsection{Características de los convertidores $\Sigma-\Delta$}

Los convertidores analógico-digitales $(\mathrm{AD})$ tradicionales operan reteniendo un valor de tensión en un instante dado y entregando, de distintas maneras según la tecnología de conversión, un número digital que aproxima el valor medido en relación a una tensión de referencia. En general, el número de bits disponibles para representar el valor de una muestra dicta el rango dinámico del convertidor, ya que el mayor valor representable corresponde a un múltiplo de la referencia, y el menor al peso del bit menos significativo.

Los convertidores AD llamados $\Sigma-\Delta$ operan de un modo distinto. La salida instantánea se obtiene a partir de una señal sobremuestreada que luego es procesada en un filtro digital y decimada (Schreier y Temes, 2005). Por lo tanto, el rango dinámico a la salida del decimador es arbitrario: cuanto mayor sea la tasa de sobremuestreo se obtiene un rango dinámico cada vez mayor (Aziz et al., 1996). Alternativamente, si el convertidor tiene un reloj de sobremuestreo fijo, es usual que puedan seleccionarse las características del filtro digital y la tasa deseada de salida, resultando un mayor o menor rango dinámico.

Las muestras a la salida del convertidor se colocan en una palabra de $N$ bits, pero sólo una porción de ellos contendrá información útil y el resto se modelan como enmascarados por una señal de ruido. Por ese motivo, el rango dinámico no se expresa por su número de bits de representación nominal $N$, sino por su número de bits libres de ruido. Asimismo, la resolución se expresa por medio de la tensión de ruido referido a la entrada. Si en lugar de considerar el valor equivalente de ruido pico a pico se considera el valor eficaz del ruido, se obtiene la representación del rango dinámico en número de bits eficaces (ENOB por sus siglas en inglés).

Además del alto rango dinámico que alcanzan estos convertidores, otra característica atractiva es que se relajan los requisitos del filtro anti-replicado necesario. La señal se muestrea originalmente a la tasa de sobremuestreo $f_{\text {mod }}$, por lo cual el filtro debe atenuar componentes a partir de la frecuencia $f_{\text {mod }} / 2$, varios órdenes de magnitud mayor que $f_{s}$. El filtro digital pasa-bajos actúa luego durante la decimación para evitar el efecto de replicado.

La contracara del mecanismo que hace ventajosos a los convertidores $\Sigma-$ $\Delta$ es que no pueden obtenerse tasas de salida elevadas sin disminuir el rango dinámico. La señal de entrada no puede conmutarse para multiplexar varios canales analógicos ya que existe un retardo hasta que el filtro digital produce salidas válidas.

Por estos motivos, los AFEs que utilizan convertidores $\Sigma-\Delta$ incorporan un ADC $\Sigma-\Delta$ por cada canal de conversión, y es común que incluyan un pre-amplificador que funciona como buffer con baja impedancia de salida. En esos casos, la limitación de ancho de banda del pre-amplificador puede funcionar como filtro anti-aliasing, de manera que no se requiere ningún acondicionamiento de señal adicional para asegurar una conversión apropiada. A su vez, puede aumentarse la resolución del sistema aumentando la ganancia del pre-amplificador.

\subsubsection{Seguridad eléctrica}

Cuando el cuerpo humano conduce corrientes eléctricas, puede ser dañado por la destrucción del tejido si la intensidad de la corriente es muy alta, o por la interferencia disruptiva de procesos electro-fisiológicos cuando la corriente, aún de baja intensidad, atraviesa regiones sensibles como el corazón. 


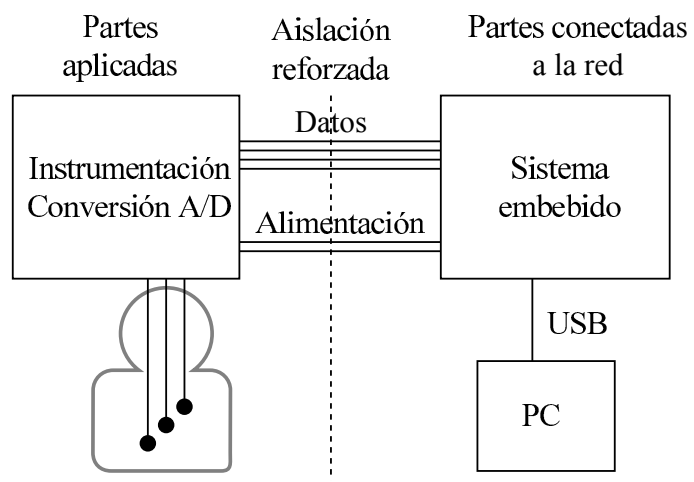

Figura 4.2: Ejemplo del esquema de aislación para un equipo de adquisición de biopotenciales conectado a través del bus USB a una PC.

Las personas conviven a diario con artefactos e instalaciones eléctricas que pueden potencialmente provocar el paso de corrientes peligrosas por su cuerpo. Si bien es imposible evitar completamente que se establezcan tales corrientes, pueden tomarse recaudos en el diseño de los sistemas eléctricos para reducir la probabilidad de que esto suceda hasta niveles aceptados como "seguros".

Los equipos de medida de biopotenciales aumentan las probabilidades de establecer corrientes peligrosas porque establecen una conexión galvánica de baja impedancia a través de los electrodos disminuyendo la impedancia que el cuerpo normalmente presenta a distintas fuentes de tensión. Por lo tanto, estos equipos deben cumplir condiciones especiales que garanticen su seguridad. Estas condiciones se explicitan en normas de seguridad.

La norma IEC 60601-1 (IEC EN 60601-1-2 2003) es el estándar internacionalmente aceptado de seguridad eléctrica, con el que están compatibilizadas, con desviaciones menores, las normas en Estados Unidos, la Unión Europea, y Argentina (Norma IRAM 4220-1: 2002, "Aparatos Electromedicos. Parte 1: Requisitos generales de seguridad") entre otros. Este documento establece una serie de reglas de diseño e implementación de equipamiento médico, y medidas para verificar los parámetros logrados.

La primera condición importante que establece la norma es que los equipos con conexión al paciente (clasificados como "tipo BF") es que deben estar aislados de tierra. Un equipo alimentado a batería automáticamente cumple este requisito, pero en el caso de alimentarse de la tensión de red, o por ejemplo de un puerto de una computadora conectada a la red, es necesario interponer una barrera de aislación con características especiales. Cuando la tensión excede los $25 \mathrm{~V}$ de alterna o $60 \mathrm{~V}$ de continua se denota como tensión peligrosa. En este caso, también debe existir una barrera de aislación. El equipo queda dividido en dos partes: la parte conectada con cualquier elemento que entre en contacto con la persona (llamada parte aplicada) y la parte que entra en contacto con tensiones peligrosas (la parte conectada a la red ${ }^{1}$ ).

Un equipo que esté conectado a una tensión peligrosa y tenga partes aplicadas al paciente deberá cumplir las siguientes condiciones (Marcus y Biersach, 2003):

- Debe tener dos grados de protección entre la parte aplicada y la parte conectada a la red, o equivalentemente una barrera de aislación certificada como aislación reforzada

\footnotetext{
${ }^{1}$ Traducción de mains part. Si bien la palabra "red" refleja la red comercial de distribución eléctrica, se entiende cualquier fuente de tensión peligrosa
} 
- En su construcción física las partes que aísla entre sí deben estar separadas por una distancia mínima a través del aire (distancia de arco) y un camino mínimo recorrido sobre cualquier superficie (distancia de fuga).

- No se debe exceder el límite de corriente de fuga de paciente de $10 \mu \mathrm{A}$ de continua o $100 \mu \mathrm{A}$ de alterna

- El diseño del equipo debe garantizar que, en condición de falla simple, no se aplique sobre el cuerpo de la persona una tensión peligrosa ni exista una corriente de fuga mayor a $50 \mu \mathrm{A}$ de continua o $500 \mu \mathrm{A}$ de alterna.

La condición de falla simple ocurre cuando un componente del sistema, y solo uno, sufre un desperfecto y opera fuera de su condición nominal. La figura 4.2 muestra un caso ejemplo de la aplicación de esta norma al diseño de un equipo de adquisición conectado a una PC. Una condición de falla simple ocurriría al fallar la aislación reforzada (en ese caso sólo se aplican los $5 \mathrm{~V}$ no peligrosos del bus USB a las partes aplicadas), o al fallar la fuente del bus USB (puede aparecer una tensión peligrosa en el bus, pero la aislación reforzada evita riesgos), o puede fallar una parte aplicada (el cuerpo puede quedar conectado a la masa del sistema, pero la masa está separada de tierra por la barrera de aislación reforzada).

\subsection{Realimentación de modo común independiente}

Como se describió previamente, en sistemas vestibles es importante reducir la tensión de modo común $V_{M C}$ debido a que el efecto divisor de potencial produce transformaciones de modo que no pueden ser rechazadas por un alto CMRR. El objetivo del circuito de DRL es anular la tensión de modo común que se desarrolla entre el nodo de medida (el cuerpo) y la masa del sistema de medida conectados a través del tercer electrodo. Para ello mide $V_{M C}$ y cierra un lazo de realimentación negativa aplicando la tensión necesaria sobre el tercer electrodo para anularla (Neuman, 2009).

Se implementó un módulo de DRL independiente apto para los equipos diseñados. El circuito toma del núcleo del equipo la alimentación de fuente simple aislada y la tensión de referencia de bajo ruido.

En la figura 4.3(a) se repite el modelo EMI por conveniencia, con elementos de interés para el análisis del lazo del DRL. Este modelo es ampliamente aceptado en el análisis del DRL en la literatura (Winter y Webster, 1983; Metting van Rijn et al., 1990; Alnasser, 2012). Los acoplamientos capacitivos desde el potencial de la línea de distribución de energía eléctrica $V_{l}$ y la tierra hacia el cuerpo y el sistema de medida se representan con capacidades concentradas $C_{p}, C_{b}, C_{\text {sup }} \mathbf{y}$ $C_{s}$. Las impedancias de los electrodos de medida y el tercer electrodo, o electrodo de realimentación, se denominaron $Z_{m}$ y $Z_{f}$ respectivamente, y el circuito de DRL se representó por la transferencia $H_{d r l}$ con impedancias de entrada y salida $Z_{i}$ y $Z_{o}$.

El circuito de la figura 4.3(a) puede entenderse mejor redibujándolo con todos sus nodos referidos a la masa del sistema de medida. Para poder hacerlo resulta útil definir algunos parámetros. $\mathrm{El}$ acoplamiento entre $V_{l}$ y la tensión de modo común $V_{C M}$ puede expresarse mediante un equivalente Thèvenin con fuente $V_{t h}$ y una impedancia capacitiva dada por $C_{t h}$. La impedancia vista desde el nodo $V_{C M}$ hacia la masa del sistema mediante $Z_{e q}$. La definición de estos parámetros 


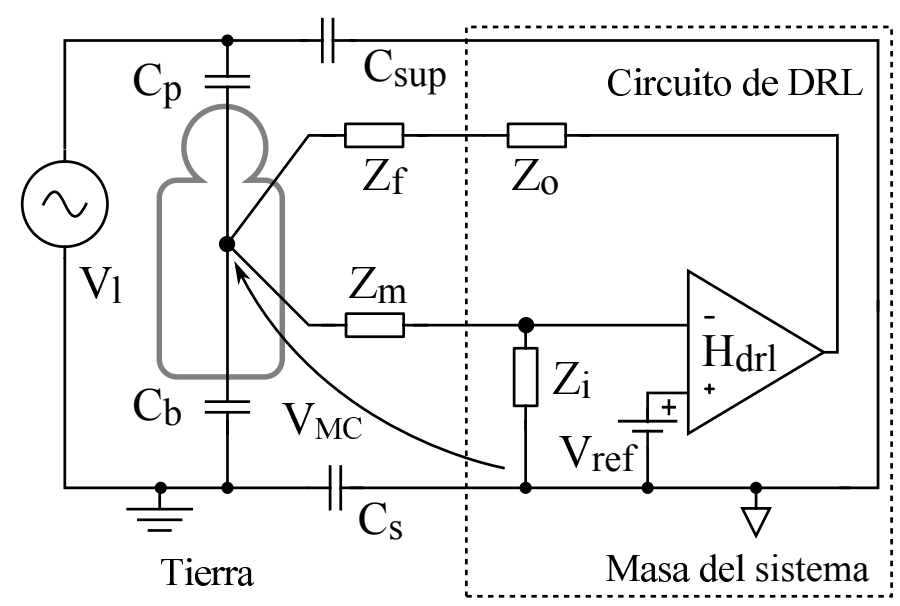

(a)

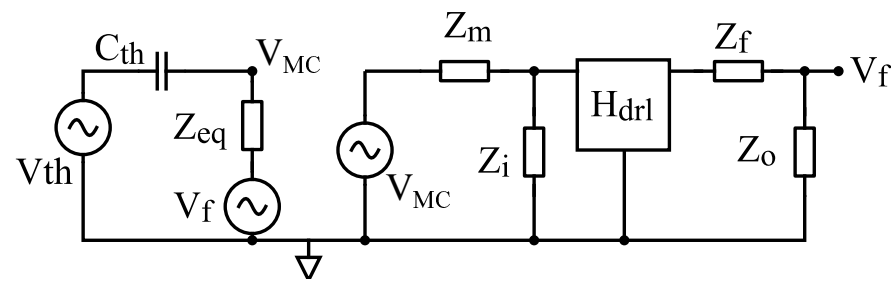

(b)

Figura 4.3: (a) Modelo EMI para el análisis del circuito de DRL. (b) Circuito redibujado con sus nodos referidos a la masa del sistema de medida.

es:

$$
\begin{aligned}
V_{t h} & =V_{l}\left(\frac{1}{1+C_{b} / C_{p}}-\frac{1}{1+C_{s} / C_{\text {sup }}}\right)=V_{l} \gamma \\
C_{t h} & =\frac{\left(C_{b}+C_{p}\right)\left(C_{s}+C_{\text {sup }}\right)}{\left.\left(C_{s}+C_{\text {sup }}+C_{b}+C_{p}\right)\right)} \\
Z_{\text {eq }} & =\left(Z_{o}+Z_{f}\right) / /\left(Z_{i}+Z_{m}\right) / / C_{t h}=\frac{1}{s C_{t h}+\frac{1}{Z_{o}+Z_{f}}+\frac{1}{Z_{i}+Z_{m}}}
\end{aligned}
$$

Utilizando estas definiciones, el circuito puede dibujarse como en la figura 4.3(b), que a su vez permite obtener una ecuación de transferencia sencilla para el modelo por inspección:

$$
\frac{V_{M C}}{V_{l}}=s Z_{e q} C_{t h} \gamma \frac{1}{1-\frac{Z_{i}}{Z_{m}+Z_{i}} H_{d r l}(s) \frac{Z_{e q}}{Z_{o}+Z_{f}}}=H_{t h} \frac{1}{1+H_{i} H_{d r l} H_{o}}
$$

La ecuación 4.4 se representa en el diagrama de bloques de la figura 4.4, que muestra al modelo en la forma clásica de un sistema de control. El diagrama así planteado permite analizar el lazo de realimentación y el rol del circuito de DRL. La tensión de línea es una perturbación actuando a través de la transferencia $H_{t h}$, y puede ser rechazada si se le asigna una ganancia alta al bloque de DRL.

La ganancia que puede darse a $H_{d r l}$ dependerá de la dinámica del lazo. Para encontrar una expresión analítica útil del lazo de DRL, es conveniente determinar las características de las impedancias involucradas y asignarles un rango de valores. Las siguientes consideraciones permiten hacerlo: 


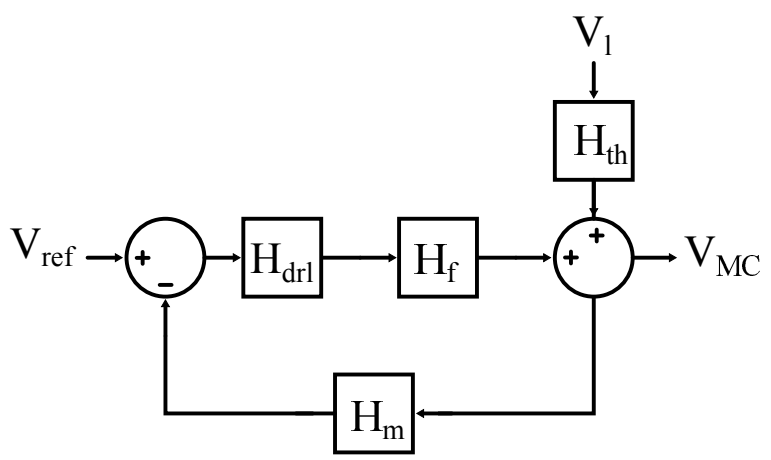

Figura 4.4: Diagrama en bloques equivalente del lazo del DRL.

- Puede asignarse un valor puramente resistivo a las impedancias de electrodo, de manera que $Z_{m}=R_{m}$ y $Z_{f}=R_{f}$. Esta simplificación en apariencia excesiva se justifica ya que la capacidad paralela despreciada contribuiría con adelanto de fase que como se verá, haría al sistema menos proclive a la inestabilidad. Como señala C. L. Levkov, 1988 el diseño final será conservador.

- Las impedancias de entrada y salida pueden considerarse como las de un amplificador operacional operando con realimentación negativa. Por lo tanto $Z_{i}=1 / s C_{i}$ y $Z_{o}=R_{o}$.

Con los parámetros del circuito así simplificados, la ecuación de transferencia del lazo resulta:

$$
L(s)=\frac{H_{d r l}}{s^{2} C_{i} R_{m} C_{t h}\left(R_{f}+R_{o}\right)+s\left(C_{t h}\left(R_{f}+R_{o}\right)+C_{i}\left(R_{f}+R_{o}+R_{m}\right)\right)+1}
$$

Esta transferencia tiene dos polos que para valores esperados de los parámetros del circuito son reales, como se verá más adelante. Adicionalmente, incluye la dinámica de la transferencia $H_{d r l}$ que como mínimo incluye los polos del los amplificadores utilizados en su implementación. Por lo tanto, aumentar la ganancia del sistema puede conducir a la inestabilidad del lazo y la transferencia del DRL debe implementar un compensador apropiado.

La compensación clásica descripta por Webster, 1988 es una compensación por polo dominante. Impone un polo de baja frecuencia que fuerza a la transferencia de lazo a cruzar la línea de $0 \mathrm{~dB}$ a una frecuencia $f_{c}$, ubicada en el mismo lugar o antes del polo más bajo que surge de la ecuación 4.5. Esto es necesario para asegurar que se cumpla el criterio se estabilidad de Nyquist con al menos $45^{\circ}$ de margen de fase.

A partir del cruce por $0 \mathrm{~dB}$ de la recta del polo en $f_{c}$, la magnitud crece con una pendiente de $20 \mathrm{~dB}$ por década hacia las frecuencias más bajas. Por lo tanto, para lograr la mayor ganancia posible a la frecuencia de línea, es deseable empujar la frecuencia $f_{c}$ al valor más alto posible. La condición más desfavorable para obtener una buena compensación se da cuando el menor polo de la acuación 4.5 toma su valor más bajo, es decir, cuando la constante de tiempo más lenta del lazo toma su mayor valor.

Para estimar ese valor en condiciones razonablemente pesimistas se busca el valor de $C_{t h}$ que genera la mayor constante de tiempo y dada su expresión (ecuación 4.2) corresponde seleccionar los mayores valores de la tabla 2.3. Las resistencias de electrodo pueden fácilmente tomar valores en el orden de $R_{m}=$ $R_{f}=100 \mathrm{k} \Omega$. Los amplificadores operacionales de bajo ruido tienen en general 


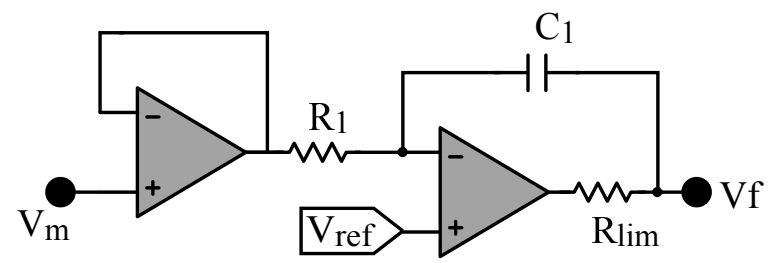

Figura 4.5: Diagrama esquemático del circuito de DRL independiente. Consta simplemente de un DRL tradicional mas un buffer para medir el potencial del cuerpo.

capacidades en un rango del que puede seleccionarse representativamente un valor $C_{i} \approx 5 \mathrm{pF}$, y la impedancia de salida será menor a $R_{o}=1 \mathrm{k} \Omega$.

Con estos valores, los polos de la ecuación 4.5 quedan localizados aproximadamente en $f_{1}=10 \mathrm{kHz}$ y $f_{2}=330 \mathrm{kHz}$. El polo en $10 \mathrm{kHz}$ es el que determinará la dinámica de la compensación. El segundo polo, junto con aquellos pertenecientes a los AOs que aporta la transferencia $H_{d r l}$ están ubicados más de una década por encima.

Se diseña por lo tanto un circuito de DRL con una transferencia tal que corte el eje de $0 \mathrm{~dB}$ en la frecuencia $f_{c}=10 \mathrm{kHz}$. Un esquema de amplificador inversor permite restar la señal de entrada a una referencia para implementar el lazo de realimentación, al mismo tiempo que permite intercalar un polo dominante para asegurar el corte en $f_{c}$.

El diagrama esquemático del circuito se muestra en la figura 4.5. Se compone de un amplificador operacional configurado como buffer para medir el potencial del cuerpo respecto de la masa del sistema de medida, y un segundo AO para implementar la transferencia. Los nodos $V_{m}$ y $V_{f}$ se conectan en el PCB a broches compatibles con los conectores de electrodos comerciales.

\subsection{Electrodos activos}

Para la prueba preliminar del equipo bajo el paradigma de la figura 4.1 se fabricaron distintos juegos de electrodos activos. Se utilizaron para ello amplificadores operacionales en configuración de ganancia unitaria, seleccionados según los criterios presentados en la sección 3.4.1. Cada electrodo activo requiere tres cables: $5 \mathrm{~V}$, masa, y salida de señal. Los operacionales se montaron sobre PCBs junto con un broche para poder cambiar el tipo de electrodo utilizado fácilmente.

El modelo circuital de la medida se presenta en la figura 4.6 donde se han diagramado dos electrodos activos en un canal diferencial de medida. En el EA superior se detallan los parámetros del modelo del AO que tienen impacto en la medida. También se explicita el modelo de impedancia del electrodo, donde se ha despreciado la impedancia serie del cuerpo y de la interfaz metal-electrolito. Incluso la capacidad del electrodo produce constantes de tiempo por encima del ancho de banda de las señales de biopotencial por lo que se puede despreciar para el análisis, con la seguridad de que hacerlo resultará en aproximaciones más pesimistas.

El ruido total referido a la entrada de los electros activos resultará entonces:

$$
e_{n, t o t}^{2}=2 e_{n}^{2}+2\left(i_{n} R_{e}\right)^{2}
$$

Por otro lado, debe tenerse $i_{b}<10 \mu \mathrm{A}$ ya que circulará por el cuerpo (requisito dado por normas de seguridad eléctrica) y la capacidad de entrada debe ser en 


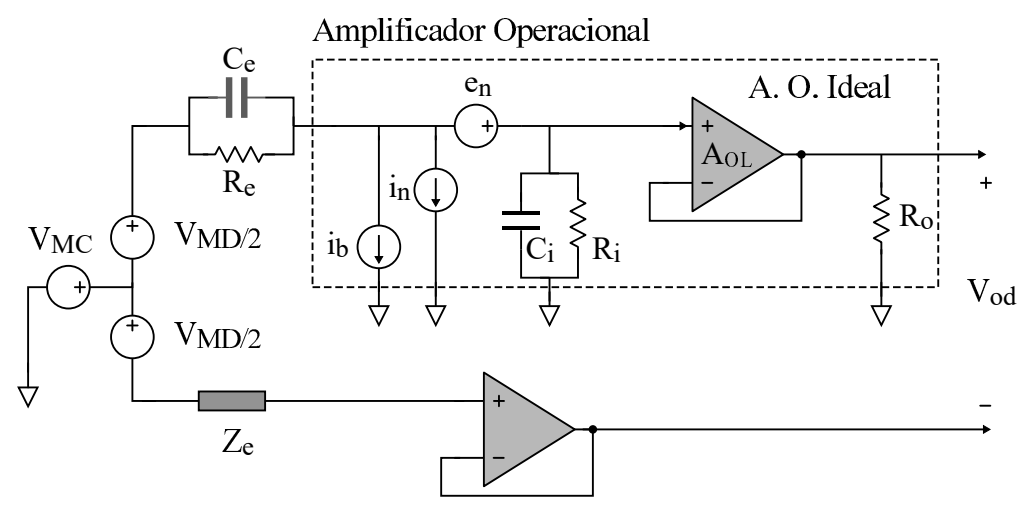

Figura 4.6: Modelo del electrodo activo implementado con amplificador operacional (AO) con realimentación unitaria. Se diagrama la situación de medida con dos electrodos activos y se incluyen los parámetros del modelo de AO real relevantes, para uno de ellos.

\begin{tabular}{lcccc}
\hline & \multicolumn{2}{c}{ OPA333 } & \multicolumn{2}{c}{ TLC2201 } \\
\hline Ruido & $\mathrm{EEG}^{1}$ & $\mathrm{EMG}^{2}$ & $\mathrm{EEG}$ & $\mathrm{EMG}$ \\
Tensión de Ruido $\left[\mu \mathrm{V}_{\mathrm{rms}}\right]$ & 0.46 & 1.68 & 0.19 & 0.2 \\
Corriente de Ruido $\left[\mathrm{fA}_{\mathrm{rms}}\right]$ & 830 & 2000 & 4.1 & 10 \\
\hline Impedancia de entrada & $4 \mathrm{pF}$ & $\approx 20 \mathrm{pF}$ \\
\hline Ancho de banda & $350 \mathrm{kHz}$ & $1.8 \mathrm{MHz}$ \\
\hline Rango de entrada & rail-to-rail & $0-2.7 \mathrm{~V}$ \\
\hline Corriente de polarización & $\pm 200 \mathrm{pA}$ & $1 \mathrm{pA}$ \\
\hline Consumo & $17 \mu \mathrm{A}$ & $1.5 \mathrm{~mA}$ \\
\hline Ganancia L.A. típ. (mín.) & $130(106) \mathrm{dB}$ & $110(103) \mathrm{dB}$ \\
\hline Precio relativo & 1 & 2 \\
\hline 1: Ancho de banda entre $0.01 \mathrm{y} 70 \mathrm{~Hz}$ & & \\
2: Ancho de banda entre $10 \mathrm{y} 450 \mathrm{~Hz}$ & &
\end{tabular}

Tabla 4.1: Parámetros de dos operacionales utilizados en la confección de electrodos activos.

principio menor a $30 \mathrm{pF}$ para cumlir al menos con los requisitos de medidas de biopotenciales estándar que requieren impedancias de entrada mayores a $100 \mathrm{M} \Omega$ a $50 \mathrm{~Hz}$ (Nuwer et al., 1998; Sinha et al., 2016). Los amplificadores operacionales seleccionados dictarán características importantes del equipo: el ruido total mínimo y la impedancia de entrada, y tendrán efectos sobre otras como el CMRR total y el consumo de energía.

La tabla 4.1 lista parámetros de dos operacionales seleccionados, el TLC2201 y OPA333 de texas instruments. Puede observarse que el OPA333 posee un número de ventajas muy interesantes para constituir un EA para biopotenciales: su capacidad de entrada está en el rango de las más bajas, admite cualquier rango de tensiones a la entrada (lo que se conoce como rail-to-rail), su consumo de energía es extremadamente bajo, tiene un diseño especial que anula el ruido $1 / f$ de baja frecuencia, y una ganancia de lazo abierto elevada. Sin embargo, su desempeño en tensión, y sobre todo corriente de ruido es inferior al TLC2202. 


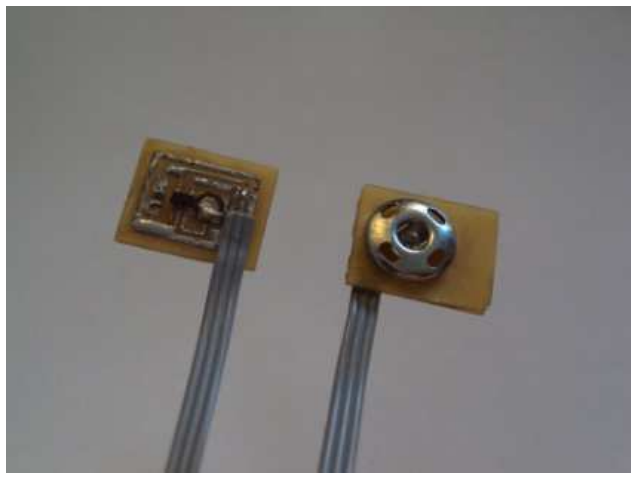

Figura 4.7: Fotografía de un par de electrodos activos fabricados con AOs OPA333.

En general, lograr parámetros de ruido especialmente bajos en el diseño de OAs compromete otros factores. En el caso del TLC2201 resalta como desventaja su mayor capacidad de entrada, en el límite de la admisible, y su consumo. Sin embargo, la comparación de ruido total para un electrodo de $1 \mathrm{M} \Omega$ de impedancia a partir de la ecuación 4.6 resulta:

$$
\begin{array}{lll}
\text { TLC2201: } & \text { EEG } & e_{n, t o t}=0.19 \mu \mathrm{V}_{\text {rms }} \\
& \text { EMG } & e_{n, t o t}=0.20 \mu \mathrm{V}_{\text {rms }} \\
\text { OPA333: } & \text { EEG } & e_{n, t o t}=0.95 \mu \mathrm{V}_{\text {rms }} \\
& \text { EMG } & e_{n, t o t}=2.61 \mu \mathrm{V}_{\text {rms }}
\end{array}
$$

Estos resultados muestran que mientras el aporte de ruido del TLC2201 sería despreciable, el OPA333 podría contribuir con ruido notable aunque no excesivo en las medidas.

La figura 4.7 muestra la implementación de los electrodos activos. El circuito incluye un capacitor de bypass de $1 \mu \mathrm{F}$ y la salida del operacional se distribuyó como guarda del contacto del electrodo. El mismo broche, de acero inoxidable, puede utilizarse como electrodo seco si no se adiciona ningún electrodo.

Se fabricó un arreglo lineal de electrodos secos para EMG similar al reportado por Merletti, Farina et al., 2003 con 8 varillas metálicas doradas de $1 \mathrm{~cm}$ de largo y sección cuadrada de $0,64 \mathrm{~mm}$ de lado, separadas cada $10 \mathrm{~mm}$. Cada varilla se conectó a un buffer, para lo que se utilizaron dos integrados con operacionales cuádruples TLC2274. El objetivo de este arreglo fue realizar en forma práctica una medida de biopotencial multicanal.

Finalmente se fabricaron electrodos para EMG basados en TLC2202 (de similares características que el TLC2201 pero dual) utilizando los mismos contactos de electrodo que en el arreglo lineal.

\subsection{Implementación I: Equipo de laboratorio}

\subsubsection{Diseño e Implementación}

Se implementó un equipo de adquisición con instrumentación diseñada según el diagrama de la figura 4.1. El núcleo del sistema se basó en el circuito integrado ADS1298 de Texas Instruments. Este componente incluye las características mencionadas en la sección 4.1. En particular, cuenta con 8 canales diferenciales, cada uno con una ganancia programable de valores entre 
1 y 12 veces, convertidores $\Sigma-\Delta$ con muestras de 24 bits y tasa de conversión programable entre 500 y 16000 muestras por segundo. Este dispositivo también incorpora un filtro pasa-bajos en cada canal para filtrar EMI de alta frecuencia, y una fuente de tensión de bajo ruido que puede ser presentada en un pin externo.

El ADS1298 se montó en un PCB de dos capas diseñado con planos de tierra analógica y digital conectados en estrella para evitar interferencia por impedancias compartidas entre los retornos de etapa analógica y digital del sistema. Si bien se trata de un IC de señal mixta, está implementado con una separación física entre las funciones analógicas y digitales para facilitar el diseño de los planos del PCB. El conexionado con conmutación de topología se implementó a través de selectores manuales para cada canal que permiten alternar entre una topología completamente diferencial y una single-ended. Los selectores se encuentran dentro del gabinete.

Para la seguridad eléctrica, nuevamente un ASSP puede aportar una solución: en concordancia con las especificaciones de seguridad eléctrica descriptas en la sección 4.1.3, el componente ADUM6401 de Analog Devices provee aislación reforzada para un bus SPI de datos y un bus de alimentación de $5 \mathrm{~V}$ o 3.3 $\mathrm{V}$ regulados, entregando hasta $100 \mathrm{~mA}$. Para ajustarse a la norma, en la construcción física del prototipo se respetaron distancias mínimas entre las partes aplicadas al paciente y el resto del circuito, a través del aire y sobre superficies dieléctricas (distancias de arco y de fuga).

El segundo módulo del sistema cumple la función de administrar la comunicación con la PC. Un microcontrolador PIC18f2550 de 8 bits funciona como maestro en el bus SPI que lo conecta al ADS1298 y recupera las muestras al ser interrumpido por el convertidor en cada período de muestreo. El firmware del microprocesador fue programado en lenguaje $\mathrm{C}$ y compilado con el compilador MPLAB C18. Consiste en una máquina de estados finitos que responde a instrucciones enviadas desde la PC.

La comunicación con la PC, incluyendo el envío de muestras en tiempo real se realizó a través del bus estándar USB, que también provee la alimentación a todo el sistema.

Para el control del módulo USB en el firmware se utilizaron funciones de las librerías provistas por Microchip y el equipo se configuró como dispositivo o periférico HID (dispositivo de interfaz humana, por sus siglas en inglés), lo que garantiza, como mínimo, el envío de un paquete de 64 bytes por cada milisegundo. Esto es suficiente para el envío en tiempo real de los datos de 8 canales muestreados a 2000 muestras por segundo.

Para administrar los datos en la PC, se implementó una librería en lenguaje $\mathrm{C} / \mathrm{C}++$ con una capa de abstracción de hardware que utiliza la API de Windows para las transferencias HID del bus USB. Se implementó un protocolo de comunicación basado en paquetes de 64 bytes entre esta capa y una superior que da acceso a funciones de alto nivel para controlar el dispositivo. La aplicación de usuario se implementó en lenguaje C Sharp .Net, incluyendo la visualización en tiempo real de las señales adquiridas y su almacenamiento en disco.

La figura 4.8(a) muestra el PCB fabricado con los componentes montados. Se observa la división necesaria para mantener la barrera de aislación reforzada. Para conectar distintos periféricos de instrumentación al equipo se fabricó un frente con 8 conectores que pueden utilizarse como 4 pares diferenciales, utilizando las entradas no-inversora e inversora de 4 canales del ADS1298, o 8 canales single-ended, conectando las entradas inversoras a la tensión de referencia y utilizando las 8 entradas no inversoras como entrada activas de medida. Cada conector posee tres contactos, uno para la señal y los restantes para la alimentación del electrodo activo utilizado. Un noveno conector presenta 


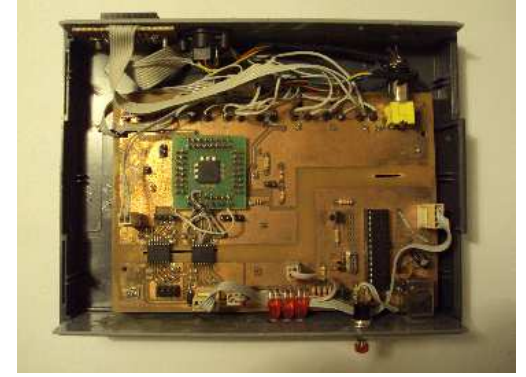

(a)

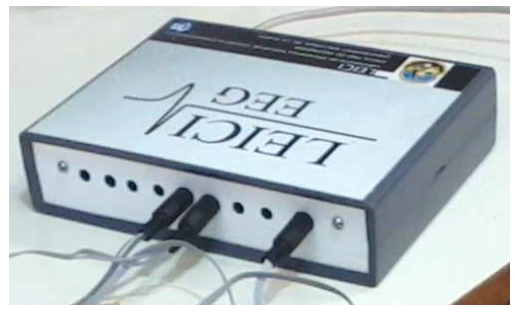

(b)

Figura 4.8: Fotografías de (a) el PCB del equipo de adquisición y (b) el gabinete con cables de electrodos activos conectados.

también tres contactos, dos de alimentación y uno con la tensión de referencia para el circuito de DRL independiente. El equipo completo con el frente de conexionado puede observarse en la figura 4.8(b).

La fuente de referencia de bajo ruido interna del ADS1298 se derivó a través de un buffer implementado con un amplificador que el ASSP tiene originalmente reservado para implementar el circuito de DRL. En este caso se realimentó unitariamente el amplificador, se conectó su entrada a la referencia y se tomó su salida para constituir tanto la referencia de los canales single-ended como del DRL.

\subsubsection{Resultados}

Para evaluar el equipo implementado se midieron sus parámetros de funcionamiento.

El ancho de banda se evaluó con un barrido en frecuencias inyectando una señal diferencial en un canal incluyendo electrodos activos.

Se midió el CMRR conectando ambos electrodos activos de un canal diferencial a un generador con una salida sinusoidal con $2.5 \mathrm{~V}$ de offset y se obtuvo el componente de esta señal presente en la tensión diferencial medida a través de estimación por el método de cuadrados mínimos.

Se midió el ruido equivalente de tensión referido a la entrada del dispositivo cortocircuitando las entradas de un canal diferencial con la tensión de referencia, y se adquirieron 120 segundos de esta señal. Se limitó el ancho de banda con un filtro pasa-banda de primer orden y se calculó el valor cuadrático medio. Se repitió la medida con y sin electrodos activos.

Los parámetros asociados a valores estándar de los componentes utilizados se obtuvieron de las hojas de datos de los componentes (i.e., la impedancia de entrada).

Los resultados se resumen en la tabla 4.2. Los parámetros obtenidos muestran que el equipo es apropiado para medidas de señales de EMG y EEG, y también reflejan el límite en las prestaciones que significa utilizar componentes comerciales con topologías sencillas.

Se condujeron medidas de biopotencial en el laboratorio para evaluar el sistema. La figura 4.9(b) muestra una captura de las señales obtenidas utilizando el arreglo lineal de EMG colocado sobre el bíceps utilizando una banda elástica con broche de velcro. Los canales se procesaron restando el octavo canal a los demás y aplicando un filtro pasa-banda entre 10 y $450 \mathrm{~Hz}$. 
4.5. Implementación II: Módulo para plataforma vestible

\begin{tabular}{lcc}
\hline Configuración & EEG & EMG \\
\hline Tasa de muestreo & $500 \mathrm{mps}$ & $2000 \mathrm{mps}$ \\
\hline Ancho de banda & $0-131 \mathrm{~Hz}$ & $0-524 \mathrm{~Hz}$ \\
\hline Ganancia & 12 & 4 \\
\hline Tensión de ruido & $0.35 \mu \mathrm{V}_{\mathrm{rms}}(0.01-70 \mathrm{~Hz})$ & $1.3 \mu \mathrm{V}_{\mathrm{rms}}(10-450 \mathrm{~Hz})$ \\
\hline T. de ruido Con E.A. & $1.26 \mu \mathrm{V}_{\mathrm{rms}}$ & $1.85 \mu \mathrm{V}_{\mathrm{rms}}$ \\
\hline CMRR (con E.A.) & \multicolumn{2}{c}{$96 \mathrm{~dB}$} \\
\hline Número de canales & \multicolumn{2}{c}{$1-4$ Dif. ; 1-8 S.E. } \\
\hline Offset & $\pm 200 \mathrm{mV}$ & $\pm 625 \mathrm{mV}$ \\
\hline
\end{tabular}

Tabla 4.2: Parámetros de funcionamiento de la implementación I utilizando electrodos activos implementados con AOs TLC2201.

La figura 4.9(a) muestra un gráfico de una señal de EEG obtenida colocando electrodos de $\mathrm{Ag} / \mathrm{AgCl}$ humedecidos aplicando solución fisiológica con un paño, sobre las posiciones $\mathrm{O} 1$ y O2 del sistema international 10-20. Puede observarse el comienzo y continuidad de un ritmo $\alpha$ a partir del segundo 11, cuando la persona que portaba los electrodos cerró los ojos.

\subsection{Implementación II: Módulo para plataforma vestible}

\subsubsection{Diseño e Implementación}

El prototipo descripto en las secciones anteriores implementa el paradigma de instrumentación necesario para los dispositivos vestibles. Sin embargo, para extender las pruebas a situaciones realistas de uso se manufacturó un segunto prototipo con dimensiones reducidas, apropiado para ser directamente transferible como etapa de instrumentación de una NPV.

Se utilizó el integrado ADS1299, de características muy similares al ADS1298 pero con un rango dinámico superior. Se diseñó un PCB de dimensiones reducidas, de $5 \mathrm{~cm} \times 5 \mathrm{~cm}$ para soportar el ASSP y proveer la salida de referencia para el DRL, conexión de electrodos activos, y el puerto de comunicaciones digitales para recuperar las muestras.

Para mantener el módulo de instrumentación separado del resto del sistema que da soporde de comunicación con la PC en el laboratorio, se implementó por separado un módulo de aislación con dos ADUM6401 capaces de entregar $3.3 \mathrm{~V}$ y $5 \mathrm{~V}$ aislados a partir de una fuente de $5 \mathrm{~V}$ y de transmitir datos a través de la barrera de aislación. Finalmente, se implementó un módulo USB de administración de datos y comunciaciones con la PC, con la misma función que el implementado para el ADS1298 pero en un factor de forma de $5 \mathrm{~cm} \times 5 \mathrm{~cm}$. El mismo software creado para la implementación I se utilizó en para este equipo ya que el protocolo de capa intermedia tiene la flexibilidad de aceptar distintos equipos.

El sistema se utilizó como plataforma para probar electrodos de sEMG como se verá en el capítulo 6 y se utilizó para adquirir señales de EEG como parte de una ICC basada en SSVEP (García et al., 2014). 


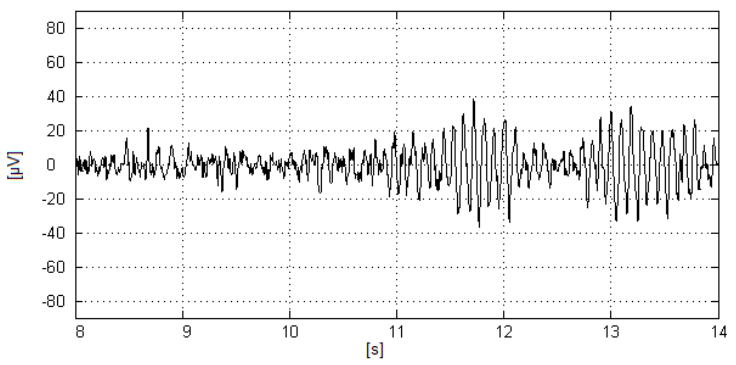

(a)

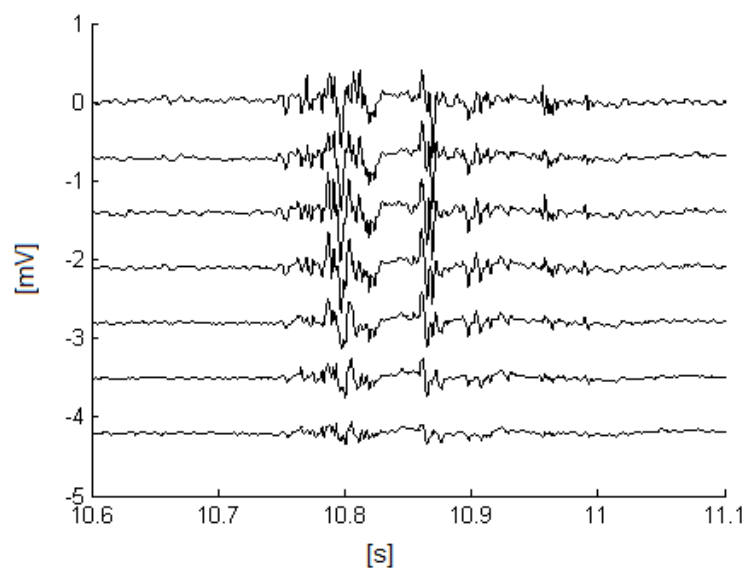

(b)

Figura 4.9: Medidas de biopotencial obtenidas con el equipo implementado. (a) Señal de EEG con presencia de ritmo $\alpha$ a partir del segundo 11 aproximadamente, medida con un canal diferencial utilizando electrodos activos implementados con AOs TLC2201. (b) Señales de EMG tomadas con un arreglo lineal utilizando los 8 canales del equipo con topología single-ended.

\subsubsection{Resultados}

Los resultados se presentan en la tabla 4.3. Las medidas se condujeron del mismo modo que las descriptas para la implementación I. Se relevó la respuesta en frecuencia del sistema incluyendo los electrodos activos para una tasa de muestreo de 2000 muestras por segundo y resultó en una buena correspondencia con la curva teórica del filtro digital de forma $\operatorname{sinc} c^{3}$, como se observa en la figura 4.11 .

Los módulos de menores dimensiones pueden colocarse en un gabinete factible de ser llevado sobre el cuerpo, como se muestra en la figura 4.12. Esto cambia los valores de las impedancias de acoplamiento, permitiendo reflejar condiciones de medida de un sistema vestible. En los capítulos 5 y 7 se utiliza esta plataforma para probar el funcionamiento de un circuito DRL y electrodos activos de alta impedancia de entrada, logrando adquirir exitosamente señales de EMG y EEG de alta calidad. Se publicó el sistema junto con software accesorio (Guerrero, M. Haberman et al., 2014) y como soporte de un sistema de medida de sEMG con electrodos secos (Guerrero y E. Spinelli, 2015). 


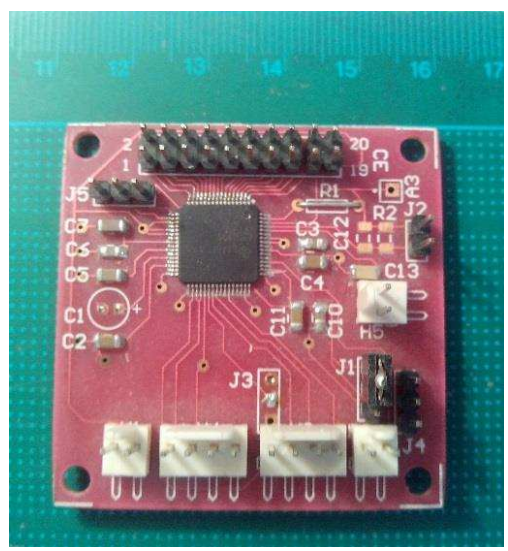

Figura 4.10: Módulo basado en ADS1299.

\begin{tabular}{lcc}
\hline Configuración & EEG & EMG \\
\hline Tasa de muestreo & $250 \mathrm{mps}$ & $2000 \mathrm{mps}$ \\
\hline Ancho de banda & $0-65 \mathrm{~Hz}$ & $0-524 \mathrm{~Hz}$ \\
\hline Ganancia & 12 & 4 \\
\hline Tensión de ruido & $0.15 \mu \mathrm{V}_{\mathrm{rms}}(0.01-65 \mathrm{~Hz})$ & $0.35 \mu \mathrm{V}_{\mathrm{rms}}(10-450 \mathrm{~Hz})$ \\
\hline T. de ruido Con E.A. & $0.95 \mu \mathrm{V}_{\mathrm{rms}}$ & $1.37 \mu \mathrm{V}_{\mathrm{rms}}$ \\
\hline CMRR (con E.A.) & \multicolumn{2}{c}{$90 \mathrm{~dB}$} \\
\hline Número de canales & \multicolumn{2}{c}{$1-8$ Dif. ; 1-8 S.E. } \\
\hline Offset & $\pm 200 \mathrm{mV}$ & $\pm 625 \mathrm{mV}$ \\
\hline
\end{tabular}

Tabla 4.3: Parámetros de funcionamiento de la implementación II.

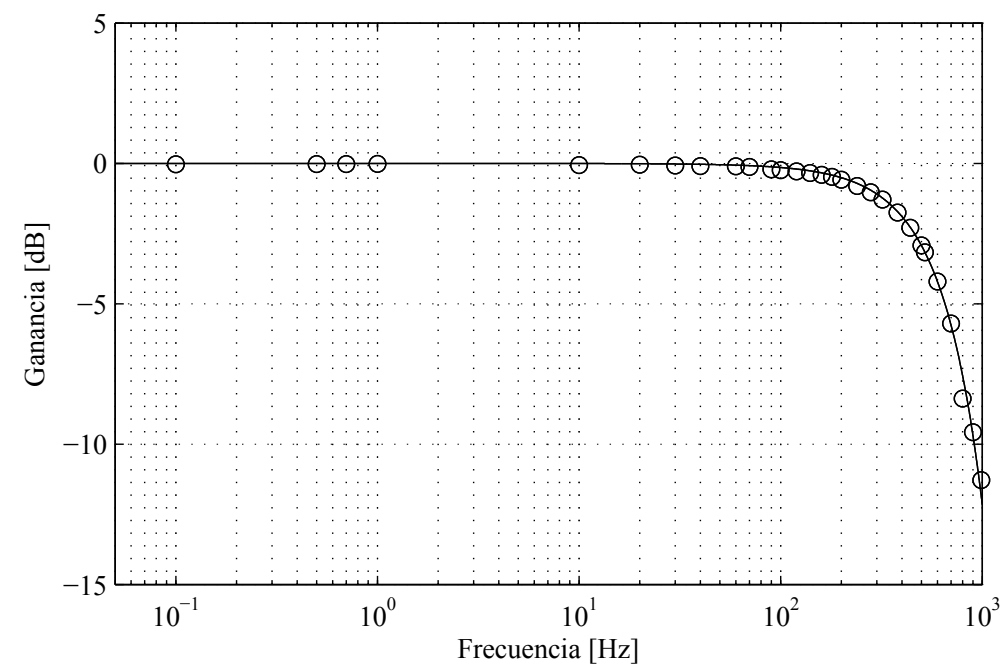

Figura 4.11: Respuesta en frecuencia del sistema de adquisición. Se muestran con círculos los puntos medidos, y en línea continua la respuesta del filtro digital del ADS1299. 


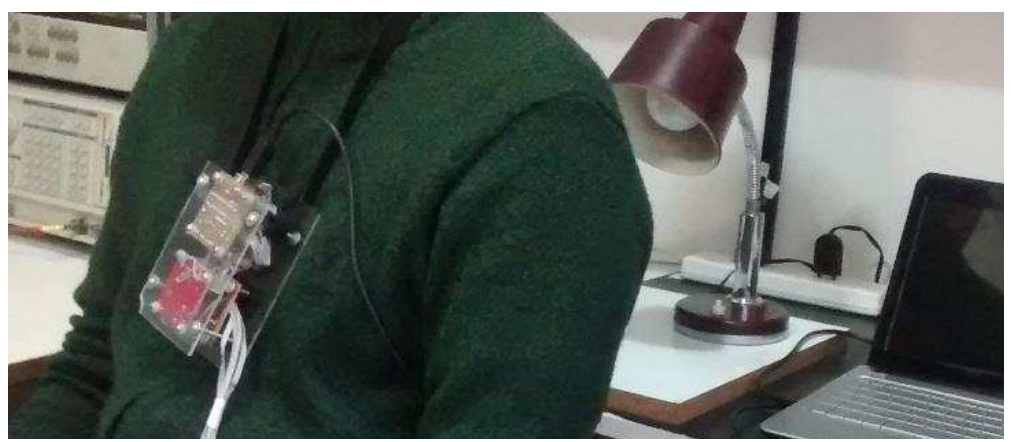

Figura 4.12: Uso del módulo con aislación y conexión USB a una computadora portátil.

\subsection{Conclusiones}

Se diseñaron e implementaron prototipos de equipos de instrumentación para biopotenciales siguiendo el paradigma de instrumentación propuesto el capítulo 3. Los equipos mostraron alcanzar las propiedades necesarias para la medida de biopotenciales que funcionan como entrada de información para las NPs que interpretan la voluntad.

Los diseños resultaron sencillos aprovechando la elevada integración de funcionalidad existente en los ASSPs, tanto el AFE de medida de biopotenciales como el IC de aislación de datos y alimentación. Se adaptaron a ellos los periféricos de instrumentación que funcionan como punto de partida para el trabajo de tesis: electrodos activos y el circuito de DRL. En particular el uso de un DRL independiente reduce los puntos críticos para asegurar el funcionamiento del sistema.

Si bien estos equipos son efectivos para medidas de biopotenciales en el laboratorio, las técnicas convencionales de electrodos activos y reducción de modo común son limitados. Por un lado existe una relación de compromiso establecida por la compensación por polo dominante del DRL, entre la estabilidad del lazo y el rechazo. Por otro lado la tecnología disponible en la etapa de entrada de amplificadores operacionales de bajo ruido degrada el CMRR frente a impedancias altas de electrodo.

Los sistemas implementados funcionaron como plataforma para el trabajo de tesis posterior, constituyendo el núcleo sobre el cual poner a prueba los circuitos de acondicionamiento orientados a sistemas vestibles bajo un paradigma en el estado del arte. 


\title{
Circuito DRL con mejora de ganancia
}

\begin{abstract}
El circuito de realimentación de modo común tradicional con compensación por polo dominante, ha resultado un diseño sumamente exitoso, estable frente a la incertidumbre presente en el modelo de interferencia electromagnética, aunque imponiendo un límite al rechazo que puede obtenerse. Las condiciones de los sistemas vestibles y la evolución de la interferencia electromagnética hacen necesario mejorar el rechazo aportado por este circuito de acondicionamiento. En este capítulo se presenta una compensación alternativa que permite mejorar el rechazo sin comprometer la estabilidad del sistema, ya que su diseño se basa en los mismos criterios ampliamente probados en la práctica. El circuito resultante posee el mismo grado de complejidad que el tradicional, pero permite aumentar el rechazo cerca de $20 \mathrm{~dB}$ aportando a la robustez de los sistemas vestibles.
\end{abstract}

\subsection{Realimentación de modo común}

Uno de los mecanismos más significativos por los cuales las señales electromagnéticas del entorno interfieren con las medidas de biopotencial es la transformación de la tensión de modo común $\left(V_{M C}\right)$ en modo diferencial. Los amplificadores de biopotencial pueden alcanzar valores muy altos de rechazo de modo común, a costa de diseños más complejos, componentes más costosos con un buen apareamiento, o diseños integrados con parámetros específicos controlados. Sin embargo, cuando se buscan topologías sencillas a implementar con componentes comerciales, los desbalances en estos componentes limitan el CMRR alcanzable a unos $90 \mathrm{~dB}$. Aún más, el CMRR está fundamentalmente limitado por el efecto divisor de potencial causado por las impedancias de electrodo.

Frente a la imposibilidad de rechazar la interferencia de modo común, se recure a otra estrategia: disminuir la tensión de modo común $V_{M C}$ mediante el circuito de DRL para que no pueda provocar interferencia. En el capítulo 4 se presentó una implementación clásica utilizando la compensación por polo dominante (PD). Evidentemente la compensación por polo dominante establece 
una relación de compromiso: dado un requerimiento de estabilidad, la reducción de $V_{M C}$ posible queda fijada. La estimación realizada, y las configuraciones usuales reflejadas en la literatura (Metting van Rijn et al., 1990; Winter y Webster, 1983; Acharya, 2011), permite obtener una mejora en el rechazo de modo común entre $30 \mathrm{~dB}$ y $50 \mathrm{~dB}$ a $50 \mathrm{~Hz}$, y decreciendo a una tasa de $20 \mathrm{~dB}$ por década.

En sistemas vestibles, el problema del efecto divisor de potencial se acrecienta debido a la alta impedancia y desbalance de los electrodos secos descriptos en el capítulo 2. Además, las neuroprótesis además requieren señales de EMG o EEG como entradas lo cual significa electrodos de área pequeña y muchas veces con el cabello impidiendo un buen contacto. Para ayudar a enfrentar estos desafíos es deseable incrementar la reducción de $V_{M C}$. Una reducción suficiente de la tensión de modo común puede incluso permitir el uso de topologías de medida single-ended, simplificando ampliamente los diseños de sistemas multicanales (C. L. Levkov, 1988; Metting van Rijn et al., 1991; Dias et al., 2012; M. A. Haberman y E. M. Spinelli, 2012). Adicionalmente, el contenido armónico de la interferencia electromagnética aumenta gradualmente con la evolución de los dispositivos de consumo (Bollen y Olofsson, 2015; Berthet et al., 2003), y el circuito de DRL es una herramienta que puede ser utilizada para mejorar el rechazo a las frecuencias de armónicos de línea.

La literatura refleja la búsqueda de circuitos que permitan aportar una mayor ganancia y a mayores frecuencias que la permitida por la compensación por polo dominante, por medio del uso de amplificadores de transconductancia (E. M. Spinelli, Martínez et al., 1999; Alnasser, 2012) o implementaciones basadas en técnicas digitales (M. Haberman y E. Spinelli, 2010). En este capítulo se presenta una compensación alternativa para el circuito de DRL que permite incrementar el rechazo de $V_{M C}$ dentro del ancho de banda completo de operación. Este enfoque permite conservar los mísmos criterios probados de estabilidad que utiliza el diseño tradicional del DRL. Al mismo tiempo, mantiene la simplicidad de implementación, ya que solo demanda la modificación de los componentes pasivos del circuito.

\subsection{Una compensación alternativa}

En la sección anterior se presentó el esquema de compensación por PD ampliamente aceptado. Se basa en estimar la frecuencia más baja del polo más bajo del lazo de DRL, $f_{c}$, e incluir un polo dominante a partir del cual la pendiente de $20 \mathrm{~dB} / \mathrm{dec}$ permite cortar el eje de $0 \mathrm{~dB}$ a $f_{c} \mathrm{~Hz}$. Una ventaja importante de este esquema es que ha probado su estabilidad en forma práctica durante décadas a pesar de la incertidumbre de los parámetros involucrados durante décadas de uso en los equipos de adquisición.

El nuevo esquema de compensación propuesto se muestra en línea cortada en la figura 5.1. La clave del diseño es conseguir una alta ganancia en bajas frecuencias, pero incluir luego dos polos $p_{1} \mathbf{y} p_{2}$, para obtener una pendiente $o$ roll-off de $40 \mathrm{~dB}$ que permite alcanzar el cruce por $0 \mathrm{~dB}$ a la frecuencia $f_{c}$. Para mantener un margen de fase cercano a los $45^{\circ}$, debe introducirse un cero $z_{1}$ cerca de una década antes de $f_{c}$. Esto se conoce como compensación por retraso de fase. Las restricciones sobre este diseño son que $p_{2} \mathrm{y} z_{1}$ deben estar aproximadamente una década separados para evitar que la fase se acerque a $180^{\circ}$ más alla de un margen seguro, y que la ganancia deseada en baja frecuencia pueda ser obtenida con el amplificador operacional utilizado. 

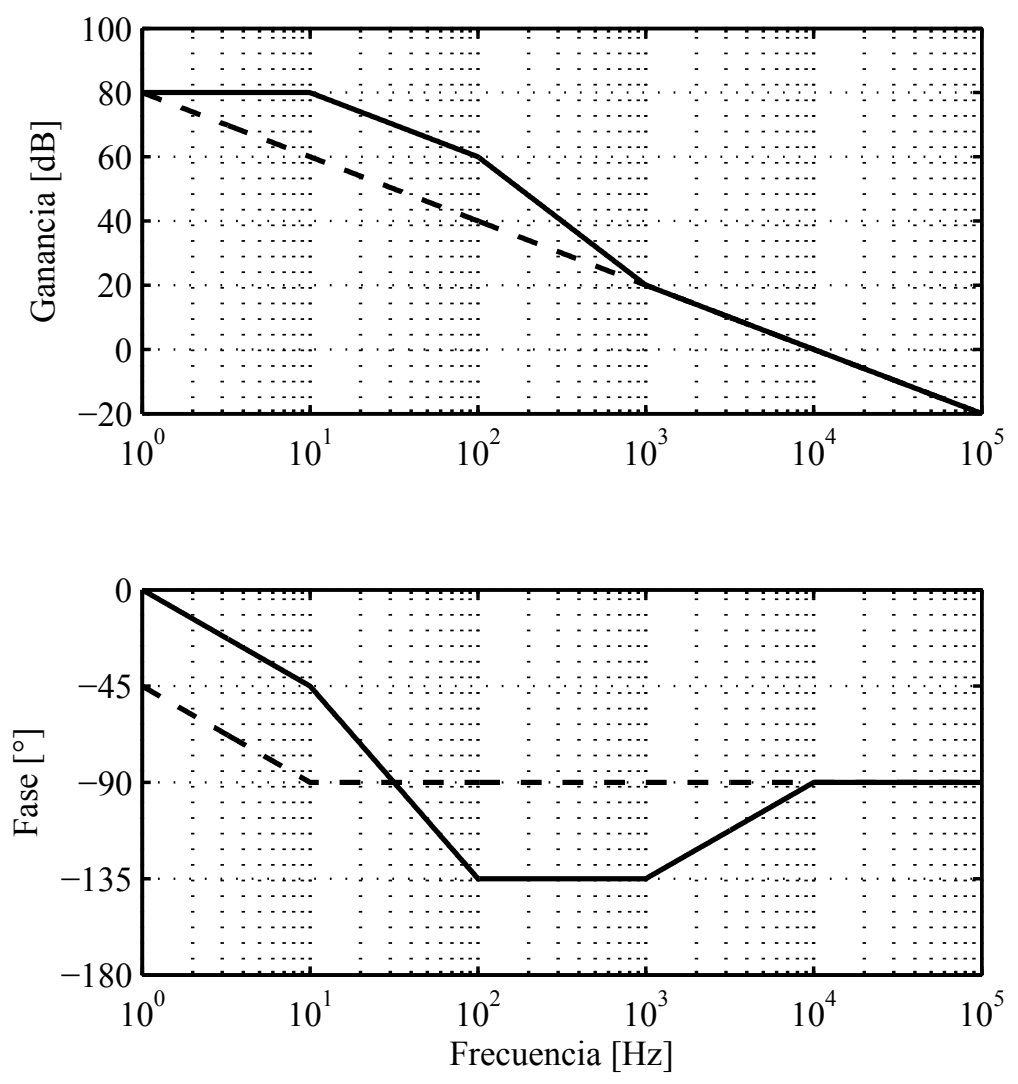

Figura 5.1: Diagrama de Bode aproximado de la compensación por polo dominante (linea a rayas) y el compensador propuesto (línea completa).

La compensación propuesta puede ser implementada con el circutio de la figura 5.2(a). Este circuito solo difiere del necesario para la compensación por polo dominante en el uso de componentes pasivos adicionales, como se puede observar por comparación con la figura 5.2(b). La red de realimentación pasiva provee los dos polos y el cero requeridos para la compensación, mientras que la resistencia $R_{\text {lim }}$ limita la corriente que puede ser inyectada al cuerpo por motivos se seguridad eléctrica. La función de transferencia del circuito es:

$$
\frac{V_{f}}{V_{m}}=-\frac{\alpha}{R_{4}} \frac{s \frac{R_{1} \tau_{1}+R_{2} \tau 2}{\alpha}+1}{\left(s \tau_{1}+1\right)\left(s \tau_{2}+1\right)}
$$

Donde

$$
\begin{aligned}
\tau_{1} & =R_{1} C_{1} \\
\tau_{2} & =R_{2} C_{2} \\
\alpha & =R_{1}+R_{2}+\frac{R_{1} R_{2}}{R_{3}}
\end{aligned}
$$

Una vez que las locaciones de los ceros y los polos son conocidas, i.e., cuando se ha estimado el polo inferior de la ecuación 4.5, el método para asignar valores a los componentes puede ser ejecutado con los siguientes pasos: 


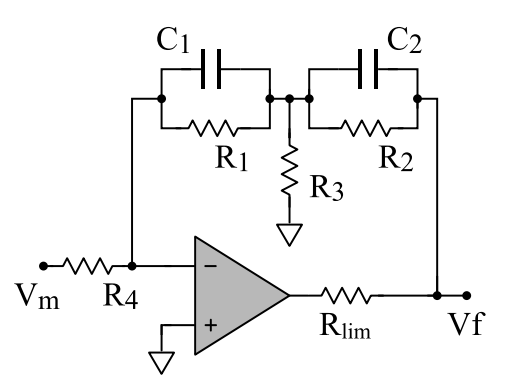

(a)

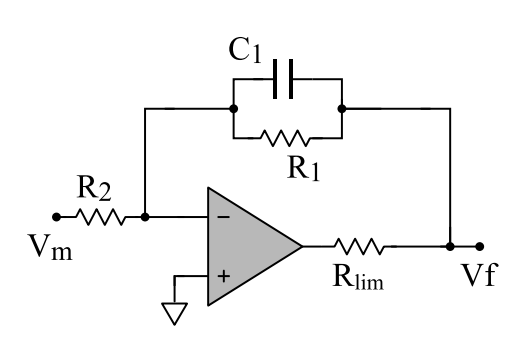

(b)

Figura 5.2: Circuito de DRL implementado con (a) el compensador propuesto y (b) la compensación por polo dominante.

1. Ubicar los polos $p_{1}$ y $p_{2}$ directamente utilizando los valores $\tau_{1}$ y $\tau_{2}$.

2. Ajustar la frecuencia deseada para el cero $f_{z}$ asignando $R_{3}$ :

$$
R_{3}=R_{1} R_{2} /\left(f_{z} 2 \pi \alpha-\left(R_{1}+R_{2}\right)\right)
$$

3. Programar la ganancia de continua $G_{0}$ usando $R_{4}$ :

$$
R_{4}=\left(R_{3}\left(R_{1}+R_{2}\right)+R_{1} R_{2}\right) /\left(G_{0} R_{3}\right) ;
$$

Debe notarse que la entrada del circuito para medir $V_{M C}$ es el nodo $V_{m}$. En la configuración usual de DRL, $R_{4}$ representaría la combinación equivalente de las resistencias de promediado de cada canal. En un DRL independiente como se propone en la sección 3.4.3 puede proveerse un buffer adicional para proveer una alta impedancia de entrada al circuito de la figura 5.2(a) (lo mismo aplica para la compensación tradicional).

Una implementación alternativa en circutos de DRL independiente se muestra en la figura 5.3. La función de transferencia en este caso queda dada por la ecuación:

$$
\frac{V_{f}}{V_{m}}=\left(1+\frac{R_{1}}{R_{2}}\right) \frac{s C_{1} R_{1} / / R_{2}+1}{s C_{1} R_{2}+1}\left(\frac{R_{4}}{R_{3}}\right) \frac{1}{s C_{2} R_{4}+1}
$$

Si $R_{1}<<R_{2}$ el cero resulta $z_{1} \approx C_{1} R_{1}$ y el polo $p_{1}=C_{1} R_{2}$, con $p_{2}=C_{2} R_{4}$. Habiendo fijado estas constantes, $R_{3}$ puede ajustarse para obtener la ganancia deseada.

El esquema de compensación y circuito de implementación presentados en esta sección son aportes originales de la tesis publicados (Guerrero y E. Spinelli, 2017). 


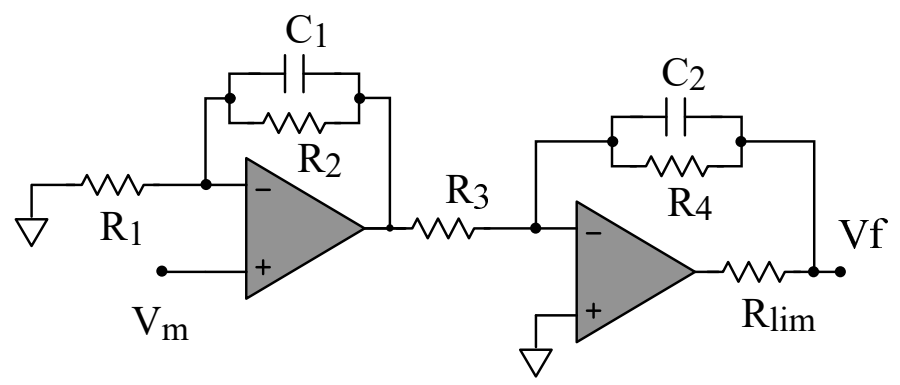

Figura 5.3: Implementación para DRL independiente.

\subsection{Implementación del DRL}

Se implementaron dos circuitos de DRL, uno con la compensación propuesta y otro con la compensación tradicional por polo dominante (en adelante referido como DRL PD), ambos respetando el mismo margen de estabilidad para obtener diseños comparables. La frecuencia del menor polo de la ecuación 4.5 fue estimada siguiendo el razonamiento expuesto en secciones anteriores. Se consideró $R_{m}=R_{f}=100 \mathrm{k} \Omega, C_{i} \approx 5 \mathrm{pF}, R_{o}<1 \mathrm{k} \Omega$ y $C_{t h}$ a partir de la tabla 2.3 resultando en polos ubicados aproximadamente en $f_{1}=10 \mathrm{kHz}$ y $f_{2}=330 \mathrm{kHz}$.

Con el polo de menor frecuencia ubicado en $10 \mathrm{kHz}, z_{1}$ puede ser colocado cerca de $1 \mathrm{kHz}$ y $p_{1}$ una década antes en $100 \mathrm{~Hz}$. Entonces, si se ubica $p_{2}$ en $10 \mathrm{~Hz}$ se obtiene una ganancia de continua razonable de $80 \mathrm{~dB}$, que puede implementarse con la mayoría de los AOs.

Algunos autores estiman la posición del polo más bajo de la ecuación 4.5 en una frecuencia mayor, y pueden por tanto asignar una mayor ganancia a la compensación por polo dominante. Exactamente el mismo criterio podría aplicarse al compensador propuesto: el cero $z_{1}$ y el polo $p_{2}$ podrían llevarse a una frecuencia superior, incrementando el rechazo. En ese caso, el diseño propuesto tendría incluso una mayor ventaja comparativa, ya que la ganancia extra de de $20 \mathrm{~dB}$ otorgada por la pendiente de $40 \mathrm{~dB}$ por década entre $p_{2}$ y $z_{1}$ estaría completamente desarrollada desde una frecuencia más alta, mejorando aún más la atenuación de armónicos en el rango de $100 \mathrm{~Hz}$ a $1000 \mathrm{~Hz}$.

Los componentes pasivos del DRL se seleccionaron siguiendo el procedimiento de diseño dado. El circuito final se muestra en la figura 5.4(a) y en la figura 5.4(b) se observa una fotografía del circuito impreso (PCB, por sus siglas en inglés). Se obtuvieron los valores $R_{1}=R_{2}=160 \mathrm{k} \Omega, C_{1}=100 \mathrm{nF}, C_{2}=10 \mathrm{nF}, R_{3}=1.5 \mathrm{k} \Omega$ y $R_{4}=1.8 \mathrm{k} \Omega$. Un amplificador operacional dual OPA2320 de Texas Instruments se seleccionó para implementar el compensador del DRL y el buffer de medida en el mismo PCB.

El DRL compensado por polo dominante fue implementado utilizando los mismos componentes con un trazado de PCB similar, configurado con $R_{1}=160 \mathrm{k} \Omega$, $C_{1}=100 \mathrm{nF}, \mathrm{y} R_{2}=160 \Omega$ para obtener la misma frecuencia de corte de $0 \mathrm{~dB}$.

Si el DRL se implementa para un sistema con alimentación de fuente única, los nodos de masa del circtuito de la figura 5.2(a) deben elevarse a un potencial de continua $V_{r e f}$, que será el offset impuesto sobre el cuerpo. En ese caso, la fuente de referencia debe proveer una impedancia de salida suficientemente baja para evitar que se desarrollen tensiones de interferencia por acoplamiento en la referencia. 


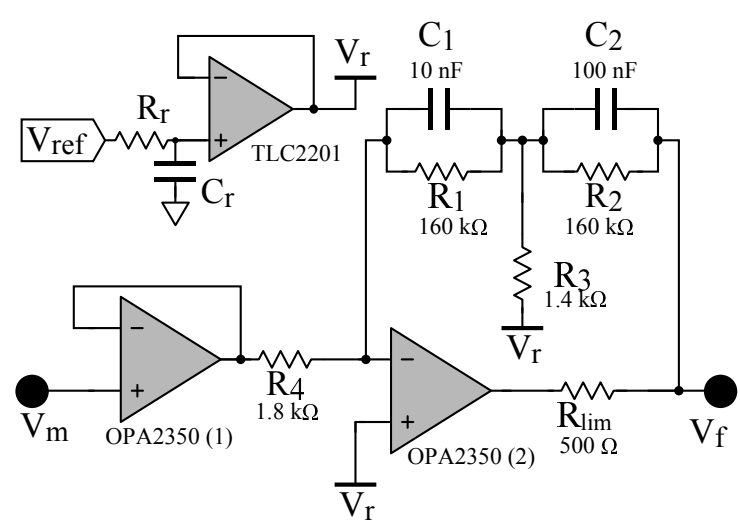

(a)

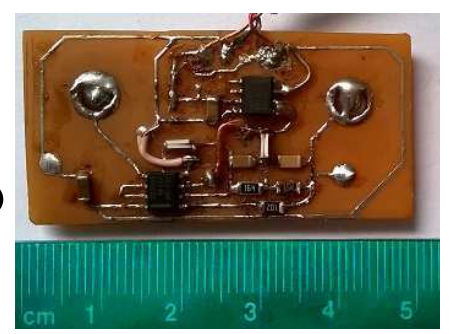

(b)

Figura 5.4: (a) Circuito esquemático para la implementación del DRL propuesto. $V_{m}$ y $V_{f}$ son los nodos de electrodos de medida y realimentación de modo común respectivamente. (b) Fotografía del circuito implementado.

\subsection{Validación del DRL propuesto}

\subsubsection{Diseño experimental}

En primer lugar se midió la transferencia de los DRLs implementados para confirmar el aporte de ganancia y el margen de fase de la compensación propuesta. A continuación, se evaluaron comparativamente ambos DRLs en medidas sobre el cuerpo de varios voluntarios.

Para ello se incluyeron los DRLs implementados como parte del equipo de adquisición de la implementación II (sección 4.5) con electrodos activos en base al AO TLC2201 (sección 4.3). Cada DRL podía utilizarse alternativamente en el mismo experimento. La disposición de elementos para el experimento se muestra en la figura 5.5(a). Se colocó una silla frente a un escritorio para que los voluntarios pudiesen sentarse cómodamente con los brazos descansando sobre sus piernas. El equipo de adquisición se colocó dentro de una caja acrílica colgando del cuello de la persona con los electrodos. El cable USB se extendió desde el equipo hasta una PC portátil colocada sobre el escritorio.

El ambiente donde se desarrollaron las pruebas fue un laboratorio de electrónica dentro de una Facultad, con lineas de red de $220 \mathrm{~V}_{\mathrm{rms}} \mathrm{y}$ frecuencia fundamental de $50 \mathrm{~Hz}$. Al momento de realizar las pruebas se encontraban en funcionamiento dentro de la oficina PCs de escritorio, una unidad de aire acondicionado, y luminarias de bajo consumo.

\section{Experimento 1}

El primer experimento consistió en una prueba de referencia utilizando señales de MC controladas, aplicadas al cuerpo del sujeto. Para ello el asiento y el respaldo de la silla se cubrieron parcialmente con cinta adhesiva de cobre. La cinta conductora se aisló con una capa de cinta plástica común, además de la ropa de la persona.

Un generador se señales Tektronix AFG2021 se colocó sobre el escritorio con una toma con contacto de tierra enchufada a un alargue, y configurado de manera que la salida de señal estuviese referida a tierra. La salida del generador se conecto a la cinta conductora de la silla para acoplar la señal de salida al cuerpo. 


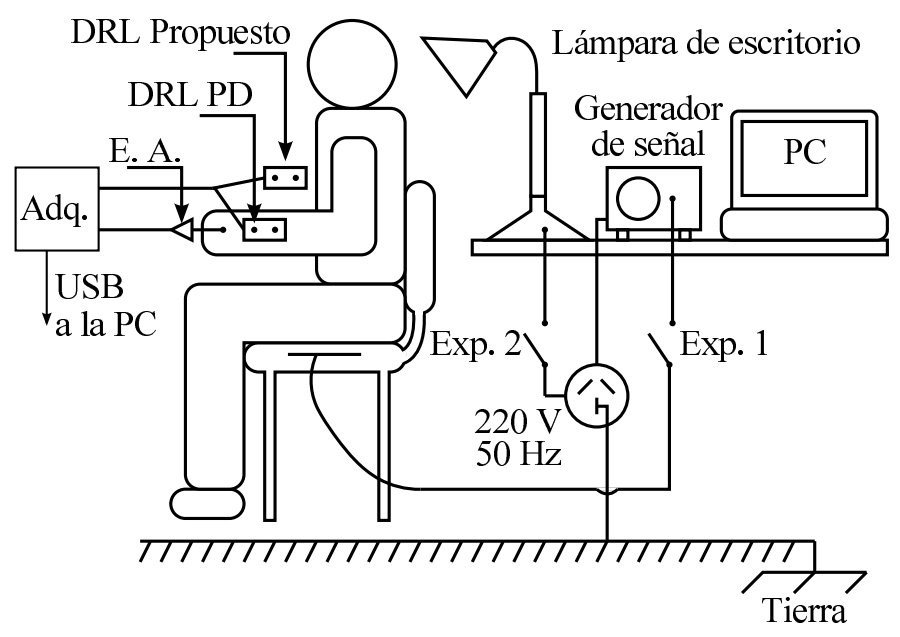

(a)

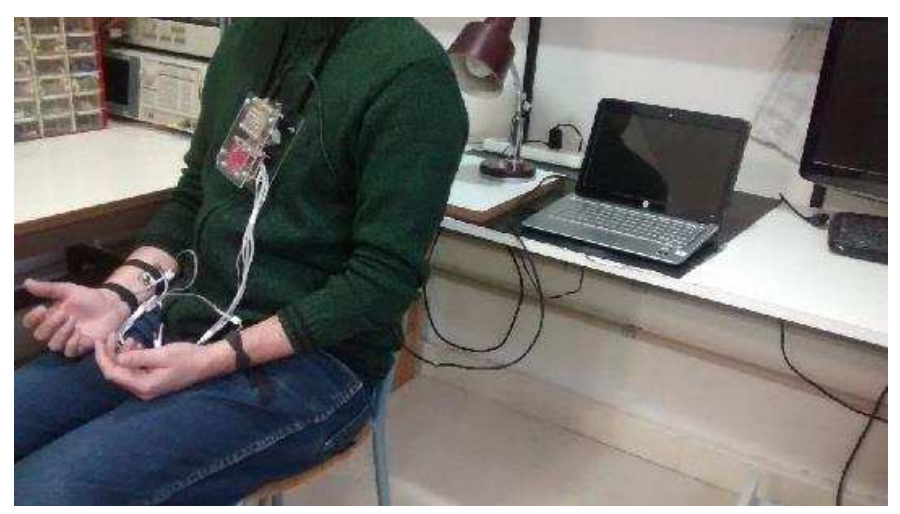

(b)

Figura 5.5: Disposición experimental para la evaluación comparativa de los circuitos de DRL. Para el experimento 1 el generador de señal se conecta a la silla. Para el experimento 2, el generador se desconecta y se energiza la lámpara de escritorio. En cada medida se aplican alternativamente el DRL PD y el propuesto y la tensión $V_{M C}$ resultante se adquiere por medio de un electrodo activo (E.A.).

Un electrodo de medida se colocó en la cara interna del antebrazo derecho y el circuito de DRL propuesto fue colocado a $10 \mathrm{~cm}$, sostenidos con sendas bandas de tela elástica.

Se aplicaron señales senoidales de $0.5 \mathrm{~V}$ de amplitud a frecuencias de la tensión de red y sus armónicos $(50 \mathrm{~Hz}$ to $250 \mathrm{~Hz})$. La amplitud se seleccionó de manera que todas las componentes fuesen significativas por sobre el ruido e interferencia de otras fuentes.

Se tomó un registro de $20 \mathrm{~s}$ para cada valor de frecuencia y el set de medidas se repitió para el DRL PD.

La salida del electrodo fue adquirida con una tasa de muestreo de $2000 \mathrm{~Hz}$, un ancho de banda entre 0 y $500 \mathrm{~Hz}$ y aplicando un filtrado pasa-banda digital de tipo Butterworth de dos polos entre $0.5 \mathrm{~Hz}$ y $450 \mathrm{~Hz}$. Se utilizaron ventanas de tipo flat-top para calcular la amplitud espectral con la FFT con el objetivo de comparar la amplitud de los componentes de interferencia. 


\section{Experimento 2}

A continuación se realizó un conjunto de medidas para cuantificar la mejora en el rechazo de $V_{M C}$ del DRL propuesto bajo condiciones no controladas de interferencia.

Para esta prueba, se utilizó una lámpara de escritorio metálica con un enchufe sin conexión a tierra. La lámpara se colocó aproximadamente $20 \mathrm{~cm}$ detrás de la silla aproximadamente para proveer una fuente dominante de interferencia. La lámpara se encontraba apagada para minimizar interferencia por acoplamiento magnético.

Debido a la impredecible variabilidad de las fuentes no controladas de interferencia, esta prueba se condujo con varios voluntarios. Participaron 7 hombres y 1 mujer sanos, de 23 a 52 años (media 34 años) de edad, entre 1.7 y $1.9 \mathrm{~m}$ de altura (media $1.77 \mathrm{~m}$ ), y de 54 a $90 \mathrm{~kg}$ de peso (media $78 \mathrm{~kg}$ ).

El protocolo experimental fue el siguiente:

1. Se le pide al voluntario sentarse en la silla con sus manos descansando cómodamente sobre sus muslos.

2. Un electrodo seco de medida se fija a la cara interna de un antebrazo con una banda de tela elástica, sin preparación de la piel de ningún tipo.

3. Uno de los DRLs se coloca en el mismo antebrazo con otra banda elástica y se espera 1 min luego sel cual se toma un registro de $30 \mathrm{~s}$.

4. El paso 3 se repite con el otro DRL.

Los elementos de medida y el procesamiento de señal fueron los mismos que en el experimento 1 .

\subsubsection{Resultados y discusión}

El circuito de la figura 5.2(a) permitió implementar con éxito la compensación propuesta, con una frecuencia de corte por $0 \mathrm{~dB}$ de $10 \mathrm{kHz}$, y un margen de fase de $40^{\circ}$. El DRL con compensación por polo dominante tiene la misma frecuencia de corte por $0 \mathrm{~dB}$ con un margen de fase de $45^{\circ}$. Debido a que la estimación de la posición del menor polo de la ecuación 4.5 es muy pesimista, la diferencia de $5^{\circ}$ en el margen de fase es negligible. Podría reducirse colocando el cero en una posición más baja, a costa de un rechazo más bajo.

Las primeras dos filas de la tabla 5.1 muestran los valores de ganancia de lazo abierto a la frecuencia de los 5 primeros armónicos de red del DRL propuedto $\left(G_{P C}\right)$ y el DRL PD $\left(G_{P D}\right)$. La diferencia entre las curvas de ganancia debe ser aproximadamente igual a la diferencia de reducción de $V_{M C}$ lograda por los dos DRLs. Para contar con este valor como referencia para los siguientes resultados, se calculó esta diferencia de ganancia $\left(\Delta=G_{P C} d B-G_{P D} d B\right)$ y se muestra en la tercera fila de la tabla.

Los resultados del Experimento 1 se muestran en la 4ta fila de la tabla 5.1. Los componentes de $V_{M C}$ controlada acoplados al cuerpo fueron efectivamente mejor rechazados por el circuito de DRL propuesto. La diferencia de amplitud resultante se presenta etiquetada como $\Delta$ Exp. 1. Estos valores coinciden con buena aproximación con la diferencia predicha en la fila 3 de acuerdo a la diferencia de ganancia de lazo abierto medida, validando por tanto la operación del DRL propuesto.

La performance relativa fue verificada con las medidas de interferencia no controlada sobre varios voluntarios en el Experimento 2. La fila 5 de la tabla 5.1 muestra el valor medio de la diferencia de amplitud resultante y la desviación estándar (etiquetada $\Delta$ Exp. 2). No se listan valores para armónicos pares debido 

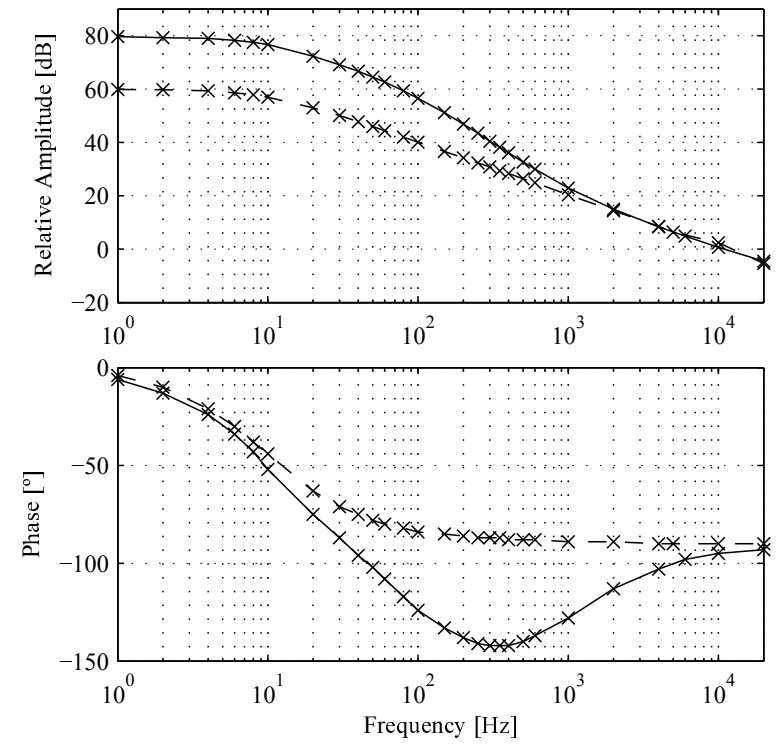

Figura 5.6: Respuesta en frecuencia del compensador de polo dominante implementado (línea a rayas) y el compensador propuesto (línea completa). Los puntos medidos se marcan con cruces.

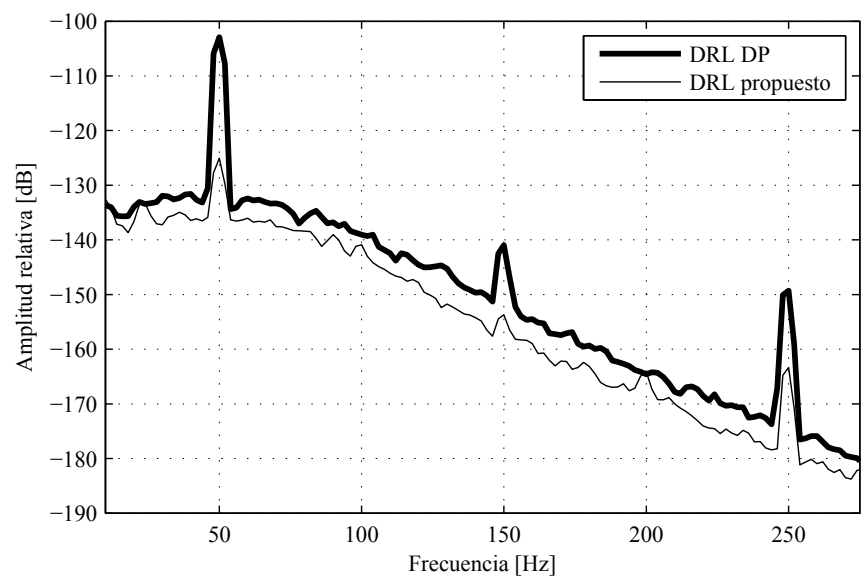

Figura 5.7: Resultado representativo de medidas sobre voluntarios utilizando el DRL PD (linea gruesa) y el propuesto. Se observa que los armónicos pares están por debajo del nivel de ruido, así como el 3er armónico de baja amplitud.

a que no estaban presentes en la señal de MC. Los registros mostraron que el primer armónico fue el de mayor amplitud, seguido por el 5to. Las medidas con el DRL propuesto redujeron el 3er armónico por debajo del piso de ruido una gran parte de las medidas, por lo cual la diferencia obtenida no refleja el valor predicho para esa frecuencia. Se muestran señales representativas en la figura 5.7 .

El DRL propuesto logró reducir con éxito la tensión de modo común excediendo el rendimiento del DRL con compensación por polo dominante, de acuerdo a los valores dados por diseño a la transferencia del circuito. 


\begin{tabular}{llllll}
\hline $\begin{array}{l}\text { Freq. } \\
{[\mathrm{Hz}]}\end{array}$ & 50 & 100 & 150 & 200 & 250 \\
\hline & \multicolumn{5}{c}{$[\mathrm{dB}]$} \\
\cline { 2 - 6 }$G_{P C}$ & 64.4 & 56.5 & 51.1 & 46.8 & 43.4 \\
$G_{P D}$ & 45.9 & 40.1 & 36.6 & 34.2 & 32.3 \\
\cline { 2 - 6 }$\Delta$ & 18.5 & 16.4 & 14.5 & 12.6 & 11.1 \\
\cline { 2 - 6 }$\Delta$ Exp.1 & 18.3 & 15.6 & 15.0 & 13.4 & 11.8 \\
\cline { 2 - 6 }$\Delta$ Exp.2 & 18.3 & - & 11.7 & - & 11.2 \\
& $(2.8)$ & & $(3.4)$ & & $(1.7)$ \\
\hline
\end{tabular}

Tabla 5.1: Magnitud de la respuesta en frecuencia, evaluada en armónicos de línea de bajo orden, del DRL propuesto $\left(G_{P C}\right)$ y el tradicional $\left(G_{P D}\right)$. Se explicita la diferencia $(\Delta)$ para compararla con la reducción de tensión de $\mathrm{MC}$ obtenida en medidas sobre el cuerpo con condiciones de interferencia controladas ( $\Delta \operatorname{Exp} .1)$ y no controladas ( $\Delta \operatorname{Exp} .2$, con la desviación estándar indicada entre paréntesis).

\subsection{Conclusiones}

Las NPVs enfrentan condiciones particulares de interferencia debido al uso de electrodos secos con altos valores de impedancia. La impedancia del tercer electrodo produce mayores tensiones de modo común para las mismas corrientes acopladas de fuentes de interferencia, y el efecto divisor de potencial transforma la tensión de modo común en interferencia diferencial sin que el CMRR del sistema de medida pueda rechazarlo.

Por este motivo interesa contar con un circuito de DRL como acondicionamiento para los AFEs de instrumentación de biopotenciales modernos que logre una reducción de la tensión de modo común aumentada comparada con la alternativa tradicional desarrollada para sistemas basados en electrodos húmedos. Una práctica estándar en el diseño del circuitos de DRL es comenzar con la estimación de la posición del polo más bajo de la transferencia del lazo de realimentación de modo común, de manera de asegurar la estabilidad del sistema. Este criterio ha probado ser robusto y es ampliamente utilizado junto con un diseño de compensación por polo dominante. Sin embargo, esta combinación limita la ganancia del DRL y por lo tanto la atenuación de la tensión de modo común que puede lograrse.

Como un rediseño de este circuito en función de los requisitos de los sistemas vestibles, se propuso una compensación alternativa que permite incrementar la ganancia, manteniendo el mismo criterio de estabilidad. El circuito que implementa esta compensación puede ser construido con el mismo número de amplificadores operacionales que el DRL de polo dominante tradicional, sólo modificando la red pasiva de realimentación.

Se presentó una guía para calcular los parámetros del circuito, y se implementó como ejemplo y demostración un diseño conservador junto con su equivalente con compensación por polo dominante. Se midieron las respuestas en frecuencia de los circuitos de DRL implementados y se verificó experimentalmente la mejora predicha en el rechazo a la tensión de modo común, comparándola contra la obtenida con el DRL de polo dominante. Se comprobó el rendimiento del circuito en medidas de biopotencial tanto en condiciones controladas de interferencia como en las condiciones arbitrarias presentes en el entorno de medida, mostrando una reducción de modo común dentro del rango esperado. 


\title{
Electrodos activos doble-diferenciales para EMG
}

\begin{abstract}
Los biopotenciales musculares son una herramienta extremadamente útil para las neuroprótesis vestibles. Para esta aplicación es deseable conseguir una mayor selectividad espacial de las medidas y evitar interferencia de origen no sólo electromagnético sino también de otros músculos. Esto se logra mediante el uso de electrodos activos con amplificadores de múltiples entradas. En este capitulo se desarrollan herramientas teóricas para el análisis de estos amplificadores y se presenta un electrodo doble diferencial de baja complejidad.
\end{abstract}

\subsection{Multi-Electrodos para la medida de sEMG}

El EMG es una ventana hacia la actividad cerebral que expresa la voluntad de una persona y es útil como entrada para NPVs (Navarro et al., 2005). Los periféricos de instrumentación necesarios para suplir a los AFEs (frentes analógicos) de medida de biopotenciales son distintos para el caso del EMG que en otras medidas de biopotencial y necesitan un desarrollo particular.

El fenómeno básico observado en electromiografía es la presencia de potenciales de acción en un músculo específico y por eso la distancia inter-electródica (IED por sus siglas en inglés) suele ser pequeña en comparación con, por ejemplo, el ECG. En general, los electrodos se colocan a distancias entre 0.5 y $4 \mathrm{~cm}$ entre sí para obtener un buen compromiso entre la localización del fenómeno y la amplitud detectada. Al mismo tiempo, el ancho de banda de las señales de EMG es en general más alto que otros biopotenciales. Por lo tanto, el efecto de filtrado pasa-bajo que tiene la superficie equipotencial de los electrodos no es despreciable: el área de los contactos no puede tener dimensiones mayores a $5 \mathrm{~mm}$ en el sentido longitudinal de las fibras de interés para mantener una frecuencia de corte mayor a $400 \mathrm{~Hz}$ (Farina et al., 2003).

Es importante lograr una buena localización espacial en sEMG porque permite especificar qué unidades motoras están siendo activadas y comprender 


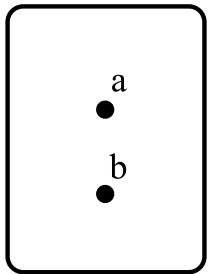

(a)

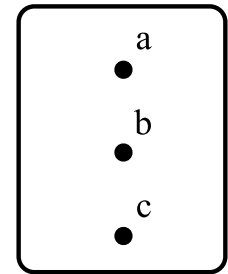

(b)

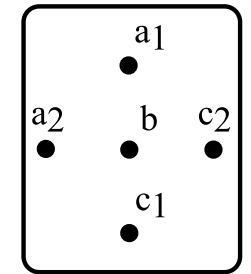

(c)

Figura 6.1: Configuraciones de electrodos para mejorar la localización espacial en medidas de sEMG.

la intención en la persona que produjo ese fenómeno. También tiene una gran importancia en otras aplicaciones como el diagnóstico médico y el estudio del sistema neuro-muscular. Con este propósito se recurre a distintas topologías de medición que intentan reducir la amplitud de las señales de EMG que provienen de fuentes alejadas. En general, interesa detectar la actividad generada en un volumen directamente debajo del electrodo y rechazar toda otra señal de EMG, que pasa a ser llamada crosstalk por analogía con la interferencia entre canales contiguos de sistemas electrónicos (C. J. De Luca y Merletti, 1988).

Las topologías de medida para rechazo de crosstalk se conocen como filtros espaciales y consisten en aumentar el número de contactos en distintas configuraciones geométricas y obtener la salida del electrodo como una combinación lineal de las señales en cada contacto, como se muestra en la figura 6.1. Algunos arreglos de contactos tienen un eje preferencial que debe alinearse con las fibras musculares para maximizar la selectividad en una dirección. En estos casos los contactos suelen ser de forma alargada, varillas de entre 5 y $10 \mathrm{~mm}$ de largo con un ancho de 1 a $2 \mathrm{~mm}$, para promediar las señales propagadas por fibras paralelas. Otros arreglos no tienen una dirección preferencial y sus contactos son áreas circulares con radio en el orden de $1 \mathrm{~mm}$. En todos los casos la IED está en el orden de 5 a $10 \mathrm{~mm}$, lo cual dificulta la aplicación de gel ya que puede cortocircuitar los contactos y se utilizan electrodos secos.

En la literatura se analizan comparativamente los distintos filtros espaciales y se observa, en general, un aumento de la selectividad al utilizar arreglos más complejos (Disselhorst-Klug et al., 1997; Reucher et al., 1987). Sin embargo, estas conclusiones varían dependiendo de un amplio rango de factores como la orientación de las fibras musculares respecto de la piel o la anisotropía del músculo, por lo tanto puede ser conveniente uno u otro arreglo según la aplicación.

Cuando la configuración es muy compleja, se implementa en lo que se conoce como arreglos de sEMG, que son matrices o arreglos lineales de un gran número de electrodos. Las configuraciones más sencillas son ampliamente utilizadas en neuroprótesis, la clínica médica y en investigación, siendo el principal el electrodo doble diferencial (DD), de tres contactos, seguido del electrodo normal doble diferencial, en el centro de la figura 6.1. La señal DD se obtiene como la diferencia de la diferencia entre pares de electrodos:

$$
V_{D D}=\left(V_{a}-V_{b}\right)-\left(V_{b}-V_{c}\right)=V_{a}-2 V_{b}+2 V_{c}
$$

Debido a las características de estos electrodos, conformados por una distribución rígida que respeta distancias predefinidas, es útil implementarlos con todos sus contactos en un mismo soporte, conformando una unidad independiente con un cable de varios hilos que la une con el sistema de adquisición. Los contactos 


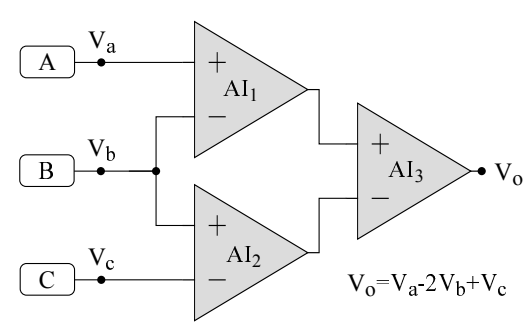

(a)

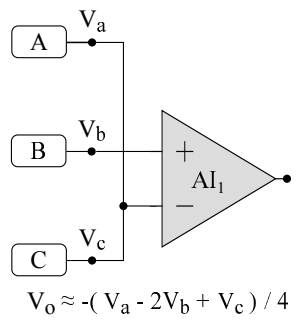

(b)

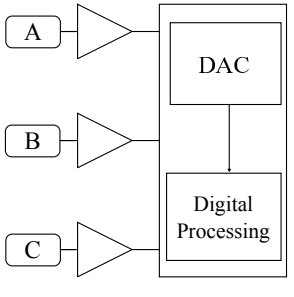

(c)

Figura 6.2: Alternativas de implementación para amplificadores que permiten obtener la señal doble diferencial de EMG (a) utilizando tres amplificadores de instrumentación (Merletti y Parker, 2004; Rieger, 2011), (b) procesando digitalmente canales single-ended (Van Vugt y Van Dijk, 2001), (c) aproximación de la señal DD obtenida con el electrodo ramificado o branched (Christova et al., 2007).

en estos electrodos son de área pequeña y tienen consecuentemente una alta impedancia, por esto es una práctica común implementar electrodos activos en el mismo encapsulado. Los electodos comerciales Ottobock 13E200 y Delsys DE3.1 utilizan electrodos activos DD.

Tempranamente se implementaron amplificadores en el electrodo mismo para las medidas de sEMG con electrodos diferenciales (S. Johnson et al., 1977; C. De Luca et al., 1979). Cuando se aumenta el número de contactos en multi-electrodos, una solución es procesar digitalmente la salida de canales monopolares o bipolares (Van Vugt y Van Dijk, 2001). Esta solución es normalmente adoptada para arreglos de electrodos porque permite utilizar distintos filtros, pero para el caso de electrodos independientes con geometrías fijas no es conveniente porque incrementa la complejidad y costo innecesariamente.

Para electrodos más sencillos como el DD, se encuentran alternativas de implementación que permiten obtener electrodos activos de pocos componentes como se muestra en la figura 6.2.

La más sencilla se conoce como electrodo branched (inglés para "ramificado") que, a partir de dividir uno de los electrodos del par diferencial en dos, permite obtener una señal proporcional a la DD con un simple amplificador de diferencia (Figura 6.2(b)) siempre y cuando las impedancias de contacto sean aproximadamente iguales (Van Vugt y Van Dijk, 2001).

Los diseños de front-ends para el electrodo DD se presentan en la literatura como accesorios en trabajos relacionados a las características de la señal de EMG. Los primeros ejemplos están relacionados con la estimación de velocidad de conducción en fibras musculares como en el trabajo de Broman et al., 1985 y otros autores allí referenciados. Esta implementación y las posteriores son variaciones sobre el circuito de 3 amplificadores de instrumentación de la figura 
$6.2(a)$.

Los amplificadores que implementan estos electrodos activos son evidentemente distintos de los amplificadores diferenciales usuales en biopotenciales: tiene múltiples entradas. Por lo tanto, se genera un problema para el análisis de estos circuitos por cuanto no es suficiente la descomposición en los modos diferencial y común. En un amplificador de biopotenciales diferencial, se calcula el rechazo de modo común como factor de mérito, porque ese modo da cuenta mayormente de la señal de interferencia, mientras que el modo diferencial transporta la señal de interés. Cuando la entrada está compuesta por más puertos, existen más grados de libertad y por lo tanto más modos.

\subsection{Modos de señal en electrodos doble-diferenciales}

\subsubsection{Definición de modos de señal para electrodos activos DD}

El análisis de amplificadores diferenciales se basa en la descomposición de las señales en componentes ortogonales llamados modos que se eligen de manera que cada uno transporte señales con origen independiente, que el circuito debe tratar de modo distinto. En un amplificador con puertos de entrada de potenciales $V_{a}$ y $V_{b}$, los modos usualmente convenientes para el análisis son el modo diferencial (MD) y el modo común (MC), que se definen a partir de la transformación lineal:

$$
\left[\begin{array}{l}
V_{\mathrm{MD}} \\
V_{\mathrm{MC}}
\end{array}\right]=\left[\begin{array}{cc}
1 & -1 \\
1 / 2 & 1 / 2
\end{array}\right]\left[\begin{array}{l}
V_{a} \\
V_{b}
\end{array}\right]
$$

En un amplificador de biopotenciales, esta descomposición es útil porque la señal deseada es usualmente la diferencia de potencial entre los dos electrodos mientras que en la señal de modo común predominan componentes de interferencia electromagnética que es necesario rechazar.

En un amplificador para multi-electrodos, hay $N$ entradas con potenciales $V_{e 1} \ldots V_{e N}$ que forman un espacio de señales que puede transformarse para obtener $N$ modos $V_{m 1} \ldots V_{m N}$.

El criterio para definir modos que lleva a la descomposición en MC-MD puede aplicarse en este caso para obtener, primero, un modo correspondiente a la señal deseada del electrodo, y luego modos ortogonales que permitan identificar señales de otras fuentes.

El electrodo Doble Diferencial tiene 3 contactos con tensiones $V_{a}, V_{b}$ y $V_{c}$, que pueden describirse con 3 modos.

El primer modo, que se obtiene como la señal de salida doble diferencial, puede llamarse modo doble diferencial o MDD. El segundo modo debe contener componentes de interferencia electromagnética, que está presente por igual en los 3 electrodos en forma análoga al modo común de un amplificador diferencial, por lo que puede llamarse modo común o MC.

El electrodo DD tiene como función aumentar la selectividad espacial comparado con el diferencial, es decir que la señal diferencial de EMG tiene componentes de crosstalk que interesa rechazar en un electrodo DD. Entonces es útil que el tercer modo contenga estos componentes. Se define entonces un modo diferencial (MD) del electrodo DD como la resta de los electrodos extremos. Este modo resulta ortogonal a los anteriores, con la matriz de transformación completa como:

$$
\left[\begin{array}{c}
V_{\mathrm{MDD}} \\
V_{\mathrm{MC}} \\
V_{\mathrm{MD}}
\end{array}\right]\left[\begin{array}{ccc}
1 & -2 & 1 \\
1 / 3 & 1 / 3 & 1 / 3 \\
1 & 0 & -1
\end{array}\right]\left[\begin{array}{l}
V_{a} \\
V_{b} \\
V_{c}
\end{array}\right]
$$




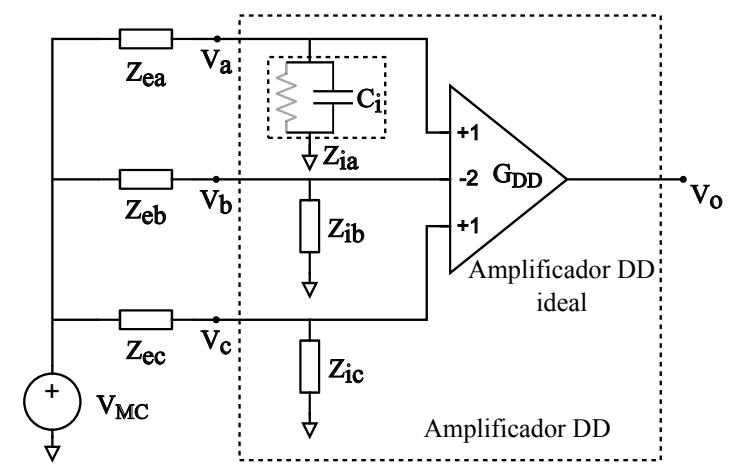

Figura 6.3: Representación de una medida doble diferencial con una tensión de modo común aplicada. Se modelan las impedancias de electrodo y las de cada puerto de entrada del amplificador.

Un análisis similar, para electrodos Normal Doble Diferenciales, puede encontrarse en el apéndice A. El desarrollo de estos modos es un aporte original de la tesis publicado en un congreso internacional (Guerrero, García et al., Aceptado 2016) y merecedor de un premio (XXIV Jornadas Jóvenes Investigadores AUGM, UnESP, San Pablo, Brasil).

\subsubsection{Transformaciones de modo}

\section{Coeficientes de rechazo}

La salida de un amplificador doble diferencial práctico, considerando las transformaciones de modo que pueda tener, puede escribirse como:

$$
\begin{aligned}
V_{o} & =G_{\mathrm{DD}} V_{\mathrm{MDD}}+G_{\mathrm{C}} V_{\mathrm{MC}}+G_{\mathrm{D}} V_{\mathrm{MD}} \\
& =G_{\mathrm{DD}}\left(V_{\mathrm{MDD}}+\frac{G_{\mathrm{C}}}{G_{\mathrm{DD}}} V_{\mathrm{MC}}+\frac{G_{\mathrm{D}}}{G_{\mathrm{DD}}} V_{\mathrm{MD}}\right)
\end{aligned}
$$

A partir de esta ecuación pueden definirse dos figuras de mérito:

$$
\begin{aligned}
& \mathrm{CMRR}:=G_{\mathrm{DD}} / G_{\mathrm{C}} \\
& \mathrm{DMRR}:=G_{\mathrm{DD}} / G_{\mathrm{D}}
\end{aligned}
$$

El CMRR es el coeficiente de rechazo de modo común, análogo al de amplificadores diferenciales, mientras que el DMRR es el coeficiente de rechazo de modo diferencial. Ambos representan la capacidad del amplificador de rechazar interferencia, pero la fuente de señal de la interferencia diferencial es electromiográfica, por lo que el orden del DMRR puede ser mucho menor que el CMRR según el nivel de crosstalk admisible.

\section{Transformaciones por efecto de las impedancias}

El efecto divisor de potencial presentado en la sección 2.5.5 puede cuantificarse claramente en el caso de las medidas diferenciales. El desbalance se expresa por un único grado de libertad $\Delta Z_{e}$ que es la resta de las dos impedancias de electrodo del canal. Sin embargo, las tres entradas de un amplificador DD pueden producir un desbalance de impedancias con dos grados de libertad. El circuito de la figura 6.3 permite analizar este efecto para distintos casos de desbalance. 
En primer lugar se analizó el efecto de un desbalance en la impedancia de los electrodos, manteniendo un valor único para las impedancias de entrada de modo común, $Z_{\mathrm{i}}$. Los dos grados de libertad del desbalance entre las tres impedancias de electrodo se representaron reescribiendo sus valores como:

$$
\begin{aligned}
Z_{\text {ea }} & =Z_{\mathrm{e}}-\Delta_{\text {ea }} \\
Z_{\mathrm{eb}} & =Z_{\mathrm{e}} \\
Z_{\mathrm{ec}} & =Z_{\mathrm{e}}-\Delta_{\mathrm{ec}}
\end{aligned}
$$

Así, la ganancia de transformación de MC a MDD, $G_{\mathrm{C}, Z_{\mathrm{e}}}$, puede encontrarse calculando la relación $V_{\mathrm{MDD}} / V_{\mathrm{MC}}$ en función de los desbalances $\Delta_{\text {ea }} \mathrm{y} \Delta_{\mathrm{ec}}$.

$$
G_{C, Z_{\mathrm{e}}}=G_{\mathrm{DD}} Z_{\mathrm{i}} \frac{\left(\Delta_{\mathrm{ea}}+\Delta_{\mathrm{ec}}\right)\left(Z_{\mathrm{i}}+Z_{\mathrm{e}}\right)-2 \Delta_{\mathrm{ea}} \Delta_{\mathrm{ec}}}{\left(Z_{\mathrm{i}}+Z_{\mathrm{e}}-\Delta_{\mathrm{ea}}\right)\left(Z_{\mathrm{i}}+Z_{\mathrm{e}}-\Delta_{\mathrm{ec}}\right)\left(Z_{\mathrm{i}}+Z_{\mathrm{e}}\right)}
$$

Esta ecuación no permite extraer conclusiones fácilmente, pero puede obtenerse una aproximación más útil para el caso de $Z_{\mathrm{e}}$ menor a un $10 \%$ de la magnitud de $Z_{\mathrm{i}}$ :

$$
G_{C, Z_{\mathrm{e}}} \approx G_{\mathrm{DD}}\left(\frac{\Delta_{\mathrm{ea}}+\Delta_{\mathrm{ec}}}{Z_{\mathrm{i}}}-\frac{2 \Delta_{\mathrm{ea}} \Delta_{\mathrm{ec}}}{Z_{\mathrm{i}}^{2}}\right)
$$

La ecuación 6.6 muestra que la simetría del desbalance es importante. $\mathrm{Si}$ $\Delta_{\text {ea }}=-\Delta_{\text {ec }}$, el primer término es igual a 0 y $G_{C, Z_{\mathrm{e}}}=-2 G_{\mathrm{DD}}\left(\Delta_{\mathrm{e}} / Z_{\mathrm{i}}\right)^{2}$. Pero cuando $Z_{\mathrm{ea}}$ y $Z_{\mathrm{eb}}$ están simétricamente desbalanceadas con respecto a $Z_{\mathrm{eb}}$, es decir, $\Delta_{\text {ea }}=\Delta_{\text {ec }}=\Delta_{\mathrm{e}}$, el primer término es mayor y el segundo es despreciable por estar dividido por $Z_{\mathrm{i}}^{2}$. Esto representa una cota superior para $G_{C, Z_{\mathrm{e}}}$ que puede ser expresada como un coeficiente de rechazo mínimo:

$$
\left(\mathrm{CMRR}_{Z_{\mathrm{e}}}\right)_{\min }=\frac{Z_{\mathrm{i}}}{2 \Delta_{\mathrm{e}}}
$$

Un efecto similar se produce cuando las impedancias de amplificador están desbalanceadas. Para analizar ese caso se asignaron valores $Z_{\mathrm{ia}}=Z_{\mathrm{i}}+\Delta_{\mathrm{ia}}, Z_{\mathrm{ib}}=$ $Z_{\mathrm{i}}, \mathrm{y} Z_{\mathrm{ic}}=Z_{\mathrm{i}}+\Delta_{\mathrm{ic}}$. Se asignó un valor común $Z_{\mathrm{e}}$ a las impedancias de electrodo. La expresión resultante es similar a la ecuación 6.5 y también encuentra su cota superior para un desbalance simétrico tal que $\Delta_{\mathrm{ia}}=\Delta_{\mathrm{ic}}=\Delta_{\mathrm{i}}$. En esas condiciones el CMRR mínimo resulta:

$$
\left(\mathrm{CMRR}_{Z_{\mathrm{i}}}\right)_{\min }=\frac{Z_{\mathrm{i}}^{2}}{2 \Delta_{\mathrm{i}} Z_{\mathrm{e}}}
$$

\subsection{Electrodos activos de tipo branched}

\subsubsection{Características y diseño}

El electrodo de tipo branched permite adquirir la señal DD, pero bajo ciertas circunstancias (Koh y Grabiner, 1993)s. Dadas impedancias de electrodo $Z_{a}, Z_{b}$ y $Z_{c}$, e impedancias de entrada del sistema de medida $Z_{i+}$ y $Z_{i-}$ para la entrada no inversora $V_{i+}$ e inversora $V_{i-}$ respectivamente, se tiene la siguiente ecuación de salida sólo considerando la transferencia dada por las impedancias:

$$
V_{o}=V_{i+}-V_{i-}=V_{b} \frac{Z_{i+}}{Z_{i+}+Z_{b}}-\left(V_{a} \frac{Z_{c} \| Z_{i-}}{Z_{a}+Z_{c} \| Z_{i-}}+V_{c} \frac{Z_{a} \| Z_{i-}}{Z_{c}+Z_{a} \| Z_{i-}}\right)
$$

Si es válido suponer que $\left|Z_{a, b, c}\right|<<\left|Z_{i+, i-}\right|$ se obtiene la expresión:

$$
V_{o}=V_{b}-\left(V_{a} \frac{Z_{c}}{Z_{a}+Z_{c}}+V_{c} \frac{Z_{a}}{Z_{c}+Z_{a}}\right)
$$




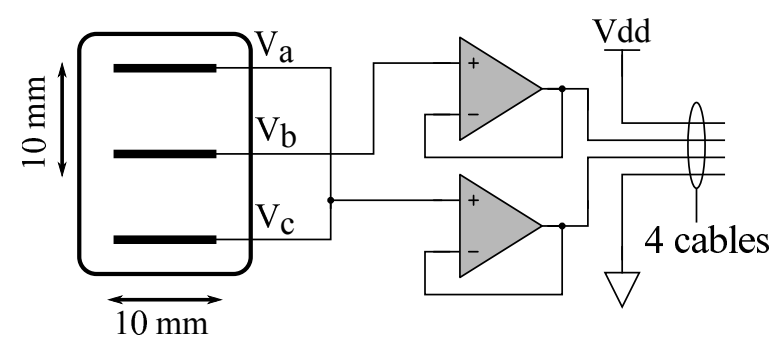

Figura 6.4: Esquema de una implementación de electrodo branched para sistema de medida con entrada diferencial.

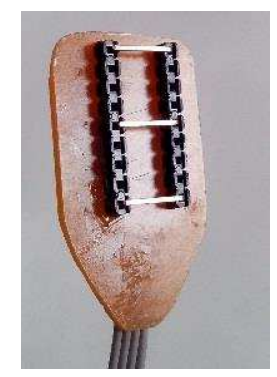

Figura 6.5: Fotografía del electrodo branched implementado, desde el lado de los contactos de electrodo.

$\mathrm{Y}$ suponiendo $Z_{a}=Z_{c}$ resulta:

$$
V_{o}=V_{b}-\left(V_{a} \frac{1}{2}+V_{c} \frac{1}{2}\right)=-\frac{V_{D D}}{4}
$$

Por lo tanto el electrodo branched logra producir una señal proporcional a la señal DD; se establece una relación de compromiso entre las garantías que puedan obtenerse en una NPV de que se cumplirán las condiciones mencionadas y la gran simplicidad de implementación de esta topología. En sistemas basados en convertidores con entrada completamente diferencial, la implementación es aún más sencilla.

El diagrama esquemático de un circuito que los implementa puede verse en la figura 6.3.1: utiliza los mismos componentes que un par diferencial de electrodos activos y aprovecha los canales completamente diferenciales de un adquisidor basado en convertidores $\Sigma-\Delta$.

\subsubsection{Implementación y resultados}

Se implementaron y evaluaron electrodos branched como módulos de acondicionamiento para adquisición de EMG de la implementación II reportada en el capítulo 4. Los electrodos se implementaron utilizando AOs TLC2202, de características similares al TLC2201 pero en encapsulado dual y contactos de electrodo solidarios al PCB fabricados con varillas metálicas doradas de $1 \mathrm{~cm}$ de largo y sección cuadrada de $0.64 \mathrm{~mm}$ de lado, separadas $10 \mathrm{~mm}$ una de otra. Se observa una foto de la implementación en la figura 6.5.

Se midió la tensión de ruido referida a la entrada cortocircuitando los electrodos con la fuente de referencia de tensión utilizada para el DRL. Se tomaron registros de todos los canales con una duración de $100 \mathrm{~s}$ y se procesaron 


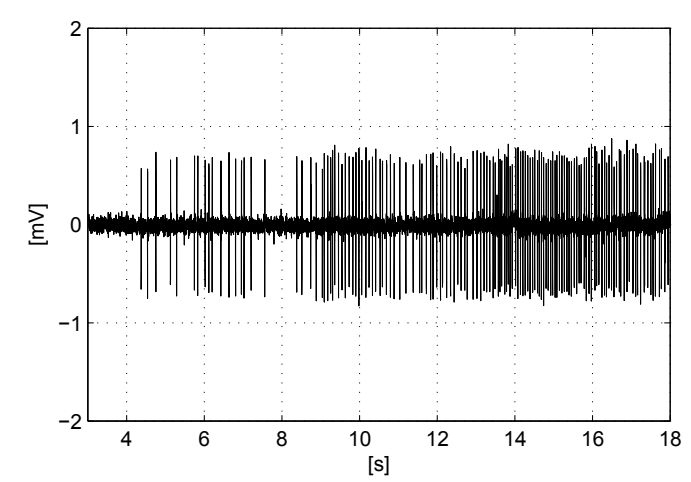

Figura 6.6: Actividad de EMG causada por flexiones del dedo indice con fuerza en incremento.

aplicando un filtrado pasa-banda entre 5 y $450 \mathrm{~Hz}$. Se realizaron estas medidas con diferentes ganancias programadas en el ADS1299.

El ruido en tensión equivalente referido a la entrada resultó en menos de $3 \mu V_{\text {rms }}$ con ganancia unitaria. Este ruido está dominado por el propio del convertidor. Pueden utilizarse ganancias superiores para obtener un menor ruido, donde la cota inferior que podrá obtenerse será el ruido de los AOs utilizados en los electrodos activos. Una ganancia de 4 veces permitió obtener una tensión de ruido de $0.89 \mu \mathrm{V}_{\mathrm{rms}}$.

Se midió la respuesta en frecuencia conectando un generador de funciones entre la masa del sistema y la entrada de los electrodos. La respuesta en frecuencia aproximó cercanamente la correspondiente a la tranferencia del filtro digital del convertidor $\Sigma-\Delta$ que tiene una forma de $\operatorname{sinc}^{3}$. Con una tasa de adquisición de 2000 sps, resulta un ancho de banda de $3 \mathrm{~dB}$ desde la continua hasta $512 \mathrm{~Hz}$.

Se calculó el CMRR para distintas condiciones, primero aplicando una señal de $50 \mathrm{~Hz}$ a la entrada de los electrodos cortocircuitada. Luego se aplicaron distintas impedancias desbalanceadas entre el generador y la entrada incluyendo las recomendadas para pruebas en el estándar AAMI para electrocardiografía: $51 \mathrm{k} \Omega$ en paralelo con $47 \mathrm{nF}$.

El CMRR resultó de $90 \mathrm{~dB}$ cuando no se le asignó un desbalance de impedancia. Al aplicar $51 \mathrm{k} \Omega$ y $47 \mathrm{nF}$ el CMRR resultó de solo $46 \mathrm{~dB}$. A su vez, se probaron desbalances de $90 \mathrm{k} \Omega$ y $9 \mathrm{k} \Omega$ resultando en CMRRs de 56 y $79 \mathrm{~dB}$ respectivamente.

Se condujeron medidas de EMG para testear la performance del sistema. Bandas elástica se utilizaron para colocar los electrodos en posición. Primero, un único electrodo Branched se colocó en el antebrazo derecho y se realizaron flexiones del dedo índice con progresivamente más fuerza, que pueden verse en la figura 6.6. Luego, un arreglo de cuatro electrodos se colocó también en el antebrazo y se ejecutaron distintos movimientos de muñeca cuyo resultado se observa en la figura 6.7.

\subsubsection{Conclusiones: simplicidad y limitaciones}

La implementación de los electrodos resultó muy sencilla, y se obtuvo un dispositivo funcional que permitió realizar exitosamente medidas de EMG.

Sin embargo, se demostró experimentalmente la degradación del CMRR que ocurre al incluir desbalances en la impedancia de electrodos. En ese caso, la señal 

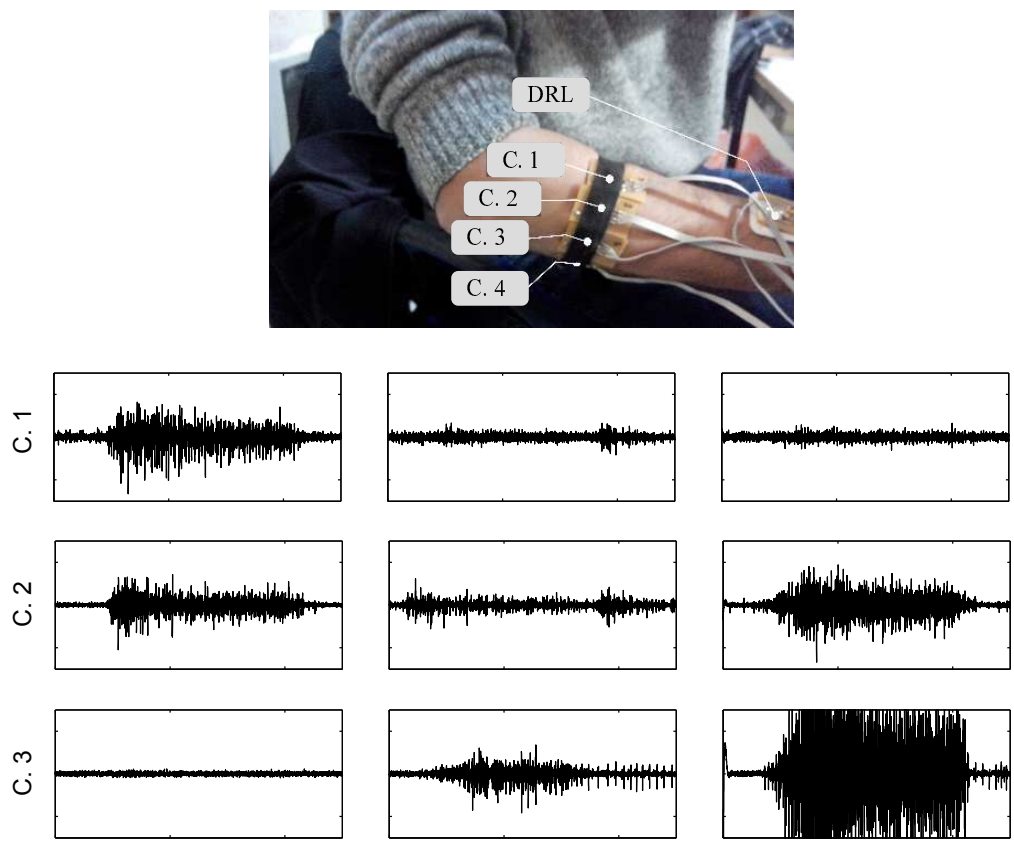

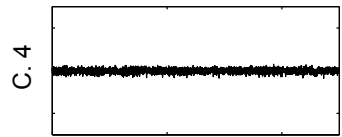

(a)

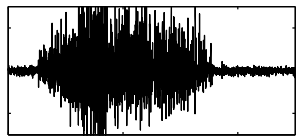

(b)

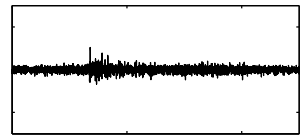

(c)

Figura 6.7: Señales tomadas en sobre músculos del antebrazo como se observa en la imagen superior. Las columnas representan adquisiciones simultáneas de: (a) La extensión de todos los dedos de la mano, (b) la flexión de los dedos, (c) Giro de la muñeca.

de salida no es proporcional a la señal DD como se mostró en la ecuación 6.9. El uso de un circuito de DRL con ganancia aumentada permite que un valor de CMRR tan bajo como $70 \mathrm{~dB}$ pueda ser suficiente para alcanzar medidas de buena calidad. Sin embargo, la robustez exigida por las NPVs hacen deseable una topología naturalmente más robusta, o la utilización de dispositivos con mayor impedancia de entrada. El electrodo branched por tanto es una excelente opción cuando el costo y facilidad de mantenimiento puedan primar sobre la necesidad de robustez frente a interferencia.

La limitación del electrodo branched radica en la dependencia de la señal obtenida con la impedancia de electrodo, y en el empobrecimiento del rechazo de modo común al aumentar la magnitud de la impedancia de electrodo. Una limitación adicional es propuesta por Dimitrov et al., 2003, quienes plantean que los contactos de electrodo ramificados fuerzan la equipotencialidad de sus áreas de contacto y por tanto distorsionan la señal medida. Surgen como alternativas superadoras las implementaciones basadas en la obtención directa de la salida doble diferencial. 


\subsection{Electrodo activo doble diferencial}

\subsubsection{Limitaciones de la topología de $3 \mathrm{AI}$}

La topología propuesta en la literatura para medidas doble diferenciales se basa en el amplificador de 3 amplificadores de instrumentación (3 AI) (ver figura 6.2(a), página 65 ). Esta topología implica un número de componentes y complejidad de circuito elevada, sobre todo comparada con el electrodo branched, pero permite obtener la señal DD independientemente de las impedancias de electrodo. La ecuación de salida del amplificador es:

$$
V_{o}=G_{3}\left(G_{1}\left(V_{a}-V_{b}\right)-G_{2}\left(V_{b}-V_{c}\right)\right)
$$

La salida DD se obtiene configurando las ganancias $G_{1}=G_{2}=G$ y una ganancia $G_{3}$ arbitraria. En ese caso resulta $V_{o}=G_{3} G V_{M D D}$ por lo que $G_{D D}=G_{3} G$. Al aplicar una señal de modo común en las tres entradas la salida es:

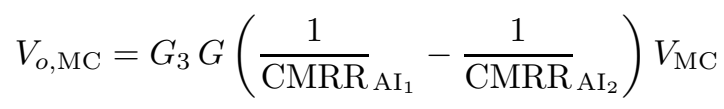

Reconociendo $G_{D D}$ en la ecuación anterior puede escribirse el CMRR del amplificador:

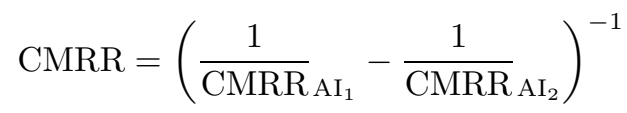

En el caso de existir desbalances entre las ganancias $G_{1}$ y $G_{2}$ habrá una transformación de modo adicional. Para investigarla pueden reescribirse las ganancias como $G_{1}=G+\delta G$ y $G_{2}=G-\delta G$ de manera que la ecuación 6.12 resulta

$$
\begin{aligned}
V_{o} & =G_{3}\left(G\left(V_{a}-2 V_{b}+V_{c}\right)-\delta G\left(V_{a}-V_{c}\right)\right) \\
& =G_{3} G\left(V_{\mathrm{MDD}}+\frac{\delta G}{G} V_{\mathrm{MD}}\right)
\end{aligned}
$$

En la ecuación 6.15 se reconoce que un desbalance en las ganancias de los AIs resulta en una transformación de MD a MDD, y en la ecuación 6.14 que un desbalance en sus CMRRs resulta en una transformación de MC a MDD. Estas figuras de mérito son muy buenas pues dependen de desbalances entre los parámetros de los amplificadores de instrumentación y no de sus valores absolutos.

Sin embargo, análogamente al problema del efecto divisor de potencial, la topología de 3 IA sufre una degradación de su rechazo de modo común a pesar de ser idealmente tan alto. La impedancia de entrada del amplificador de $3 \mathrm{AI}$ es desbalanceada porque el nodo $B$ es compartido por la las entradas de dos AIs, y la impedancia que ve es la mitad de la del nodo $A$ o $C$. En la ecuación 6.8 entonces, $\Delta_{\mathrm{i}}=Z_{\mathrm{i}} / 2$ y resulta:

$$
\mathrm{CMRR}_{Z_{\mathrm{i}}}=\frac{Z_{\mathrm{i}}^{2}}{2\left(Z_{\mathrm{i}} / 2\right) Z_{\mathrm{e}}}=\frac{Z_{\mathrm{i}}}{Z_{\mathrm{e}}}
$$

Por lo tanto en este caso existe un CMRR efectivo que depende de la impedancia de entrada y del valor medio de las impedancias de electrodo (no del desbalance entre ellas, que sería un caso más benigno). Por ejemplo para $Z_{\mathrm{e}}=$ $1 \mathrm{M} \Omega @ 50 \mathrm{~Hz}$, una capacidad de entrada relativamente baja de $3 \mathrm{pF}$ produciría un CMRR de sólo $60 \mathrm{~dB}$. 


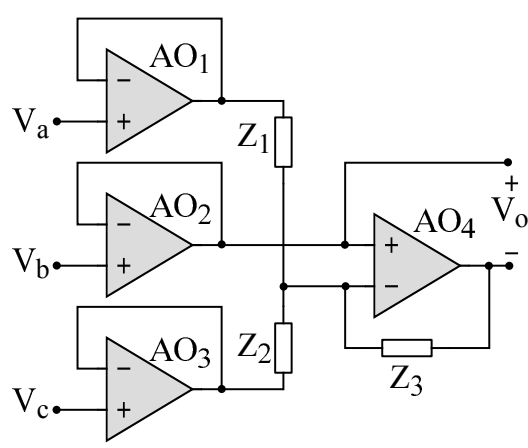

(a)

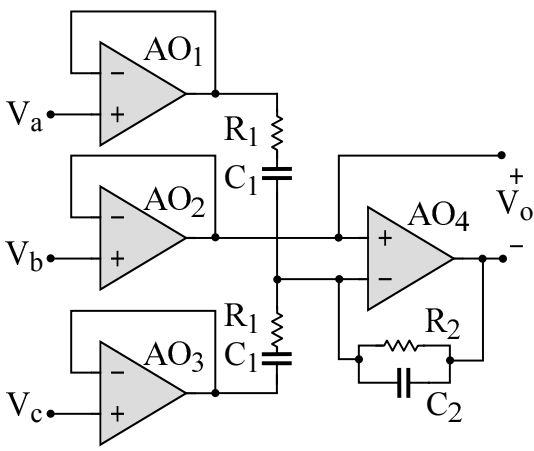

(b)

Figura 6.8: (a) Circuito para implementar electrodos activos DD. Cada nodo de entrada tiene un buffer individual para evitar la degradación del CMRR y su salida es diferencial, compatible con la entrada diferencial de los convertidores $\mathrm{AD}$ de alta resolución. (b) Especialización del circuito propuesto con ganancia y filtrado pasa-banda.

\subsubsection{Amplificador DD de baja complejidad y entrada balanceada}

Para subsanar los problemas de degradación de CMRR y complejidad del electrodo de $3 \mathrm{AI}$, la función DD puede lograrse con el circuito de la figura 6.8. Es apropiado para implementar electrodos activos compactos y de bajo costo con salida doble diferencial.

El circuito propuesto utiliza una topología basada en 4 amplificadores operacionales. Tres de ellos son buffers que proveen una alta impedancia de entrada. El cuarto AO y la red pasiva realizan la función $\mathrm{DD}$, de manera que la salida resulta:

$$
V_{\mathrm{o}}=V_{\mathrm{a}} \frac{Z_{3}}{Z_{1}}-V_{\mathrm{b}} \frac{Z_{3}}{Z_{1} \| Z_{2}}+V_{\mathrm{c}} \frac{Z_{3}}{Z_{2}}
$$

que para $Z_{1}=Z_{2}$ es

$$
V_{\mathrm{o}}=\left(V_{\mathrm{a}}-2 V_{\mathrm{b}}+V_{\mathrm{c}}\right) \frac{Z_{3}}{Z_{1}}=V_{\mathrm{MDD}} \frac{Z_{3}}{Z_{1}}
$$

La salida presenta baja impedancia y es diferencial. Los valores dados a las impedancias de la red pasiva permiten configurar la transferencia del electrodo. La opción más sencilla es asignar valores puramente resistivos $Z_{1}=Z_{2}=R_{1}$ y $Z_{3}=R_{2}$. La salida en este caso resulta $V_{\mathrm{o}}=V_{\mathrm{MDD}}\left(R_{2} / R_{1}\right)$. También puede implementarse en el electrodo mismo un filtrado pasa altos para eliminar la deriva, pasa bajos a modo de filtrado anti-alias, y dar una ganancia mayor a 1 . Esto se logra con la red pasiva de la figura 6.8(b), que tiene la siguiente función de transferencia:

$$
\begin{aligned}
V_{\mathrm{o}} & =V_{\mathrm{MDD}} \frac{\left(R_{2} / R_{1}\right) s \tau_{1}}{\left(1+s \tau_{1}\right)\left(1+s \tau_{2}\right)} \\
\tau_{1} & :=R_{1} C_{1} \\
\tau_{2} & =R_{2} C_{2}
\end{aligned}
$$

La frecuencia de corte pasa-altos es $f_{\mathrm{l}}=\left(2 \pi \tau_{1}\right)^{-1}$, la pasa-bajos $f_{\mathrm{h}}=\left(2 \pi \tau_{2}\right)^{-1}$ y la ganancia en el centro de la banda de paso es $A_{0}=R_{2} / R_{1}$.

El circuito presentado en esta sección junto con el análisis comparativo derivado a continuación son aportes publicados (Guerrero, E. M. Spinelli et al., 2015). 


\subsubsection{Figuras de mérito. Comparación con electrodo de 3 IA}

La ecuación 6.18 muestra que la ganancia de modo doble diferencial del circuito es $G_{\mathrm{DD}}=Z_{3} / Z_{1}$.

Si las impedancias $Z_{1}$ y $Z_{2}$ son iguales, el CMRR del circuito es, sin considerar efectos de segundo orden:

$$
\mathrm{CMRR}=\frac{1}{2}\left(\frac{1}{\mathrm{CMRR}_{\mathrm{AO} 4}}+\frac{1}{A_{\mathrm{AO} 4}}\right)^{-1}
$$

Donde $\mathrm{CMRR}_{\mathrm{AO} 4}$ y $A_{\mathrm{AO} 4}$ son el CMRR y la ganancia de lazo abierto del amplificador operacional $\mathrm{AO}_{4}$ en la figura 6.8(a).

Por supuesto, la otra fuente de degradación del CMRR es el desbalance en las impedancias de entrada. Para combatir este fenómeno se utilizaron $3 \mathrm{AO}$ para implementar un buffer individual por cada electrodo. Esta es una solución aceptada en la literatura (Merletti y Parker, 2004; Nonclercq y Mathys, 2004) que alcanza una alta impedancia de entrada utilizando componentes monolíticos comerciales de bajo costo, aunque no está libre de limitaciones como se analizará en el capítulo 7.

Cuando las impedancias $Z_{1}$ y $Z_{2}$ no están bien apareadas y puede definirse un desbalance respecto a una impedancia promedio de manera que $Z_{1}=\bar{Z}(1+\delta)$ y $Z_{2}=\bar{Z}(1-\delta)$, la ecuación de salida del circuito resulta:

$$
V_{\mathrm{o}}=\frac{Z_{3}}{\bar{Z}}\left(\frac{V_{\mathrm{a}}}{1+\delta}-\frac{2 V_{\mathrm{b}}}{\bar{Z}(1-\delta)(1+\delta)}+\frac{V_{\mathrm{c}}}{1-\delta}\right)
$$

Que para el caso $\delta \ll 1$ puede ser aproximada como:

$$
\begin{aligned}
V_{\mathrm{o}} & =\frac{Z_{3}}{\bar{Z}}\left(V_{\mathrm{a}}(1-\delta)-\frac{2}{\delta} V_{\mathrm{b}}+V_{\mathrm{c}}(1+\delta)\right) \\
& =\frac{Z_{3}}{\bar{Z}}\left(\left(V_{\mathrm{a}}-2 V_{\mathrm{b}}+V_{\mathrm{c}}+V_{\mathrm{c}} \delta-V_{\mathrm{a}} \delta\right)\right. \\
& =G_{\mathrm{DD}}\left(V_{\mathrm{MDD}}+\delta V_{\mathrm{MD}}\right) \\
\Rightarrow & \frac{G_{\mathrm{DD}}}{G_{\mathrm{D}}}=\frac{1}{\delta}=\frac{Z_{1}+Z_{2}}{Z_{1}-Z_{2}}
\end{aligned}
$$

Entonces, el desbalance en los componentes de la red pasiva de realimentación resulta en una degradación del rechazo al modo diferencial. El parámetro $\delta \equiv\left(Z_{1}-Z_{2}\right) /\left(Z_{1}+Z_{2}\right)$ por su definición. Cuando $Z_{1}$ y $Z_{2}$ son implementadas como en la figura $6.8(\mathrm{~b})$, la impedancia de los capacitores domina para frecuencias bajas y $\left(G_{\mathrm{DD}} / G_{\mathrm{D}}\right)_{\min }=\delta C$, donde $\delta C$ es la tolerancia de los capacitores utilizados.

La tabla 6.1 muestra una comparación entre las figuras de mérito calculadas para este amplificador y su alternativa establecida. El amplificador de 3 AI tiene un coeficiente de rechazo de modo común muy alto, pero debido a las características de su etapa de entrada, esta figura de mérito queda fundamentalmente limitada por el efecto divisor de potencial. El circuito propuesto tiene la desventaja de depender de la selección de un AO con una alta ganancia de lazo abierto para mantener un alto CMRR, sin embargo, una vez logrado el valor deseado de rechazo, el mismo puede mantenerse independientemente de los valores de impedancia de electrodo. Por otro lado, el DMRR del circuito depende del desbalance de componentes pasivos, sin embargo, como se muestra en la sección 6.2.1, el DMRR sólo debe ser suficiente para rechazar señales del mismo orden de magnitud que la señal de interés y por lo tanto un desbalance de un $1 \%$ es aceptable. 


\begin{tabular}{lcc}
\hline Amplificador & CMRR & DMRR \\
\hline $3 \mathrm{AI}$ & $\left(\mathrm{CMRR}_{\mathrm{IA} 1}^{-1}-\mathrm{CMRR}_{\mathrm{IA} 2}^{-1}\right)^{-1}$ & $G / \delta G$ \\
$4 \mathrm{AO}$ & $\frac{1}{2}\left(\mathrm{CMRR}_{\mathrm{AO} 4}^{-1}+\mathrm{A}_{\mathrm{OL}, \mathrm{AO} 4}^{-1}\right)^{-1}$ & $\bar{Z} / \delta Z$ \\
\hline
\end{tabular}

Tabla 6.1: Figuras de mérito del amplificador de 3 AI y 4 AO.

\subsubsection{Resultados Experimentales}

Se validó experimentalmente el circuito propuesto con los siguientes objetivos particulares:

1. Validar la obtención de la señal de MDD contra la señal obtenida por la alternativa establecida que es el amplificador de $3 \mathrm{AI}$.

2. Verificar el problema de rechazo de interferencia del electrodo de 3 AI y la mejora provista por el propuesto en situaciones de uso real

3. Demostrar el uso del amplificador como electrodo activo DD.

Para cumplir estos objetivos se implementaron distintas versiones del amplificador propuesto y del amplificador de $3 \mathrm{AI}$, y se diseñaron experimentos para obtener las medidas necesarias. A continuación se detalla la implementación de los circuitos, los diseños experimentales, y se presentan los resultados.

\section{Implementación de los electrodos}

Se implementaron dos versiones del amplificador DD de 4 AO. Se utilizó un AO cuádruple OPA4243 de Texas Instruments, que cuenta con una baja capacidad de entrada $(2 \mathrm{pF})$, un alto CMRR $(104 \mathrm{~dB} @ 50 \mathrm{~Hz})$, ruido equivalente de entrada relativamente bajo $\left(0.6 \mu \mathrm{V}_{\mathrm{rms}}\right.$ en $\left.10-500 \mathrm{~Hz}\right)$ y alimentación con fuente simple de $5 \mathrm{~V}$.

Una versión del amplificador se implementó con ganancia 1, utilizando resistencias de $1 \mathrm{k} \Omega$ para todas las impedancias del circuito de la figura 6.8(a). La otra versión se implementó con limitación del ancho de banda, como en la figura 6.8(b), frecuencias de corte de $3 \mathrm{~dB}$ de 16 a $500 \mathrm{~Hz}$ y una ganancia en el centro de la banda de 10 veces, obtenida con los siguientes valores de componentes: $R_{1}=1 \mathrm{k} \Omega, R_{2}=10 \mathrm{k} \Omega, C_{1}=10 \mu \mathrm{F}, C_{2}=32 \mathrm{nF}$.

Los contactos del electrodo fueron implementados con conectores tipo pin estándar, de $10 \mathrm{~mm}$ de largo, sección cuadrada de $0.64 \mathrm{~mm}$ de lado y dorados. Estas varillas fueron colocadas paralelas entre sí, separadas $10 \mathrm{~mm}$ y soldadas en el mismo PCB que el circuito del amplifiador, siguiendo la disposición habitual. Se separaron los contacos del PCB con un soporte adicional para asegurar un buen contacto con la piel, y se utilizó cable plano estándar de computación para conectar el electrodo con el equipo de adquisición. El electrodo completo tuvo un tamaño de $35 \mathrm{~mm} \times 25 \mathrm{~mm} \times 10 \mathrm{~mm}$ sin gabinete, puede verse una foto en la figura 6.9.

Se soldaron dos cables adicionales a las salidas de $\mathrm{AO}_{1}$ y $\mathrm{AO}_{3}$, de manera que junto a la salida de $\mathrm{AO}_{2}$ permiten adquirir la señal de cada contacto individualmente (es decir, $V_{a}, V_{b}$ y $V_{c}$ ). Esta modificación se hizo sólo para las pruebas experimentales en el prototipo, para obtener la señal bipolar de cualquier par de contactos además de la señal DD.

Se midieron los parámetros de funcionamiento del electrodo implementado, presentados en la tabla 6.2. Todos los parámetros enumerados conforman los requisitos mencionados en la literatura (Merletti y Parker, 2004; T.-Y. Wang et 


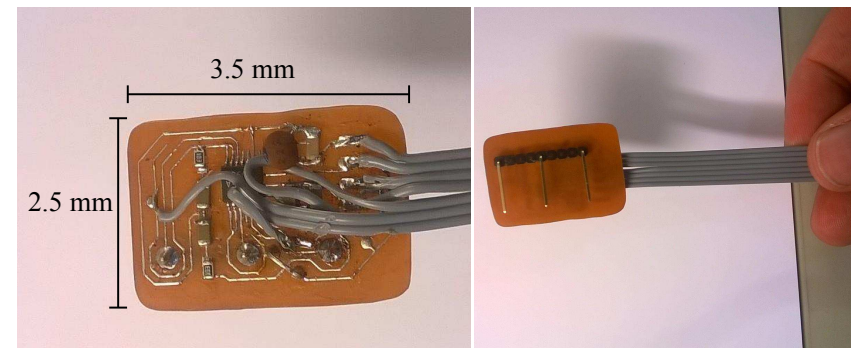

Figura 6.9: Implementación del electrodo DD con el circuito de la figura 6.8(b). Cuatro cables proveen la alimentación y el canal diferencial de salida. Se añadieron cables adicionales para adquirir la salida de cada buffer individualmente para fines de pruebas experimentales.

\begin{tabular}{|c|c|c|}
\hline Parámetro & Valor & Ajuste \\
\hline CMRR & $\begin{array}{c}86 \mathrm{~dB} @ 50 \mathrm{~Hz} \\
78 \mathrm{~dB} @ 100 \mathrm{~Hz}\end{array}$ & $\begin{array}{l}\mathrm{AO}_{4} \text { : Ganancia de } \\
\text { lazo abierto y CMRR }\end{array}$ \\
\hline SDMRR & $\geq 40 \mathrm{~dB}$ & \multirow{4}{*}{ Selección del AO } \\
\hline Consumo & $\approx 220 \mu \mathrm{A}$ & \\
\hline Impedancia de entrada & $10 \mathrm{G} \Omega \| 2 \mathrm{pF}$ & \\
\hline Ruido & $1.6 \mu \mathrm{V}_{\mathrm{rms}}(17-500 \mathrm{~Hz})$ & \\
\hline Ganancia & $20 \mathrm{~dB}$ & $\approx R_{2} / R_{1}$ \\
\hline Ancho de banda de $3 \mathrm{~dB}$ & $17-500 \mathrm{~Hz}$ & $R_{1} C_{1}, R_{2} C 2$ \\
\hline
\end{tabular}

Tabla 6.2: Parámetros típicos de funcionamiento y de ajuste

al., 2014; C. De Luca, 1997), y pueden ser ajustados a necesidades especiales como se indica en la tercera columna de la tabla.

\section{Circuitos auxiliares}

Un segundo electrodo fue construído con la topología de 3 AI de la figura 6.2(a) por ser una alternativa establecida para la adquisicón de la señal DD. Se seleccionaron AIs AD623 de Analog Devices por su baja capacidad de entrada de $2 \mathrm{pF}$ y alimentación de fuente simple. Todos los AIs se configuraron para obtener una ganancia unitaria.

La adquisición de biopotenciales se realizó con la implementación II reportada en el capítulo 4. La salida diferencial DD se conectó a una de las entradas diferenciales del equipo. Debido a que estas entradas pueden conmutarse para ser single-ended, queda disponible en esa entrada también la señal $V_{b}$. Los dos cables adicionales de pruebas se conectaron en otras dos entradas del equipo, configuradas en el modo single-ended. De esta manera las señales adquiridas fueron $V_{a}, V_{c}$, y $V_{\mathrm{DD}} \circ V_{b}$. En una cuarta entrada se conectó la salida del amplificador de $3 \mathrm{AI}$, adquiriendo así la señal de los dos electrodos simultáneamente. En la figura 6.10 se muestra la conexión completa del sistema de medida.

El rango de entrada de los AI AD623 es más limitado que el del AO OPA4243, por lo que en medidas simultaneas se configuró una tensión de referencia de $1.75 \mathrm{~V}$ que permite una excursión de la señal de $\pm 0.5 \mathrm{~V}$. 


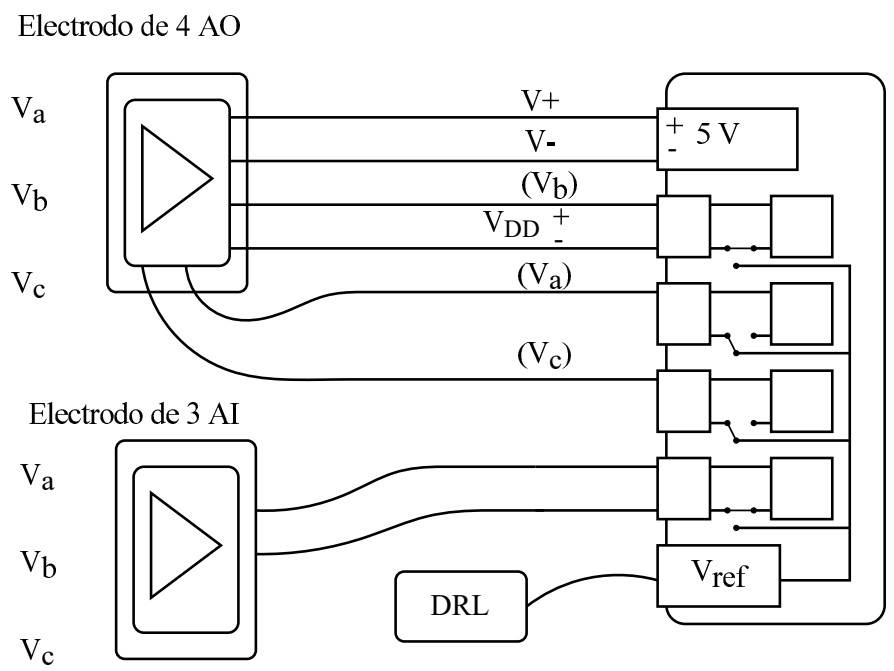

Figura 6.10: Diagrama de la conexión del electrodo propuesto, el electrodo de 3 AI utilizado como referencia, y el sistema de adquisición incluyendo el DRL.

\section{Validación contra la alternativa establecida}

Los dos amplificadores DD implementados fueron soldados a los mismos electrodos para adquirir simultáneamente la respuesta a la misma señal de EMG de entrada. La versión con ganancia unitaria del amplificador de 4 AOs (sin limitación de ancho de banda) fue utilizada para evitar diferencias debido a la tolerancia de componentes en la transferencia.

Este electrodo "dual" fue colocado sobre el antebrazo, sostenido por una banda elástica. El DRL se colocó en la cara anterior de la muñeca utilizando electrodos descartables estándar 3M. Se configuró una tasa de adquisición de $2000 \mathrm{~Hz}$ y ganancia 1 y se ejecutaron flexiones completas del dedo índice. Las señales fueron luego filtradas con un filtro pasabanda Butterworth de segundo orden, entre $10 \mathrm{~Hz}$ y $600 \mathrm{~Hz}$.

Las señales obtenidas como salida de ambos electrodos eran visualmente similares. Se calculó la correlación cruzada normalizada de las dos señales sobre un segmento de $4 \mathrm{~s}$ con contracción muscular mantenida, obteniendo un coeficiente de correlación $\rho=0,99$, verificando que los electrodos producen la misma salida y por lo tanto el amplificador propuesto produce la misma salida DD que la alternativa establecida.

\section{Rechazo a interferencia de modo común}

La principal desventaja de la topología tradicional de $3 \mathrm{AI}$ es la degradación del CMRR producida por sus impedancias de entrada desbalanceadas. Se verificaron experimentalmente los valores de CMRR predichos por la ecuación 6.16 para esta topología, y se contrastó con el resultado para el electrodo propuesto.

Para esta prueba se implementó el setup de medida de la figura 6.3. $V_{\mathrm{CM}}$ se aplicó con un generador de funciones configurado con una onda senoidal de $70 \mathrm{~Hz}$ y $1 V_{\text {pp }}$ y las impedancias $Z_{\text {ea }}, Z_{\text {eb }}$ y $Z_{\text {ec }}$ se implementaron con tres resistencias de igual valor. Se realizaron tres sets de medidas para cada electrodo; en cada medida se variaron los valores de las tres resistencias. 


\begin{tabular}{ccc}
\hline $\begin{array}{c}Z_{e a, e b, e c} \\
{[\mathrm{k} \Omega]}\end{array}$ & $\begin{array}{c}\text { Valor medido } \\
{[\mathrm{dB}]}\end{array}$ & $\begin{array}{c}\text { Valor predicho (Eq. 6.16) } \\
{[\mathrm{dB}]}\end{array}$ \\
\hline 22 & 83.2 & 94.2 \\
\hline 220 & 73.6 & 74.2 \\
\hline 2200 & 51.4 & 54.2 \\
\hline
\end{tabular}

Tabla 6.3: CMRR del amplificador de $3 \mathrm{AI}$ a $70 \mathrm{~Hz}$ para valores ascendentes de resistencia de fuente.

El CMRR del electrodo propuesto fue de $81 \mathrm{~dB}$ y no sufrió cambios significativos al variar las resistencias de electrodo. Los resultados para la topología de 3 AI se muestran en la tabla 6.3: Para el menor valor de resistencia, de $22 \mathrm{k} \Omega$, no se notó el efecto del desbalance en la entrada debido a que el CMRR del AD623 es menor, pero cuando se utilizaron resistencias de mayor valor, se observa que se degradó el CMRR alcanzando valores cercanos a los predichos por la ecuación 6.16 .

Este efecto también fue medido sobre el cuerpo. La figura 6.3 y la tabla 6.3 muestran que cuando la impedancia de electrodo es muy alta, el efecto divisor de potencial, proporcional a $\Delta Z_{\mathrm{e}}$, y el desbalance en la impedancia de entrada, proporcional a $Z_{\mathrm{e}}$ para el electrodo de $3 \mathrm{AI}$, pueden convertirse en los mecanismos de transformación de modo común que mayor interferencia aportan. Por lo tanto, la interferencia de modo común en el electrodo propuesto será siempre menor o igual a aquella en el electrodo de $3 \mathrm{AI}$, ya que la relación sera proporcional al cociente de $\Delta Z_{\mathrm{e}}$ a $Z_{\mathrm{e}}$, que puede ser como máximo 1.

El experimento consistió en aplicar una señal de modo común de $70 \mathrm{~Hz}$ al cuerpo (para evitar que otros mecanismos de interferencia enmarscaren el fenómemo a observar) y observar la señal de salida de los electrodos de 3 AI y el propuesto. La señal de modo común, presente en todos los contactos de los electrodos, puede medirse a través de uno de los cables auxiliares del electrodo de $4 \mathrm{AO}$. Ambos electrodos se colocaron en el antebrazo, uno junto al otro, y se tomaron 5 registros en distintas condiciones: con la banda elástica de sujeción más o menos ajustada, intercambiando la posición de los electrodos y con distintos tiempos entre aplicaciones entre $10 \mathrm{~s}$ y $60 \mathrm{~s}$.

Luego de tomar los registros se midió la amplitud de la onda de $70 \mathrm{~Hz}$ utilizando un ajuste por cuadrados mínimos y se calculó la diferencia del rechazo aportado entre un electrodo y otro. El electrodo propuesto alcanzó un rechazo que superó en $(15 \pm 4) \mathrm{dB}$ al electrodo tradicional de $3 \mathrm{AI}$.

\section{Rechazo de Crosstalk}

El electrodo DD tiene valor por su selectividad espacial en medidas se sEMG. Se realizaron medidas para visualizar la capacidad del electrodo activo implementado de rechazar componentes indeseados de crosstalk. Se eligieron dos ubicaciones en el cuerpo donde movimientos específicos activaran músculos cercanos pero con una separación suficiente.

Los cables adicionales del prototipo implementado se utilizaron para adquirir la señal diferencial de los contactos con potencial $V_{b}$ y $V_{c}$ (que tienen una IED de $10 \mathrm{~mm}$ ) en simultáneo con la señal DD. Las señales adquiridas se pos-procesaron con un filtro de media móvil con ventana de $100 \mathrm{~ms}$.

La figura 6.11(a) muestra los resultados obtenidos al posicionar el electrodo en el antebrazo, sobre los músculos extensores de los dedos, cerca del codo. Se 


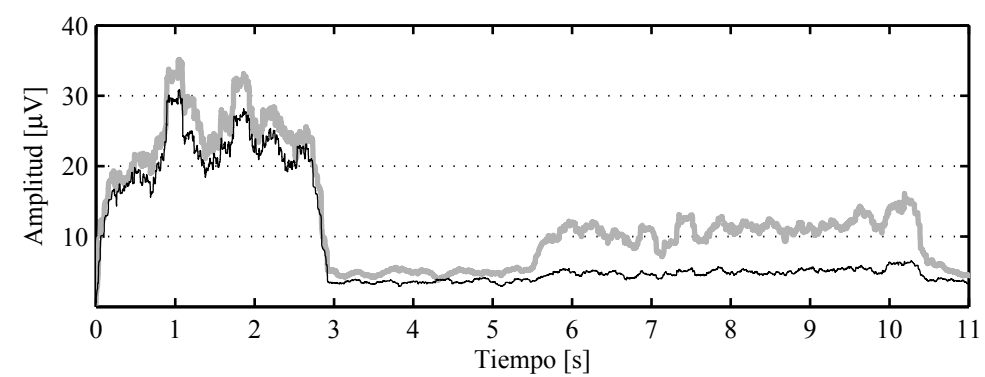

(a)

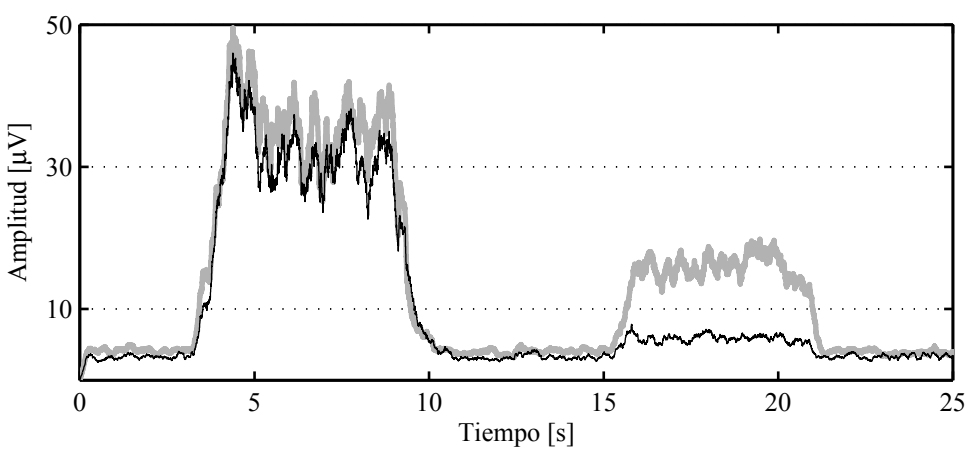

(b)

Figura 6.11: Superposición de señales de sEMG DD (línea negra) obtenidas con el electrodo propuesto y bipolar (línea gris) obtenidas de dos contactos contiguos del mismo electrodo separados $10 \mathrm{~mm}$, simultáneamente. Las señales en (a) fueron medidas en el antebrazo extendiendo el dedo índice y luego el meñique y en (b) en la mejilla sonriendo y luego apretando las mandíbulas.

eligió una ubicación donde la extensión del dedo índice producía la señal de mayor amplitud. Las curvas de la figura se obtuvieron realizando primero una extensión del dedo índice, luego relajándolo y finalmente extendiendo el dedo meñique.

Luego se posicionó el electrodo en la mejilla de manera de detectar la contracción del músculo cigomático mayor. La actividad observada en la figura 6.11(b) resultó de realizar primero una sonrisa seguida de apretar las mandíbulas.

Ambas experiencias muestran que el electrodo DD logró atenuar los componentes del sEMG producidos por músculos que no se ubican directamente debajo, comparado con el electrodo bipolar formado por sólo dos de sus contactos más cercanos.

\subsection{Conclusiones}

Los electrodos multi-contacto son herramientas valiosas en EMG no-invasivo, clave en las neuroprótesis vestibles porque permiten aumentar la selectividad espacial de las medidas. Los tipos más sencillos se implementan como electrodos activos, colocando el amplificador directamente sobre los contactos y debido a la corta distancia inter-electródica se utilizan electrodos secos. En particular, el electrodo de tres contactos llamado doble diferencial tiene amplio uso. 
Desde el punto de vista del diseño electrónico de los amplificadores necesarios para estos electrodos multi-contacto activos, es necesario contar con las herramientas de análisis apropiadas para crear amplificadores que rechacen las señales de interferencia que no solo son de origen externo electromagnético, sino de origen electromiográfico. Si el objetivo de estas topologías de filtrado espacial es rechazar componentes cruzados, el amplificador no debe convertirse en una etapa donde esos componentes puedan interferir con la señal DD idealmente deseada.

Por lo tanto se presentó una descomposición del espacio de señales de entrada de los electrodos DD en tres modos de señal que independizan los componentes de distintas fuentes: un modo para la señal de interés (MDD); uno para la interferencia electromagnética predominante, presente por igual en todos los contactos y por lo tanto llamado modo común (MC); y un modo que da cuenta de los componentes de crosstalk, que es en este caso el modo diferencial (MD). Siguiendo el mismo razonamiento se encontró una descomposición de modos similar para el electrodo NDD que se muestra en el anexo A.

Los modos planteados permiten analizar las no-idealidades de los amplificadores y encontrar las transformaciones de modo que es necesario combatir, permiten definir las figuras de mérito de los amplificadores, el CMRR y DMRR para electrodos DD, y surge así que desbalances en un amplificador DD no solo pueden producir transformaciones de MC en MDD sino también de MD en MDD. Con estas herramientas pudo caracterizarse la etapa de entrada de un amplificador DD y las transformaciones de modo que ocurren debido a desbalances en las impedancias de electrodo o las impedancias de entrada. Estos desbalances tienen dos grados de libertad, por lo que se simplificaron las expresiones obtenidas para obtener ecuaciones que representen las cotas más pesimistas, contribuyendo al diseño para la robustez frente a EMI.

Las neuroprótesis vestibles imponen necesidades estrictas sobre los electrodos activos de sEMG: bajo consumo y complejidad y alta robustez. Por lo tanto se presentaron soluciones alternativas para adquirir la señal DD: una con simplicidad y bajo costo como criterio preferencial, el electrodo branched, y una segunda de mayor complejidad que permite capturar la señal DD independientemente de desbalances de impedancia de electrodo. Esta segunda implementación es una alternativa al amplificador de $3 \mathrm{AI}$, de menor complejidad. Sus parámetros de rechazo de modo común son peores pero presenta mayor robustez frente a EMI gracias a contar con impedancias de entrada balanceadas.

El amplificador se implementó con componentes comerciales y es fácilmente replicable, con la posibilidad de ajustar sus parámetros. Tiene salida diferencial, adaptada a los canales completamente diferenciales de los sistemas de adquisición modernos. Esto es una relación de compromiso entre la robustez frente a EMI que otorga el canal diferencial y la ductilidad del cable para evitar artefactos. El amplificador propuesto fue evaluado experimentalmente, mostrando que una topología sencilla puede producir la misma salida DD que el electrodo basado en $3 \mathrm{AI}$ en medidas estándar de biopotenciales. Se demostró también el uso del electrodo en distintas ubicaciones en el cuerpo utilizando electrodos secos sin preparación de la piel. Las medidas resultaron en señales electromiográficas de alta calidad sin presencia apreciable de EMI y observando el efecto práctico en el rechazo de crosstalk. 


\title{
Electrodo de Dos Hilos con bootstrap de fuente
}

\begin{abstract}
La punta de lanza de los sistemas de instrumentación para neuroprótesis vestibles es el electrodo activo, y, específicamente, su alta impedancia de entrada necesaria para atenuar las transformaciones de modo y artefactos que producen los electrodos secos. Este parámetro debe mejorarse respecto al disponible en dispositivos comerciales para dar el paso necesario hacia la robustez deseada de las neuropótesis vestibles. Se propone entonces un método de muy baja complejidad que permite superar estas limitaciones aumentando la impedancia de entrada a través de la técnica de bootstrap de fuente y permitiendo además utilizar solo dos conductores para transmitir señal y alimentación.
\end{abstract}

\subsection{Introducción}

\subsubsection{Electrodos Activos: Interferencia de modo común}

Las NPVs enfrentan dos fenómenos que perturban sus señales de entrada: la interferencia y los artefactos. Ambos son desafíos actuales que la etapa de instrumentación debe resolver (Meziane et al., 2013; Ha et al., 2014).

En la sección 2.3 se ha discutido el problema de la impedancia de electrodos secos, la cual es excepcionalmente alta sobre todo cuando se colocan sin preparación previa y sin asistencia de un profesional, como es el caso de uso en NPVs. Los valores de impedancia oscilan entre $100 \mathrm{k} \Omega$ y $100 \mathrm{M} \Omega$ a $50 \mathrm{~Hz}$ con variaciones entre aplicaciones de hasta el $100 \%$.

Estas impedancias producen interferencia por el mencionado efecto divisor de potencial (sección 2.5.5) causando una transformación de modo común a modo diferencial que el equipo no puede rechazar.

La solución aceptada para este problema es el uso de electrodos activos (S. Johnson et al., 1977; Nishimura et al., 1992; Nonclercq y Mathys, 2004), que interponen una etapa con la máxima impedancia de entrada posible antes del adquisidor de biopotenciales al que entregan la señal. En particular, pueden 


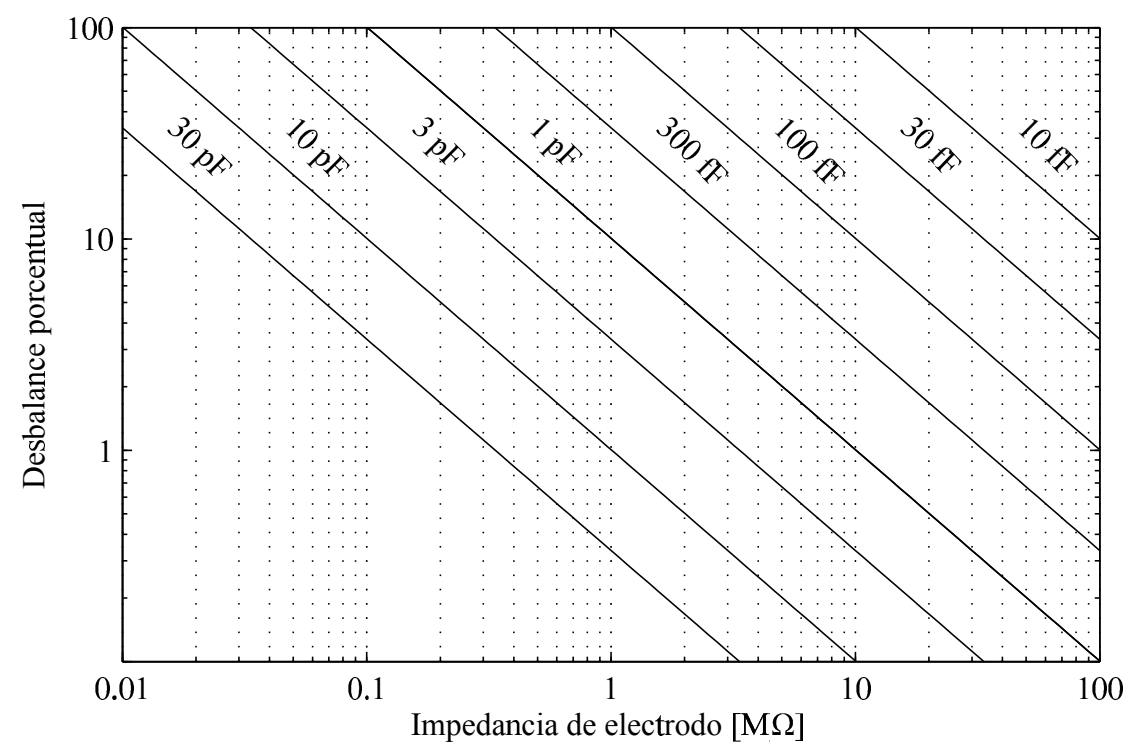

Figura 7.1: Curvas de nivel de $90 \mathrm{~dB}$ de CMRR parametrizadas por la capacidad de entrada del amplificador, que domina la impedancia de entrada. Son función de la impedancia promedio de electrodo $Z_{e}$, y el desbalance porcentual.

implementarse electrodos activos basados en componentes comerciales utilizando amplificadores operacionales en configuración de buffer (Taheri et al., 1994; Fernandez y Pallàs-Areny, 1996).

\subsubsection{La limitación de la impedancia de entrada}

El CMRR debido al efecto divisor de potencial en un canal diferencial con desbalance de impedancias de electrodo $\Delta Z_{e}$ e impedancias de entrada de valor $Z_{i}$ es:

$$
\mathrm{CMRR} \approx \frac{Z_{i}}{\Delta Z_{e}}
$$

Los dispositivos comerciales de bajo ruido actuales, tanto AOs como amplificadores de instrumentación, tienen impedancias de entrada principalmente impuestas por su capacidad de entrada, por lo que $Z_{i n} \approx\left(2 \times \pi \times 50 \mathrm{~Hz} \times C_{i}\right)^{-1}$. Los valores usuales para $C_{i}$ están en el rango de $1 \mathrm{pF}$ a $30 \mathrm{pF}$, a los cuales deben adicionarse las capacidades parásitas del PCB que pueden contribuir con algunos $\mathrm{pF}$.

Considerando este rango de valores para la ecuación 7.1, en la figura 7.1 se trazaron curvas de nivel de $90 \mathrm{~dB}$ de CMRR parametrizadas por la capacidad de entrada del amplificador. Las curvas son función del módulo de la impedancia de electrodo $Z_{e}$ en el eje horizontal y el desbalance porcentual de impedancia en el eje vertical (es decir, de un parámetro $\delta=\Delta Z_{e} / Z_{e} \times 100$ ).

En un sistema con etapas diferenciales en cascada, el rechazo de modo común total será siempre más bajo que el menor entre las etapas (Pallás-Areny y Webster, 1991). En sistemas implementados con componentes comerciales con tolerancias estándar, es razonable alcanzar un CMRR de $90 \mathrm{~dB}$, que sumado al aporte del DRL resulta en un nivel de rechazo aceptable (e.g., capítulo 4). Por lo tanto en la figura 7.1 se fijó este valor como un límite aceptable para la degradación de CMRR proucida por el efecto divisor de potencial. 
La región por encima de una curva de nivel dada de la figura 7.1 indica que, para la capacidad de entrada que corresponde a esa curva, los valores de impedancia de electrodo y desbalance producen un CMRR menor a $90 \mathrm{~dB}$. Por ejemplo, para una impedancia con magnitud de $1 \mathrm{M} \Omega$ un desbalance de electrodo mayor al $10 \%$ resultaría en interferencia inaceptable incluso para los mejores AOs. El criterio para aceptar parámetros dentro de una determinada región del gráfico varía según la aplicación; para medidas con electrodos secos por ejemplo el límite de la curva de nivel de $100 \mathrm{fF}$ asegura un rechazo de $90 \mathrm{~dB}$ para electrodos de $1 \mathrm{M} \Omega$ aún con desbalances de un orden de magnitud, y admite un desbalance del $10 \%$ en electrodos con $10 \mathrm{M} \Omega$.

Estos valores de capacidad de entrada no se encuantran disponibles en amplificadores operacionales comerciales. En la literatura se encuentran distintos métodos para obtener dispositivos conocidos como de impedancia ultraalta que pueden alcanzarlos. Algunos métodos se basan en la implementación de integrados monolíticos con características particulares (Chi, Maier et al., 2011; Ng y Xu, 2013; Zhou y Warr, 2016), mientras que otros utilizan componentes discretos, como es el caso de la neutralización de capacidad (Dobrev et al., 2005; E. Spinelli y M. Haberman, 2010). La Neutralización es una solución difundida, sobre todo para electrodos capacitivos, pero requiere un ajuste para cada electrodo y es difícil de implementar.

\subsubsection{La solución de Bootstrapping}

Una forma de lograr buffers de impedancia ultra-alta con componentes discretos es la técnica conocida como bootstrap de fuente de alimentación. Este método se basa en alimentar al amplificador operacional con un potencial que sigue las variaciones de la entrada, manteniendo una tensión continua suficiente para la operación del dispositivo (figura 7.2(a)). De esa manera, el nodo de entrada no "ve" diferencia de potencial hacia ningún otro nodo del circuito y su impedancia es por tanto idealmente infinita.

Para el caso de un amplificador operacional, la impedancia de entrada puede considerarse como la compuesta por dos (7.2(b)): una, $Z_{i h}$, referida al nodo de alimentación positivo $V_{h}$ y la otra, $Z_{i l}$, al nodo negativo $V_{l}$. De esa manera, la corriente total de entrada $I_{i}$ debida a la tensión de entrada $V_{i}$ es:

$$
I_{i}=\frac{V_{i}-V_{h}}{Z_{i h}}+\frac{V_{i}-V_{l}}{Z_{i l}}
$$

El circuito de bootstrap produce potenciales $V_{h}$ y $V_{l}$ con componentes de AC idealmente iguales a $V_{i}$. Sin embargo, la implementación práctica del circuito producirá potenciales aproximados, pero no iguales. Puede suponerse que los potenciales resultantes tendrán un componente linealmente dependiente de $V_{i}$, más un término de offset para alimentar al dispositivo con tensión total $V_{D C}$. La constante de proporcionalidad debería ser idealmente 1 para lograr un bootstrap perfecto, pero se asume que se desvía de la idealidad por un factor $\alpha$, de manera que:

$$
\begin{aligned}
V_{h} & =V_{i} \alpha_{h}-\beta V_{D C} \\
V_{l} & =V_{i} \alpha_{l}+(1-\beta) V_{D C}
\end{aligned}
$$

Por lo tanto, la ecuación para la corriente entrante al nodo $V_{i}$ resulta:

$$
I_{i}=V_{i}\left(\frac{1-\alpha_{h}}{Z_{i h}}+\frac{1-\alpha_{l}}{Z_{i l}}\right)+V_{D C}\left(\frac{\beta}{Z_{i l}}+\frac{1-\beta}{Z_{i l}}\right)
$$




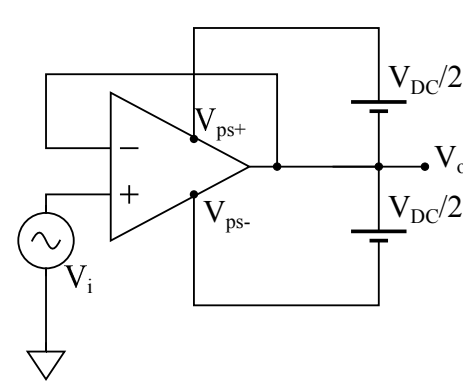

(a)

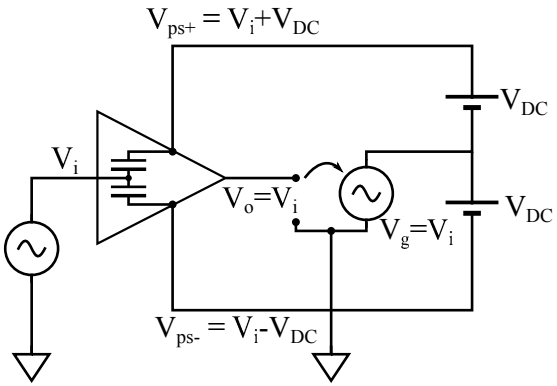

(b)

Figura 7.2: (a) Diagrama de la técnica de Bootstrapping de fuente. La tensión de alimentación tiene superpuesta una copia de la tensión de entrada, de manera que la diferencia de potencial entre el nodo de entrada del amplificador y los demás elementos del circuito es sólo de continua y su impedancia de entrada resulta idealmente infinita. (b) Detalle de la impedancia de entrada dominada por su capacidad.

Que, sin considerar la corriente entrante de continua y nombrando $\gamma=$ $(1-\alpha)^{-1}$ resulta:

$$
I_{i}=V_{i}\left(\frac{1}{Z_{i h} \gamma_{h}}+\frac{1}{Z_{i l} \gamma_{l}}\right)
$$

Las impedancias $Z_{i h, i l}$ son las pertenecientes a la entrada del AO, y pueden ser modeladas como una resistencia de valor $R_{i}$ en paralelo con un capacitor de valor $C_{i}$. Usando este modelo para las impedancias de la ecuación 7.6, la impedancia efectiva con el bootstrap resulta en un paralelo de valores $\gamma R_{i}$ y $C_{i} / \gamma$. Por lo tanto, la capacidad de entrada se ve reducida por un factor $(1-\alpha)^{-1}$.

Este método fue aplicado por primera vez con amplificadores operacionales en el trabajo de Kootsey y E. A. Johnson, 1973 y luego desarrollado por Hribik et al., 2008, Lányi, 2001 y Lányi y Pisani, 2002. Una desventaja de la técnica de bootstrap es que incrementa la cantidad necesaria de componentes y la complejidad del circuito.

\subsubsection{Electrodos Activos: Artefactos}

La relación entre la impedancia de entrada del amplificador y la impedancia de electrodo, tiene consecuencias para la robustez frente a artefactos. Los electrodos secos no se sujetan con adhesivos sino con estructuras de soporte que aplican una cierta presión sobre ellos, por ejemplo cintas elásticas, mangas o chalecos. Esta presión cambia con el movimiento y afecta a la impedancia de los electrodos (Liu et al., 2013), produciendo una fluctuación en la señal.

La variación de impedancia de los electrodos no es la única fuente de artefactos. El efecto conocido como potencial de la piel es quizás la fuente de artefactos más notable (Tam y Webster, 1977), además las cargas triboeléctricas por fricción de los cables también puede contribuir (Webster, 1984). La solución de remover la capa externa de la piel para evitar consecuencias de estos fenómenos (Thorsen, 1999) no es practicable en NPVs y además no funciona en el largo plazo (días) debido al crecimiento de piel nueva (Taheri et al., 1994).

Desde la instrumentación puede ayudarse a mitigar el origen mecánico de los artefactos. En primer lugar, debe favorecerse la disminución de la masa de los electrodos activos para atenuar esfuerzos debido al momento de inercia de los mismos (Roy et al., 2007), haciendo deseables diseños sencillos de pocos componentes. En segundo lugar, los electrodos activos necesitan cables de 


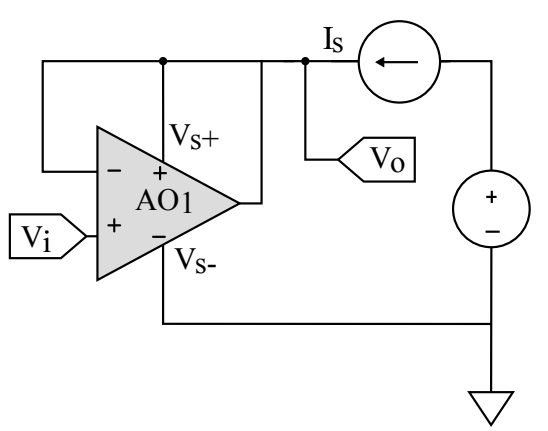

(a)

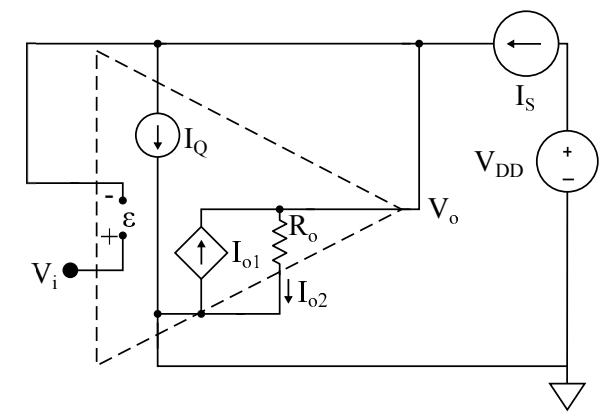

(b)

Figura 7.3: (a) Electrodo de dos hilos propuesto por T. Degen, Torrent et al., 2007. (b) Modelo para analizar la salida del electrodo.

conexión adicionales porque además de transmitir la señal de biopotencial, deben recibir alimentación del equipo de adquisición. Esto produce una mayor rigidez en los cables y aumenta el costo de partes con la flexibilidad apropiada.

\subsubsection{Electrodos de dos hilos}

Una solución propuesta para el problema de los artefactos por rigidez en los cables es el uso de electrodos llamados de dos hilos ya que necesitan solo dos conductores para transmitir la señal y la alimentación. Esta estrategia además hace más práctico el despliegue de sistemas multicanal, como se demuestra en el sistema comercial ActiveTwo de Biosemi que no utiliza cables mallados sino un par de finos conductore, y reduce el costo de los materiales.

El diseño de este tipo de electrodos de dos hilos basado en amplificadores operacionales y con transistores fue abordado en el trabajo de tesis de T. W. Degen, 2011, quien obtuvo una implementación notablemente simple y robusta, utilizando una topología realimentada que fuerza a uno de los nodos de alimentación a seguir la salida del AO. Uno de los circuitos propuestos por T. Degen, Torrent et al., 2007 se observa en la figura 7.3(a)

En la figura 7.3(b) se ha representado el mismo circuito con un modelo del AO sencillo, apropiado para comprender su funcionamiento. La etapa de salida se ha representado por el modelo equivalente Norton de fuente de corriente, que para una ganancia de lazo abierlo $A_{o l}$ produce:

$$
I_{o}=\epsilon \times \frac{A_{o l}}{R_{o}}=\left(V_{i+}-V_{i-}\right) \times \frac{A_{o l}}{R_{o}}
$$

Parece extraño conectar la entrada inversora y la salida del AO a la fuente positiva de alimentación. Para el funcionamiento de los circuitos internos del AO deben cumplirse requisitos mínimos de tensión entre distintos nodos. Para aceptar esta idea debe pensarse en el subconjunto de AOs capaces de admitir que se exceda la tensión de alimentación en la entrada (muchos admiten excesos de hasta $100 \mathrm{mV}$ ) y salida riel-a-riel que puede llegar al potencial de alimentación sin problemas. Si se garantiza que la tensión de entrada (y por lo tanto la de salida) tendrá un valor superior al mínimo necesario para alimentar al AO, el mismo podrá operar normalmente.

Para que este esquema funcione, debe proveerse la corriente mínima de alimentación $I_{Q}$, permitiendo a la tensión del nodo $V_{o}$ flotar libremente. Por lo 
tanto se alimenta al circuito con una fuente de corriente constante $I_{S}$. El AO entonces producirá una corriente $I_{o 1}$ tal que el resto de la corriente que atraviesa $R_{o}$ resultará en la tensión de salida $V_{o}$ que copia a la de entrada:

$$
\begin{aligned}
V_{o} & =I_{o 2} R_{o} \\
& =\left(I_{S}-I_{Q}+I_{o 1}\right) R_{o}
\end{aligned}
$$

Redistribuyendo y utilizando la ecuación 7.7 para reemplazar $I_{o 1}$ se tiene:

$$
V_{o}=\left(I_{S}-I_{Q}\right) R_{o}+\frac{\left(V_{i+}-V_{i-}\right) A_{o l}}{R_{o}} R_{o}
$$

La entrada $V_{i-}$ está conectada al nodo de tensión $V_{o}$ y la entrada $V_{i+}$ a la entrada del electrodo $V_{i}$, por lo que luego de reemplazar estos valores y despejar resulta:

$$
V_{o}=\frac{\left(I_{S}-I_{Q}\right) R_{o}}{A_{o l}+1}+V_{i} \frac{A_{o l}}{A_{o l}+1}
$$

En esta instancia puede despreciarse el primer término, constante por un lado y mucho menor que el segundo por el otro (para una corriente $I_{S}$ en el rango de los $\mathrm{mA}$, una resistencia de salida del orden de $\mathrm{k} \Omega$, y una ganancia de lazo abierto de $100 \mathrm{~dB}$ se tendría un offset de $10 \mu \mathrm{V}$ ). La tensión de salida resulta entonces:

$$
V_{o} \approx V_{i} \frac{A_{o l}}{A_{o l}+1}
$$

Que es la conocida ecuación de un seguidor de tensión realimentado unitariamente.

Aquí puede observarse algo notable: la simple topología de este electrodo de dos hilos resulta en que la tensión de alimentación positiva copia a la tensión de entrada. Es decir, que se tiene un circuito con "1/2 bootstrap" de fuente funcionando. Si puede lograrse que la fuente negativa también siga la tensión de entrada de una manera sencilla, se habrá conseguido un electrodo de dos hilos con impedancia de entrada ultra-alta.

\subsection{Solución propuesta}

\subsubsection{Desarrollo del circuito}

La figura 7.4 muestra un diagrama conceptual del circuito propuesto, que conjuga la solución de bootstrap con la del electrodo activo de dos hilos.

Una fuente de corriente constante $I_{s}$ permite que el nodo $V_{o}$ varíe su tensión manteniendo una porción de la corriente para suministrar la energía necesaria al AO, mientras que las corriente restante es absorbida por la etapa de salida del AO.

El circuito de la figura 7.4 es un esquema conceptual que diagrama la adición del bootstrap de fuente negativa a la topología del electrodo de dos hilos. Para completar el bootstrap, la alimentación negativa, que en el esquema original está conectada al potencial de masa, ahora sigue a la tensión de salida $V_{o}$ con un desplazamiento $V_{s}$ que define la tensión de alimentación.

Para indagar en las características de esta topología y diseñar un circuito práctico que la implemente, debe modelarse el comportamiento del amplificador operacional considerando que, en verdad, es un dispositivo de 4 entradas: la entrada no inversora $V_{i+}$, la inversora $V_{i-}$, la alimentación positiva $V_{p s+}$ y la negativa $V_{p s-}$. Corresponde a cada una de estas entradas una ganancia que 


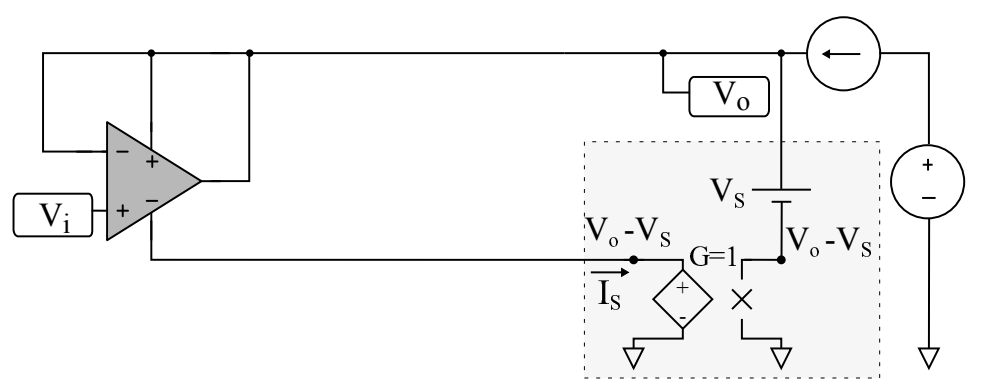

Figura 7.4: Diagrama conceptual del circuito propuesto de bootstrap con dos hilos utilizando componentes ideales. Al diseño preexistente de dos hilos se le agrega el bootstrap de fuente negativa remarcado en el área sombreada.

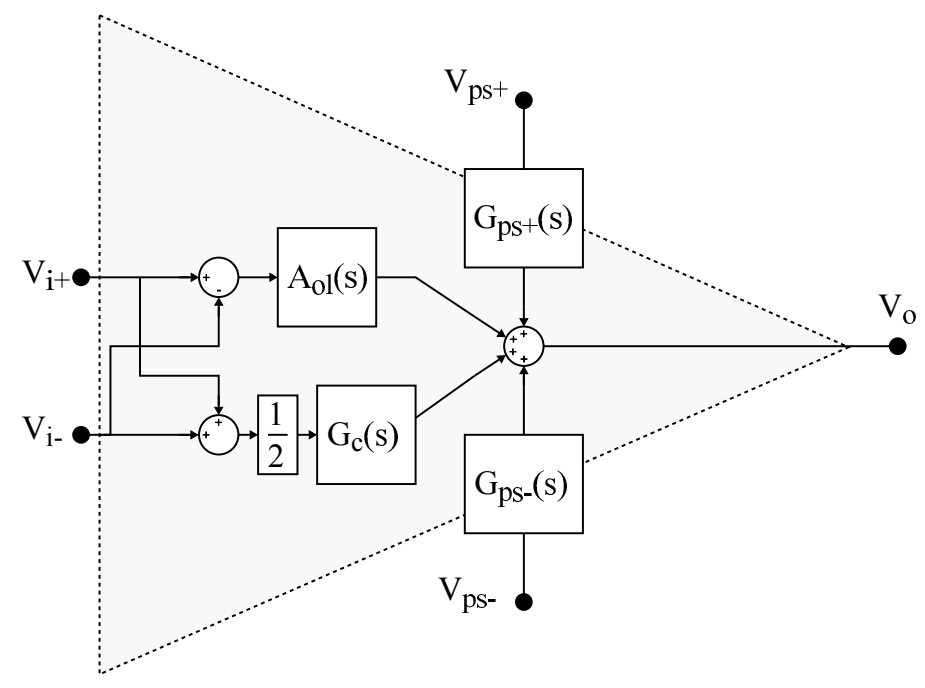

Figura 7.5: Modelo de diagrama de bloques del amplificador operacional explicitando sus 4 entradas y la transferencia a la salida.

propaga los potenciales presentes en ellas hasta la salida $V_{o}$. Las señales $V_{i+} \mathrm{y}$ $V_{i-}$ se acostumbran transformar en modo común y diferencial previo a establecer las ganancias. Resulta el diagrama de la figura 7.5

Sackinger et al., 1991 sostienen que las ganancias en este modelo del amplificador operacional son co-dependientes, y se tiene, dada una impedancia de carga mucho mayor a la impedancia de salida del AO:

$$
G_{c}+G_{p s-}+G_{p s+} \approx 1
$$

Recordando que CMRR $=A_{o l} / G_{c}, \mathrm{PSSR}_{-}=A_{o l} / G_{p s-} \mathrm{y}^{\mathrm{PSSR}_{+}}=A_{o l} / G_{p s+}$ la misma expresión puede reescribirse de forma explícita para las curvas habituales de los AOs:

$$
\frac{1}{C M R R}+\frac{1}{P S R R_{-}}+\frac{1}{P S R R_{+}} \approx \frac{1}{A_{o l}}
$$

Esta relación permite realizar una aproximación para modelar en forma sencilla al AO considerando sus múltiples entradas: si dos de las ganancias son despreciables frente a una tercera en la ecuación 7.12, la transferencia resulta aproximadamente igual a 1 para esa ganancia y 0 para las restantes. El caso 


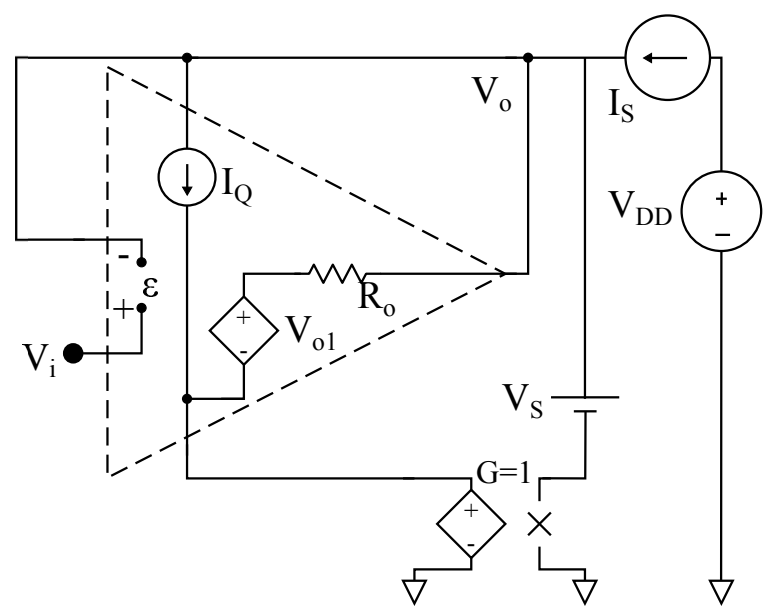

(a)

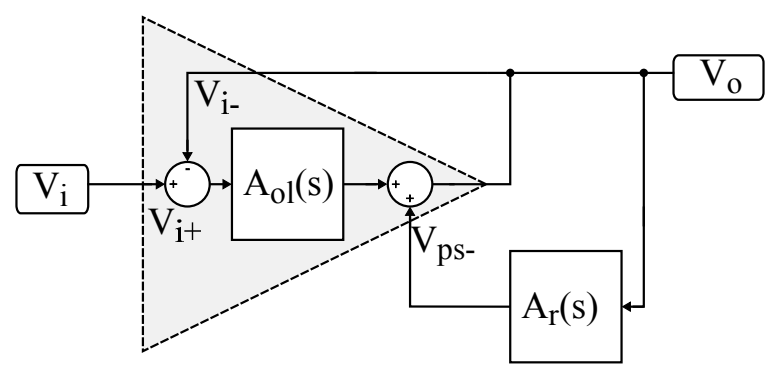

(b)

Figura 7.6: Modelo circuital (a) y de bloques (b) donde se ha aproximado $G_{p s-} \approx 1$. En el diagrama de bloques además se reconoce que la transferencia entre la salida y el bootstrap negativo incluirá una dinámica $A_{r}(s)$.

de un amplificador operacional real, el OPA333, se analiza en el apéndice B y muestra que la transferencia entre la entrada $V_{p s}$ y la salida es 1 en un rango de frecuencias que corresponde a las de interés. Esto permite obtener un modelo sencillo para el circuito de la figura 7.4, que se muestra en la figura 7.6. En este esquema la ganancia del modo común a la salida y de la fuente positiva se han despreciado y se ha asignado una ganancia $G_{p s-}=1$. El modelo en su forma de diagrama de bloques en la figura 7.6(b) representa la transferencia entre la salida del electrodo y el bootstrap negativo por una transferencia $A_{r}(s)$.

El diagrama de bloques de la figura 7.6(b) revela que el bootstrap ha creado un lazo de realimentación positiva en la rama de transferencia directa de la realimentación negativa del $\mathrm{AO}$, resultando por tanto la ecuación de lazo cerrado:

$$
\frac{V_{o}}{V_{i}}=\frac{A_{o l} \frac{1}{1-A_{r}}}{1+A_{o l} \frac{1}{1-A_{r}}}
$$

La ecuación característica del lazo es entonces:

$$
G H=A_{o l}(s) \frac{1}{1-A_{r}(s)}
$$

La ecuación 7.14 es fundamental para el diseño de un circuito práctico. $A_{r}$ debe ser idealmente igual a 1 para que el bootstrap negativo copie la tensión de 


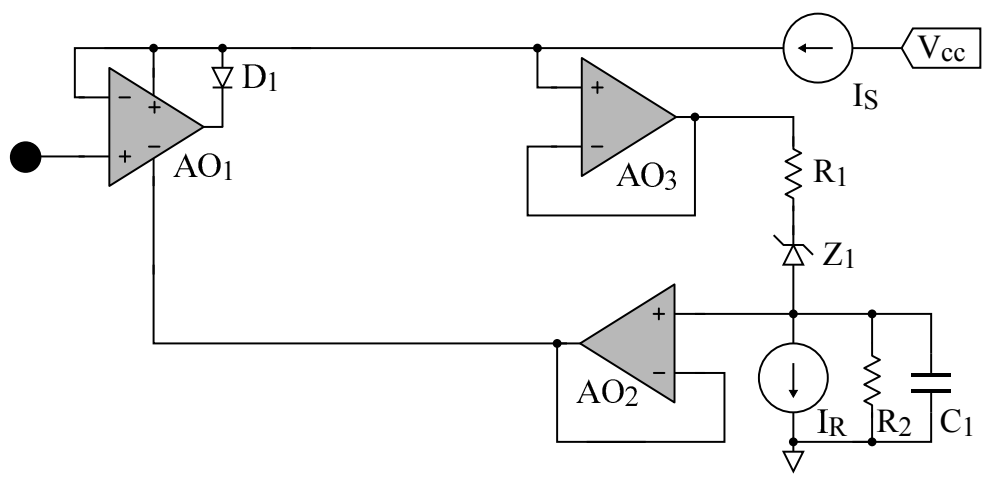

Figura 7.7: Diagrama del circuito práctico de bootstrap con dos hilos que implementa la topología propuesta.

entrada y cumpla su función de reducir la impedancia de entrada del electrodo. Pero $A_{r}$ no puede ser igual a 1 porque el circuito resultaría inestable. Es necesario entonces que se cumpla:

$$
\alpha<1
$$

y debe encontrarse entonces una relación de compromiso con $\alpha$ suficientemente buena para el aumento de impedancia necesario, que no comprometa la estabilidad.

Es conveniente expresar la dinámica de la transferencia del bootstrap negativo con su ganancia de continua separada, debido a su dependencia con el factor escalar $\alpha$ :

$$
A_{r}(s)=A_{r 0} A_{r, a . c .}(s)=\frac{1}{1-\alpha} A_{r, a . c .}(s)
$$

La ganancia $A_{r 0}$ será mayor a uno y aumentará cuanto más se acerque $\alpha$ a 1 . Esto tiene un impacto importante en la ecuación característica 7.15 ya que la ganancia de lazo abierto del AO está en general compensada para ser estable en realimentación unitaria con un escaso margen de ganancia. Por lo tanto, si se adiciona la ganancia $A_{r 0}$, deberá diseñarse $A_{r, a . c .}$ como un compensador apropiado para asegurar la estabilidad del lazo.

\subsubsection{Circuito práctico}

Las consideraciones de la sección anterior permiten obtener y comprender un circuito práctico a partir del circuito conceptual de la figura 7.4. En la figura 7.7 se observa un esquema que constituye una implementación directa del electrodo propuesto. A continuación se enumera el rol de cada componente.

(1) La fuente de corriente $I_{s}$ y el amplificador operacional $A O_{1}$ cumplen la misma función que sus contrapartes ideales. Sin embargo, la fuente $I_{S}$ requiere una tensión mínima de operación (denominada compliancia) en el orden de $1 \mathrm{~V}$, que limita el rango de excursión de $V_{o}$ por debajo de $V_{D D}$. Al mismo tiempo, $A O_{1}$ debe cumplir una serie de características que se describirán más adelante.

(2) El diodo $D_{1}$ cumple la función de alejar el potencial de la salida de $A O_{1}$ de la alimentación. Si bien existen operacionales que son rail-to-rail a la salida, al operar cerca del rango de decenas de $\mathrm{mV}$ de la alimentación aumentan la corriente e impedancia de salida. Por lo tanto, mediante $D_{1}$ se adiciona un 
offset entre la salida del AO y $V_{o}$ para disminuir el consumo, la resistencia de salida, y evitar modulaciones no contempladas en el modelo simplificado. Como consecuencia, deberá asignarse una corriente $I_{S}$ suficiente para polarizar el diodo.

(3) La referencia flotante de tensión $Z_{1}$ introduce el offset necesario de tensión para satisfacer la alimentación de $A O_{1}$. El componente necesita que se mantenga una corriente mínima para operar en una zona de tensión constante, por lo que se introduce la fuente de corriente $I_{R}$. Esta fuente, de la misma manera que $I_{S}$ limita el rango de excursión positivo, limita el rango de excursión de $V_{p s-}$ y por lo tanto de $V_{o}$ ya que debe asegurarse su compliancia.

(4) Las resistencias $R_{1}$ y $R_{2}$ fijan una atenuación entre $V_{o}$ y $V_{p s-}$, es decir, establecen el valor de $\alpha$ (ecuación 7.16). $R_{1}$ está en serie con la resistencia serie de $Z_{1}$ mientras que $R_{2}$ está en paralelo con la resistencia paralela de $I_{R}$, por lo que serán las resistencias dominantes en ambos casos.

(5) $\mathrm{El}$ amplificador operacional $A \mathrm{O}_{2}$ implementa la fuente de tensión controlada que permite fijar el potencial $V_{p s-} \mathrm{y}$ al mismo tiempo da un camino de retorno para la corriente $I_{S}$.

(6) El capacitor $C_{1}$ junto con la resistencia $R_{1}$ dan forma a la transferencia $A_{r}(s)$ imponiendo un polo que permite a la ecuación característica 7.15 cortar el eje de $0 \mathrm{~dB}$ con margen de fase suficiente para asegurar la estabilidad del sistema. Esta compensación se explicará en datalle más adelante.

(7) El amplificador operacional $A_{3}$ actúa como separador para evitar cargar a $A O_{1}$ con la baja impedancia que representan $R_{1}$ y $C_{1}$.

Los amplificadores operacionales modernos suelen incluir circuitos especiales que van mas allá del modelo sencillo que se considera en primera instancia. Una medida muy común es la inclusión de un circuito de protección contra descarga electrostática (protección ESD por sus siglas en inglés) en los pines de entrada del circuito. Un modelo para estos circuitos es el de diodos de protección. Cuando la tensión aplicada a un pin del AO excede las condiciones nominales de funcionamiento, los circuitos internos de ESD pueden entrar en conducción y cortocircuitar efectivamente dos puertos (Texas Instruments, 2016). Cuando $A O_{1}$ inicia su operación, la tensión de la entrada no inversora no está definida respecto a la de alimentación y puede polarizarse su diodo de protección. Por lo tanto $A O_{1}$ debe ser un amplificador operacional etiquetado como de protección ESD limitada o sin protección.

Más allá de esta condición especial, $A O_{1}$ debe cumplir con los requisitos deseables en un amplificador seguidor de electrodo activo: debe ser, principalmente, de bajo ruido, y de bajo consumo. Por otro lado, un sistema portable de bajo ruido tendrá en general una tensión de alimentación de $5 \mathrm{~V}$ o menor. El circuito propuesto necesita un margen de aproximadamente $1 \mathrm{~V}$ en su riel superior para la compliancia de la fuente $I_{S}$ y otro tanto en el inferior para la fuente $I_{R}$. De esa manera se permite alimentar a $A O_{1}$ y dejar un rango disponible para la excursión de la señal dentro de un margen de $3 \mathrm{~V}$. Dado que debe poder aplicarse un offset de $\pm 300 \mathrm{mV}$ a cualquier entrada diferencial, esto permite un rango para la alimentación de tan solo $2.7 \mathrm{~V}$ en el mejor caso.

Si bien el número de amplificadores operacionales que pueden alimentarse con tensiones tan bajas como $1.8 \mathrm{~V}$ es cada vez mayor, no existe una oferta amplia de aquellos que al mismo tiempo presentan muy bajo ruido a bajo costo. Aún sin este limitante, es deseable un rango de tensiones de la mayor amplitud posible para admitir artefactos sin saturar el sistema y el uso de materiales no convencionales para electrodos secos. Por lo tanto, se modificó la topología propuesta en la figura 7.7 utilizando el circuito de la figura 7.8 que coloca a la 


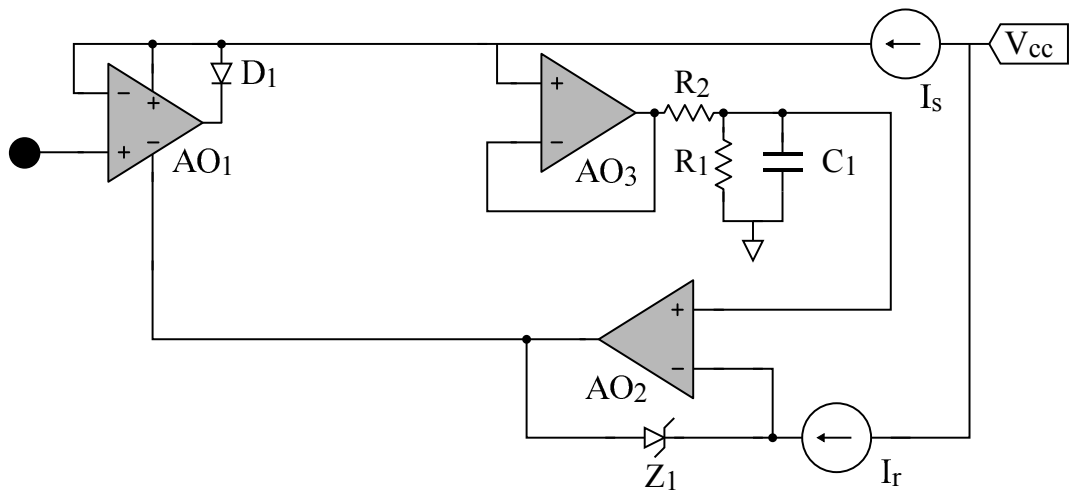

Figura 7.8: Alternativa al circuito de bootstrap de la figura 7.7 para permitir una excursión de la alimentación negativa hasta $0 \mathrm{~V}$.

fuente de corriente $I_{R}$ del lado del riel positivo, permitiendo una excursión de $V_{p s-}$ hasta $0 \mathrm{~V}$.

Debe notarse que la atenuación para programar $\alpha$ y el polo de compensación han sido separados del circuito que impone el offset de continua.

El circuito de la figura 7.8 sin embargo tiene una desventaja, la fuente de tensión de referencia $Z_{1}$ debe ser de muy buena calidad ya que su tensión de ruido no puede ser filtrada (no puede establecerse un camino de baja impedancia para derivar corriente a masa sin alterar la transferencia $A_{r}$ ). Por lo tanto este circuito exigiría una fuente especial por cada canal. Por otro lado, la capacidad parásita paralela de la fuente de corriente $I_{R}$ modifica notablemente la transferencia $A_{R}$.

Una alternativa que logra el propósito original de este circuito sin los inconvenientes mencionados se presenta en la figura 7.9. En esta implementación, el offset necesario se logra utilizando la referencia de bajo ruido general del sistema de medida, $V_{r e f}$. La ecuación del circuito de $\mathrm{AO}_{2}$ realimentado es:

$$
V_{p s-}=V_{o, O A 3}=V_{1}\left(1+\frac{R_{4}}{R_{3}}\right)-V_{\text {ref }} \frac{R_{4}}{R_{3}}
$$

Para poder escalar la tensión $V_{\text {ref }}$ se establece una relación entre $R_{4}$ y $R_{3}$ que amplificará $V_{1}$. Esta ganancia debe tenerse en cuenta al configurar los valores de $R_{1}$ y $R_{2}$ que deben atenuar no sólo en un factor $\alpha$ sino $\alpha /\left(1+R_{4} / R_{3}\right)$.

El procedimiento de diseño puede estipularse como sigue:

1. Fijar la constante de tiempo de $C_{1}\left(R_{1} \| R_{2}\right)$ según los requisitos de estabilidad. Puede estimarse para una primera aproximación $R_{1} \approx R_{2}$ ya que las ganancias necesarias son cercanas a 1 .

2. Ajustar la relación entre $R_{3}$ y $R_{4}$ para obtener la tensión de alimentación necesaria a partir de $V_{\text {ref }}$.

3. Ajustar la relación entre $R_{1}$ y $R_{2}$ para programar el valor deseado de $\alpha$.

\subsubsection{Análisis de estabilidad}

Como muestra la ecuación 7.15, la transferencia de lazo abierto $A_{o l}(s)$ del AO del electrodo queda multiplicada por la transferencia $A_{r}(s)$.

La curva 1 de la figura 7.10 muestra la transferencia $A_{o l}(s)$ para un amplificador operacional (OPA333) con ganancia de continua de $130 \mathrm{~dB}$ y producto 


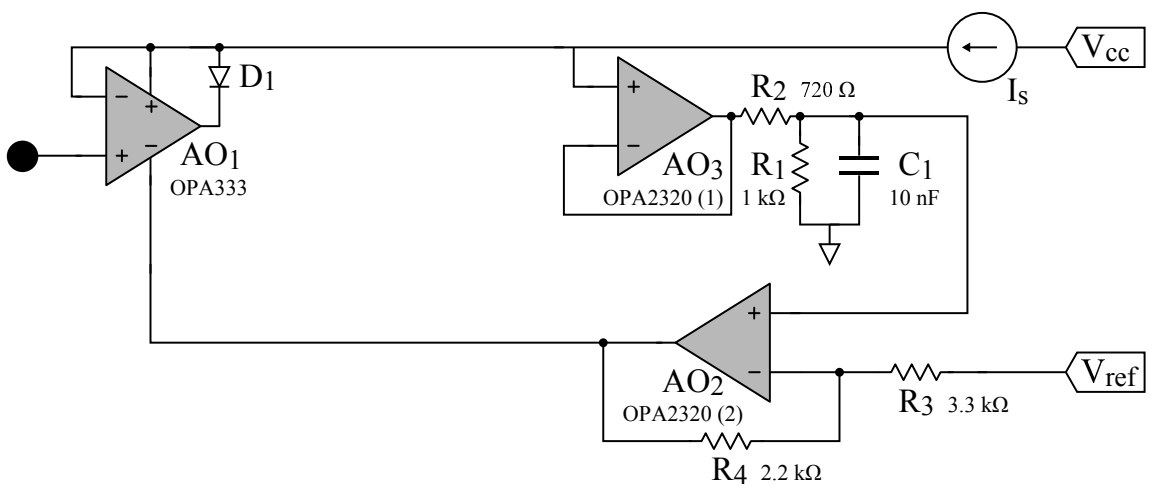

Figura 7.9: El diseño en 7.8 requiere una fuente de tensión de alta calidad por cada canal, la versión modificada utiliza un sumador para tomar ventaja de la fuente de referencia con que ya cuenta el sistema de medida.

ganancia por ancho de banda de $350 \mathrm{kHz}$. El AO está diseñado para ser estable con realimentación negativa unitaria y por lo tanto su polo dominante asegura que cruce $0 \mathrm{~dB}$ con aproximadamente $45^{\circ}$ de margen de fase. Luego de este cruce, aparecen los polos de alta frecuencia del AO.

El circuito de bootstrap copia la tensión de salida con una constante de proporcionalidad $\alpha$ muy cercana a 1 . Despreciando la dinámica de este circuito, esa constante en realimentación negativa da lugar a una ganancia que multiplica a $A_{o l}(s)$ :

$$
G H=A_{o l}(s) \frac{1}{1-A_{r}}=A_{o l}(s) \frac{1}{1-\alpha}=A_{o l}(s) \gamma
$$

Esta ganancia tiene el efecto de elevar la curva de magnitud, resultando en la curva 2 de la figura 7.10. El circuito de lazo cerrado en este caso sería claramente inestable ya que margen de ganancia es positivo.

Por lo tanto, la dinámica del circuito de bootstrap negativo debe implementar una compensación tal que permita mantener un $\alpha$ cercano a la unidad en el ancho de banda donde interesa mantener una impedancia elevada (el de las señales de biopotencial, aproximadamente por debajo de $1 \mathrm{kHz}$ ), y al mismo tiempo debe garantizar la estabilidad del sistema. Intuitivamente, eso podría lograrse eliminando aquello que inestabilizó el sistema, el bootstrap, a altas frecuencias; es decir que debe disminuirse $\alpha$ a medida que aumenta la frecuencia lo cual se logra fácilmente con un capacitor en paralelo con la resistencia $R_{2}$ del par atenuador $R_{1}, R_{2}$.

La transferencia resulta:

$$
\begin{aligned}
G H & =A_{o l}(s) \frac{1}{1-\alpha \frac{1}{s \tau_{r}+1}} \\
& =A_{o l}(s) \frac{1}{1-\alpha} \frac{s \tau_{r}+1}{s \frac{1}{1-\alpha} \tau_{r}+1} \\
& =A_{o l}(s) \gamma \frac{s \tau_{r}+1}{s \gamma \tau_{r}+1}
\end{aligned}
$$

Esta ecuación muestra la forma del compensador resultante: un compensador por retardo de fase que permite atenuar la ganancia $\gamma$ aportada en baja frecuencia permitiendo que la transferencia retome el comportamiento correspondiente a $A_{o l}$ en altas frecuencias como se muestra en la curva 3 de la figura 7.10. El 

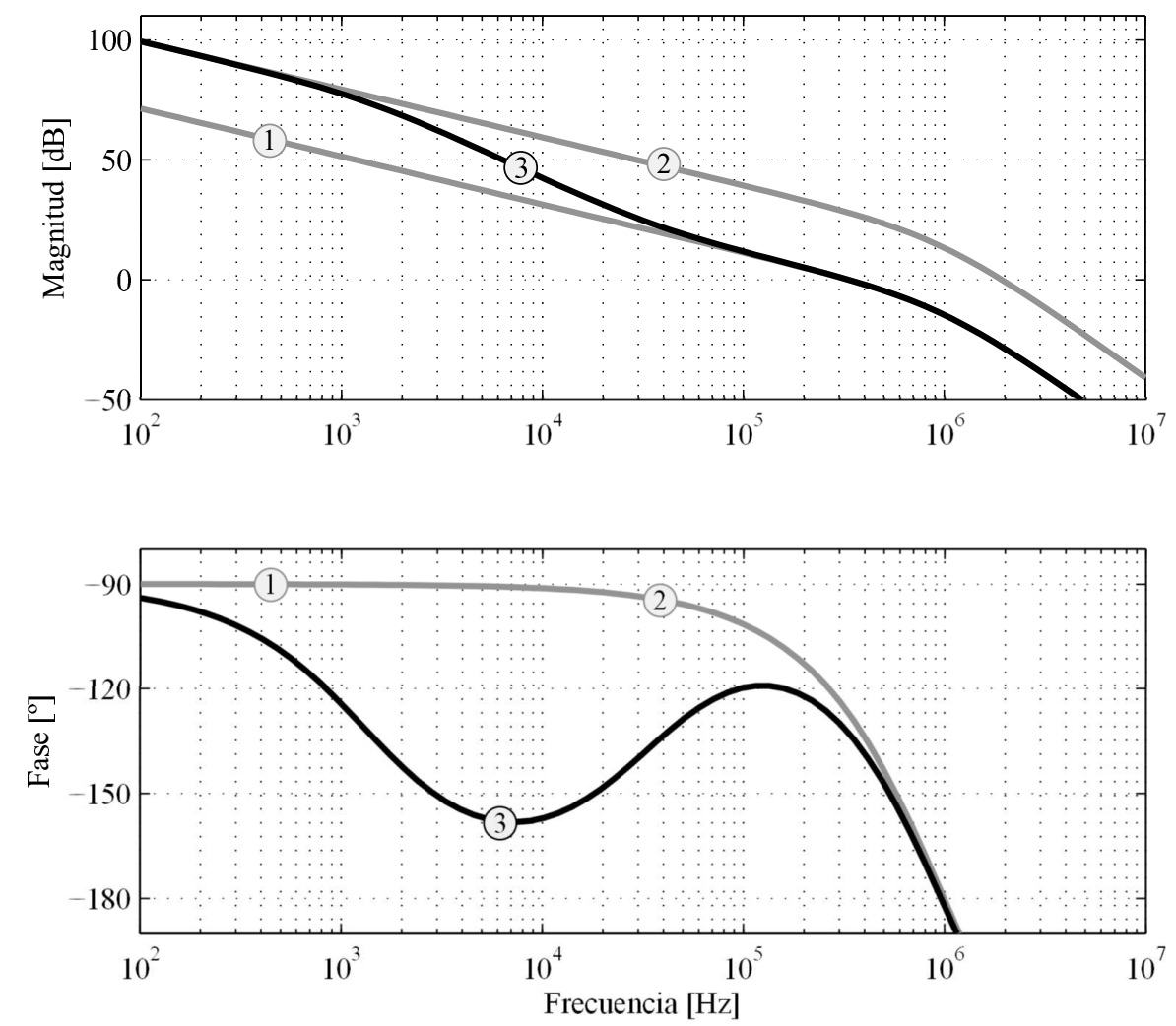

Figura 7.10: Diagramas de bode de la transferencia de lazo abierto del amplificador operacional del electrodo de dos hilos (curva 1), de la ecuación característica del lazo de bootstrap, que vuelve inestable al lazo (curva 2) y de la ecuación característica incluyendo la compensación que estabiliza el lazo (curva 3).

costo es que la fase se acerca a $180^{\circ}$ si el polo y el cero están muy separados, por lo cual $\gamma$ no puede ser demasiado elevado.

Las condiciones de estabilidad imponen un doble límite al bootstrap: se limita su ancho de banda de operación, y el valor máximo que puede alcanzar.

\subsubsection{Análisis de ruido}

Para analizar el ruido total del circuito propuesto se utilizó el modelo de la figura 7.11. Se distinguen los aportes de las fuentes de tensión y corriente equivalentes del $\mathrm{AO}$ del electrodo, $e_{n, A O 1}$ e $i_{n, A O 1}$; la fuente de corriente de ruido de la fuente $I_{S}$; y los aportes del circuito de bootstrap negativo que se han representado por una fuente equivalente de tensión de ruido $e_{n, B-}$. Se incorporó al modelo la resistencia de electrodo $R_{e}$ así como las resistencias dinámicas del diodo y de la fuente de corriente, $R_{D}$ y $R_{S}$. Las fuentes de ruido del diodo se despreciaron directamente por su bajo valor relativo a las demás contribuciones. Finalmente, se representa la etapa de salida y realimentación de $A O_{1}$ incluyendo la resistencia de salida $R_{o}$.

Utilizando este modelo puede obtenerse la tensión de ruido en el nodo de salida del electrodo $V_{o}$. El ruido debido a $A O_{1}$ resulta:

$$
v_{n 1}^{2}=e_{n, A O 1}^{2}+\left(i_{n, A O 1} R_{e}\right)^{2}
$$




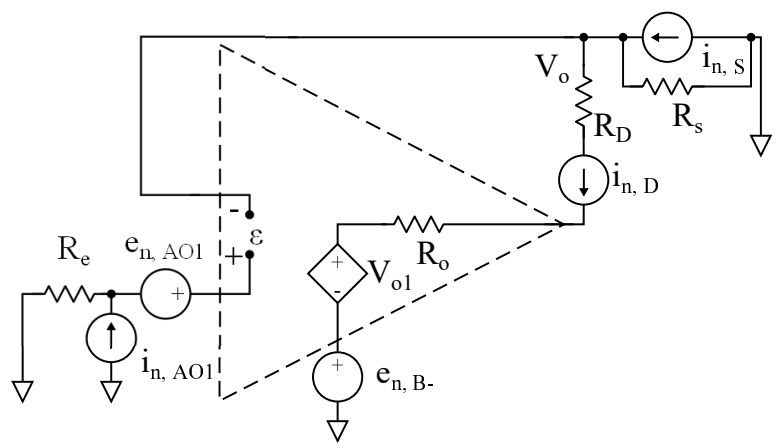

Figura 7.11: Modelo para el análisis de ruido del circuito propuesto. El aporte de las fuentes del circuito de bootstrap negativo se representaron por una fuente equivalente $e_{n, B-}$.

La ecuación 7.10 muestra que la salida del electrodo con la corriente $I_{s}$ aplicada dependerá de esta corriente y por lo tanto se tendrá sumada a la salida la tensión de ruido:

$$
v_{n 2}^{2}=i_{n, S}^{2}\left(R_{o}+R_{D}\right)^{2}
$$

Se utilizó el mismo criterio que en la sección anterior para determinar el efecto de la fuente de ruido del bootstrap negativo, interponiéndola directamente en serie con la salida del AO. La tensión de ruido que produce a la salida es por tanto:

$$
v_{n 3}=\frac{e_{n, B-}}{1+A_{o l}}
$$

La tensión de ruido total sobre el nodo de salida del electrodo resulta:

$$
\begin{aligned}
v_{n o}^{2} & =v_{n 1}^{2}+v_{n 2}^{2}+v_{n 3}^{2} \\
& =e_{n, A O 1}^{2}+\left(i_{n, A O 1} R_{e}\right)^{2}+i_{n, S}^{2}\left(R_{o}+R_{D}\right)^{2}+\left(\frac{e_{n, B-}}{1+A_{o l}}\right)^{2} \\
& \approx e_{n, A O 1}^{2}+\left(i_{n, A O 1} R_{e}\right)^{2}
\end{aligned}
$$

En la ecuación 7.23 se ha despreciado el ruido de aportado por la fuente de corriente por estar en el orden de la decena de pA sobre resistencias de a lo sumo algunos $\mathrm{k} \Omega$, y la tensión de ruido del circuito de bootstrap negativo ya que con ganancias de lazo abierto en el orden de los $100 \mathrm{~dB}$ y superiores, la tensión de ruido $e_{n, B}$ - debería estar en el orden de $\operatorname{los} 100 \mathrm{mV}_{\mathrm{rms}}$ para resultar significativa. En el apéndice $\mathrm{C}$ se calcula la tensión de ruido total y se muestra que está muy por debajo de ese orden. Finalmente, si bien podría despreciarse la corriente de ruido del AO, en algunos casos de impedancia de electrodo extremas podría contribuir al ruido total. Por ejemplo, una corrientes de ruido con densidad en el orden de $10 \mathrm{fA} / \sqrt{\mathrm{Hz}}$ en una resistencia de $10 \mathrm{M} \Omega$ generaría $2 \mu \mathrm{V}_{\text {rms }}$ en un ancho de banda de $450 \mathrm{~Hz}$.

La ecuación 7.23 muestra entonces que el ruido a la salida del electrodo propuesto provendrá de $O A_{1}$, y la contribución de los demás factores resulta despreciable. 


\subsection{Resultados}

\subsubsection{Implementación del circuito}

El circuito se implementó utilizando AOs OPA333 de Texas Instruments ya que satisfacen todos los requerimientos impuestos por la topología sobre $O A_{1}$ : es de tipo rail-to-rail, no tiene protección ESD, tiene un encapsulado pequeño de tipo SOT-25, y su tensión de operación mínima es de 1.8 V. Si bien la tensión de ruido es superior a otras alternativas, resulta atractiva su característica de no tener ruido $1 / f$ por lo que en las bajas frecuencias de los biopotenciales el ruido total resulta aceptable. El electrodo activo en si logra dimensiones y masa pequeñas ya que solo debe portar el amplificador operacional y el diodo, como se observa en la figura 7.12.

El sistema se implementó con una fuente simple de $5 \mathrm{~V}$. Para la fuente de corriente $I_{s}$ se utilizó un LM334, que tiene una compliancia mínima de $0.9 \mathrm{~V}$. Por lo tanto se seleccionó una referencia de $3.5 \mathrm{~V}$ para polarizar la entrada permitiendo una excursión de $0.6 \mathrm{~V}$ positiva y la selección de una tensión de alimentación de $2.5 \mathrm{~V}$ para $O A_{1}$ permitiendo una excursión negativa de $1 \mathrm{~V}$.

$\mathrm{AO}_{2}$ y $\mathrm{AO}_{3}$ se implementaron con un AO dual OPA2320 debido a su gran capacidad de corriente, alto ancho de banda y bajo ruido.

El circuito completo se dividió en PCBs separados: uno de dimensiones reducidas de 12 x $20 \mathrm{~mm}$ con $O A_{1}$ y $D_{1}$ y otro con el resto del circuito de bootstrap, incorporado al sistema de adquisición. De esa manera, los cables hasta el electrodo activo propiamente dicho sólo tienen dos conductores.

Dos electrodos con la topología propuesta se incorporaron a la plataforma de medida descripta en el capítulo 3, basada en ADS1299, que dispone de $5 \mathrm{~V}$ aislados para alimentar el electrodo. A su vez, se fabricó un par de electrodos activos basados en el mismo operacional OPA333, configurados como seguidores de tensión de ganancia unitaria y 3 cables, para realizar medidas comparativas.

Se evaluó el funcionamiento del bootstrap positivo y negativo y se comprobó el rango de offset admitible, que resultó de $-0.9 \mathrm{~V}$ a $0.6 \mathrm{~V}$ de acuerdo al diseño.

El parámetro $\alpha$ se diseñó para un valor:

$$
\alpha=\left(\frac{R_{1}}{R_{1}+R_{2}}\right)\left(1+\frac{R_{4}}{R_{3}}\right)=\left(\frac{1 \mathrm{k} \Omega}{1 \mathrm{k} \Omega+750 \Omega}\right)\left(1+\frac{2.2 \mathrm{k} \Omega}{3.3 \mathrm{k} \Omega}\right)=0,968
$$

Se verificó el valor del factor directamente a partir de la relación de amplitudes entre $V_{o}$ y $V_{p s-}$ al aplicar una onda senoidal a la entrada y resultó

$$
\alpha=0.97
$$

\subsubsection{Aumento de la impedancia de entrada}

La impedancia de entrada del AO utilizado para implementar el electrodo etá dada por una capacidad de entrada $C_{i}$ de $4 \mathrm{pF}$. En los AO con entrada FET la parte resistiva de la capacidad suele ser muy alta, en el orden de los $T \Omega$ y por lo tanto no suele incluirse como dato.

Esta simplificación puede utilizarse para medir la impedancia de entrada fácilmente interponiendo una resistencia de medida $R_{m}$ conocida en la entrada. De esa manera la transferencia de la etapa de entrada resulta simplemente $1 /\left(s C_{i} R_{m}+1\right)$. La fase entre una sinusoide de frecuencia $f_{m}$ aplicada a la entrada y la que resulte a la salida será $\varphi=\tan \left(2 \pi C_{i} R_{m} f_{m}\right)$.

Se inyectó una señal sinusoidal a través de una resistencia de $1 \mathrm{G} \Omega$ a la entrada del electrodo y se midió la fase relativa entrada-salida a partir de la 


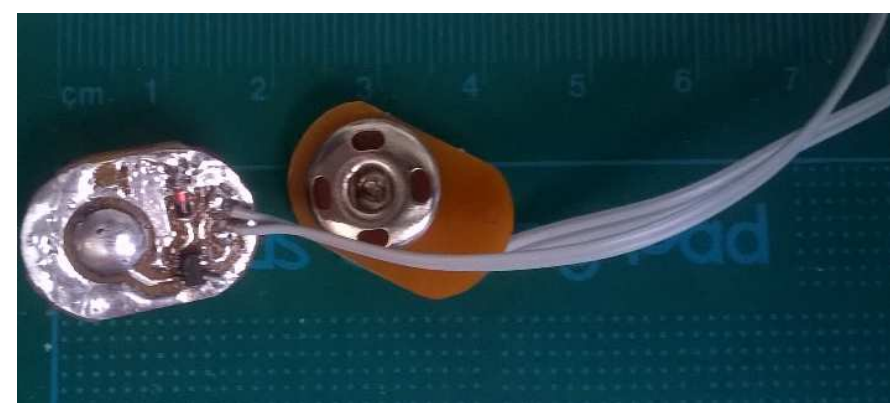

Figura 7.12: Electrodos activos. El circuito de bootstrap se implementa en PCBs separados, del lado del equipo de adquisición. Los cables de dos hilos se extienden hacia el electrodo activo en sí, de dimensiones reducidas.

captura simultánea de estas señales con un osciloscopio, para luego despejar la capacidad de entrada. La compensación del circuito degenera el bootstrap a frecuencias mayores a $1 \mathrm{kHz}$, mientras que el desfasaje resulta muy pequeño en frecuencias bajas. Por lo tanto se relevaron los valores de desfasaje entre $100 \mathrm{y}$ $500 \mathrm{~Hz}$.

El resultado fue

$$
C_{i}=71 \pm 4 \mathrm{fF}
$$

Comparando con el valor dado en la hoja de datos del OPA333 para $C_{i}$, resulta en una mejora de 56.3 veces o un factor $\alpha=0.98$. Por lo tanto se da una muy buena concordancia entre la reducción obtenida y la predicha por la ecuación 7.6 del bootstrap, validando la operación de este circuito.

$\mathrm{El}$ factor $\alpha$ es levemente mejor que el observado en la relación entre $V_{o}$ y $V_{p s-}$ en la ecuación 7.25 debido a que parte de la capacidad de entrada se refiere al riel positivo de alimentación, donde el boostrap es más cercano a 1 en varios órdenes de magnitud.

\subsubsection{Tensión de ruido}

Se midió la tensión de ruido del electrodo propuesto conectando la entrada a una tensión de referencia y la salida a la entrada no inversora de un canal diferencial con la entrada inversora a la misma tensión de referencia. Se midió al mismo tiempo el ruido de otro canal del mismo equipo cortocircuitado para desafectarlo de la medida.

La tensión de ruido referida a la entrada del electrodo resultó:

- $670 \mathrm{nV}_{\mathrm{rms}}$ en el ancho de banda de EEG (0.01-70 Hz)

- $2.03 \mu \mathrm{V}_{\text {rms }}$ en el ancho de banda de EMG (10-450 Hz)

- Densidad espectral de ruido de $92 \pm 17 \mathrm{nV}_{\mathrm{rms}}$

En la figura 7.13 se examina la amplitud espectral de la tensión de ruido medida. En linea negra se observa correspondiente al electrodo propuesto y en línea gris a un electrodo activo implementado con el el mismo amplificador operacional configurado como seguidor de tensión. Las amplitudes son iguales, confirmando que las contribuciones de ruido de los demás elementos del circuito de bootstrap no aportan ruido significativo a la salida.

Los niveles de ruido resultantes dentro del ancho de banda del EEG y EMG resultaron apropiados para esas señales de biopotencial. 


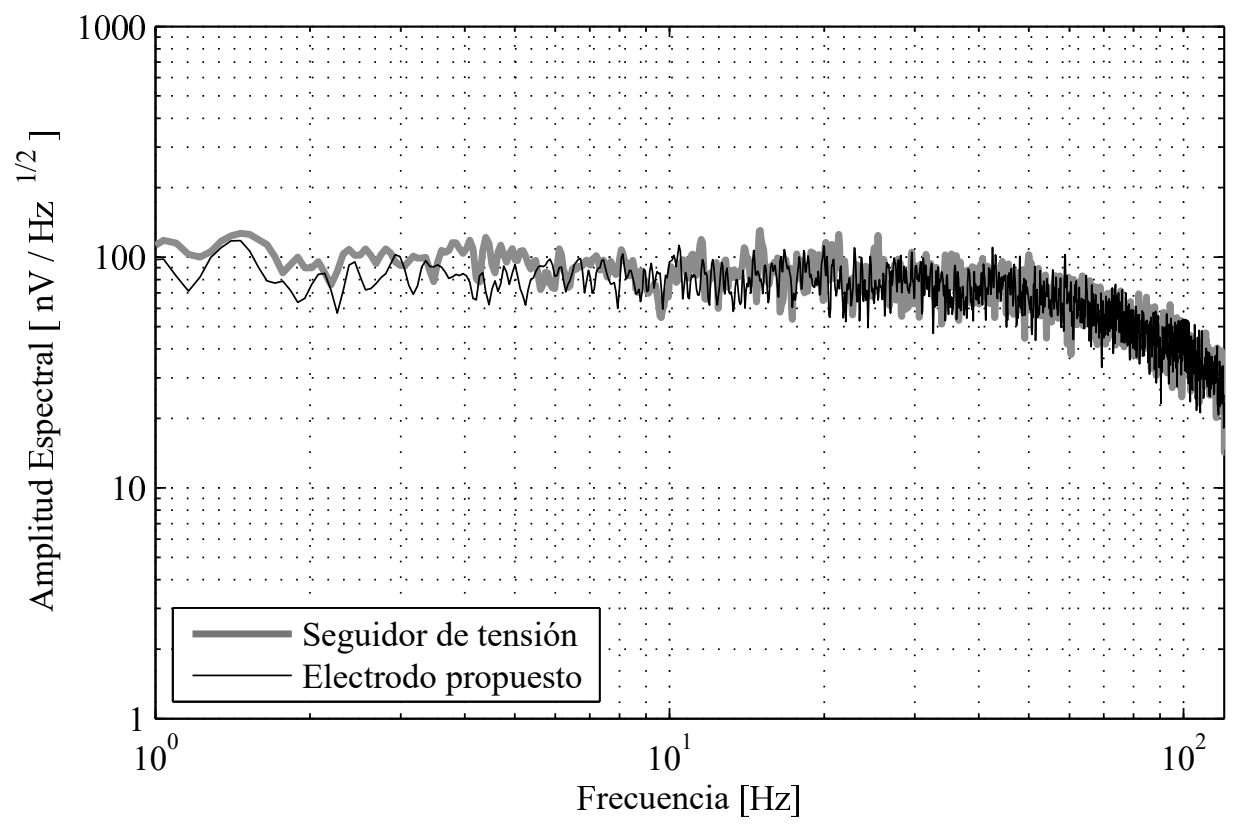

Figura 7.13: Amplitud espectral de ruido del electodo propuesto (en negro). Se compara con la de un electrodo activo implementado con el mismo amplificador operacional en configuración de seguidor de tensión (curva gris).

\subsubsection{Uso en sistema de adquisición para NPV}

Los electrodos activos fabricados se incorporaron al sistema de adquisición de bipotenciales desarrollado en el capítulo 4 (implementación II ). Se utilizó la alimentación de fuente simple de $5 \mathrm{~V}$ del equipo, mientras que se adicionó una fuente de referencia de bajo ruido con la tensión apropiada para los AEs, de $3.5 \mathrm{~V}$. La salida $V_{o}$ de los electrodos se conectó al la entrada no inversora de sendos canales, y la entrada no inversora se conectó a la referencia para realizar medidas single-ended. La misma referencia se envió al circuito de DRL independiente. La figura 7.14 muestra el conexionado completo de los dos electrodos al equipo.

Se midió simultáneamente una onda senoidal de $50 \mathrm{~Hz}$ con ambos electrodos y se obtuvo digitalmente el modo común y modo diferencial. Si bien el CMRR resultante en estas condiciones será menor que en el caso de conectar los dos electrodos a un único canal completamente diferencial, representa la topología que se usará con más frecuencia. El rechazo de modo común con este conexionado resultó de $84 \mathrm{~dB}$.

Aún con este rechazo de modo común relativamente bajo alcanzado con ele prototipo con dos canales single-ended, la baja capacitad de entrada de $70 \mathrm{fF}$ de los electrodos permite un efecto divisor de potencial con desbalances entre electrodos de hasta $720 \mathrm{k} \Omega$ sin que se degrade en más de $3 \mathrm{~dB}$ el CMRR total del sistema. En contraste, electrodos activos implementados con los mismos operacionales OPA333 como seguidores de tensión, con una capacidad de entrada de $4 \mathrm{pF}$, verían el CMRR del sistema reducido a $60 \mathrm{~dB}$ con el mismo desbalance de electrodos.

Finalmente, se comprobó la factibilidad de realizar medidas de EEG y EMG con el electrodo propuesto. 


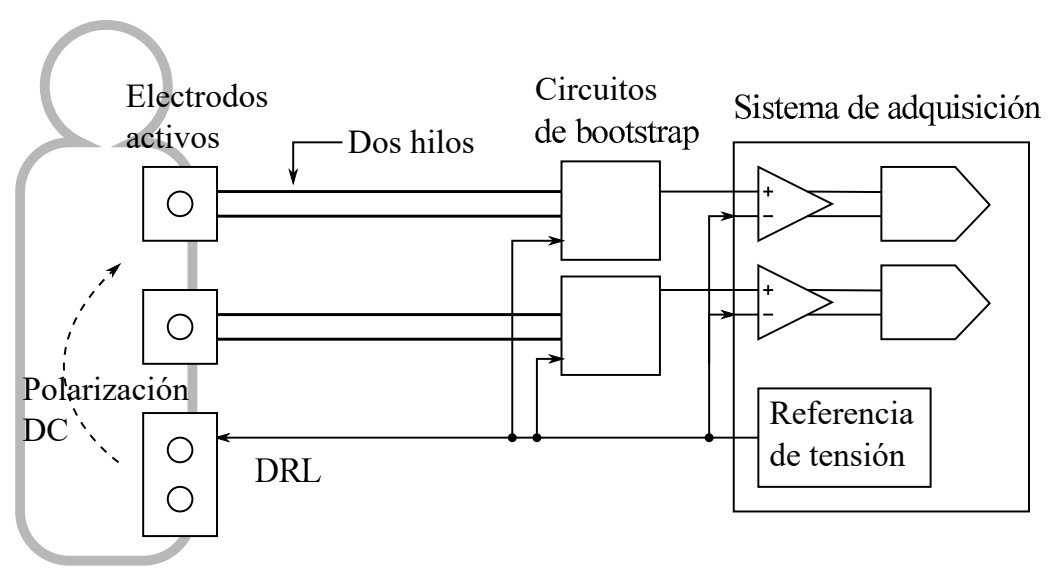

Figura 7.14: Incorporación del electrodo de dos hilos con bootstrap de fuente al sistema de adquisición.

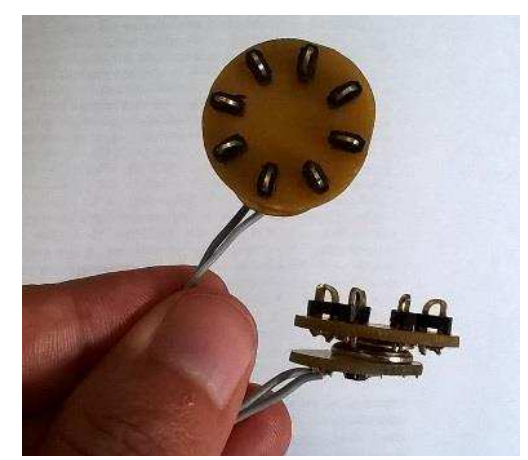

Figura 7.15: Electrodos secos para EEG.

Se utilizaron electrodos secos de EEG compuestos por 8 "dedos" con placas de contacto de $0.64 \mathrm{~mm} \times 1.5 \mathrm{~mm}$ (figura 7.15) Los electrodos se colocaron en la zona occipital de la cabeza, cerca de los puntos $\mathrm{O} 1$ y $\mathrm{O} 2$ del sistema de posicionamiento 10/20. Se fijaron en el lugar simplemente colocándolos debajo de una banda elástica, removiéndolos suavemente de lado a lado para asentarlos entre el cabello. El DRL se colocó sostenido por la misma banda elástica sobre el costado derecho de la frente. El equipo de adquisición se colocó colgando del cuello como anteriormente se indicó en la figura 4.12 (página 52).

Para las medidas de EMG se colocaron los electrodos en el antebrazo, cerca del codo en la reigión donde se ubican los músculos que mueven los dedos. Se utilizaron bandas de tela elástica para fijar los electrodos. El circuito de DRL independiente se colocó, también con una banda elástica, en la muñeca. Se realizaron contracciones del dedo índice y se probaron distintas distancias interelectródicas, como se muestra en la figura 7.17.

\subsection{Conclusiones}

La aplicación de neuroprótesis vestibles, fuera del laboratorio, exige al máximo la tecnología disponible para implementar electrodos activos robustos frente a interferencia y artefactos. 


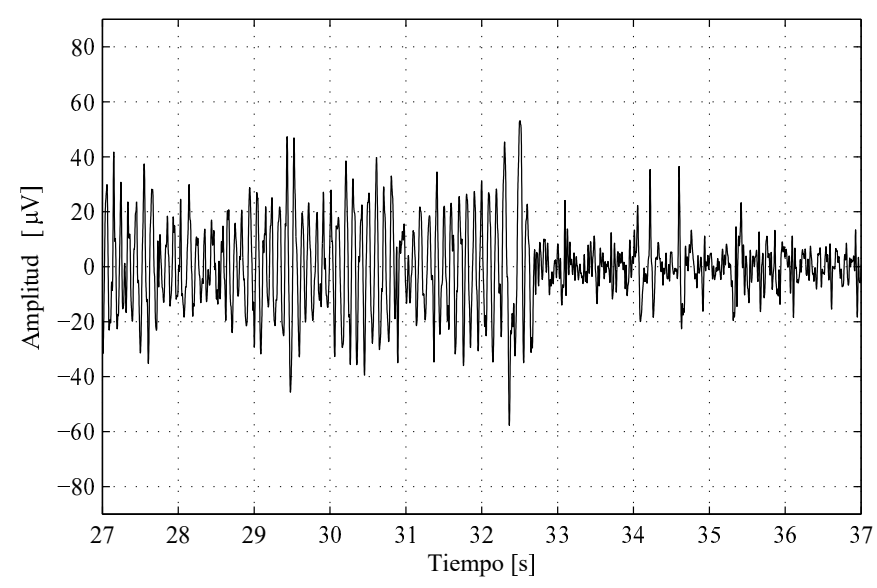

Figura 7.16: Medida diferencial de EEG con electrodos secos. Se observa un ritmo $\alpha$ hasta el segundo 32 apoximadamente, cuando el sujeto abrió los ojos.

En la literatura se buscan soluciones a este problema implementando electrodos activos de impedancia de entrada ultra-alta por medio de circuitos de componentes discretos, entre ellos la topología de bootstrap de fuente, que permite aumentar la impedancia de entrada a costa de aumentar la complejidad del sistema. A su vez, existen diseños de electrodos que sólo requieren dos hilos en su cable de conexión, para disminuir la incidencia de artefactos.

En este capítulo se presentó un electrodo activo que logra una impedancia de entrada muy baja de $71 \mathrm{fF}$. El diseño se basa en una topología que logra implementar un bootstrap de fuente de manera muy sencilla utilizando sólo un amplificador operacional dual adicional, una fuente de corriente y componentes pasivos, al mismo tiempo que logra mantener solo dos hilos de conexión entre el electrodo activo en sí y el sistema de adquisición.

Se comprobó la estabilidad de operación del electrodo y se midieron los parámetros de funcionamiento, estableciendo una relación de compromiso entre el margen de estabilidad y la impedancia de entrada lograda. Finalmente, se comprobó la factibilidad de medida de biopotenciales con el electrodo propuesto a través de la medida de señales de EEG y EMG con electrodos secos. 


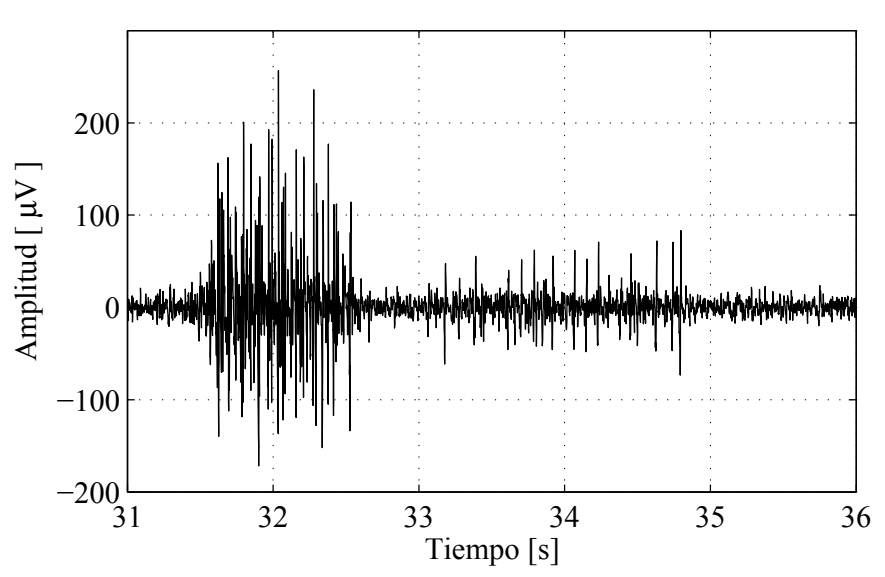

(a)

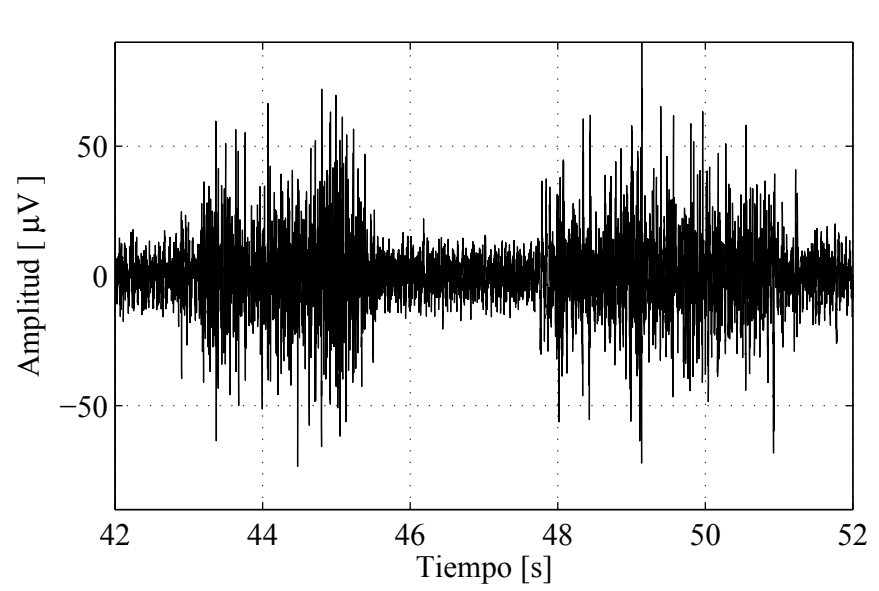

(b)

Figura 7.17: Señales de EMG capturada en el antebrazo utilizando dos electrodos con la topología propuesta. (a) Con una distancia inter-electródica de $4 \mathrm{~cm}$. Puede distinguirse una contracción completa del dedo índice seguida de un esfuerzo leve. (b) Con distancia de $1 \mathrm{~cm}$. Se observan contracciones completas del dedo índice. 


\section{Conclusiones}

La motivación de esta tesis fue el desarrollo de técnicas de instrumentación para Neuroprótesis Vestibles, dispositivos tecnológicos que intentan reemplazar o recuperar caminos de comunicación entre una persona y el mundo exterior por métodos no invasivos.

Se desarrollaron equipos de adquisición de biopotenciales en el estado del arte como plataforma de investigación, trabajo de base tecnológica que se difundió en congresos y en la colaboración en un capítulo de libro. A partir de esta base se desarrollaron los circuitos de acondicionamiento necesarios para adaptar los sistemas integrados de producción masiva a los requisitos y desafíos de robustez frente a interferencia de los dispositivos vestibles. Se trabajó sobre la mejora del circuito de DRL, electrodos activos multi-entrada de EMG, y el problema de la impedancia de entrada de los electrodos activos, realizando aportes originales en esas áreas. Este trabajo produjo tres publicaciones en revista y se difundió en congresos internacionales.

\section{Neuroprótesis vestibles}

Las neuroprótesis necesitan medir los biopotenciales relacionados con la voluntad de una persona, fundamentalmente el EMG y EEG. Para alcanzar su máximo potencial, deben hacerlo de la manera menos invasiva posible. Deben poder utilizarse con la misma simplicidad que una prenda de vestir, sin asistencia profesional. Gran parte de la responsabilidad para permitir esto recae sobre la instrumentación: debe permitir medir con electrodos de tipo seco colocados sin preparación y sin asistencia profesional, manteniendo una alta relación señal a ruido en todo momento para no perturbar los algoritmos de detección automáticos. Esto implica mantener un alto rechazo a interferencia electromagnética y a artefactos en forma robusta y confiable.

Esa tarea debe realizarse cumpliendo restricciones de acuerdo con el paradigma de los dispositivos vestibles, es decir bajo tamaño y peso, y bajo consumo. A estos ítems puede agregarse un requisito: bajo costo de insumos y fácil mantenimiento. El fin del desarrollo de las neuroprótesis vestibles es que los usuarios puedan disponer de ellas con total independencia y en forma amena, en ese sentido, que sea un dispositivo de menor costo y con partes fácilmente reemplazables da tranquilidad al usuario al mismo tiempo que quita una barrera de acceso. Por ese motivo una vertiente de la investigación en 
este tema debe abordar soluciones factibles de ser obtenidas con componentes comerciales, lo más cercanos a dispositivos de propósito general posible. La coyuntura tecnológica actual permite que esto sea posible, ya que la industria de semiconductores ha incorporado dentro de los dispositivos de producción masiva amplificadores operacionales de bajo ruido y altas prestaciones, y sistemas de adquisición integrados que incluyen convertidores analógico digitales de alto rango dinámico.

\section{Adquisición basada en ASSPs}

Es ese contexto, se analizó como paradigma de adquisición orientado a neuroprótesis vestibles el uso de front-ends integrados con convertidores $\Sigma-\Delta$ como núcleo del sistema de medida. Sin embargo, y como razón de ser de esta tesis, los desafíos particulares que proponen los electrodos secos y las condiciones agresivas de interferencia y artefactos en entornos no controlados, hacen necesario que se complemente estos sistemas con circuitos de acondicionamiento analógico para lograr la robustez necesaria. Por lo tanto, electrodos activos deben adaptar impedancias para entregar las señales a los convertidores de alto rango dinámico, y un circuito de DRL debe disminuir activamente el potencial de modo común que de otra manera accede al sistema como interferencia por el efecto divisor de potencial. Este acondicionamiento puede adaptarse a distintas medidas y resolver los desafíos de instrumentación propuestos.

Se implementó un equipo de adquisición siguiendo este paradigma, cuya utilidad y capacidades se demostraron al utilizarlo en el transcurso del trabajo de tesis para medidas de sEMG y EEG con electrodos secos de distintos tipos, y con una modularidadad que permite transferirlo a dispositivos portables sin modificar más que su fuente de energía. Este equipo demostró la utilidad de los productos estándar de aplicación específica o ASSPs, tanto por el circuito integrado de adquisición como por el integrado de aislación de grado médico utilizado.

\section{Circuito de DRL}

Para elevar la robustez frente a interferencia, se trabajó en la mejora del circuito de DRL. Este módulo se utiliza siguiendo el diseño tradicional, mientras que la interferencia electromagnética y las necesidades de los equipos han evolucionado. La necesidad de potenciar el rechazo a interferencia se manifiesta en las etapas de anulación de interferencia en los algoritmos de detección automáticos que no solo deben destinar recursos a solucionarlo, sino que pierden información al hacerlo.

La gran incertidumbre de los parámetros del modelo de interferencia contribuye a la práctica conservadora de mantener compensación tradicional para el circuito DRL. Por lo tanto, se diseñó una compensación alternativa que respeta los mismos criterios de estabilidad, pero aumenta el rechazo en todas las frecuencias de operación. Esta ganancia se produce sólo modificando los componentes pasivos del circuito.

\section{Electrodos activos de EMG}

En el caso de las medidas de EMG, los electrodos activos toman un rol preponderante porque los contactos de medida son en muchos casos secos y de área reducida, sobre todo al utilizar electrodos de múltiples contactos que 
implementan filtros espaciales. Los amplificadores para electrodos activos de múltiples contactos necesitan un análisis especial que se presentó en esta tesis: la descomposición de la señal en modos que den cuenta del espacio de señales completo, identificando las fuentes independientes de señal. Al mismo tiempo, los estrictos requisitos de los sistemas vestibles requieren superar los diseños basados en topologías de amplificadores de instrumentación y especializarlos para obtener electrodos de menor costo y consumo de energía. Se presentó un paso en esta dirección proponiendo un amplificador doble diferencial de sencilla implementaicón con un bajo número de componentes comparado con la implementación tradicional, que además cuenta con impedancias de entrada balanceadas.

\section{Impedancia de entrada}

En cualquier implementación basada en componentes comerciales, que son las buscadas en esta tesis, existirá una limitación tecnológica debido a las etapas de entrada de los amplificadores operacionales. Se mostró cómo aún los mejores amplificadores de bajo ruido tienen capacidades de entrada que no son suficientemente pequeñas para afrontar impedancias de electrodo elevadas sin perjudicar su rechazo a interferencia. Por otro lado se introdujo el problema de los artefactos y su solución en base al aporte que la instrumentación puede hacer a los aspectos mecánicos de los electrodos. Se presentó un método de sencilla implementación que permite aumentar la capacidad de entrada, pero ademas permite comunicar al electrodo activo con el equipo de adquisición a través de solo dos cables, favoreciendo una mayor flexibilidad fundamental para reducir los artefactos.

\section{Producido de la tesis}

\section{Artículos en revistas}

F. N. Guerrero y E.M. Spinelli, "High gain driven right leg circuit for dry electrode systems.," Medical Engineering \& Physics, vol. 39, pp. 117-122, Jan. 2017.

F. N. Guerrero, E. M. Spinelli y M. A. Haberman, "Analysis and Simple Circuit Design of Double Differential EMG Active Electrode," IEEE Transactions on Biomedical Circuits and Systems, vol. 10, no. 3, pp. 787-795, 2016.

F. N. Guerrero, M. Haberman y E.M. Spinelli, "Sistema multicanal para adquisición de biopotenciales," Revista Ingeniería Biomédica, vol. 8, no. 15, pp. 18-26, 2014.

\section{Capítulos de libros}

E. M. Spinelli y F. N. Guerrero, "Chapter 12 - The Biological Amplifier," en Further understanding of the human machine: The road to Bioengineering, 1era ed., M. E. Valentinuzzi, Ed. New Jersey: World Scientific Publishing Co. Pte. Ltd, 2017, pp. 463-500.

\section{Artículos en congresos internacionales}

F.N. Guerrero, P.A. García y E.M. Spinelli. "Signal modes for design-oriented analysis of active sEMG spatial filter electrodes," en Proc. VII Latin American Congress on Biomedical Engineeering CLAIB 2016, Bucaramanga, Colombia. 
F. N. Guerrero y E.M. Spinelli, "Surface EMG Multichannel Measurements Using Active, Dry Branched Electrodes," en Proc. VI Latin American Congress on Biomedical Engineering CLAIB 2014, Paraná, Argentina.

Artículos en congresos nacionales

F.N. Guerrero y E.M. Spinelli. "Driven right leg circuit compensation for improved common mode interference rejection," XX Congreso Argentino de Bioingeniería SABI 2015, San Nicolás de Los Arroyos, Argentina.

F.N.Guerrero, M.A. Haberman y E.M. Spinelli. "Configurable multichannel biopotential acquisition system for resarch applications," XIX Congreso Argentino de Bioingeniería SABI 2013, Tucumán, Argentina.

F.N. Guerrero. "Sistema modular de adquisición de biopotenciales con conexión USB," XVIII Congreso Argentino de Bioingeniería SABI 2011, Mar del Plata, Argentina.

\section{Trabajo futuro}

A partir de los aportes de esta tesis emergen las siguientes líneas de trabajo a futuro:

- Profundizar las mejoras que la teoría de control puede aportar al lazo de DRL, en particular su diseño bajo el paradigma de Control Robusto.

- Extender el trabajo de análisis de topologías de filtros espaciales para sEMG a diversas implementaciones.

- Evaluar la posibilidad de adaptar los electrodos de dos hilos con bootstrap de fuente a topologías multi-contacto. 


\section{Modos de señal en electrodos}

\section{normal-doble-diferenciales}

En el capítulo 6 se trató el electrodo con topología de filtrado espacial doble diferencial.

Otra configuración de filtro espacial suficientemente sencilla para ser implementada en un electrodo independiente es la llamada normal doble diferencial $(N D D)$, que depende de 5 contactos. El sistema Delsys dEMG por ejemplo incluye electrodos activos NDD.

El electrodo NDD se muestra en la figura 6.1 (página 64). Tiene 5 entradas:

$$
\overrightarrow{v_{i}}=\left[\begin{array}{lllll}
V_{a 1} & V_{a 2} & V_{b} & V_{c 1} & V_{c 2}
\end{array}\right]^{T}
$$

y su salida presenta la siguiente ecuación:

$$
V_{N D D}=\left(V_{a 1}+V_{a 2}\right)-4 V_{b}+\left(V_{c 1}+V_{c 2}\right)
$$

Análogamente al caso de un amplificador para electrodos DD, interesa definir los modos útiles para el análisis del electrodo NDD. Se define un primer modo normal doble diferencial (MNDD), y un modo común:

$$
\left[\begin{array}{c}
V_{\mathrm{MNDD}} \\
V_{\mathrm{MC}}
\end{array}\right]=\left[\begin{array}{ccccc}
1 & 1 & -4 & 1 & 1 \\
1 / 5 & 1 / 5 & 1 / 5 & 1 / 5 & 1 / 5
\end{array}\right] \overrightarrow{v_{i}}
$$

Las señales diferenciales captadas por el electrodo, al igual que en el caso del electrodo DD, tienen componentes de crosstalk que deben rechazarse, por lo que se identifican como modos de interferencia. Este electrodo tiene dos modos diferenciales, dado que tiene pares de electrodos con ejes transversales entre sí:

$$
\left[\begin{array}{c}
V_{\mathrm{MD} 1} \\
V_{\mathrm{MD} 2}
\end{array}\right]=\left[\begin{array}{ccccc}
1 & -1 & 0 & 0 & 0 \\
0 & 0 & 0 & 1 & -1
\end{array}\right] \overrightarrow{v_{i}}
$$

Finalmente, siguiendo el mismo razonamiento, el electrodo NDD tiene una selectividad diferente que la del DD ya que puede rechazar componentes de crosstalk no solo en el sentido de las fibras musculares sino también en el 


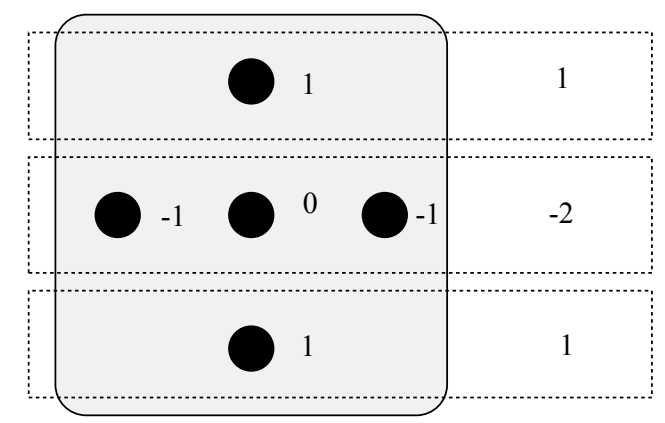

Figura A.1: El modo DD del amplificador NDD obtiene la componente doble-diferencial de una señal que se desarrolla a lo largo de uno de sus ejes.

transversal, o una composición de estas direcciones. Por lo tanto, los componentes se señal puramente DD que contienen crosstalk de fibras transversales deben ser rechazados. Los coeficiente asignados a continuación al quinto modo del electrodo NDD logran captar estas señales porque crean un electrodo DD en la geometría NDD, como se grafica en la figura A.1. Este modo se llama por tanto modo doble diferencial y se define en la siguiente ecuación:

$$
V_{\mathrm{MDD}}=\left[\begin{array}{lllll}
1 & 1 & 0 & -1 & -1
\end{array}\right]=\overrightarrow{v_{i}}
$$

La ecuación de salida de un amplificador NDD práctico puede definirse como:

$$
\begin{aligned}
V_{o}= & G_{\mathrm{NDD}} V_{\mathrm{MNDD}}+G_{\mathrm{C}} V_{\mathrm{MC}} \\
& +G_{\mathrm{D} 1} V_{\mathrm{MD} 1}+G_{\mathrm{D} 2} V_{\mathrm{MD} 2}+G_{\mathrm{DD}} V_{\mathrm{MDD}}
\end{aligned}
$$

$\mathrm{Y}$ en consecuencia las figuras de mérito son:

$$
\begin{aligned}
\text { CMRR } & :=G_{\mathrm{NDD}} / G_{\mathrm{C}} \\
\text { DMxRR } & :=G_{\mathrm{NDD}} / G_{\mathrm{Dx}} \\
\mathrm{DDMRR} & :=G_{\mathrm{NDD}} / G_{\mathrm{DD}}
\end{aligned}
$$

Con la excepción del MC, las señales de interferencia en los modos restantes tienen origen electromiográfico. 


\section{Relación entre parámetros del amplificador operacional}

En el capítulo 7 se trata al amplificador operacional como un dispositivo de múltiples entradas y se recurre al planteo de Sackinger et al., 1991 sobre la codependencia de las ganancias para cada entrada.

Se repite aquí, por conveniencia, la expresión que las relaciona, válida cuando la impedancia de carga es mucho mayor que la de salida:

$$
G_{c}+G_{p s-}+G_{p s+} \approx 1
$$

Donde $G_{c}$ es la ganancia de modo común, $G_{p s-}$ la ganancia desde la fuente de alimentación negativa a la salida, y $G_{p s+}$ desde la fuente positiva. Reemplazando con CMRR $=A_{o l} / G_{c}, \mathrm{PSSR}_{-}=A_{o l} / G_{p s-} \mathrm{y} \mathrm{PSSR}_{+}=A_{o l} / G_{p s+}$ la ecuación B.1 pasa a ser:

$$
\frac{1}{C M R R}+\frac{1}{P S R R_{-}}+\frac{1}{P S R R_{+}} \approx \frac{1}{A_{\text {ol }}}
$$

De manera que pueden obtenerse los parámetros de la ecuación B.1 a partir de los coeficientes de rechazo del AO.

El amplificador operacional OPA333 presenta las curvas de la figura B.1, obtenidas de su hoja de datos. Los marcadores representan puntos tomados como datos y las líneas son aproximaciones por polinomios racionales que logran la misma respuesta en frecuencia en el ancho de banda considerado.

La figura B.2 muestra la verificación de la ecuación B.1, con una buena aproximación a 1 en el ancho de banda de interés para el diseño del electrodo de dos hilos con bootstrap de fuente. En la figura B.3 se observa que efectivamente, debido a que en este ancho de banda la ganancia de la fuente de alimentación positiva y el modo común son menores a la unidad, entonces la ganancia de fuente negativa es aproximadamente igual a 1 , permitiendo realizar el modelado utilizado en el capítulo 7. 


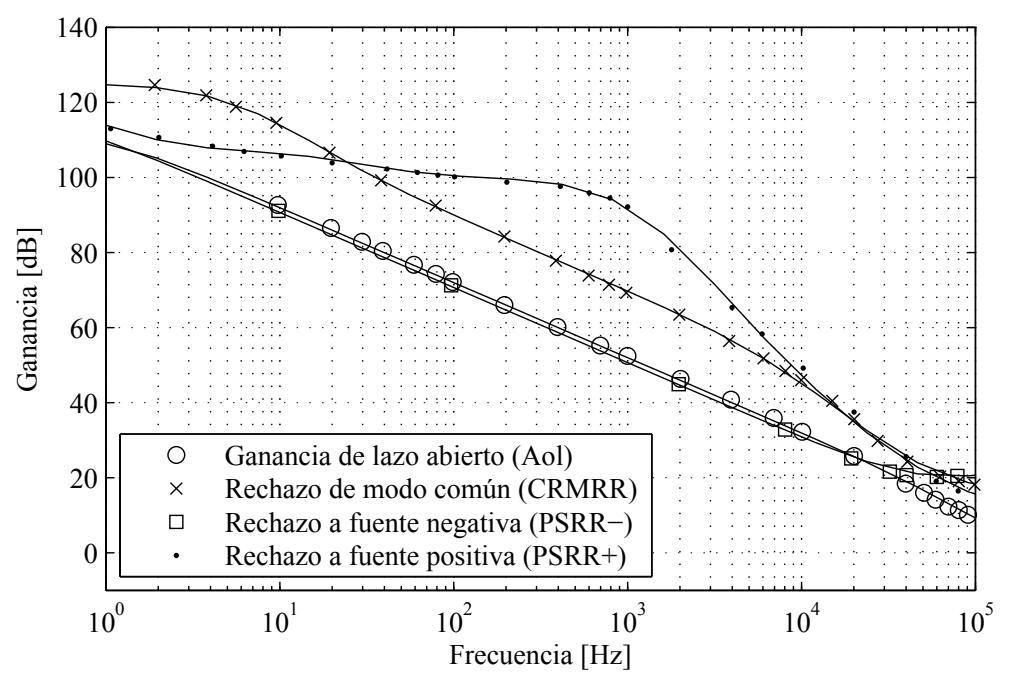

Figura B.1: Curvas de ganancia de lazo abierto y rechazo del AO OPA333.

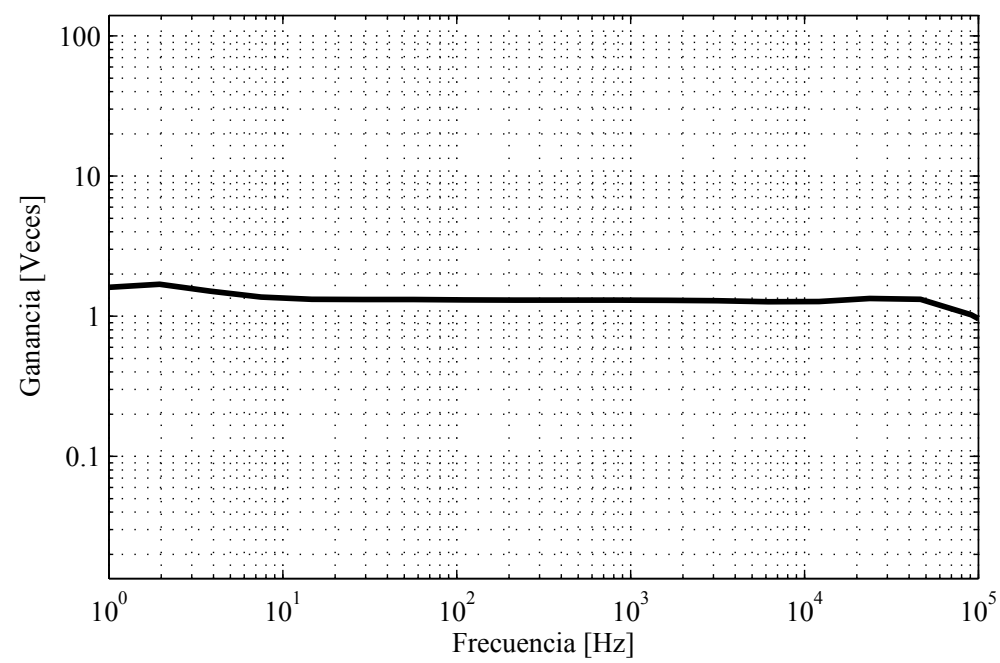

Figura B.2: Suma de las ganancias de los distintos puertos del AO. Resulta aproximada a 1 como lo predice la ecuación B.1. 


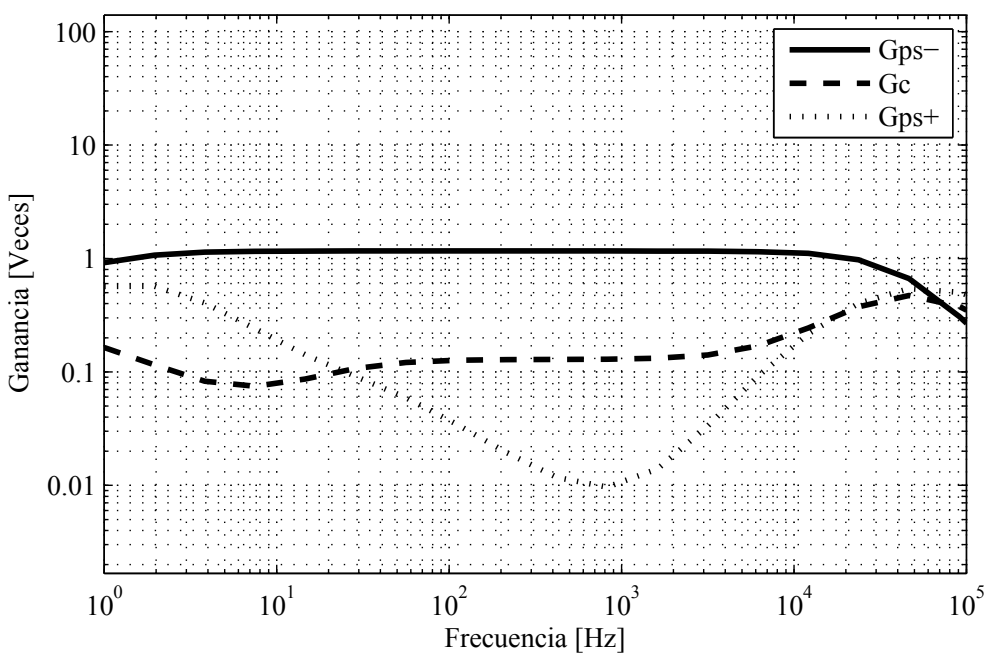

Figura B.3: Ganancias del AO OPA333. 



\section{Cálculo de ruido del circuito de bootstrap negativo}

En el capítulo 7 se presentó un electrodo activo con bootstrapping de fuente y se analizó la tensión de ruido total con el modelo de la figura 7.11 (página 94). Ese modelo incluye una fuente de tensión equivalente para el aporte de ruido del circuito de bootstrap negativo. En este apéndice se obtiene una expresión para esta tensión de ruido y se encuentra una cota para su valor, justificando la aproximación por la cual se desprecia (ecuación 7.23, página 94).

El circuito de bootstrap negativo se muestra en la figura C.1. La fuente de corriente $I_{s}$ alimenta al operacional del electrodo activo ( $A O_{1}$, no representado en la figura), circula a través del nodo de alimentación negativo $V_{p s-}$ y es absorbida por $\mathrm{AO}_{2}$, por lo cual se representa aquí directamente a la salida este operacional.

El ruido total en $V_{p s-}$ puede obtenerse mediante la suma cuadrática de los aportes de cada fuente de ruido, enumeradas a continuación.

(1) Las impedancias del circuito son de valor bajo, por lo que no se consideran en el análisis (resistencias en el orden de $1 \mathrm{k} \Omega$ generan ruido térmico del orden de $0.1 \mu \mathrm{V})$.

(2) La fuente de ruido de $I_{s}$ cae sobre la resistencia de salida de $\mathrm{AO}_{2}$ y la tensión que desarrolla aparece a la salida como:

$$
V_{n, I s}=i_{n, I s} R_{o, A O 2}
$$

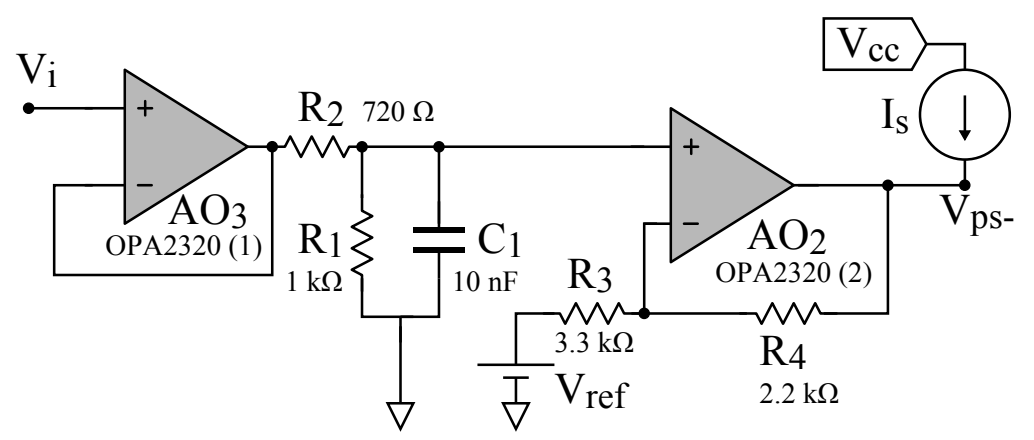

Figura C.1: Circuito de bootstrap negativo. 
(3) La fuente de corriente de ruido equivalente de $\mathrm{AO}_{2}$ produce caídas sobre impedancias de bajo valor, por lo que se desprecia. La fuente de tensión de ruido equivalente de $\mathrm{AO}_{2}, e_{n, \mathrm{AO} 2}$ puede colocarse en la rama que llega a su entrada no inversora. Por esa rama no circula corriente suponiendo un modelo ideal del AO, por lo que no habrá caída de tensión sobre la impedancia de $R_{1}, R_{2}$ y $C_{1}$ y $e_{n, A O 2}$ queda referida a masa. Se propaga a la salida multiplicada por la ganancia del amplificador no inversor que queda configurado, de manera que resulta:

$$
V_{n, A O 2}=e_{n, A O 2}\left(1+\frac{R_{4}}{R_{3}}\right)
$$

(4) La tensión de ruido de la fuente de referencia, $e_{n, r e f}$ aparece a la salida multiplicada por la ganancia del amplificador inversor que resulta (el signo es irrelevante):

$$
V_{n, r e f}=e_{n, r e f} \frac{R_{4}}{R_{3}}
$$

(5) La corriente de ruido de $\mathrm{AO}_{3}$ encuentra un camino a masa a través de la resistencia de salida de $A O_{1}$ por lo que se desprecia. La fuente de tensión de ruido equivalente de $\mathrm{AO}_{3}$ se copia a su salida ya que está conectado como seguidor. Produce una tensión sobre el nodo no inversor de $\mathrm{AO}_{2}$ que es amplificada por el amplificador no inversor que forma $\mathrm{AO}_{2}$ con su red pasiva de realimentación:

$$
V_{n, A O 3}=e_{n, A O 3} \frac{R_{1}}{R_{1}+R_{2}}\left(\frac{1}{s C_{1}\left(R_{1} \| R_{2}\right)+1}\right)\left(1+\frac{R_{4}}{R_{3}}\right)
$$

Debido a que la constante de tiempo del filtro se configura para degradar el bootstrap fuera del ancho de banda de los biopotenciales, no atenuará el ruido en esa banda y puede despreciarse. La ganancia total resulta entonces igual al factor $\alpha$, diseñado para valer $\approx 1$, con lo cual

$$
V_{n, A O 3}=e_{n, A O 3}
$$

El ruido total resulta entonces:

$$
\begin{aligned}
V_{n}^{2} & =V_{n, I s}^{2}+V_{n, A O 2}^{2}+V_{n, r e f}^{2}+V_{n, A O 3}^{2} \\
& =\left(i_{n, I s} R_{o, A O 2}\right)^{2}+\left(e_{n, A O 2}\left(1+\frac{R_{4}}{R_{3}}\right)\right)^{2}+\left(e_{n, r e f} \frac{R_{4}}{R_{3}}\right)^{2}+\left(e_{n, A O 3}\right)^{2}
\end{aligned}
$$

Para obtener un orden de magnitud de esta tensión de ruido, pueden hacerse algunas simplificaciones gruesas. En primer lugar, por el diseño del circuito, las relaciones de las resistencias están en el orden de la unidad, por lo cual las tensiones de ruido afectadas por ellas son directamente comparables. El ruido de la fuente de referencia, $e_{n, r e f}$, puede filtrarse hasta hacerlo despreciable comparado con el ruido de un amplificador operacional. El ruido de una fuente de corriente comercial de bajo costo (LM334) está en el orden de $100 \mathrm{pA}$ y la impedancia de salida de un AO puede ser de hasta unos $\mathrm{k} \Omega$. En un ancho de banda de $1 \mathrm{kHz}$ resulta una tensión de ruido de $3.2 \mu \mathrm{V}_{\mathrm{rms}}$. Los $\mathrm{AOs}$ de bajo ruido tienen tensiones de ruido en ese orden de valor o por debajo.

Aún suponiendo un caso pesimista, la contribución de todas las fuentes de ruido del circuito de bootstrap negativo estaría por debajo de $10 \mu \mathrm{V}_{\text {rms }}$. En el circuito completo del electrodo de dos hilos, este aporte de ruido aparece a la salida dividido por la ganancia de lazo abierto de $A O_{1}$ y, por lo tanto, resultará despreciable frente a las demás contribuciones. 


\section{Bibliografía}

Acharya, V. (2011). Improving Common-Mode Rejection Using the Right-Leg Drive Amplifier. Inf. téc. SBAA188. Texas Instruments.

Aksenov, E., Y. M. Ljashenko, A. Plotnikov, D. Prilutskiy y S. Selishchev (2001). Biomedical data acquisition systems based on sigma-delta analogue-to-digital converters. Inf. téc. Biomedical Systems Department, Moscow State Institute of Electronic Technology.

Alnasser, E. (2012). «Compensated transconductance driven-right-leg circuit». En: IET Sci. Meas. Technol. 6.6, pág. 519.

Amiri, S., A. Rabbi, L. Azinfar y R. Fazel-Rezai (2013). «A Review of P300, SSVEP, and Hybrid P300/SSVEP Brain-Computer Interface Systems». En: Brain-Computer Interface Syst. - Recent Prog. Futur. Prospect. 2013, págs. 1-8.

Ang, K. K. y C. Guan (2015). «Brain-Computer Interface for Neurorehabilitation of Upper Limb After Stroke». En: Proc. IEEE 103.6, págs. 944-953.

Aziz, P. M., H. V. Sorensen y J. Van der Spiegel (1996). «An overview of sigmadelta converters: How a 1-bit ADC achieves more than 16-bit resolution». En: IEEE Signal Process. Mag. 13.1, págs. 61-84.

Barone, U. y R. Merletti (2013). «Design of a Portable , Intrinsically Safe Multichannel Acquisition System for High-Resolution, Real-Time Processing HD-sEMG». En: IEEE Trans. Biomed. Eng. 60.8, págs. 2242-2252.

Berger, T. W., J. K. Chapin, G. A. Gerhardt, D. J. McFarland, J. C. Principe, W. V. Soussou, D. M. Taylor y P. A. Tresco (2008). Brain-Computer Interfaces: An international assessment of research and development trends. Springer Science \& Business Media, págs. 123-124.

Berry, D., F. Duignan y R. Hayes (2009). «An Investigation of the use of a High Resolution ADC as a Digital Biopotential Amplifier». En: 4th Eur. Conf. Int. Fed. Med. Biol. Eng. Págs. 142-147.

Berthet, L., D. Boudou, X. Mamo, P. Eyrolles y J. Martinon (2003). «State of play of the harmonic levels on the french low-voltage networks». En: CIRED 17th Int. Conf. Electr. Distrib. Págs. 12-15.

Bollen, M. y M. Olofsson (2015). «Consumer electronics and the power grid: What are they doing to each other?» En: IEEE Consum. Electron. Mag. 4.1, págs. 50-57.

Broman, H., G. Bilotto y C. De Luca (1985). «A Note on the Noninvasive Estimation of Muscle Fiber Conduction Velocity». En: IEEE Trans. Biomed. Eng. BME-32.5, págs. 341-344.

Cheng, M., X. Gao, S. Gao y D. Xu (2002). «Design and implementation of a brain-computer interface with high transfer rates». En: IEEE Trans. Biomed. Eng. 49.10, págs. 1181-1186. 
Chi, Y. M., C. Maier y G. Cauwenberghs (2011). «Ultra-high input impedance, low noise integrated amplifier for noncontact biopotential sensing». En: IEEE J. Emerging Sel. Top. Circuits Syst. 1.4, págs. 526-535.

Chi, Y. M., T.-P. Jung y G. Cauwenberghs (2010). «Dry-contact and Non-contact Biopotential». En: IEEE Rev. Biomed. Eng. 3, págs. 106-119.

Chi, Y. M., Y. T. Wang, Y. Wang, C. Maier, T. P. Jung y G. Cauwenberghs (2012). «Dry and noncontact EEG sensors for mobile brain-computer interfaces». En: IEEE Trans. Neural Syst. Rehabil. Eng. 20.2, págs. 228-235.

Chimeno, M. F. y R. Pallàs-Areny (2000). «A comprehensive model for power line interference in biopotential measurements». En: IEEE Trans. Instrum. Meas. 49.3, págs. 535-540.

Chin-Teng Lin, C.-T., C.-H. Chun-Hsiang Chuang, C.-S. Chih-Sheng Huang, S.-F. Shu-Fang Tsai, S.-W. Shao-Wei Lu, Y.-H. Yen-Hsuan Chen y L.-W. LiWei Ko (2014). «Wireless and Wearable EEG System for Evaluating Driver Vigilance». En: IEEE Trans. Biomed. Circuits Syst. 8.2, págs. 165-176.

Christova, L., D. Stephanova y A. Kossev (2007). «Branched EMG electrodes for stable and selective recording of single motor unit potentials in humans.» En: Biomedizinische Technik / Biomedical engineering 52.1, págs. 117-21.

Costa, M. H. y M. C. Tavares (2009). «Removing harmonic power line interference from biopotential signals in low cost acquisition systems». En: Comput. Biol. Med. 39.6, págs. 519-526.

Curtin, M. (1994). «Sigma-delta techniques reduce hardware count and power consumption in biomedical analog front end». En: Analog Dialogue 28.2, págs. 6-7.

Davis, G., C. McConnell, D. Popovic, C. Berka y S. Korszen (2013). «Soft, Embeddable, Dry EEG Sensors for Real World Applications». En: Int. Conf. Augmented Cognition. Springer, págs. 269-278.

De Luca, C. J. y R. Merletti (1988). «Surface myoelectric signal cross-talk among muscles of the leg». En: Electroencephalogr. Clin. Neurophysiol. 69.6, págs. 568-575.

De Luca, C. (1997). «The use of surface electromyography in biomechanics». En: J. Appl. Biomech. 13.2, págs. 135-163.

De Luca, C., R. Le Fever y F. Stulen (1979). «Pasteless electrode for clinical use». English. En: Med. Biol. Eng. Comput. 17.3, págs. 387-390.

Degen, T. W. (2011). «Portable Devices for Mobile Health Monitoring». Tesis doct. Université de Neuchâtel.

Degen, T. y H. Jäckel (2004). «Enhancing interference rejection of preamplified electrodes by automated gain adaption.» En: IEEE Trans. Biomed. Eng. 51.11, págs. 2031-9.

Degen, T., S. Torrent y H. Jäckel (2007). «Low-noise two-wired buffer electrodes for bioelectric amplifiers.» En: IEEE Trans. Biomed. Eng. 54.7, págs. 1328-32.

Dias, N. S., J. P. Carmo, P. M. Mendes y J. H. Correia (2012). «Wireless instrumentation system based on dry electrodes for acquiring EEG signals». En: Med. Eng. Phys. 34.7, págs. 972-981.

Dimitrov, G. V., C. Disselhorst-Klug, N. a. Dimitrova, E. Schulte y G. Rau (2003). «Simulation analysis of the ability of different types of multi-electrodes to 
increase selectivity of detection and to reduce cross-talk». En: J. Electromyogr. Kinesiol. 13.2, págs. 125-138.

Disselhorst-Klug, C., J. Silny y G. Rau (1997). «Improvement of spatial resolution in surface-EMG: a theoretical and experimental comparison of different spatial filters.» En: IEEE Trans. Biomed. Eng. 44.7, págs. 567-74.

Dobrev, D., T. Neycheva y N. Mudrov (2005). «Simple two-electrode biosignal amplifier». En: Med. Biol. Eng. Comput. 43.6, págs. 725-30.

Farina, D., E. Schulte, R. Merletti, G. Rau y C. Disselhorst-Klug (2003). «Single motor unit analysis from spatially filtered surface electromyogram signals. Part I: Spatial selectivity». English. En: Med. Biol. Eng. Comput. 41.3, págs. 330-337.

Farwell, L. A. y E. Donchin (1988). «Talking off the top of your head: toward a mental prosthesis utilizing event-related brain potentials». En: Electroencephalogr. Clin. Neurophysiol. 70.6, págs. 510-523.

Fernandez, M. y R. Pallàs-Areny (1996). «A simple active electrode for power line interference reduction in high resolution biopotential measurements». En: Proc. 18th Annu. Int. Conf. IEEE Eng. Med. Biol. Soc. 1, págs. 97-98.

Fonseca, C., J. P. S. Cunha, R. E. Martins y V. M. Ferreira (2007). «A Novel Dry Active Electrode for EEG Recording». En: IEEE Trans. Biomed. Eng. 54.1, págs. 162-165.

Gandhi, N., C. Khe, D. Chung, Y. M. Chi y G. Cauwenberghs (2011). «Properties of dry and non-contact electrodes for wearable physiological sensors». En: Proc. 2011 Int. Conf. Body Sensor Networks, BSN 2011, págs. 107-112.

García, P. A., E. M. Spinelli y G. M. Toccaceli (2014). «An embedded system for evoked biopotential acquisition and processing». En: Int. J. Embedded Syst. 6.1, págs. 86-93.

Gargiulo, G., P. Bifulco, M. Cesarelli, M. Ruffo, M. Romano, R. A. Calvo, C. Jin y A. van Schaik (2010). "An ultra-high input impedance ECG amplifier for long-term monitoring of athletes». En: Medical Devices: Evidence and Research 3.1, págs. 1-9.

Geddes, L. y M. Valentinuzzi (1973). «Temporal changes in electrode impedance while recording the electrocardiogram with "Dry" electrodes». English. En: Ann. Biomed. Eng. 1.3, págs. 356-367.

Grimnes, S. (1983). «Impedance measurement of individual skin surface electrodes.» En: Med. Biol. Eng. Comput. 21.6, págs. 750-5.

Guerrero, F. N., P. A. García y E. Spinelli (Aceptado 2016). «Signal modes for design-oriented analysis of active sEMG spatial filter electrodes». En: VII Lat. Am. Congress on Biomed. Eng. CLAIB 2016, Bucaramanga, Santander, Colombia 26, 27 \& 28 October 2016. Springer.

Guerrero, F. N., M. Haberman y E. Spinelli (2014). «Sistema multicanal para adquisición de biopotenciales». En: Revista Ingeniería Biomédica 8.15, págs. 18-26.

Guerrero, F. N. y E. Spinelli (2015). «Surface EMG multichannel measurements using active, dry branched electrodes». En: VI Lat. Am. Congress on Biomed. Eng. CLAIB 2014, Paraná, Argentina 29, 30 \& 31 October 2014. Springer, págs. 1-4.

Guerrero, F. N. y E. Spinelli (2017). «High gain driven right leg circuit for dry electrode systems». En: Med. Eng. Phys. 39, págs. 117-122. 
Guerrero, F. N., E. M. Spinelli y M. A. Haberman (2015). «Analysis and simple circuit design of double differential EMG active electrode». En: IEEE Trans. Biomed. Circuits Syst. 10.3, págs. 787-795.

Ha, S., C. Kim, Y. M. Chi, A. Akinin, C. Maier, A. Ueno y G. Cauwenberghs (2014). «Integrated circuits and electrode interfaces for noninvasive physiological monitoring». En: IEEE Trans. Biomed. Eng. 61.5, págs. 1522-1537.

Haberman, M. A. y E. M. Spinelli (2012). «A multichannel EEG acquisition scheme based on single ended amplifiers and digital DRL». En: IEEE Trans. Biomed. Circuits Syst. 6.6, págs. 614-618.

Haberman, M., A. Cassino y E. Spinelli (2011). «Estimation of stray coupling capacitances in biopotential measurements.» En: Med. Biol. Eng. Comput. 49.9, págs. 1067-71.

Haberman, M. y E. Spinelli (2010). «A digital Driven Right Leg Circuit». En: Proc. 32nd Annu. Int. Conf. IEEE Eng. Med. Biol. Soc. Págs. 6559-6562.

Haddad, S. A., R. P. Houben y W. Serdijin (2006). «The evolution of pacemakers». En: IEEE Eng. Med. Biol. Mag. 25.3.

Hagemann, B., G. Luhede y H. Luczak (1985). «Improved . active. ${ }^{\text {electrodes for }}$ recording bioelectric signals in work physiology.» En: Eur. J. Appl. Physiol. 54.1, págs. 95-8.

Hall, C. y T. Kuehl (2015). EMI Rejection Ratio of Operational Amplifiers ( With OPA333 and OPA333-Q1 as an Example ). Inf. téc. SBOA128A. Texas Instruments, págs. 1-14.

Hart, R., K. Kilgore y P. Peckham (1998). «A comparison between control methods for implanted FES hand-grasp systems». En: IEEE Trans. Rehabil. Eng. 6.2, págs. 208-218.

Hodgkin, A. L. y A. F. Huxley (1939). «Action potentials recorded from inside a nerve fibre». En: Nature 144.3651, págs. 710-711.

Hribik, J., S. Lányi y M. Hruskovic (2008). «A high-input-impedance buffer». En: Proc. 18th Int. Conf. Radioelektronika. Prague: IEEE, págs. 1-4.

Huhta, J. C. y J. G. Webster (1973). «60-Hz interference in electrocardiography». En: IEEE Trans. Biomed. Eng. 20.2, págs. 91-101.

IEC EN 60601-1-2 (2003). International Electrotechnical Commission.

Jewell, W. y D. Ward (2002). «Single Phase Harmonic Limit». En: PSERC EMI, Power Qual. Saf. Work.

Johnson, S., P. Lynn, J. Miller y G. Reed (1977). «Miniature skin mounted preamplifier for measurement of surface electromyographic potentials». English. En: Med. Biol. Eng. Comput. 15.6, págs. 710-711.

Jung, H. C., J. H. Moon, D. H. Baek, J. H. Lee, Y. Y. Choi, J. S. Hong y S. H. Lee (2012). «CNT/PDMS composite flexible dry electrodesfor long-term ECG monitoring». En: IEEE Trans. Biomed. Eng. 59.5, págs. 1472-1479.

Kappel, S. L. y P. Kidmose (2015). «Study of impedance spectra for dry and wet EarEEG electrodes». En: Proc. 37th Annu. Int. Conf. IEEE Eng. Med. Biol. Soc. Págs. 3161-3164.

Koh, T. J. y M. D. Grabiner (1993). «Evaluation of methods to minimize cross talk in surface electromyography». En: J. Biomech. 26 Suppl 1, págs. 151-7. 
Kootsey, J. M. y E. A. Johnson (1973). «Buffer amplifier with femtofarad input capacity using operational amplifiers.» En: IEEE Trans. Biomed. Eng. 20.5, págs. 389-391.

Kurikov, S. F., D. A. Prilutskii y S. V. Selischev (1998). «Use of a sigma-delta analog-to-digital converter in multichannel electrocardiograps». En: Biomed. Eng. (NY). 31.4, págs. 190-194.

Lányi, S. (2001). «The noise of input stages with low parasitic capacitance». En: Meas. Sci. Technol. 12.9, págs. 1456-1464.

Lányi, S. y M. Pisani (2002). «A high-input-impedance buffer». En: IEEE Trans. Circuits Syst. I, Fundam. Theory Appl. 49.8, págs. 1209-1211.

Levkov, C. L. (1988). «Amplification of biosignals by body potential driving. Analysis of the circuit performance». En: Med. Biol. Eng. Comput. 26.4, págs. 389-396.

Levkov, C. (1982). «Amplification of biosignals by body potential driving». English. En: Med. Biol. Eng. Comput. 20.2, págs. 248-250.

Liao, L.-D., C.-Y. Chen, I.-J. Wang, S.-F. Chen, S.-Y. Li, B.-W. Chen, J.-Y. Chang y C.-T. Lin (2012). «Gaming control using a wearable and wireless EEG-based brain-computer interface device with novel dry foam-based sensors». En: $J$. NeuroEng. Rehabil. 9.1, pág. 5.

Liu, H., X. Tao, P. Xu, H. Zhang y Z. Bai (2013). «A dynamic measurement system for evaluating dry bio-potential surface electrodes». En: Measurement: Journal of the International Measurement Confederation 46.6, págs. 1904-1913.

Looned, R., J. Webb, Z. G. Xiao y C. Menon (2014). «Assisting drinking with an affordable BCI-controlled wearable robot and electrical stimulation: a preliminary investigation.» En: J. NeuroEng. Rehabil. 11.1, pág. 51.

Marcus, M. y B. Biersach (2003). «Regulatory requirements for medical equipment». En: IEEE Instrum. Meas. Mag 6.4, págs. 23-29.

McKee, J., N. Evans y D. Wallace (1996). «Sigma-delta analogue-to-digital converters for ECG signal acquisition». En: Proc. 18th Annu. Int. Conf. IEEE Eng. Med. Biol. Soc. 1, págs. 19-20.

Merletti, R., A. Botter, A. Troiano, E. Merlo y M. A. Minetto (2009). «Technology and instrumentation for detection and conditioning of the surface electromyographic signal: state of the art.» En: Clin. Biomech. (Bristol, Avon) 24.2, págs. 122-34.

Merletti, R., D. Farina y M. Gazzoni (2003). «The linear electrode array: a useful tool with many applications». En: J. Electromyogr. Kinesiol. 13.1, págs. 37-47.

Merletti, R. y P. A. Parker (2004). Electromyography: Physiology, Engineering, and Noninvasive Applications. Vol. 53. 9. Hoboken: John Wiley \& Sons.

Metting van Rijn, A. C., A. Peper y C. A. Grimbergen (1990). «High-quality recording of bioelectric events. Part 1 . Interference reduction, theory and practice». En: Med. Biol. Eng. Comput. 28.5, págs. 389-397.

Metting van Rijn, A. C., A. Peper y C. A. Grimbergen (1991). «High-quality recording of bioelectric events. Part 2. Low-noise, low-power multichannel amplifier design.» En: Med. Biol. Eng. Comput. 29.4, págs. 433-440.

Meziane, N., J. G. Webster, M. Attari y A. J. Nimunkar (2013). «Dry electrodes for electrocardiography». En: Physiol. Meas. 34.9, R47-R69. 
Mihajlovic, V., B. Grundlehner, R. Vullers y J. Penders (2015). «Wearable, Wireless EEG Solutions in Daily Life Applications: What are we Missing?» En: IEEE J. Biomed. Heal. Informatics 19.1, págs. 6-21.

Morrison, T., M. Nagaraju, B. Winslow, A. Bernard y B. Otis (2014). «A $0.5 \mathrm{~cm} 3$ Four-Channel $1.1 \mathrm{~mW}$ Wireless Biosignal Interface With $20 \mathrm{~m}$ Range». En: IEEE Trans. Biomed. Circuits Syst. 8.1, págs. 138-147.

Nagel, J. (1995). «Biopotential amplifiers». En: The Biomedical Engeneering Handbook, págs. 1185-1195.

Nathan, V. y R. Jafari (2014). «Reducing the noise level of EEG signal acquisition through reconfiguration of dry contact electrodes». En: IEEE 2014 Biomed. Circuits Syst. Conf. BioCAS 2014 - Proc. Págs. 572-575.

Navarro, X., T. B. Krueger, N. Lago, S. Micera, T. Stieglitz y P. Dario (2005). «A critical review of interfaces with the peripheral nervous system for the control of neuroprostheses and hybrid bionic systems.» En: J. Peripher. Nerv. Syst. 10.3, págs. 229-58.

Neuman, M. R. (2009). «Medical instrumentation: application and design». En: Med. Instrum. Appl. Des. Ed. por J. G. Webster. Fourth. John Wiley \& Sons. Cap. Biopotential Amplifiers, págs. 241-292.

Ng, K. A. y Y. P. Xu (2013). «A Compact, Low Input Capacitance Neural Recording Amplifier». En: IEEE Trans. Biomed. Circuits Syst. 7.5, págs. 610-620.

Nishimura, S., Y. Tomita y T. Horiuchi (1992). «Clinical application of an active electrode using an operational amplifier». En: IEEE Trans. Biomed. Eng. 39.10, págs. 1096-1099.

Nonclercq, A. y P. Mathys (2004). «Reduction of power line interference using active electrodes and a driven-right-leg circuit in electroencephalographic recording with a minimum number of electrodes». En: Proc. 26th Annu. Int. Conf. IEEE Eng. Med. Biol. Soc. Vol. 1. IEEE, págs. 2247-2250.

Nonclercq, A. y P. Mathys (2010). «Quantification of motion artifact rejection due to active electrodes and driven-right-leg circuit in spike detection algorithms.» En: IEEE Trans. Biomed. Eng. 57.11, págs. 2746-2752.

Nuwer, M. R., C. Comi, R. Emerson, a. Fuglsang-Frederiksen, J. M. Guerit, H. Hinrichs, a. Ikeda, F. J. C. Luccas y P. Rappelsburger (1998). «IFCN standards for digitial recording of clinical EEG». En: Electroencephalogr. Clin. Neurophysiol. 106, págs. 259-261.

Pallás-Areny, R. y J. G. Webster (1991). «Common mode rejection ratio in differential amplifiers». En: IEEE Trans. Instrum. Meas. 40.4, págs. 669-676.

Park, S. y S. Jayaraman (2003). «Enhancing the Quality of Life Through Wearable Technology». En: IEEE Eng. Med. Biol. Mag. 22.3, págs. 41-48.

Plassche, R. van de (1978). "A sigma-delta modulator as an A/D converter». En: IEEE Trans. Circuits. Syst. 25.7, págs. 510-514.

Plonsey, R. y R. C. Barr (2000). Bioelectricity. Second. Boston, MA: Springer US.

Pons, J., E. Rocon y J. Gallego (2013). «A Wearable Neuroprosthesis for the Suppression of Pathological Tremor». En: Newsletter 2, pág. 2006.

Prutchi, D. y M. Norris (2005). Design and development of medical electronic instrumentation: a practical perspective of the design, construction, and test of medical devices. John Wiley \& Sons. 
Reucher, H., G. Rau y J. Silny (1987). «Spatial filtering of noninvasive multielectrode EMG: Part I-Introduction to measuring technique and applications.» En: IEEE Trans. Biomed. Eng. BME-34.2, págs. 98-105.

Rieger, R. (2011). «Variable-gain, low-noise amplification for sampling front ends». En: IEEE Trans. Biomed. Circuits Syst. 5.3, págs. 253-261.

Rivera-Ruiz, M., C. Cajavilca y J. Varon (2008). «Einthoven's string galvanometer: the first electrocardiograph.» En: Texas Heart Institute journal / from the Texas Heart Institute of St. Luke's Episcopal Hospital, Texas Children's Hospital 35.2, págs. 174-178.

Roy, S., G. De Luca, M. Cheng, A. Johansson, L. Gilmore y C. De Luca (2007). «Electro-mechanical stability of surface EMG sensors». English. En: Med. Biol. Eng. Comput. 45.5, págs. 447-457.

Sackinger, E., J. Goette y W. Guggenbuhl (1991). «A general relationship between amplifier parameters, and its application to PSRR improvement». En: IEEE Trans. Circuits Syst. 38.10, págs. 1173-1181.

Schreier, R., G. C. Temes et al. (2005). Understanding delta-sigma data converters. Vol. 74. IEEE press Piscataway, NJ.

Searle, A. y L. Kirkup (1999). «Real time impedance plots with arbitrary frequency components.» En: Physiol. Meas. 20.1, págs. 103-114.

Searle, A. y L. Kirkup (2000). "A direct comparison of wet, dry and insulating bioelectric recording electrodes.» En: Physiol. Meas. 21.2, págs. 271-283.

Sinha, S. R., L. Sullivan, D. Sabau, D. San-Juan, K. E. Dombrowski, J. J. Halford, A. J. Hani, F. W. Drislane y M. M. Stecker (2016). "American Clinical Neurophysiology Society Guideline 1: Minimum Technical Requirements for Performing Clinical Electroencephalography.» En: J. Clin. Neurophysiol. 33.4, págs. 303-307.

Spinelli, E. M., N. H. Martínez y M. a. Mayosky (1999). "A transconductance driven-right-leg circuit.» En: IEEE Trans. Biomed. Eng. 46.12, págs. 1466-70.

Spinelli, E. M., M. A. Mayosky y R. Pallàs-Areny (2006). «A practical approach to electrode-skin impedance unbalance measurement». En: IEEE Trans. Biomed. Eng. 53.7, págs. 1451-1453.

Spinelli, E. M., R. Pallàs-Areny y M. A. Mayosky (2003). «AC-coupled frontend for biopotential measurements». En: IEEE Trans. Biomed. Eng. 50.3, págs. 391-395.

Spinelli, E. y M. Haberman (2010). «Insulating electrodes: a review on biopotential front ends for dielectric skin-electrode interfaces.» En: Physiol. Meas. 31.10, S183.

Taheri, B. A., R. T. Knight y R. L. Smith (1994). «A dry electrode for EEG recording». En: Electroencephalogr. Clin. Neurophysiol. 90.5, págs. 376-383.

Taji, B., S. Shirmohammadi, V. Groza y I. Batkin (2013). «Impact of SkinElectrode Interface on Electrocardiogram Measurements Using Conductive Textile Electrodes». En: IEEE Trans. Instrum. Meas. 63.6, págs. 1-11.

Tallgren, P., S. Vanhatalo, K. Kaila y J. Voipio (2005). «Evaluation of commercially available electrodes and gels for recording of slow EEG potentials.» En: Clin. Neurophysiol. 116.4, págs. 799-806.

Tam, H. W. y J. G. Webster (1977). «Minimizing Electrode Motion Artifact by Skin Abrasion». En: IEEE Trans. Biomed. Eng. BME-24.2, págs. 134-139. 
Texas Instruments (2016). OPA2x11 1,1nV/ $\sqrt{H} z$ Noise, Low Power, Precision Operational Amplifier. SBOS377I Rev. I.

Thorsen, R. (1999). «An artefact suppressing fast-recovery myoelectric amplifier». En: IEEE Trans. Biomed. Eng. 46.6, págs. 764-766.

Valchinov, E. S. y N. E. Pallikarakis (2004). «An active electrode for biopotential recording from small localized bio-sources.» En: Biomed. Eng. Online 3.1, pág. 25.

Van Der Horst, M. J., A. C. Metting van Rijn, A. Peper, C. A. Grimbergen y M. J. Van Der Horst (1998). «High frequency interference effects in amplifiers for biopotential recordings». En: Proc. 20th Annu. Int. Conf. IEEE Eng. Med. Biol. Soc. 6.6, págs. 3309-3312.

Van Vugt, J. P. P. y J. G. Van Dijk (2001). «A convenient method to reduce crosstalk in surface EMG». En: Clin. Neurophysiol. 112.4, págs. 583-592.

Vanhatalo, S., J. Voipio y K. Kaila (2005). «Full-band EEG (FbEEG): an emerging standard in electroencephalography.» En: Clin. Neurophysiol. 116.1, págs. 1-8.

Wang, T.-Y., M.-R. Lai, C. Twigg y S.-Y. Peng (2014). «A Fully Reconfigurable Low-Noise Biopotential Sensing Amplifier With 1.96 Noise Efficiency Factor». En: IEEE Trans. Biomed. Circuits Syst. 8.3, págs. 411-422.

Waterhouse, E. (2003). «New Horizons in Ambulatory Electroencephalography». En: IEEE Eng. Med. Biol. Mag. 22.3, págs. 74-80.

Webster, J. G. (1984). «Reducing Motion Artifacts and Interference in Biopotential Recording». En: IEEE Trans. Biomed. Eng. 32.12, págs. 823-826.

Webster, J. G. (1988). Medical Devices and Instrumentation. Wiley-Interscience.

Winter, B. B. y J. G. Webster (1983). «Driven-right-leg circuit design.» En: IEEE Trans. Biomed. Eng. BME-30.1, págs. 62-6.

Wong, W. Y., R. Sudirman, N. H. Mahmood, S. Z. Tumari y N. Samad (2012). «Study of environment based condition of electromagnetic interference during ECG acquisition». En: 2012 Int. Conf. Biomed. Eng. ICoBE 2012 Feb, págs. 579-584.

Wood, D. E., D. J. Ewins y W. Balachandran (1995). «Comparative analysis of power-line interference between two- or three-electrode biopotential amplifiers». En: Med. Biol. Eng. Comput. 33.1, págs. 63-68.

Woźniak, K., D. Piatkowska, M. Lipski y K. Mehr (2013). «Surface electromyography in orthodontics - a literature review.» En: Med. Sci. Monit. 19, págs. 416-23.

Yamamoto, Y. y T. Nakamura (1998). «Elimination of power line interference in ECG signal using inverse loop». En: Proc. 20th Annu. Int. Conf. IEEE Eng. Med. Biol. Soc. 6.6, págs. 3-4.

Yokus, M. y J. Jur (2015). «Fabric-Based Wearable Dry Electrodes for Body Surface Biopotential Recording». En: IEEE Trans. Biomed. Eng. 9294.c, págs. 1-1.

Yoo, J., L. Yan, S. Lee, H. Kim y H. J. Yoo (2009). «A wearable ECG acquisition system with compact planar-fashionable circuit board-based shirt». En: IEEE Trans. Inf. Technol. Biomed. 13.6, págs. 897-902. 
Zeng, F.-G., S. Rebscher, W. Harrison, X. Sun y H. Feng (2008). «Cochlear implants: system design, integration, and evaluation». En: IEEE Rev. Biomed. Eng. 1, págs. 115-142.

Zheng, Y. L., X. R. Ding, C. C. Y. Poon, B. P. L. Lo, H. Zhang, X. L. Zhou, G. Z. Yang, N. Zhao y Y. T. Zhang (2014). «Unobtrusive sensing and wearable devices for health informatics». En: IEEE Trans. Biomed. Eng. 61.5, págs. 1538-1554.

Zhou, Z. y P. A. Warr (2016). «A High Input Impedance Low Noise Integrated Front-End Amplifier for Neural Monitoring». En: IEEE Trans. Biomed. Circuits Syst. 10.6, págs. 1079-1086.

Zivanovic, M. y M. González-Izal (2013). «Simultaneous powerline interference and baseline wander removal from ECG and EMG signals by sinusoidal modeling». En: Med. Eng. Phys. 35.10, págs. 1431-1441. 



\section{Agradecimientos}

Quiero agradecer a todos los que contribuyeron a mi formación y a esta tesis. En especial a su director, el Dr. Enrique M. Spinelli o Kike, quien ha sido extremadamente generoso en el aporte de ideas, trabajo codo a codo, y motivación durante estos años. También a mis compañeros de trabajo, Marcelo Haberman y Pablo García, que me ayudaron de muchas maneras, a través de ideas, conversaciones, respuestas pacientes, y el combustible fundamental, el mate.

Agradezco a Graciela Toccaceli que ha sido una "tía académica" y a Carlos Muravchik; ambos, entre otras cosas, me recibieron en sus cátedras en las cuales tuve una experiencia muy enriquecedora. El laboratorio (ahora Instituto) LEICI donde trabajé estos años y probablemente los que vendrán, tiene una calidad humana muy especial que es el motor de su calidad académica.

Dedico un especial agradecimiento a mi familia y amigos. A mi familia de Ranchos, de Neuquén, a mis amigos de la CM con quienes compartimos muchos kilómetros en ruta, y a Martina, que me acompañó casi desde el inicio de esta tesis en los altibajos correspondientes.

Por supuesto agradezco a mis padres, que me obligaron a estudiar inglés (igracias!) y me regalaron el juego Meccano con el cual comencé mi carrera de ingeniería solucionando todo con "metal y madera", tradición que hoy mantengo.

Finalmente, quiero agradecer a los hombres y mujeres del país que lo dotaron de sus aspectos más positivos y a todas las personas que con su trabajo e impuestos sustentaron esta tesis, a las familias que junto a la mía mantienen el sistema educativo y científico público, en el cual me formé enteramente. 
